\title{
THE TRANSFER OF LEARNING FROM THE CLASSROOM TO THE WORKPLACE: A NEW ZEALAND CASE STUDY
}

By

Sarah Isabella Leberman

\author{
A thesis \\ submitted to the Victoria University of Wellington \\ in fulfilment of the \\ requirements for the degree of \\ Doctor of Philosophy \\ in Management
}

Victoria University

1999 


\section{ACKNOWLEDGEMENTS}

I would like to sincerely thank all the participants of this research for their time and energy they gave to me which made this study possible. Without them there would have been no research. Many of them provided me not only with time for interviews and focus groups, but also collected and dropped me at the airport, as well as inviting me into their homes. I hope that in some way, being part of this research has enabled them to reflect on their personal and professional development as a result of completing the Victoria University of Wellington Diploma in Rehabilitation Studies, and that the implications of this research will be of benefit to other people employed in the human services industry.

This thesis would not be as it is now without the guidance of my supervisors, Dr Vicky Mabin and Professor Leon Fulcher. Their feedback, insights, questions and unfailing support has enabled me to work my way through the process of completing this $\mathrm{PhD}$. The manner of supervision adopted by Vicky and Leon encouraged me to learn from the experience and to realise that research is indeed a journey and not a destination.

My thanks must also go to those people who have helped me with the intricacies of using computer software. In particular, my friend Bill Cohen, who always had time to help me out when the computer would not do what I wanted it to do. Thanks also to Shelley Solomon and Derrylea Hardy for their assistance in compiling the graphs and figures.

Last, but in no means least, I must thank my best friend and husband Brett Guthrie for his constant support over the last three and a half years, but in particular the last three months. He was always ready to look at the next draft, the new graph or figure, and spent much of the Christmas break on his own when I was working away at the computer. 


\section{ABSTRACT}

The transfer of training and learning from the classroom to the workplace has been an area of interest to researchers in a number of different fields of study, including psychology (Baldwin \& Ford, 1988; Collinson \& Brook, 1997; Cormier \& Hagman, 1987, McSherry \& Taylor, 1994; Tracey, Tannenbaum \& Kavanagh, 1995), education (Bereiter, 1995; Gass, 1989; Marini \& Genereux, 1995) and management (Analoui, 1993; Broad \& Newstrom, 1992; Garavaglia, 1993; Holton, 1996; McGraw, 1993; Xiao, 1996). Of particular interest have been the long-term effect training has once back in the workplace, the avoidance of the 'fade-out' effect and the identification of factors which facilitate transfer. Within the context of this research the focus has been on the management of the transfer process as it pertains to service management, and in particular case management services delivered by the Accident Rehabilitation and Compensation Insurance Corporation in New Zealand.

The purpose of this research was to identify the factors, which facilitated the transfer of learning from an adult learning environment, using action learning methods of instruction, to the workplace. The research also sought to develop a model which optimises the transfer of learning from the classroom to the workplace for adult learners.

The forty-seven participants in this research were graduates of the first three cohorts of students from the Victoria University of Wellington (VUW) Diploma in Rehabilitation Studies. A phenomenological paradigm was adopted, within which a longitudinal case study method linked with grounded theory was employed as the research methodology. The methods of data collection included semi-structured and unstructured, face-to-face and telephone interviews, as well as focus groups. The data collection took place at six monthly intervals post course - at twelve months, eighteen months and twenty-four months. By the third time interval the number of research participants had diminished to thirty-eight.

The findings suggest that there was a relationship between the educational process adopted, the personal development of the participants and the desired organisational objective of improved service delivery. The transfer model which emerged from the data indicated that the educational process is the foundation upon which to build, if the transfer of learning back to the workplace is to be achieved. The role of the organisation in this process is also discussed. 
It is suggested that an experiential/action learning approach is the key component of the educational process, coupled with a combination of personal and professional development components. In addition, the use of a supervised work-based practicum following the university-based modules, appears to have facilitated the transfer process. The increase in confidence indicated by the participants is associated with the educational process and has subsequently enabled them to adopt case management practices, learned on the VUW Diploma in Rehabilitation Studies, as part of their daily personal practice as Case Managers. This in turn has been linked to the participants' perception of improved service delivery to their clients. The positive relationship between the various elements in the emergent transfer of learning model was strongest twelve months post course. Two further theoretical models are also presented - the Task/Setting/Risk Matrix and the Setting/Task/Risk/Competence model.

The results of the ACC funded evaluation of the VUW Diploma in Rehabilitation Studies (Collinson \& Brook, 1997) further strengthen the conclusions of this research. Their research focussed on both participant's and supervisor's perceptions of the transfer of training back to the corporate environment up to six months post course and made similar inferences to those made in this research.

There are a number of managerial implications related to the conclusions of this research. These have been divided into those pertinent to general management, professional practice and educational providers. The key implications are summarised below:

- the importance of linking training to organisational strategic planning;

- the need for training to be regarded as a process involving all the key stakeholders of the organisation;

- the value of experiential and action learning to adult learners;

- the significance of combining personal and professional development opportunities in training programmes;

- the potential benefit to both the educational provider and the organisation;

- and finally that the transfer of training and learning should be regarded as an integral component of an organisation's service management strategy. 


\section{TABLE OF CONTENTS}

ACKNOWLEDGEMENTS

ABSTRACT ...II

CHAPTER 1 INTRODUCTION.

THE RESEARCH CONTEXT.

1

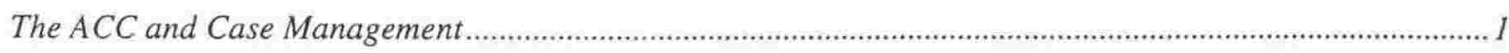

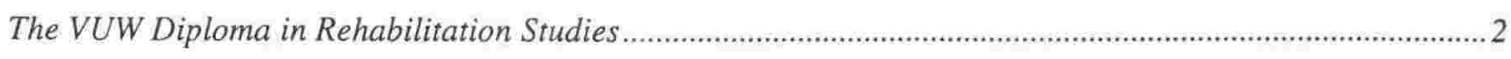

PERSONAL INTEREST IN THE RESEARCH TOPIC

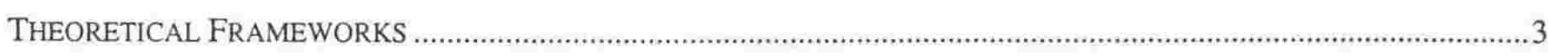

Service Management, Case Management and the Human Services ...........................................................4

Experiential Learning, Action Learning and Adult Education ................................................................

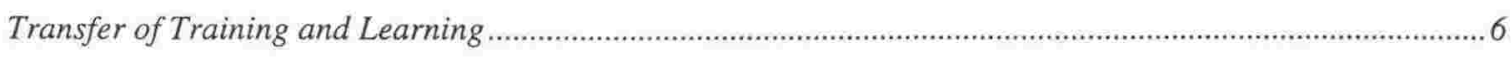

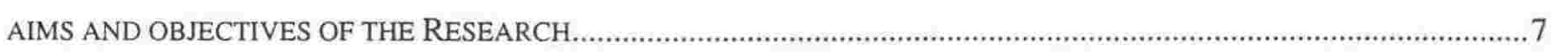

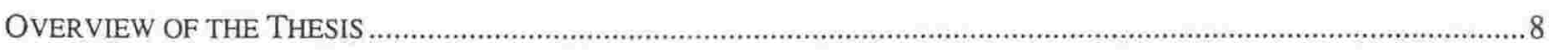

Chapter Summary

\section{CHAPTER 2 MANAGING A NATIONAL REHABILITATION SERVICE: THE TARGET ORGANISATION ......................................................................................................................................}

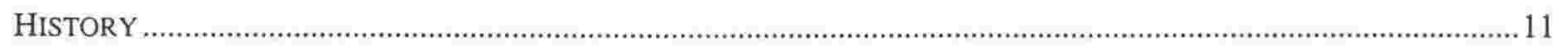

THE ACCIDENT REHABILITATION AND COMPENSATION INSURANCE CORPORATION …….......................................14

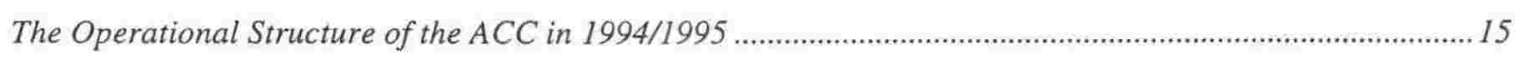

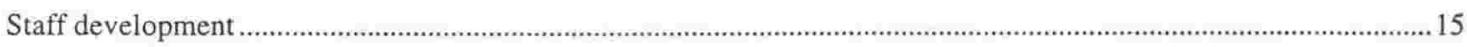

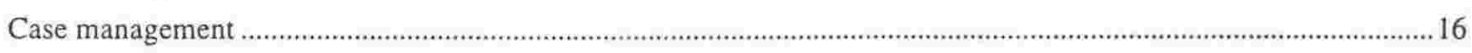

THE VUW DIPLOMA IN REHABILITATION STUDIES

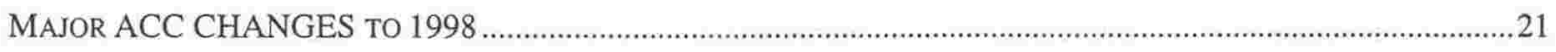

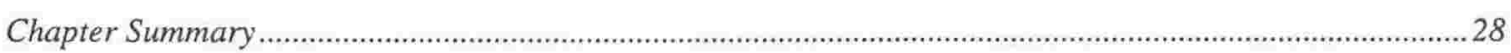

CHAPTER 3 MANAGING THE THEORETICAL FRAMEWORKS: A LITERATURE REVIEW .........29

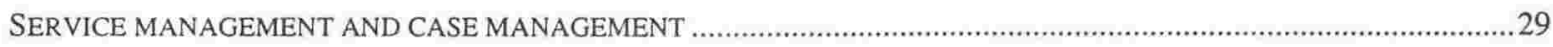

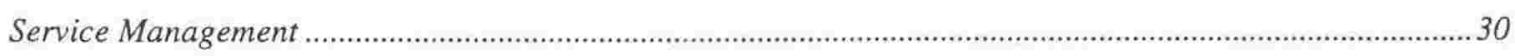

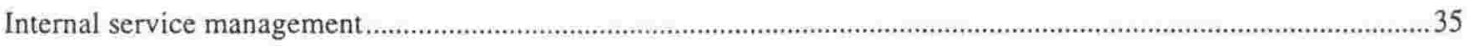

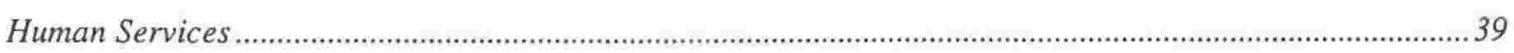

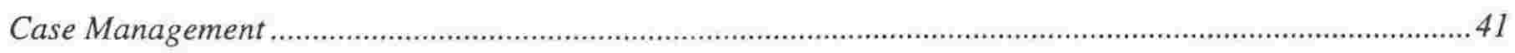

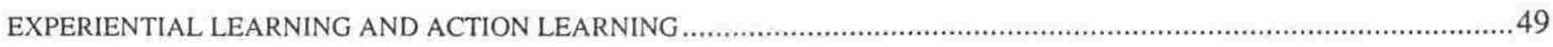

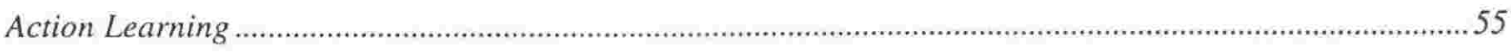

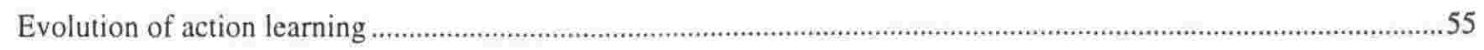

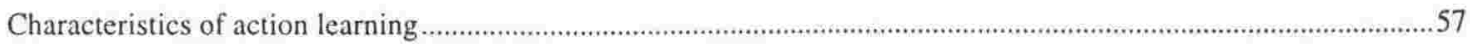


TRANSFER OF LEARNING AND TRAINING

Terminology .67

What is transfer of learning?

Why is it important? 69

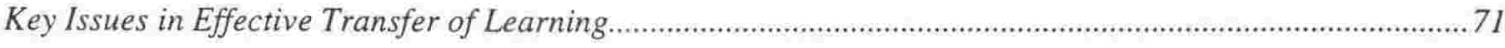

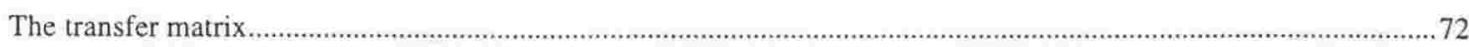

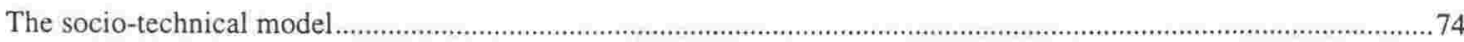

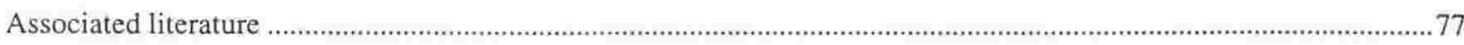

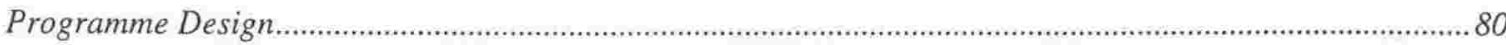

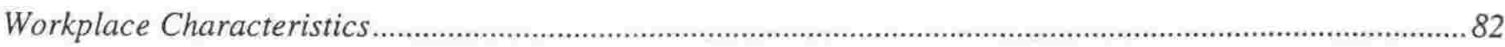

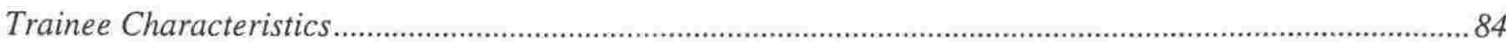

Funded Evaluation of the VUW Diploma in Rehabilitation Studies ......................................................... 88

Chapter Summary and Location of this Research ................................................................................... 89

CHAPTER 4 MANAGING THE ENQUIRY: THE CHOICE OF METHODOLOGY...............................90

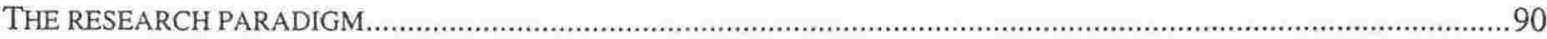

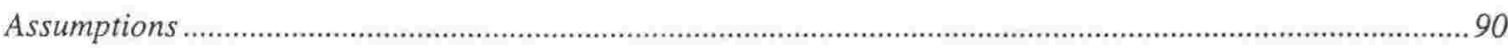

My Choice of Research Paradigm and World View ....................................................................................93

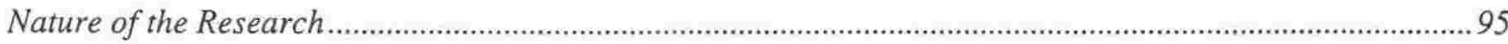

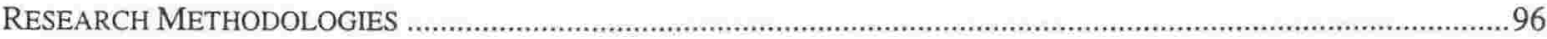

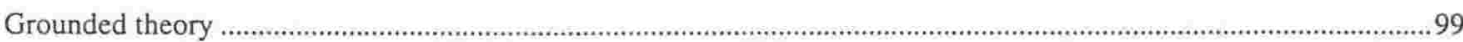

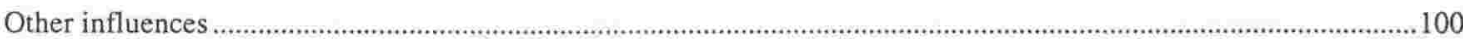

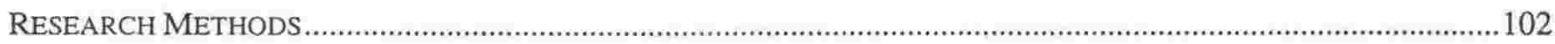

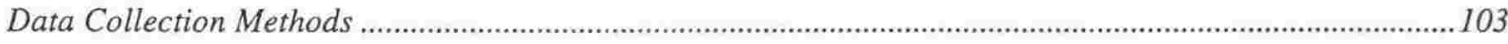

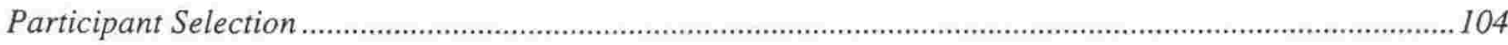

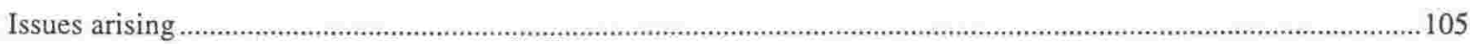

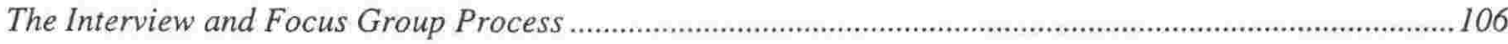

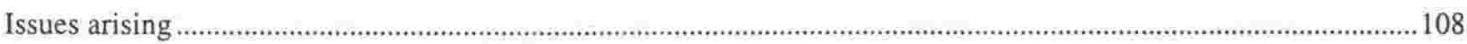

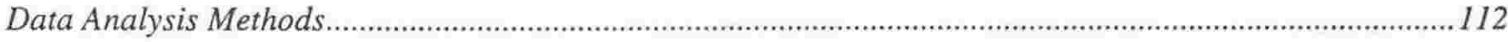

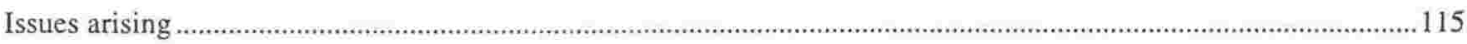

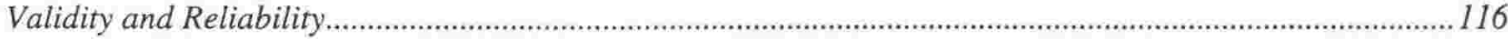

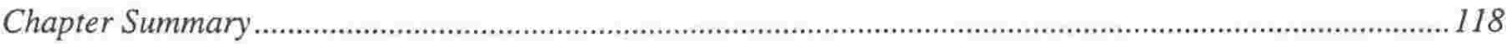

CHAPTER 5 MANAGING THE DATA: A SUMMARY OF THE FINDINGS

DATA COLLECTED TWELVE MONTHS POST COURSE......

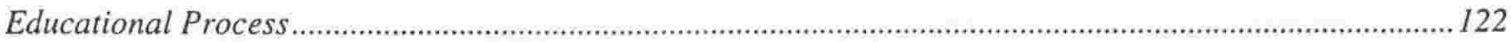

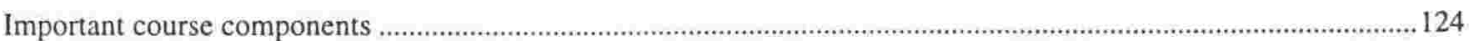

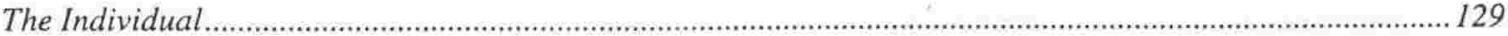

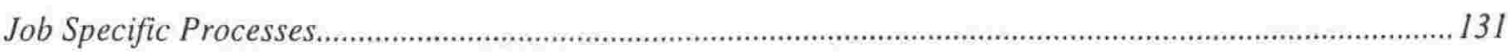


Organisational Factors

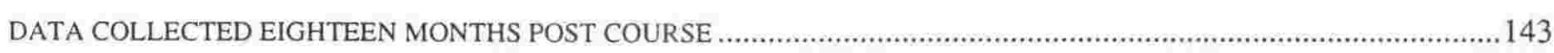

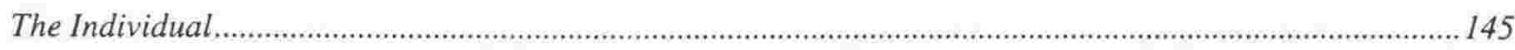

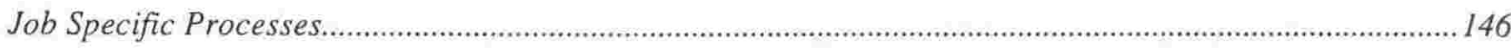

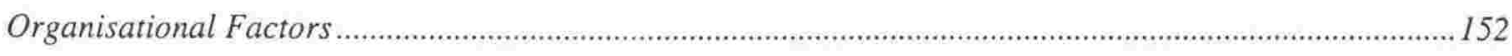

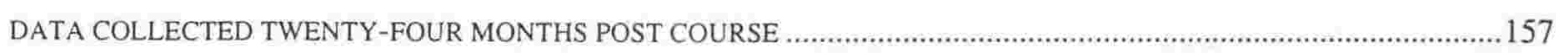

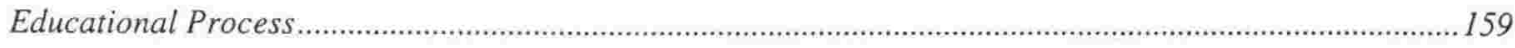

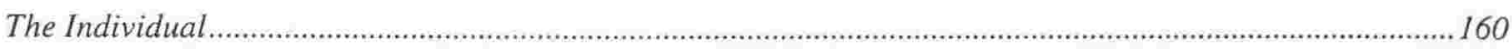

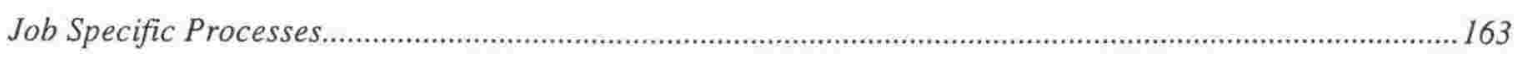

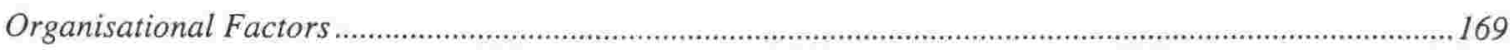

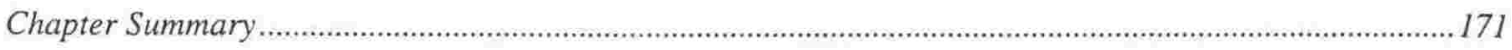

CHAPTER 6 MANAGING THE ANALYSIS OF THE FINDINGS: A DISCUSSION............................172

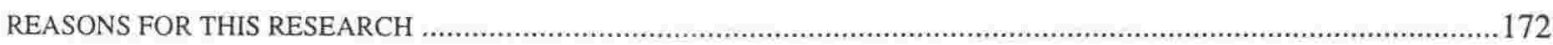

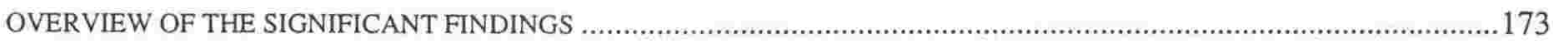

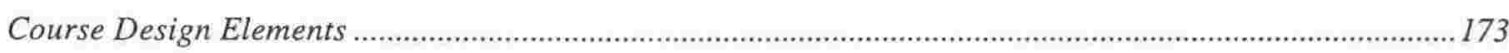

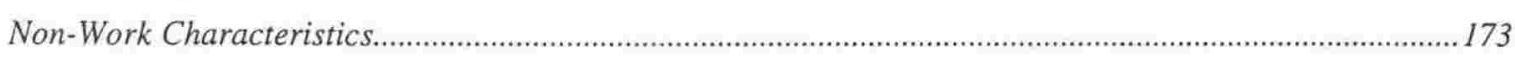

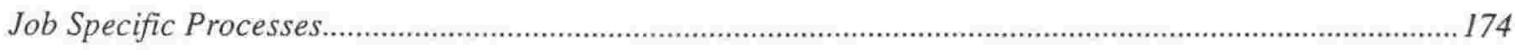

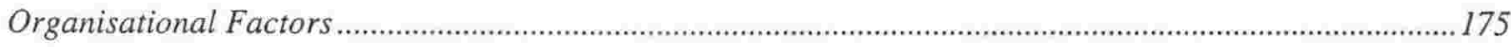

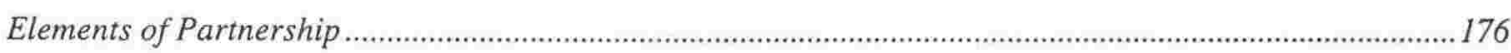

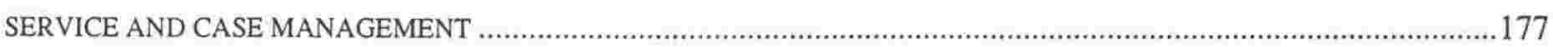

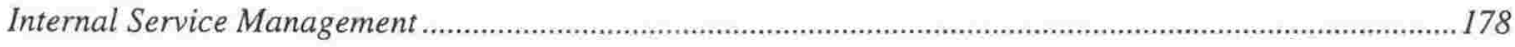

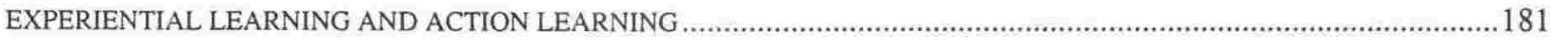

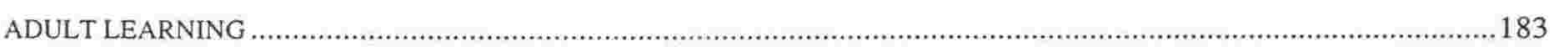

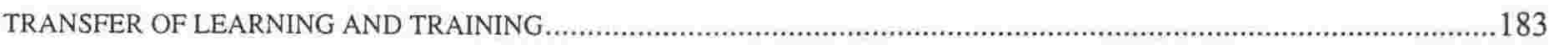

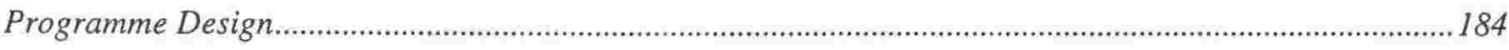

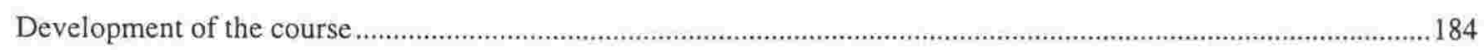

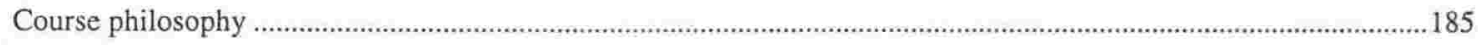

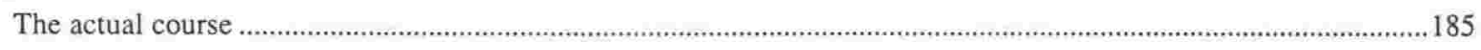

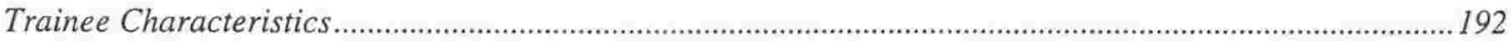

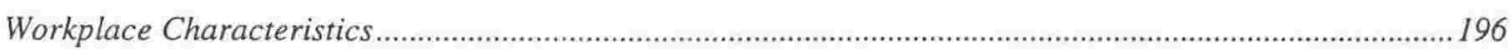

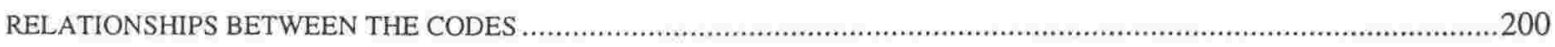

The Relationship between the Educational Process and Personal Development ......................................200

The Relationship between Personal Development, Praxis Development and Using an Holistic Approach ..202

The Relationship between Personal Development, Job Specific Processes and a Change in Practice.......... 203

The Relationship between Organisational Support and a Change in Practice .........................................204

The Relationship between Organisational Detractions and a Change in Practice ....................................206

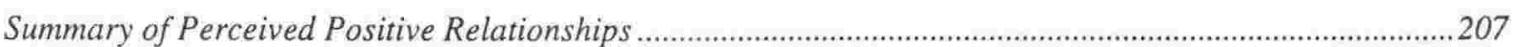

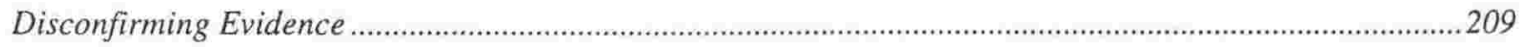

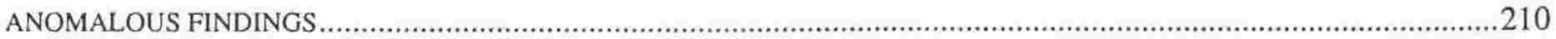


The Task/Setting/Risk Matrix.

The Setting/Task/Risk/Competence Model ….......................................................................................213

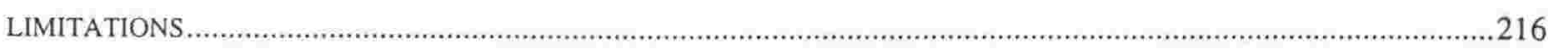

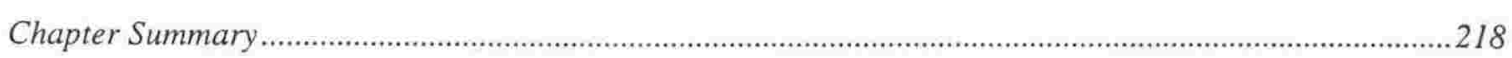

CHAPTER 7 MANAGING THE TRANSFER OF LEARNING FROM CLASSROOMS TO WORKPLACES: CONCLUSIONS AND IMPLICATIONS FOR MANAGEMENT PRACTICE...............219

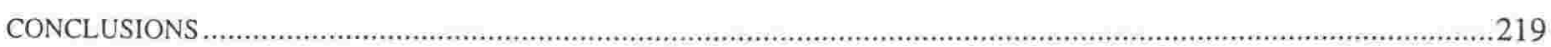

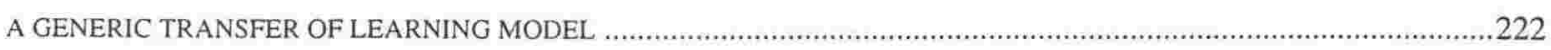

IMPLICATIONS FOR MANAGEMENT, PROFESSIONAL PRACTICE AND EDUCATIONAL PROVIDERS ..........................224

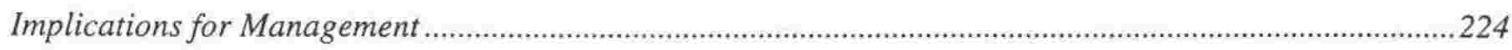

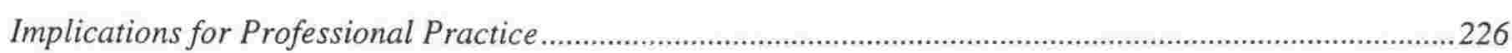

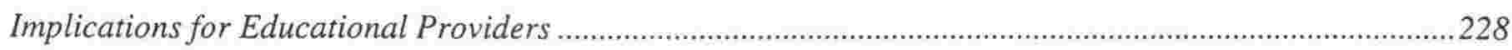

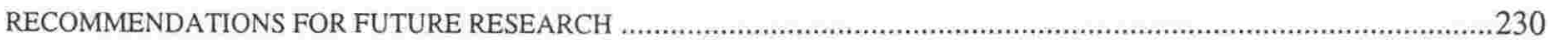

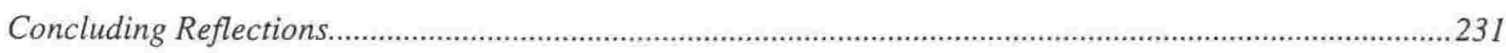

BIBLIOGRAPHY

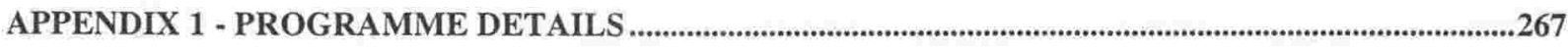

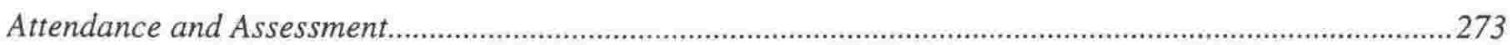

APPENDIX 2 - TRANSFER OF LEARNING LITERATURE REVIEWED..............................................274

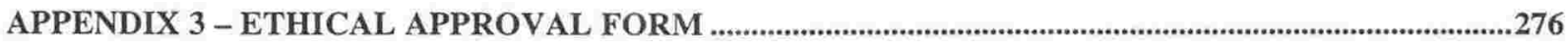

APPENDIX 4 - INTERVIEW AND FOCUS GROUP LETTERS, INFORMATION SHEET AND

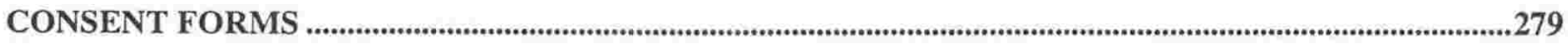

SAMPLE INTERVIEW LETTER TO SOUTHERN REGION STUDENTS - Cohort 1 ................................2279

SAMPLE INTERVIEW LETTER TO SOUTHERN REGION STUDENTS -Cohorts 2 \& $3 \ldots \ldots \ldots \ldots \ldots \ldots \ldots . . . . . . . . . . . . .280$

SAMPLE FOCUS GROUP LETTER TO NON-SOUTHERN REGION STUDENTS -Cohort 1 ...................281

SAMPLE FOCUS GROUP LETTER TO NON-SOUTHERN REGION STUDENTS-Cohorts 2 \& $3 \ldots \ldots \ldots . . .282$

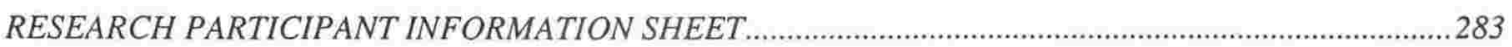

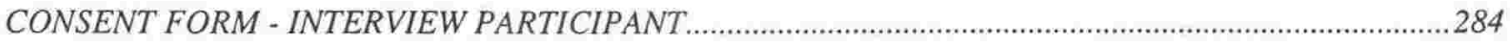

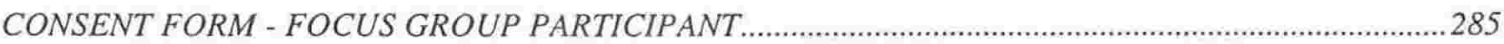

APPENDIX 5 - DRAFT 12 MONTH INTERVIEW AND FOCUS GROUP QUESTIONS ..........................286

APPENDIX 6 - FINAL 12 MONTH INTERVIEW AND FOCUS GROUP QUESTIONS...........................287

APPENDIX 7 - 18 MONTH \& 24 MONTH INTERVIEW AND FOCUS GROUP QUESTIONS ...............288 
APPENDIX 8 - ORIGINAL CODES

APPENDIX 9 - GROUPED CODES.

APPENDIX 10 - FINAL CODES USED

APPENDIX 11 - EXAMPLE OF CLIENT CONTACT SHEET DEVELOPED BY ONE PARTICIPANT

.298

APPENDIX 12 - HYPOTHESES FOR TESTING TRANSFER MODEL

GLOSSARY 304 


\section{LIST OF FIGURES}

Figure 2.1: National/Branch Relationships 22

Figure 2.2: Typical Branch Structure 25

Figure 3.1: An Overview of a Market-orientated Strategy ........................................... 33

Figure 3.2: Three-tiered View of Service Organisations .................................................. 35

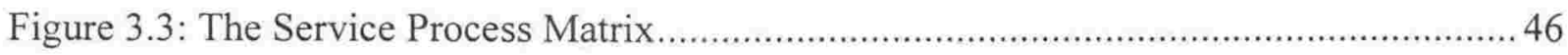

Figure 3.4: Kolb's (1984) Experiential Learning Cycle.................................................... 50

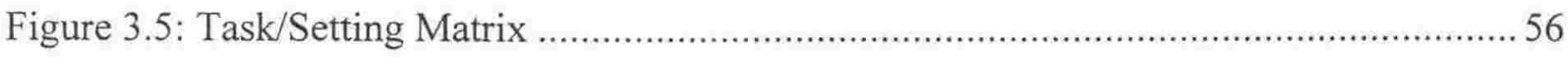

Figure 3.6: Revan's Action Learning Cycle ......................................................... 57

Figure 3.7: Learner Empowerment through a Process of Transformative Learning...............64

Figure 3.8: The Transfer Matrix ........................................................................................ 72

Figure 3.9: A Taxonomy of the Socio-technical Model of Transfer and Types of Training

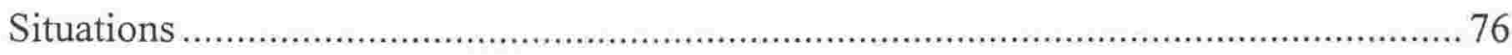

Figure 3.10: HRD Evaluation Research and Measurement Model ..................................... 78

Figure 3.11: A Model of the Transfer of Training ............................................................ 79

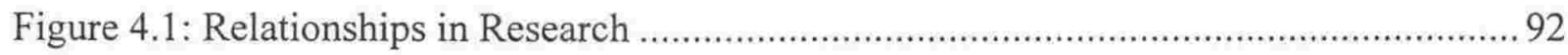

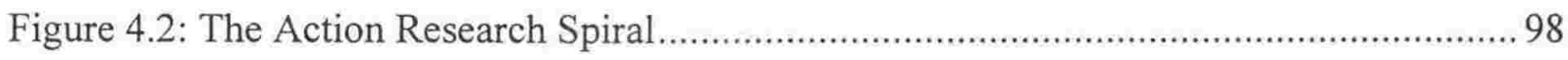

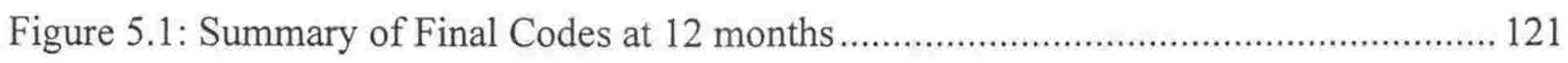

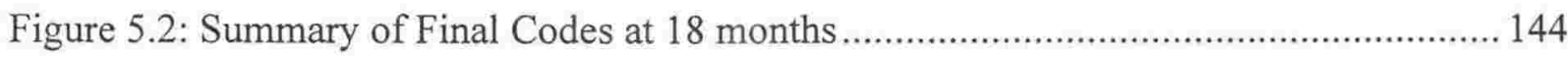

Figure 5.3: Summary of Final Codes at 24 months ..................................................... 158

Figure 6.1: Transfer of Learning Model as representative of the data collected.................. 211

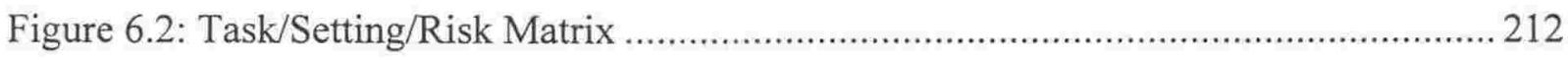

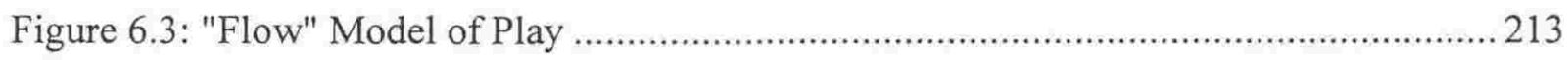

Figure 6.4: Competence/Difficulty Model for Adventure .......................................... 214

Figure 6.5: Risk/Competence Model .............................................................................. 214

Figure 6.6: Setting/Task/Risk/Competence Model ................................................... 215

Figure 7.1: Recommended Transfer of Learning Model ............................................. 223 


\section{LIST OF GRAPHS}

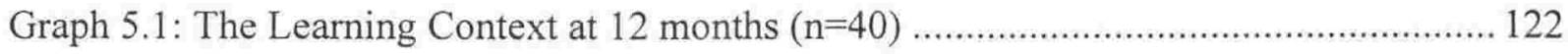

Graph 5.2: Personal \& Professional Development Day at 12 months $(\mathrm{n}=37) \ldots \ldots \ldots \ldots \ldots \ldots \ldots \ldots . . . . .124$

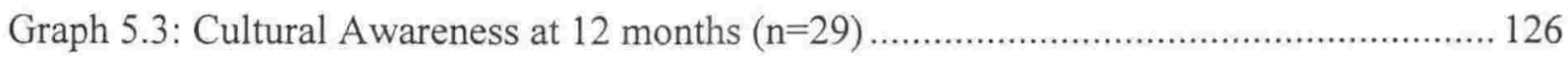

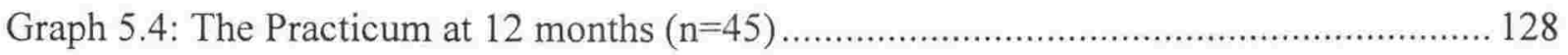

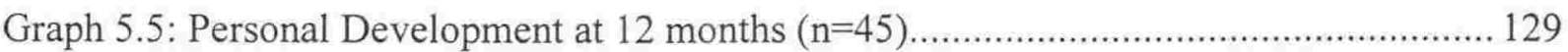

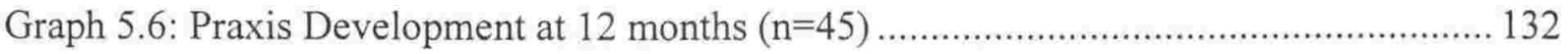

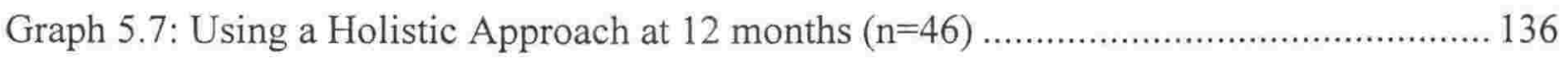

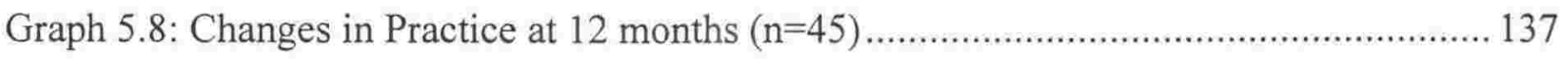

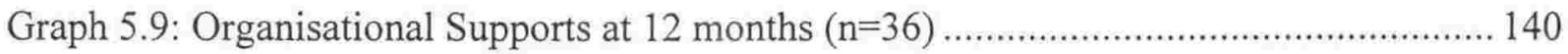

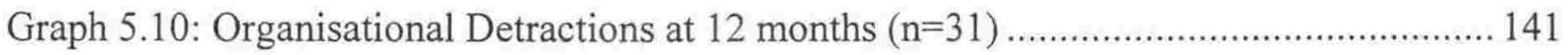

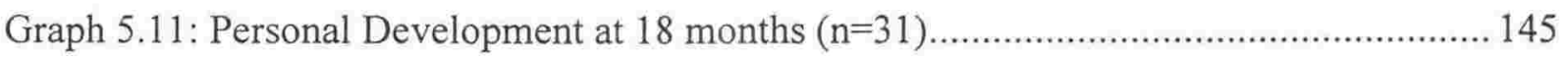

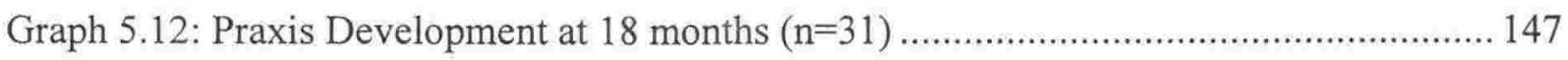

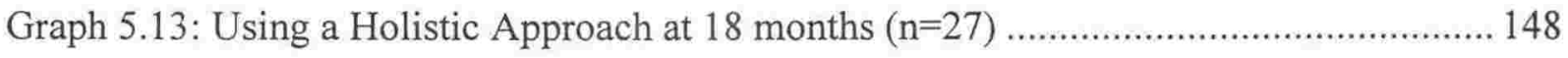

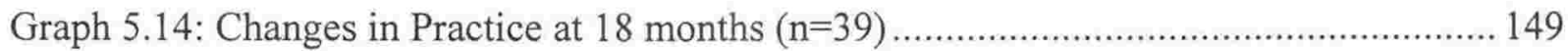

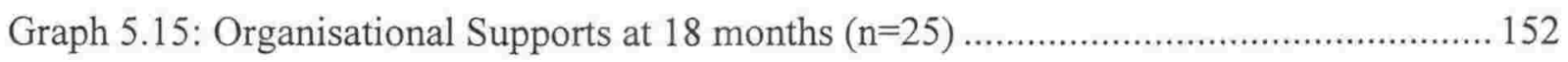

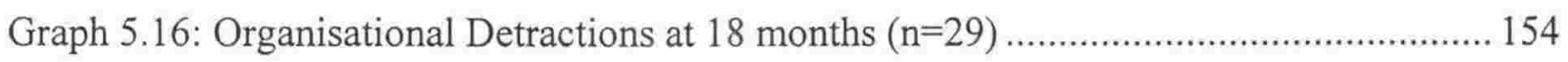

Graph 5.17: Course Components at 24 months $(n=12)$.................................................... 159

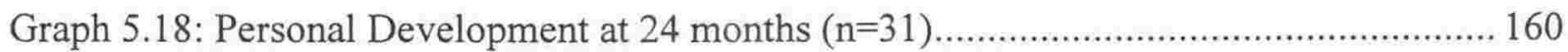

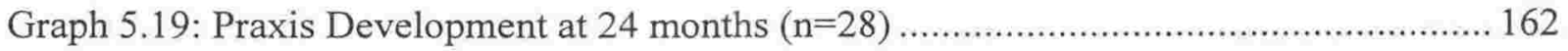

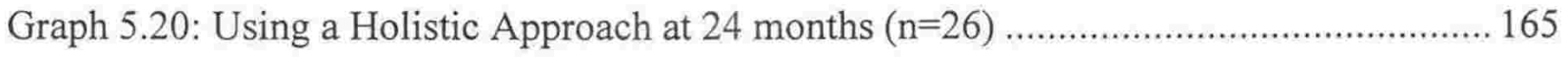

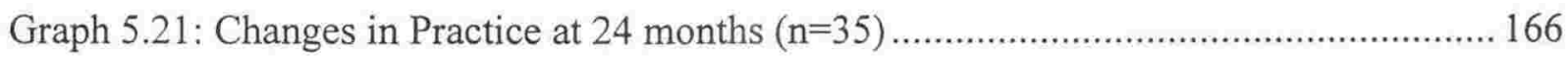

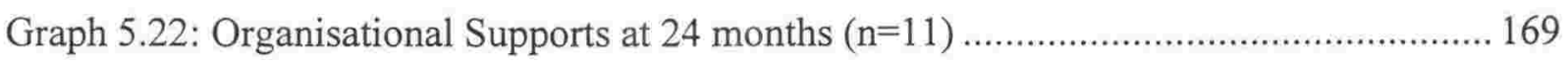

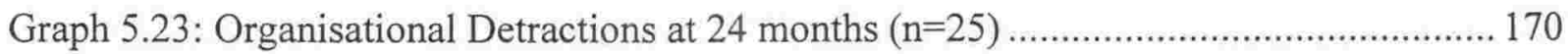




\section{LIST OF TABLES}

Table 2.1: ACC Changes during the Research Period.............................................................. 23

Table 4.1: Interview and Focus Group Data Collection Time Points................................... 104

Table 6.1: Perceived Positive Relationships between Key Themes of the Transfer of Learning Process 


\section{CHAPTER 1 INTRODUCTION}

\section{THE RESEARCH CONTEXT}

The transfer of learning is seen as an important part of any course of study. This is of particular importance when employers are paying for their staff to attend the courses. How do they know whether they receive a return on their investment? How long before the course fades into insignificance? What are the key components, which facilitate this transfer of learning?

This study focuses on the transfer of learning from the classroom to the workplace of Case Managers, who either are or were working for the Accident Rehabilitation and Compensation Insurance Company (ACC) during the period 1995 to 1998. All participants in the research were members of one of the first three cohorts of students to complete the Victoria University of Wellington (VUW) Diploma in Rehabilitation Studies. The longitudinal case study adopted for this research is set within a phenomenological paradigm, with the methodology being informed by grounded research.

\section{The ACC and Case Management}

The ACC is a government agency, which provides for no-fault, rehabilitation and compensation insurance twenty-four hours a day to all New Zealanders. The ACC scheme was based on the notion that "the people of New Zealand should share responsibility for the consequences of accidental injury, regardless of cause or fault, and that the injured should be effectively treated, and returned to their role in the community as quickly as possible, without significant personal financial loss" (ARCIC, 1995b, p.5). The rationale for its inception therefore places the ACC within the health and social welfare areas of the New Zealand government. The prevailing political thought of successive governments with respect to health and social policy have impacted on and are reflected in the varying strategic directions of the ACC, as detailed in Chapter 2. During the time of the research the ACC was the national provider of rehabilitation services to the New Zealand public. 
On 7 March 1994 case management was introduced within the ACC. According to the 1994 Annual Report, "case management was developed to provide a much higher quality of customer service to ACC claimants and to increase their rate and quality of recovery" (ARCIC, 1994a, p.16). Case management was introduced overnight with many clerical workers instantly becoming Case Managers. No training in case management was provided to staff prior to implementation and the subsequent two-day Platform training offered was essentially content driven. By the end of 1994 the ACC realised that there was a need for more in-depth training.

\section{The VUW Diploma in Rehabilitation Studies}

In December of 1994, Victoria University of Wellington was approached by the ACC to design and deliver a tailor-made course, which would change the practice of their Case Managers and improve service delivery through case management. The course was fully funded by the ACC and consisted of the twenty-seven week post-experience VUW Diploma in Rehabilitation Studies. The VUW Diploma was divided into a twelve-week residential period at Victoria University covering six modules of study, followed by a supervised fourteen-week work-based practicum - module seven. The eighth and final module was held back in Wellington. The first Cohort of forty students started their course on 1 May 1995. The VUW Diploma in Rehabilitation Studies was offered until 31 May 1997. The course is still listed in the Victoria University Calendar, but is dormant whilst the University undergoes restructuring.

\section{PERSONAL INTEREST IN THE RESEARCH TOPIC}

My interest in the transfer of training and learning originally developed from outdoor management development programmes and my interest in experiential learning. At first I was considering a comparative study looking at how well transfer took place from the VUW Diploma in Rehabilitation Studies, an experientially based non-outdoor programme, compared with an outdoor programme. However, the complexities of this, including cost and time, proved prohibitive. In addition, the VUW Diploma programme was much longer than any outdoor management development programme in New Zealand and had different 
specified objectives. Most outdoor management programmes focus on team building, leadership, problem solving and more generic leadership skills, whereas the VUW Diploma focused on developing some of these generic skills, but also placed an emphasis on specific skills development for Case Managers, as well as personal development in accordance with individual needs.

On further reflection it seemed possible to develop a case study based entirely on the experiences of the VUW Diploma participants. This study could still focus on the transfer of training and learning and be over the long term (up to twenty-four months after completing the course) rather than the short term, as had been intended with the comparative study. I wanted the study to be more than evaluative, in also portraying the participant's perspectives rather than relying on course designer's and supervisor's input, as has been the case in most other studies on the transfer of training and learning. My research would still consider the value of experientially based courses, with a particular focus on action learning and its link with adult education.

\section{THEORETICAL FRAMEWORKS}

This research could be located in a number of fields of study and as such the literature drawn on is eclectic, rather than firmly situated in one area. Having said this, the overarching framework is service management and the research should be seen in that light. Whilst it is recognised that the role of the external customer in defining and assessing service quality is important, the focus of this research was on the process and limited to the participants perceptions of service improvement. The service management literature reviewed focuses, therefore, on human resource management and internal service provision. In order to address the issue of improved service delivery as sought by the ACC, participants were asked to qualify and exemplify how they had achieved this in their practice and is detailed in Chapter 5. The literature from the main theoretical areas is briefly introduced at this stage, before being discussed in detail in Chapter 3. 


\section{Service Management, Case Management and the Human Services}

Quality customer service is seen as important in most organisations (Grönroos, 1990, 1994; Gummesson, 1994; Mattsson, 1994; Schneider, 1994; Schneider \& Bowen, 1995), and should be considered as an integral, not merely important, component of the human services (Blois, 1992; Dickens, 1996; Skelcher, 1992). The service industry differs from industries selling a product, as there is only one opportunity to provide quality customer service. It is based on one point in time and an experience, often called the 'moment of truth' (Carlzon, 1987; Normann, 1984). Case management can be argued to be part of the human services, as it is associated with providing the co-ordination of services to a particular individual and improving peoples' welfare. Within this, Case Managers are the deliverers of the service - the managers of the 'moments of truth'. Having staff, who can provide this service in a timely, professional and cost-effective manner, is crucial to an organisation such as the ACC. To achieve this an integrated organisational approach to case management is advocated by Aliotta (1996) and Stiller \& Brown (1996), requiring appropriate policies and practices for its implementation to be successful. This is similar to much of the internal service management literature, which argues that employees must be satisfied with their work environment before they can provide quality customer service (Bailyn, Fletcher \& Kolb, 1997; Bowen \& Lawler, 1995; Hallowell, Schlessinger \& Zornitsky, 1996; Redman \& Mathews, 1998; Schneider \& Bowen, 1995).

Training and development is considered an important part of an organisation's investment (Blanchard \& Thacker, 1999). Good staff are particularly important in the human services industry and investment in them is seen as crucial. However, until recently this has not been reflected in the time and money spent on staff training and development (Blanchard \& Thacker, 1999; Hargreaves \& Jarvis, 1998). All too often training was seen as remote and not applicable to the job at hand, with one day and week long courses being the favoured options as this meant staff were not away from the office for too much time. In more recent years there has been a realisation by human resource departments that a concerted effort needs to be put into staff training (Redman \& Mathews, 1998; Schneider, 1994; Schneider \& Bowen, 1995) and with this, specifically designed courses have become more common. This raises the question of how to identify the best course design, which will meet the training needs identified by the organisation. 


\section{Experiential Learning, Action Learning and Adult Education}

Much management training has been deemed too theoretical with the skills learned not being transferable to the workplace on return from training (Flor, 1991b; Reed \& Anthony, 1992). Given this situation, experientially based courses became more popular in an endeavour to try to move away from theoretical courses, many of which were based in the outdoors (Bank, 1994; Krouwel \& Goodwill, 1994; Priest, Attarian \& Schubert, 1993; Roland, Wagner \& Weigand, 1995). The basis of these courses is that the participant can experience a situation, debrief what has happened, reflect and learn from this and then transfer the skills back to the workplace. In the 1980s, it became fashionable to extend staff member's comfort zones by taking them away from their normal work environment and to extend them in physical and mental ways. Outdoor training for managers was one way in which this was hoped to be achieved. Activities - individual and group - were set, to elicit certain behaviours, which could be debriefed and would then, on return to work, be transferable to the work place. It was argued that by taking people away from their usual environment and introducing an element of perceived risk - mainly physical - participants would learn how to behave under stress and, once successful, would be able to apply these new found skills back in the work place (Flor, 1991b; Priest et al., 1993).

Action learning, a form of experiential education introduced by Revans in the late 1940s seeks to combine personal and professional development by integrating the work place with the learning experience (Bunning, 1992; Inglis, 1994; McGill \& Beaty, 1995; Revans, 1982; Weinstein, 1995). The action learning process extends Kolb's (1984) learning cycle, which involves taking part in concrete experiences, reflecting on these, making generalisations from the reflections and then acting on the new knowledge, by including the use of relevant resources and literature relevant to the issue. The importance of reflection is also emphasised in the work of Schön (1983) who encourages professionals to reflect on their experiences and learn from them. Associated with this is the adult learning literature, which also advocates the importance of reflection in trying to achieve personal change (Cranton, 1994; Mezirow, 1990, 1996; Reynolds, 1998). 
The link between individual and organisational learning is discussed in the organisational development literature (Argyris, 1982, 1994; Argyris \& Schön, 1978; Kim, 1993; Senge, 1990). The emphasis here is on how to facilitate organisational learning from individual learning. Individuals may have learned about double-loop learning (Argyris, 1982, 1994) and challenged their mental models (Argyris, 1982; Senge, 1990) but applying this in the workplace often presents some difficulties.

\section{Transfer of Training and Learning}

Management development training has proliferated over the last ten years (Blanchard \& Thacker, 1999), and with this has come the question about its effectiveness - particularly in the long term. Organisations invest both time and money in their staff, so it is prudent to know how effective the training is likely to be, whether it will actually transfer back to the work place and what the effects of course fade-out, over time, are likely to be. The terms training and learning are often used synonymously in the literature (Cormier \& Hagman, 1987). However, in general, training has more of a task focus, whereas learning has broader implications and is seen to also include behavioural characteristics. In the context of this research the broader term - transfer of learning - will be used, as the transfer sought by the ACC included both specific task related skills and behavioural characteristics. The interest in this area is not new, with literature on this topic existing in education (Bereiter, 1995; Gass, 1989; Marini \& Genereux, 1995), psychology (Baldwin \& Ford, 1988; Collinson \& Brook, 1997; Cormier \& Hagman, 1987; McSherry \& Taylor, 1994; Tracey, Tannenbaum \& Kavanagh, 1995) and management (Analoui, 1993; Broad \& Newstrom, 1992; Garavaglia, 1993; Gregoire, Propp \& Poertner, 1998; Holton, 1996; Xiao, 1996), some of it dating back to the beginning of this century. Most of the literature, however, has evolved since the 1950s.

The factors affecting the transfer of learning are generally grouped into three areas - the programme design, the characteristics of the individual participant and the work environment (Baldwin \& Ford, 1988; Broad \& Newstrom; Gregoire et al., 1998). Research, in the adventure education (Gass, 1989) and outdoor development area (Priest, Attarian \& Schubert, 1993; Priest, 1995), identified different types of transfer, which took place as a 
result of training. These included specific, non-specific and metaphoric (see Glossary). Gass (1989) concluded that the key to transfer lay in the selection or design of appropriate learning activities and the teaching methodology. The concept of metaphoric transfer has been further developed by Priest (1995), who after extensive work with outdoor management development programmes has identified the importance of isomorphic framing (see Glossary) of activities in achieving successful transfer of learning. The importance of metaphors has also been discussed in the management literature (Morgan, 1986; Schön, 1983). McGraw (1993) approached the problem of transfer from an organisational development point of view. He draws on the work of Mol \& Vermeulen (1988) who identified six elements, which needed to be present for management development to be successful. McGraw (1993) concluded that in order for transfer of learning to be lasting for the organisation and the individual "a thorough process of consultation between provider and the client organisation must be undertaken" (1993, p.52).

\section{AIMS AND OBJECTIVES OF THE RESEARCH}

The aims of the research were to:

- identify the factors which facilitate the transfer of learning from an adult learning environment, using action learning methods of instruction, to the work place; and to

- develop a model which optimises the transfer of learning from the classroom to the workplace for adult learners.

The research objectives were to:

- consider the changes engendered in the individual and the organisation in the long term, as a result of having completed VUW Diploma in Rehabilitation Studies;

- establish the role of partnerships between course providers (Victoria University) and the sponsoring organisation (ACC);

- examine the methodological issues involved in measuring the transfer of learning from theory to practice; and to

- develop a transfer of learning model from the data collected. 
The research questions included:

- What course design elements contribute to the transfer of learning for adult learners on an action learning course?

- What non-work characteristics facilitate the transfer of learning?

- What organisational factors facilitate the transfer of learning?

- What elements of partnership are crucial for the transfer of learning to take place?

The research began in March 1996, with the data collection phase lasting from 1 November 1996 to 31 August 1998.

\section{OVERVIEW OF THE THESIS}

Chapter 2 considers the ACC as an organisation. The ACC's history and structure are presented, as well as the rationale for the development of the VUW Diploma in Rehabilitation Studies. The chapter also highlights some of the changes, which took place within the ACC during the study period.

The third chapter reviews the literature associated with service management, case management, experiential and action learning, adult learning and the transfer of training and learning. Within this chapter, it is suggested that case management, as part of the human services, can be seen as a distinct area of management within the service management field. The literature in the fields of experiential education and, in particular, action learning are considered with respect to their importance in curriculum design. There is also a brief review of the importance of adult learning, in the context of the transfer of learning. This is followed by a detailed discussion of the transfer of training and learning literature, culminating in the location of this research within the literature reviewed. The main point of the literature review is to demonstrate the links between the different fields of study and to argue that the transfer of learning should be seen as an integral component of any service management programme, rather than being considered as an optional extra.

The research paradigm, my world view, the methodologies and the research methods used are considered in Chapter 4. The focus, of the phenomenological paradigm adopted for this 
study, is on process and the meaning the participants attribute to their experiences of having completed the VUW Diploma and then returned to their place of work. This chapter documents my journey through this research, the highs and lows, my personal learning and the complex nature of dealing with different methodologies. A discussion on grounded theory as the methodology informing this research is also included. The data was collected through interviews and focus groups and was subsequently analysed manually in the first instance and then using the qualitative data analysis package HyperRESEARCH 1.56.

The data from the twelve, eighteen and twenty-four month interviews and focus groups is summarised in Chapter 5. This chapter presents the Final Codes derived from each different time period and is essentially the 'voice' of the participants. It is here that the reader can gain an insight into the thoughts, feelings and changes that have taken place in the participants over the last two years of their lives. Conclusions have been drawn from these insights. Quotes have been selected to highlight the insights I have identified, but they have been kept word for word the same, so as not to impose my voice onto their comments.

Chapter 6 provides an in-depth discussion of the key findings, which are linked to the research questions and the pertinent literature. The emergent transfer of learning model is also introduced, together with the relationships between different elements of the model using the hypothesis testing function in HyperRESEARCH 1.56. Disconfirming and anomalous findings are also considered. Two other theoretical models arising from the research are suggested, with a discussion on the limitations of this research concluding the chapter.

A generic model for facilitating the transfer of learning in the human service industry is suggested in Chapter 7. The conclusions and implications for management, professional practice and educational providers are presented. Further areas of research are also recommended, together with some concluding reflections.

Finally, I accept full responsibility for the interpretation of the data, and particularly the links, which have been developed to create the transfer model. Whilst the participants' 
voice was used to determine the original codes, the subsequent grouping of codes into themes and then the final determining of codes, was achieved through my interpretation of the participant responses. The final model which has emerged from the data has been tested by the hypotheses discussed in detail in Chapter 6, and whilst associations have been found to be true, my interpretation again played an important part.

\section{Chapter Summary}

This chapter has introduced the research context and my personal interest in the topic. A brief background to the main literature pertinent to this study has been provided, together with the aims and objectives of the research. A chapter by chapter overview of the thesis has also been included. Chapter 2 will now consider in more detail the ACC and the development of the VUW Diploma in Rehabilitation Studies. 


\section{CHAPTER 2 MANAGING A NATIONAL REHABILITATION SERVICE: THE TARGET ORGANISATION}

This chapter details the background to the ACC, from its inception to the present day. The ACC's rationale for introducing case management is explained and linked to the subsequent development of training opportunities for Case Managers, in particular the VUW Diploma in Rehabilitation Studies. Some of the key changes within the ACC during the research phase and their impact on Case Managers are also discussed.

\section{HISTORY}

New Zealand was an early leader in the field of compensation for work injuries. In 1900 New Zealand passed the Workers' Compensation Act which endured with some modifications until 1974. The Act provided injured workers with weekly benefits and, in fatal cases, benefits for dependants. In the 1960s there was growing concern about the effectiveness of the Workers' Compensation Act 1956 in delivering adequate compensation for work injuries. The benefits had fallen behind national wage levels, so that by 1973 the weekly benefit was only equivalent to $52 \%$ of the average weekly wage. Many seriously injured workers were forced onto social welfare benefits after 6 years when their benefits under the Act were halted (Campbell, 1996; Perrie \& Miller, 1992).

In 1967 the Government established a Royal Commission of Inquiry into Compensation for Personal Injury in New Zealand chaired by Mr Justice Woodhouse. The resulting Woodhouse Report (cited in Perrie \& Miller, 1992, p.2) suggested a "no fault" system based on five basic principles:

1. Community responsibility;

2. Comprehensive entitlement;

3. Complete rehabilitation;

4. Real compensation; and

5. Administrative efficiency. 
Following much debate the 1972 Accident Compensation Act was passed into law by the National Government. The Act established a limited scheme only providing compensation for injured earners and the victims of motor vehicle accidents - a scheme not fully incorporating the principles of the Woodhouse Report. With the election of the Labour Government, the Accident Compensation Amendment Act 1973 was passed providing comprehensive entitlement to compensation for all people (including visitors to the country) who suffer personal injury as the result of an accident in New Zealand. Cover for the scheme applied without proof of fault, no matter how or where the accident occurred. At the same time, the common law right to sue for damages for personal injury in a New Zealand court was abolished. The Act (cited in Perrie \& Miller, 1992, p.2) had three main purposes:

1. To promote safety by preventing accidents;

2. To promote the rehabilitation of injured people; and

3. To provide compensation for the injured and for the dependants of certain people whose death resulted from injury.

Despite the various changes over the years, Accident Compensation has been part of New Zealand's social structure for 21 years. First, as the Accident Compensation Commission (ACC) in 1974, then as a Corporation in 1981 and since 1992 as the Accident Rehabilitation and Compensation Insurance Corporation (ARCIC). The organisation despite its name change is still referred to as the ACC and this will be the abbreviation used throughout this research.

Initially, the ACC set up a network of branches to help the State Insurance Office with settling claims. These branches also provided the bases for the growing number of rehabilitation officers, which were being employed by the Commission. It was not until 1977 that the ACC split from State Insurance and set up its first full branch office in Dunedin (Campbell, 1996). The morale of staff was very high during these founding years, as "they considered themselves privileged to be taking part in such an innovative experiment" (Campbell, 1996, p.48). However, over time staff morale diminished, largely due to the Commission being too controlling, which was reflected in the service provided to 
claimants. This was echoed in a study on the ACC's rehabilitation function undertaken for the World Rehabilitation Fund. It was stated that:

All too often, claims personnel expressed low confidence in the Commission's rehabilitation efforts while the liaison [rehabilitation] officers expressed dissatisfaction with referral patterns of the claims people. After much discussion, both individually in both specialty areas (claims and rehabilitation) and at all levels of administration and service delivery, one gets the impression that claims adjusters are making rehabilitation decisions. Work return and adjustment issues were being decided by claims deadlines rather than good medical management and rehabilitation planning (Campbell, 1996, pp. 49-50).

The report was, however, complimentary about the rehabilitation liaison officers. Nevertheless, it did state that:

... they also need tools to do their job. Currently such tools are minimally evident. Role strain, role confusion, will continue to exist with role conflicts preventing the expression of a strong rehabilitation policy and strategies. The lack of rehabilitation expertise within the Commission creates a low profile for rehabilitation and an over emphasis on the economic compensation aspects (Campbell, 1996, p.50).

The change from the Commission to the Corporation in 1981 heralded a time of great change for the ACC, involving a new management structure and delegation of increased responsibility to regional and district offices. The rationale was to make the organisation more efficient and to also reduce operating costs. As the 1982 Annual Report stated:

The change in policy is a departure from what used to be called an 'insurance attitude', a somewhat grudging attitude towards claims (Campbell, 1996, p.55).

An increased emphasis on prevention and rehabilitation was also evident in the 1982 Annual Report.

Concern with respect to the escalating costs of accident compensation and the obligations on government following the removal of the right to sue led to a Ministerial Working Party on the Accident Compensation Corporation and Incapacity in 1991. Despite the wider terms of reference, the resultant report focused almost exclusively on the cost issues. It is suggested by Campbell (1996, p.80) that no detailed analysis of the financial situation was made and that "no hard data was offered to support the assertions". The introduction of the 1992 ARCIC Act brought with it considerable changes. These were primarily 
concerned with reducing the costs to funders of the scheme and in its application removed much of the discretion, which was available to the ACC originating from the Woodhouse Report in 1967. With these new changes and the emphasis on financial affordability came further issues with regard to staff. In a report on the procedures of the ACC by District Court Chief Judge Trapski in 1994 there was:

serious condemnation of the manner in which ACC claim staff handle claims. Their poor attitude to claimants, as evidenced by an intimidatory approach, was among the matters unfavourably commented on. . . . and the lack of appreciation of the need for confidentiality were severely criticised (Campbell, 1996, p.65).

This may have resulted from the fact that originally the ACC had a clerical function as a processor of compensation payments. However, over time a different skill set was being required for its staff in accordance with the changes in legislation. It was not until the Strategic Directions 1994-1997 document that any specific statement was made about the organisation's staff. It states that the organisation:

will ensure staff have the skills, confidence and positive attitudes necessary to achieve the organisation's purpose (ARCIC, 1994b, p.4).

The introduction of case management in March 1994 was seen as one of the first steps towards improving the ACC's operation, with particular emphasis on focusing on the needs of the claimant. With case management there has been a move towards an integrated managed care philosophy across the Corporation's activities, from injury prevention to rehabilitation.

\section{THE ACCIDENT REHABILITATION AND COMPENSATION INSURANCE CORPORATION}

The ACC provides for no-fault, rehabilitation and compensation insurance 24 hours a day to all New Zealanders. The Strategic Directions 1994-1997 document outlines the purpose of the $\mathrm{ACC}$ as being to:

reduce the social, economic and physical impact of personal injury on individuals and the community (ARCIC, 1994b, p.3).

The objective of ACC, as outlined in its 1996 Annual Report is to: 
administer the scheme so as to secure for injured people the prompt, sustainable and cost-effective return to independent living and employment to the maximum degree practicable (ARCIC, 1996a, p.42).

The principles and parameters of ACC operations are set out in the ARCIC Act 1992, which describes the main areas of activity as injury prevention, rehabilitation and compensation. The core business of the ACC is divided into three areas:

1. the management of claims;

2. the management of claimants, and

3. the management of the schemes finances and fund balances. (ARCIC, 1996a, p.8)

\section{The Operational Structure of the ACC in 1994/1995}

Operations within the ACC consisted of a Head Office located in Wellington, four Regional Offices (Christchurch, Wellington, Hamilton, Auckland), thirty-eight branch offices throughout New Zealand from Whangarei in the North to Invercargill in the South and four Customer Service Centres (Dunedin, Wellington, Hamilton, Auckland). In addition, there were specialist units including Sensitive Claims, Medical Misadventure, Employer Relations, Rehabilitation Programmes, Medical Advisers and Review. All of these reported to the General Manager, Operations, Mr Bert Driessen (ARCIC, 1995b). Each branch generally included a Branch Manager, a Principal Case Manager (PCM - see Glossary), Team Leaders (see Glossary), Case Managers, Departmental Support Officers (DSOs), Administrative Assistants and in some cases Injury Prevention Consultants.

\section{Staff development}

The vision the ACC identified for the organisation in 1994 as a whole included:

- embracing a philosophy of continuous improvement and

- fostering an environment where staff find satisfaction in their work through learning and coaching (ARCIC, 1994b). 
The organisation envisioned its staff as:

- being skilful, appropriately qualified, motivated and professional and

- following a team approach, with a consultative and supportive style in meeting internal and external service standards (ARCIC, 1994b).

Overall, the ACC was seeking to change from a process driven to an outcome driven organisation by 1997. In its Change Management and Human Resource Strategy, the ACC identified the following points:

- Shifting the approach to claimants from being one of staff exercising control by way of legislation and regulations to one of staff exercising discretion and judgement, and being judged by the achievement of measured outcomes.

- Developing the desired culture change.

- Enhancing training and career development opportunities and establishing an environment of learning and continuous improvement (ARCIC, 1994b, pp.15-16).

\section{Case management}

The aim of case management was to provide a high quality outcome focused service, resulting in a faster and better recovery for claimants and ultimately a reduction in duration and costs of claims. The main points of case management regarded as important by the ACC in terms of its use are stated in the 1994 Annual Report (ARCIC, 1994a, pp.17-18) as:

- Early identification and prevention to meet specific treatment, rehabilitation and compensation needs of injured people.

- Integrated delivery of services.

- Continuous follow-up.

- Individual accountability and personal responsibility for the management of all aspects of a claim. This includes co-ordinating all treatment, rehabilitation and compensation services. 
- More efficient reporting to ACC stakeholders on the quality of services and costs within each account.

- Having a clear customer focus in the way claims are managed.

- Implementing a multi-disciplinary and team approach in managing and reviewing claims.

- Focusing on outcomes rather than processes.

- Having in place a set of stringent performance management criteria.

- Placing case managers in hospitals to identify the specific needs of seriously injured claimants and assess the appropriateness of their programmes. Confidentiality is to be maintained at all times.

- Involving case managers in job retention for injured workers and achieving full commitment to claims and rehabilitation management from all parties. That is ACC, the injured worker, their family and employer, and their health care providers.

The ACC undertook six major initiatives when implementing case management.

1. A comprehensive change management strategy.

2. A comprehensive management training programme for branch managers over six months.

3. An extensive team building programme for all staff.

4. United States experts in workers' compensation and disability management were used to help develop a core training programme, implemented during the remainder of 1994.

5. A transition performance management system measuring the technical performance standards of staff directly involved in case management and measuring desired behaviour to achieve claimant satisfaction and team work.

6. A process to provide a measure for claimant and stakeholder satisfaction with $\mathrm{ACC}$ services.

(ARCIC, 1994a) 
It is within the context of this move toward case management that the development of the VUW Diploma in Rehabilitation Studies must be seen.

The one constant within the ACC's history has been change, as is the case with many Government departments. To be able to deal with these changes effectively the organisation must be able to respond in a timely manner, - starting with its key workers -, in the case of the ACC its Case Managers. As Rylatt (1994, p.1-2) so aptly says "Learning must generate an enthusiasm and vigour to meet such challenges 'head on' with a spirit of courage and delight, rather then fear and helplessness." The VUW Diploma in Rehabilitation Studies aimed to initiate this enthusiasm for learning, as well as provide Case Managers with the necessary skills and knowledge to fulfil the aims of case management as detailed by the ACC.

\section{THE VUW DIPLOMA IN REHABILITATION STUDIES}

The VUW Diploma in Rehabilitation Studies was a programme of professional education and training, which represented the combined efforts of a number of people to produce an industry training contract between the ACC and the Applied Social Sciences Department of Victoria University of Wellington, New Zealand. Some in-house training had been provided by the ACC after the introduction of case management. However, there was soon a realisation that a more comprehensive training programme was needed to meet the new demands of case management. For the course to be seen as successful, it was vital that the skills and knowledge learned on the course were transferable to the workplace, so that the ACC received a return on its investment. Therefore, the course sought to redress the "fadeout" effect often associated with training, by involving the ACC as much as possible at every stage of the process, adopting an action learning approach and using learning contracts during the work-based phase of the course.

The University was briefed with developing an intensive programme of professional education and training for adult learners employed as, or being recruited to become Case Managers with the ACC. The time frame provided for this development was two months and based on consultation with the General Manger, Operations of the ACC and other 
Head Office staff. At this stage, minimal consultation took place with Branch Offices or prospective candidates on the course. Once the first Cohort of students had started their course of study, training courses for PCMs were run in Wellington. These provided the PCMs with an overview of the course, their responsibilities, the contractual agreement between the ACC and Victoria University, their roles with respect to the learning and supervision contracts, as well as providing an opportunity for practical supervision practice. A visit to the Regional Office in Christchurch, where all Southern Region Branch Managers were meeting also took place. This was initiated by myself, as I felt it was necessary to provide more information to Branch Managers on the course content and processes and the expectations of them during the practicum.

In order to deliver a programme, which would meet the needs of both the organisation and the students, the course was designed around the following educational principles. In order to build on the life and work experience of the students, the course used an adult learning model (androgogy). This concept is supported by Maier who states that "knowledge acquisition demands a linking of new learning with existing understanding, by expanding the learner's knowledge repertoire" (1994, p.3). Many of the students came from a background incorporating little or no tertiary education, and hence felt quite daunted at the prospect of attending a university course. A learner-centred approach was taken by providing learning opportunities, which offered a mix of theory and practice, personal reflection and inquiry. In addition, there were lectures by practice specialists and researchers from the health and rehabilitation field, small group tasks, activity based learning, personal and professional skill development and directed study. The entire course was based around an action learning philosophy where the students were encouraged, and indeed required, to relate their experiences and learning back to their work environment.

The concept of action learning was introduced by Reg Revans in the late 1940s and became more accepted in management circles with the setting up of the Action Learning Trust in the United Kingdom in 1977. Revans (1982a,b) used action learning in organisations to assist them in solving their own problems rather than having the traditional expert consultant come in and tell the staff what to do. He argued that the people actually doing 
the tasks would be best suited to solving their own problems and working through change within the organisation - thus empowering the staff.

In addition, emphasis was put on the concept of the reflective practitioner (Schön, 1983) which encourages professionals to reflect on what they have done and to learn from their experiences. The model of action learning is best used with adult learners as they will have built up both personal and professional experiences, which can be developed and drawn on for reflection. Furthermore, the commitment to continuous learning is emphasised in action learning and as such can be seen as a useful model for human service agencies which are constantly changing and needing to be able to respond quickly. This is akin to being able to 'ride the waves of change' as discussed by Morgan (1988).

The VUW Diploma in Rehabilitation Studies attempted to maintain a balance between the needs of the organisation and the students. It was offered as a twenty-seven-week programme of professional education and training for Case Managers within the ACC. The work for the course was carried out across eight modules (300 classroom contact hours plus 200 hours of directed learning) and a work-based practicum (525 hours of directed learning). Students were enrolled in five papers and there were ten pieces of formally assessed work during the course of the programme, consisting of written and oral assignments, including one group project (see Appendix 1 for programme details). The course was divided into two parts. The first being twelve weeks off-site based at the university in Wellington and the second a supervised fourteen-week practicum based onsite at the student's own employment setting. This was then followed by a final one-week call-back module based in Wellington.

The first part involved seven one-week modules completed over the course of twelve weeks, with directed study and group work tasks built into each alternative week when students completed assignments and explored how the learning from each module might be applied back to the work place. These study weeks were seen as integral to the concept of developing reflective practitioners, in that they enabled students to reflect on the content of the preceding module and how it applied to their work situation. This built on the notion that often more is learned when less content is covered (Maier, 1994). The students were 
required to keep a journal throughout the twenty-seven weeks, which encouraged them to develop the habit of reflecting on their daily experiences, rather than merely 'doing' or 'participating' in activities and classes.

A supervised fourteen-week practicum followed the twelve-week modular part of the VUW Diploma. During the practicum the students fulfilled the requirements of their individual learning contract, carried out a practice study, undertook a taped interview and completed their rehabilitation project. The learning contract and project required the student to consult with their Branch Manager and PCM in addition to the university staff, to explore appropriate topic areas and negotiate the support made available to them by the ACC at the branch level. Throughout the practicum the students were expected to carry out their normal duties as Case Managers, so as to practice and apply their newly found skills and knowledge. The learning contract had to be endorsed by all parties, as it formed the basis for evaluation over the practicum period. Performance during the practicum was assessed by determining whether all the specified objectives in the learning contract had been achieved. At the end of the practicum, students attended one further call-back module to review and evaluate their learning contracts and to report on their project findings.

The different components of the course, as well as each module were evaluated by the participants using the VUW University Teaching and Development Centre to collate the results of the questionnaires. Following each Cohort, programme staff met with representatives of the ACC, to consider participants' feedback and make any necessary adjustments for the following Cohort of students. In addition to this internal evaluation, the ACC contracted the Department of Psychology at Massey University to conduct an evaluation of the transfer of training from the VUW Diploma in Rehabilitation Studies back to the branches (Collinson \& Brook, 1997).

\section{MAJOR ACC CHANGES TO 1998}

During the research period a number of substantial changes took place within the organisation (see Table 2.1 for a summary). These changes were predominantly driven by Head Office and/or the Pathways (formerly Acction) team (see Glossary). Framing these 
changes was the election of the first Mixed-Member-Proportional (MMP) government in October 1996, which resulted in a coalition between National and New Zealand First and a new Minister for the ACC - the Honourable Jenny Shipley.

The first major organisational change to take place was the dissolution of the four regional offices - based in Auckland, Hamilton, Wellington and Christchurch. This was announced at the end of 1996 and took effect as of 1 March 1997. The rationale behind this move was to remove one management layer within the organisation, making individual branches directly accountable to National Managers responsible for different areas (see Figure 2.1).

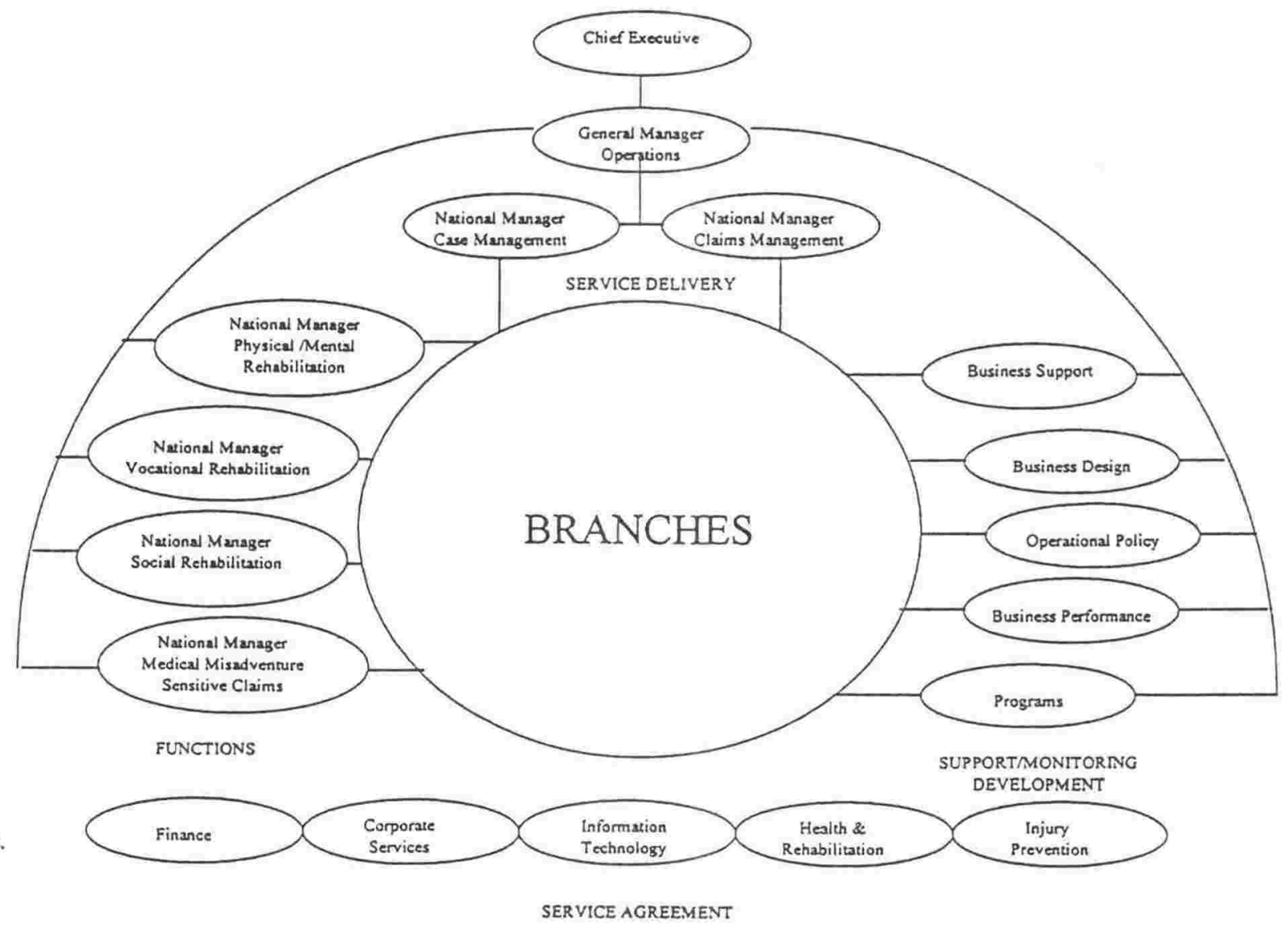

Figure 2.1: National/Branch Relationships (Driessen, 1997, p.6) 


\begin{tabular}{|c|c|}
\hline CHANGES & INTRODUCED \\
\hline \multicolumn{2}{|l|}{ Governmental } \\
\hline $\begin{array}{l}\text { MMP Election - Jenny Shipley, Minister } \\
\text { for the ACC }\end{array}$ & 15 October 1996 \\
\hline $\begin{array}{l}\text { CEO Gavin Robins dismissed for fraud - } \\
\text { acquitted of charges }\end{array}$ & $\begin{array}{l}\text { 1 September } 1997 \\
\text { November } 1998\end{array}$ \\
\hline $\begin{array}{l}\text { Jenny Shipley Prime Minister and Murray } \\
\text { McCully, Minister for the ACC }\end{array}$ & 1 December 1997 \\
\hline \multicolumn{2}{|l|}{ Structural } \\
\hline Dissolution of four Regional Offices & 1 March 1997 \\
\hline Reorganisation of Branch structure & 1 May 1997 \\
\hline $\begin{array}{l}\text { New Branch positions created, with } \\
\text { disbandonment of some of the positions } \\
\text { created in May } 1997\end{array}$ & 1 March 1998 \\
\hline $\begin{array}{l}\text { Regional Offices re-instituted with a slight } \\
\text { modification of the geographical areas }\end{array}$ & 1 March 1998 \\
\hline \multicolumn{2}{|l|}{ Operational } \\
\hline High/low risk split (see Glossary) & 1 January 1997 \\
\hline Pathways & 1 May 1997 \\
\hline \multicolumn{2}{|l|}{ Legislative } \\
\hline Weekly Compensation (see Glossary) & 1 June 1996 \\
\hline Homehelp Regulations (see Glossary) & December 1996 \\
\hline $\begin{array}{l}\text { Social Rehabilitation Regulations (see } \\
\text { Glossary) }\end{array}$ & December 1996 \\
\hline $\begin{array}{l}\text { Rehabilitation and Review of Long-Term } \\
\text { Claimants (RARLTC) (see Glossary) }\end{array}$ & June 1997 \\
\hline Work Capacity Testing (see Glossary) & November 1997 \\
\hline Accident compensation open to competition & 1 July 1999 \\
\hline
\end{tabular}

Table 2.1: ACC Changes during the Research Period 
This change was seen as:

The first step in the move to larger 'self-supporting' branches. . . The aim is to ensure that our people make a direct contribution to improving outcomes for claimants and the scheme, rather than focusing purely on co-ordinating or supervising (Driessen, 1997, p.5).

At about the same time, January 1997, the Strategic Directions 1997-2000 document was released. The vision for the ACC to the year 2000 was identified as:

A world leader in injury prevention, accident insurance and rehabilitation. Creating value through claimant satisfaction and managed scheme costs. Fair, equitable and affordable premiums. Fast and lasting return to work or independence (ARCIC, 1997b, p.3)

As can be seen, by 1997, the vision for the ACC no longer specifically mentioned the organisation and its staff in the Strategic Directions 1997-200 document. Instead, it was more general in stating that it would do everything in its "power to achieve a low-cost, effective corporation" and use the "best corporate practice to do so" (ARCIC, 1997b, p.3). The staff were, however, mentioned separately later in the document where it states that:

The Corporation will provide:

- leadership by establishing and practising values that ACC must have to be successful;

- a working environment which fosters integrity, personal responsibility, team work and cooperation, development and professionalism;

- training so that its people can accomplish their goals and be committed to achieving the goals and objectives of the Corporation and implementing its strategies (ARCIC, 1997b, p.5).

These two documents (Driessen, $1997 \&$ ARCIC, 1997b) should be seen as going hand in hand, as it is argued that the new environment for the ACC operations is directly linked to trying to support the Strategic Directions 1997-2000 in the area of service delivery. The aim of this restructuring, which not only involved regional offices but affected branches directly, was to: 
- develop an environment that promotes and encourages ACC's values so that we deal with claimants, providers and funders of the scheme through open communication; honestly; with respect; promptly and efficiently; equitably and fairly; helpfully and privately;

- link ACC's performance to each staff member's performance;

- improve the quality of service and decision-making, leading to overall scheme cost reductions;

- balance consistency, innovation and continual improvement so we can maintain business as usual and provide flexibility for the future (Driessen, 1997, p.2).

This new environment was seen as necessary in the development of case management and was seen as improving the situation for both claimants and staff. The emphasis was on promoting independence, ability, recovery and return to good health for claimants and education, accountability, forward planning and responsibility for the staff (Driessen, 1997). Accordingly the branch structure was reorganised. Essentially, each branch was separated into case management and claims management streams, with a number of specialist roles - Quality Assurance, Personal and Professional Development, Job Placement - providing support. The role of the Principal Case Manager was removed. These changes can be seen in Figure 2.2.

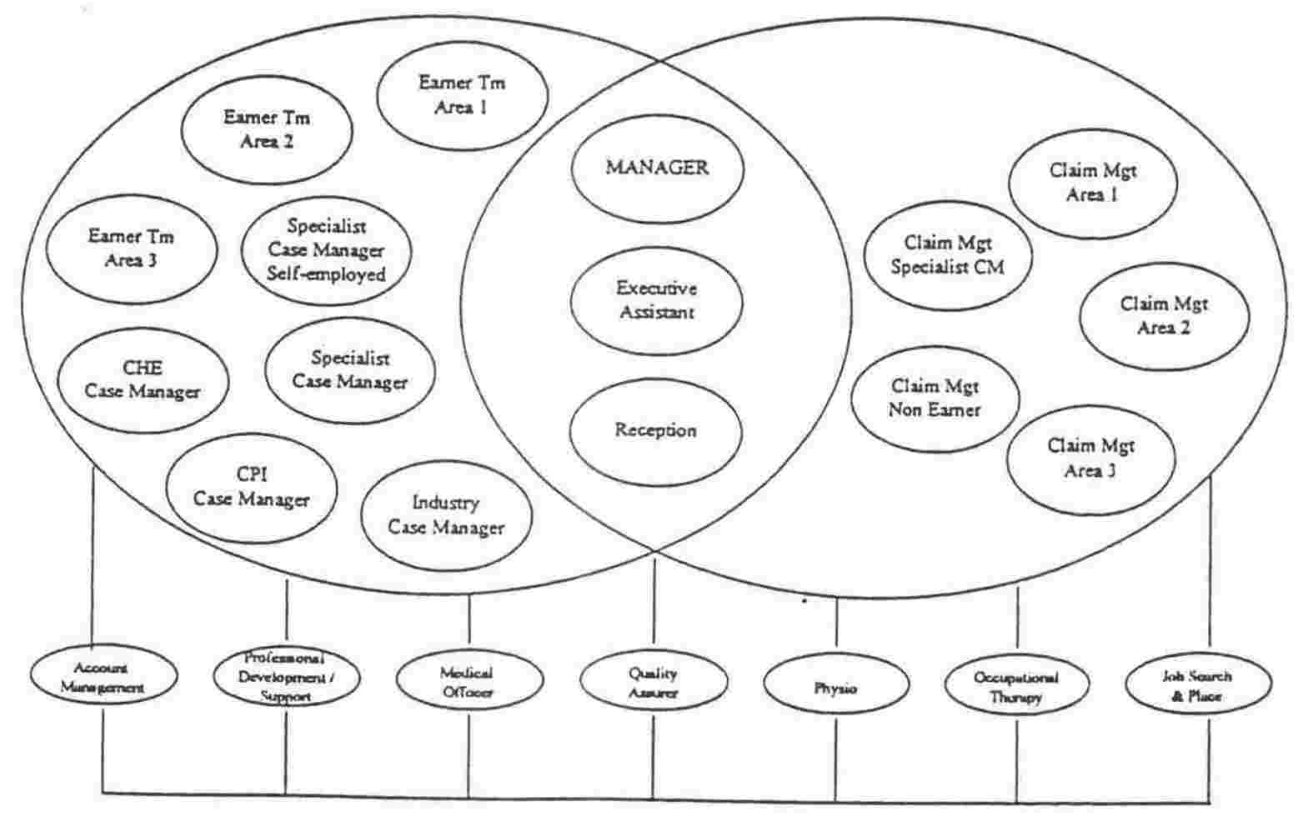

SUPPORT / MENTOR / COACH

Figure 2.2: Typical Branch Structure (Driessen, 1997, p.4) 
Other changes introduced in mid-1997, included new information technology developed by the Pathways team to enable Case Managers to focus on case managing rather than processing. The software was developed as a case management tool to provide baseline information on clients and move away from paper files. It is also meant to assist Case Managers in determining whether claimants are in the low or high risk category.

Driessen states that:

The key points of the new environment developed so far have come from feedback already received from staff over the past two years and through last year's consultation process. While the key features of the structure have been agreed by the Board of Directors, there will be a lot of opportunity for staff to be involved and share their views on the detail which must be developed of how the structure will be put in place $(1997$, p.7).

During the latter part of 1997 staff underwent psychological testing which involved change consultants (PA consulting) who then, together with the Branch Manager, decided who should do which job. In the midst of this very uncertain time for staff, the CEO Gavin Robbins was dismissed for fraud and the Chairman of the Board charged with running the organisation until a person was found to fill the role. A few months later the General Manager, Operations, Bert Driessen tendered his resignation. In December 1997 the Minister for the Accident Rehabilitation and Compensation Insurance Company - the Honourable Jenny Shipley - became Prime Minister of New Zealand, providing a new Minister in the form of the Honourable Murray McCully.

With the appointment of the new General Manager, Operations, Gary Burns, new changes were made. The position of Regional Manager was re-established to take effect from the beginning of 1998, with a slight modification of the geographical areas involved, but essentially fulfilling the same role. The new positions established mid-1997 of Quality Assurance, Personal and Professional Development and Job Placement were disbanded, with the introduction of Team Managers and Technical Claims Officers (see Glossary), to take effect from the end of March 1998. 
These changes demonstrate that what is said on paper and the practice of what happens in reality are, at times, not compatible. During the interviews and focus groups held in the months of April and May 1997 there was great uncertainty and distrust of the change management process at the branch level, with the restructuring seen as a fait accompli rather than an issue open for discussion. This is well summarised by the following statements made by staff from the New Plymouth Branch at a PSA (see Glossary) visit (March 20) where the new environment was being trialled:

- staff felt that there was too much confusion (lack of understanding) about the process

- believed the employer had already made up their mind (no demonstration of real consultation)

- most saw no reason for the changes

- staff are currently hopelessly behind in their work

- files are being "farmed" out to other ACC offices, creating further problems for the New Plymouth staff (this includes being abused by clients who can't appreciate reasons for delays, non-access to files etc.)

- some staff have "shopping baskets" full of current work

- New Plymouth staff are stressed out, some staff are on anti-depressants and other [sic] being prescribed medical treatment

- there are still no "finite" job descriptions

- there are still no salary scales

- the Office is 3-4 positions short and staff believe "the project team" will not be able a [sic] undertake a complete appraisal of the success or otherwise of the project

- staff are aware that this is a pilot and are concerned that they are visiting a plague on their colleagues

- there is a feeling that the consultants heading this change have a negative history of $\mathrm{ACC}$ and there is a feeling that the project team is not bringing staff on board - the culture of ACC

- the staff offered the view that "the project team had a preconceived idea of what they wanted, and so our views were not even going to be considered" 
- one staff member felt that on the basis of the identified change "I'd qualify for redundancy"

- staff had been frightened to speak out to the project team.

Many of these fears were echoed during this research. One of the branches came out against the changes and argued that there was no need for change in their branch as they were already the best performing branch in the country. This was followed by a visit from the General Manager Operations, Mr Driessen, who urged the staff to trust him. In an organisation where the level of trust is already low, this seemed an incongruous statement.

Since March 1998 there have been few major changes. The Work Capacity Assessment tool has become more important in terms of trying to reduce the numbers of claimants receiving financial assistance from the ACC. Team Managers and Technical Claims Officers have been appointed to most branches. Many of the Team Managers have come from outside the ACC bringing with them different cultures, which in some cases has not been well received by existing staff. The overall impression is that the ACC is seeking to change its organisational culture by bringing in people from outside, as well as placing an increasing importance on outcomes. From July 1999, the ACC will no longer be the only provider of accident compensation in New Zealand, which will open up the organisation to the competitive insurance market place. This legislative change which opens the ACC to competition from the private sector can be considered as one of the most significant changes in ACC history.

\section{Chapter Summary}

This chapter has highlighted some of the key events in the history of the ACC, and in particular the introduction of case management in order to improve service delivery to clients. It has also provided an insight into the numerous changes, which have affected the ACC over the last four years. The link between the VUW Diploma in Rehabilitation Studies and the ACC has also been discussed, together with a brief overview of the process involved in the establishment of the programme. The following chapter details the literature pertinent to this research. 


\section{CHAPTER 3 MANAGING THE THEORETICAL FRAMEWORKS: A LITERATURE REVIEW}

The relevance of a number of fields of study to this research will be discussed in this chapter. The links between the research and the literature will also be established. The research itself is located within the field of service management - this in a sense forms the overall framework for the study. Case management will then be considered to illustrate how it can be regarded as a subset of service management. As indicated in Chapter 2, the rationale for developing the VUW Diploma in Rehabilitation Studies originated from a desire to improve customer service through case management within the ACC. To more fully understand the course itself and the underlying philosophy, the pertinent literature concerning experiential and, in particular, action learning will be considered, with an emphasis on the concept of developing reflective practitioners. Reference will also be made to adult learning and how this shaped the course design. Finally, the literature surrounding the transfer of training and learning will be discussed in detail, to emphasise that the issue of transfer is crucial in terms of service management and delivery, thus coming full circle back to service management where this chapter started.

\section{SERVICE MANAGEMENT AND CASE MANAGEMENT}

The rationale for introducing case management within the ACC was to improve service delivery to people requiring their services, as well as improve its image within New Zealand (ARCIC, 1994a). Case management was seen as a way to personalise the service, as each Case Manager would have an allocated case load and would get to know their clients. It was also introduced to move away from the emphasis on financial allocation to a more people-centred approach, which would focus on individual client needs. The principles behind case management as perceived by the ACC, were to empower staff to undertake comprehensive needs assessments within a holistic framework, to identify relevant strategies for rehabilitation and to co-ordinate with other service providers, as well as being responsible for the weekly payments and entitlements pertinent to each client. Given this background, this research argues that the case management literature can be viewed within the area of human services management, a subset of service management. 
Some key concepts from the service management literature will be presented followed by a brief comment on the human services and a closer consideration of case management as a subset of service management.

\section{Service Management}

The literature in the service management area is vast. The field of study has been developing steadily since the 1950 s internationally, and since the 1980 s in New Zealand. Mattsson (1994) suggests that the reasons for this rise of research in the area of service management are associated with the number of people employed in the service industry, the poor quality of service delivery in many public service organisations and the rise in the number of private service providers. He also argues that there needs to be more research in the area of employee perception of service quality, as most of the service quality research has focused on customer perceptions by focussing on the gap between customer expectations and their subsequent experiences. Whilst this research is not concerned with quality per se, the issue cannot be ignored as it is inextricably linked with improved service delivery - the reason case management was introduced to the ACC. As this research is focusing on case management and the transfer of learning, only key authors from the general service management literature will be discussed in detail, including Grönroos (1990, 1994), Gummesson (1994), Schneider (1994) and Schneider \& Bowen (1995). The rationale for focusing on their work is that it is highly pertinent to the service aspect of case management. This will be followed by a more detailed consideration of the literature associated with internal service management.

Gummesson (1994) suggests that there are three distinct management paradigms manufacturing, bureaucratic and service. He further argues that most organisations are shifting towards the service management paradigm, which emphasises delivering a quality service to the customer, as well as seeing the customer as a partner in creating value for all concerned. The ACC can be regarded as an example of an organisation, which is attempting to shift from a bureaucratic-legal paradigm to a service paradigm. However, as Gummesson (1994) indicates the process is often slow, which would be indicative of the ACC. This 
situation may, however, change when the ACC will be open to competition from July 1999, which will no longer guarantee a constant client base for the organisation.

Grönroos (1994) regards service management as a perspective rather than a discipline on its own, and therefore suggests that the concept is not well-delineated. For him service management reflects the changing socio-economic context within which organisations find themselves. He argues that

service management as an overall management perspective gives high priority to the external efficiency of the firm, how customers perceive the quality of the core products and the total performance of a firm, instead of overemphasizing internal efficiency, economies of scale and cost reduction. This combines the overall management perspective of service management with its customer-driven and quality orientated facets, employee-orientated concerns and its long-term perspective (Grönroos, 1994, p.8).

This is similar to the service management paradigm identified by Gummesson (1994). Schneider (1994) focuses more on the internal aspects of service management, particularly human resource management. Despite this emphasis on human resource management, he takes a systems approach to organisations, which requires all parts of an organisation to be interlinked and focussed on providing service excellence. He does, however, warn of falling into the "human resources trap" (Schneider, 1994, p.64). This trap suggests that everything associated with customer service is directly related to the human resources management aspect of an organisation. More recent work by Redman \& Mathews (1998) based in the United Kingdom, focuses on the link between service quality and human resource management. They argue that a supportive work environment is needed for continuous service quality improvement to take place. The reality, however, is that in many cases the human resource policies needed to foster this environment are not in place (Redman \& Mathews, 1998).

Grönroos (1990, p.28) defines service as:

... an activity or series of activities of more or less intangible nature that normally, but not necessarily, take place in interactions between the customer and service employees and/or physical resources or goods and/or systems of the service provider, which are provided as solutions to customer problems. 
He identifies six criteria, which he perceives to be criteria of good service quality professionalism and skills; attitudes and behaviour; accessibility and flexibility; reliability and trustworthiness; recovery; and reputation and credibility. These can be further summarised into outcome-related, process-related and image-related criteria. The concept of image is particularly important to this research, as the ACC was seeking to improve its image within the New Zealand context by introducing case management. Whilst the improvement of image may be a desirable outcome of a change in service delivery, it should be noted that:

... managing image is a complicated undertaking, especially for larger service organisations that operate in a network, because image exists on several levels, corporate as well as local (Grönroos, 1990, p.173).

Furthermore, it must also be recognised that one intervention in service management may only play a small part in the overall image of an organisation. Hence, the introduction of case management within the ACC could only have a small impact on its overall image.

Within large organisations the concept of internal marketing becomes increasingly important. The main principles behind this concept are a customer-orientated and serviceminded approach by employees to their work and the ability to attract and retain good employees (Grönroos, 1990, 1994; Gummesson, 1994; Schneider (1994); Schneider \& Bowen, 1995). In terms of service training programmes, Grönroos (1990) identifies three different categories. Those focusing on developing a holistic view of the organisation, those developing task orientated skills and finally those focusing specifically on communication and service skills. In the case of the VUW Diploma in Rehabilitation Studies all of these features were included and it is therefore possible to develop training programmes which meet the three categories identified by Grönroos (1990). Grönroos (1994) goes further to suggest that training can also have benefits for productivity. By having knowledgeable and skilled staff, customers will receive better service. For example, the information provided to customers may be more accurate and the individual service more personalised.

A key concept associated with service management, originally, introduced by Normann (1984) is that of the "moment of truth" and how it should be managed. The term has 
subsequently become widespread in the service industry, particularly after Jan Carlzon published a book with the title 'Moments of Truth' in 1987. In essence, the concept suggests that with services the employee only has one chance to "get it right", which is when they have their first contact with the customer, be it by phone or in person. At that point in time, the employee must be able to respond to any of a number of unknown situations, which may present themselves, which is particularly pertinent to the situation of the ACC Case Managers. The centrality of the moment of truth is well illustrated in Figure 3.1.

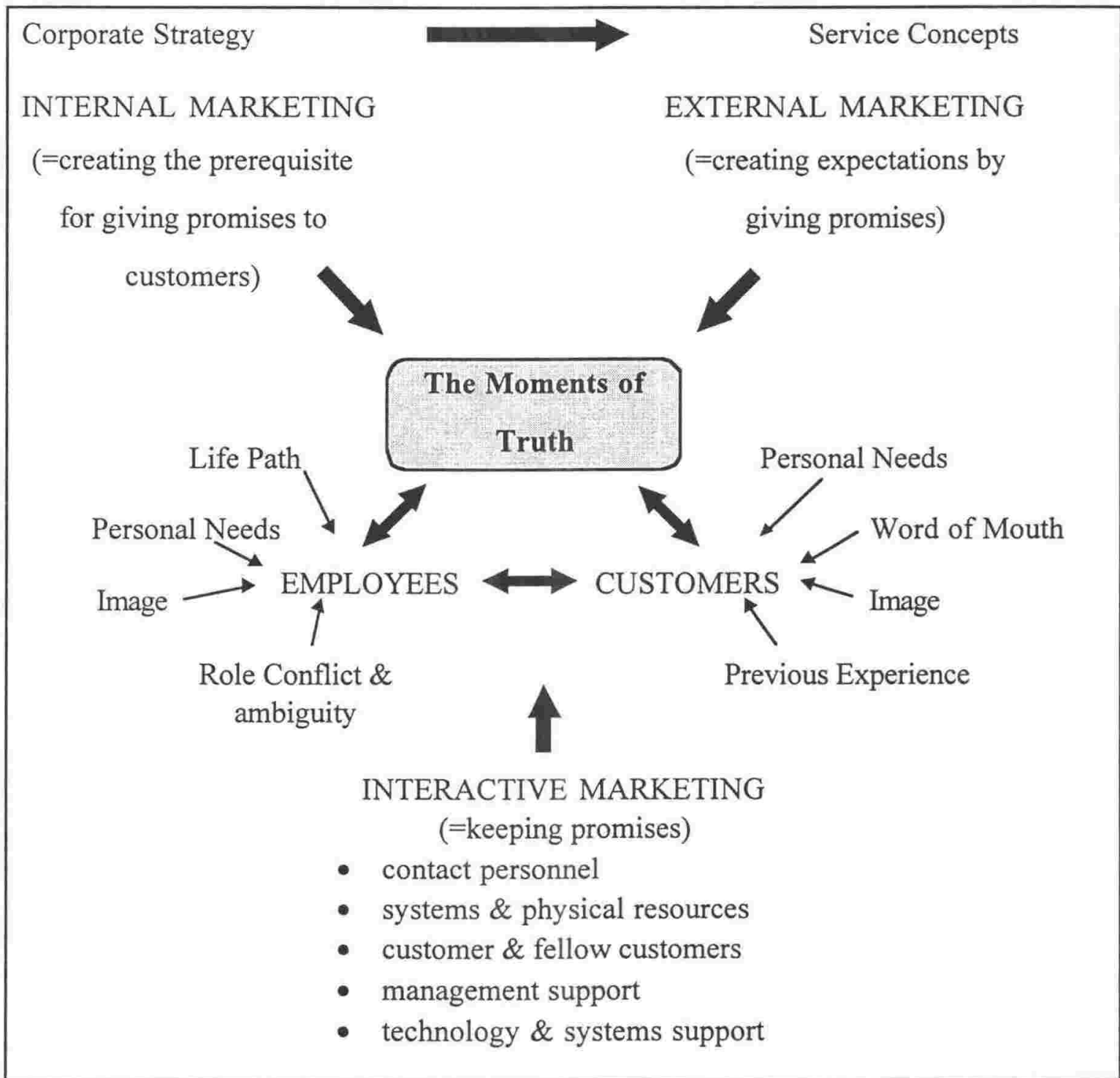

Figure 3.1: An Overview of a Market-orientated Strategy (adapted from Grönroos, 1990, p.258) 
The points highlighted in Figure 3.1 are very relevant to Case Managers working for the ACC. Many of the employees were restructured into the role of Case Manager rather than it having been a deliberate choice. Prior to the introduction of case management many of the staff had only dealt with administrative tasks and spoken to clients on the phone. Suddenly, overnight, case management was the new way of working, and staff had to adjust with no prior training. This situation is well represented by the headings of life path, personal needs and role conflict and ambiguity. The question of image is in a sense anecdotal, whereby employees of the ACC will prefer to say they work for a government department rather than name the department, because of the strong possibility of the ensuing conversation being based around either that person's experience of the ACC or somebody they know - and usually the conversation would be about negative experiences.

Customers using the services of the ACC are unlike other customers, in that they do not have a choice as to who their Case Manager is. Similarly most people have to deal with the $\mathrm{ACC}$ after a traumatic experience involving some form of injury, so the situation is probably more akin to a person having to go to the accident and emergency department of a hospital. Their reason for going is to have their personal needs met. Some clients will have pre-existing notions of the service they are likely to receive based either on previous experiences with the ACC or word of mouth from other people. Given this situation, it becomes evident that managing those moments of truth is crucial in the delivery of case management services by the ACC.

Carlzon (1987) emphasised that the structure and climate of the organisation were important in managing the 'moments of truth'. Associated with this is the importance of treating employees well, so that they can develop both personally and professionally. Linked with this are Normann's (1984) 'beautiful exits' which are opportunities for people to move into, within the organisation, once they have outgrown their present position.

Schneider \& Bowen (1995) develop the ideas of Grönroos $(1990,1994)$ further by focusing in more detail on the customer's need for security, esteem and justice. These three needs are particularly important for ACC clients given the discussion above. I would add a fourth need, namely: that of consistency, which is particularly important in an organisation which 
is based throughout New Zealand and where clients may deal with more than one Case Manager and/or branch during their association with the ACC. The key point here is that the clients are people first and clients second.

\section{Internal service management}

In the service industry the customer's experience with how the service is delivered is as, if not more, important than what is delivered. The human face of the organisation can make or break its success. These moments of truth are of prime importance, in that they often focus on the intangible side of service delivery - the tone of somebody's voice, their body language and how they relate to the client - essentially the interpersonal skills of the provider. How an employee reacts in these situations is often dependent on the environment in which they work (Bailyn, Fletcher \& Kolb, 1997; Bowen \& Lawler, 1995; Castellese, 1995; Hallowell, Schlessinger \& Zornitsky, 1996; Heskett, Sasser \& Schlessinger, 1997; Howcroft, 1993; Larkin \& Larkin, 1996; Macdonald, 1995; Mattsson, 1994; Redman \& Mathews, 1998; Reynoso \& Moores, 1995; Schneider, 1994; Schneider \& Bowen, 1995; Stauss, 1995; Tapsell, 1998; Varey, 1995). Figure 3.2 shows the link between the organisation and the customer.

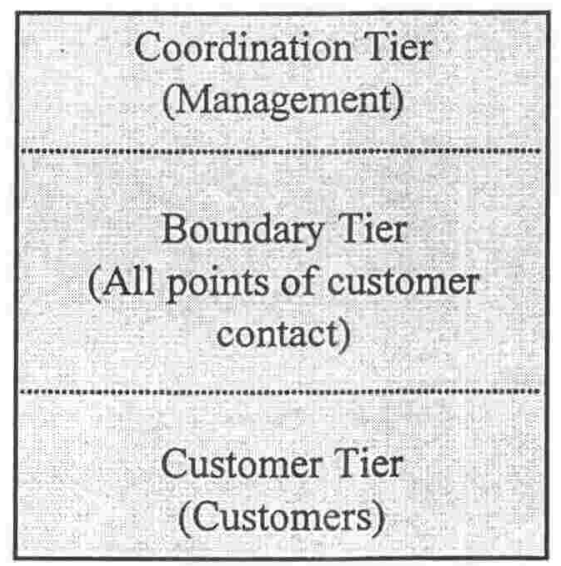

Figure 3.2: Three-tiered View of Service Organisations (Schneider \& Bowen, 1995, p.7)

The Co-ordination Tier is responsible for a clear strategic direction and the creation of a service climate and culture. Whilst the ACC had strategic directions for 1994-1997 and is currently working within its strategic directions to the year 2000, the existence of an 
internal service culture and climate does not appear to emanate from Head Office, but is instead largely dependant on the individual branch. The boundaries between the tiers are seen as permeable so as to enable movement between the tiers, where each tier is not grounded in functions. The people working in the Boundary Tier are the so-called 'impression managers' and gatekeepers of the information. These are the people who are expected to be able to manage the moment of truth and therefore need to have highly developed interpersonal skills in addition to the specific skills required for their particular task - for the ACC these are the Case Managers. Given the nature of the work Case Managers are involved in, they are also required to be able to cope with the emotional side of their work, particularly when dealing with people who have experienced a highly traumatic event in their lives, such as becoming permanently disabled, the death of a spouse or child, or people who have been sexually abused. The foundation of this model is based in the Customer Tier. It is here that the challenge is provided to the organisation in that the Boundary Tier must be able to respond to the needs, expectations and competencies of the client. The nature of the position, often means that boundary-spanning customer-contact workers experience role conflict and role ambiguity. For the ACC Case Managers, this is reflected in their dual role of providing both rehabilitation (demands of the client) and a cost-effective insurance service (demands of the organisation). Research by Weatherly \& Tansik (1993) suggests that these boundary-spanning customer contact workers employ a number of tactics to deal with the role conflict. These include

1. the use of more effort to satisfy demands of customers and management, 2. Negotiating to alter role demands, 3. Pre-empting tactics to avoid sent roles, and 4. Avoiding tactics to avoid received roles (Weatherly \& Tansik, 1993, p.4).

From the above model it is evident that much time and effort must be spent on training employees who work in the Boundary Tier, as there is '. . . only one chance to make a good first impression" (Bowen \& Schneider, 1995, p.133). In order for the training to meet the organisation's need, it needs to be tailor-made, particularly when the nature of the job requires a variety of interpersonal and technical skills, as is the case with Case Managers. The service provided by Case Managers requires total customisation for each client, as each situation is different. This leads to difficulties when the organisation expects a high turn 
around of client files, but only provides a certain number of Case Managers. In a sense the $\mathrm{ACC}$ is wanting a high level of production efficiency, but the reality is that, if a quality service is to be delivered the production efficiency may be low. The following quote is very pertinent to the situation at the ACC:

The way organisations treat employees is reflected in the way employees treat customers . . the culture employees experience will be the culture customers experience (Bowen \& Schneider, 1995, p. 240).

Linked to this is the concept of the 'cycle of failure' often found in the service industry. The term created by Heskett, Sasser \& Schlessinger in 1987 (Heskett, Sasser \& Schlessinger, 1997) essentially means that if employers do not treat their employees well, customers will in turn not be treated well. Indicators of this are low pay, lack of training and a high turn over of staff (Castellese, 1995; Huggins \& Moore, 1994). At least two of these, lack of training and high staff turnover, are issues for the ACC. The issue of training has been redressed to some extent, but the amount of training does not necessarily equal quality, timely or appropriate training. In contrast to the 'cycle of failure' is the 'cycle of capability' where employees

[I]n order to deliver results to customers, they must have the ability to relate to customers, the latitude (within well specified limits) to use their judgement in doing so, the training and technological support needed to do so, and recognition and rewards for doing so (Heskett, Sasser \& Schlessinger, 1997, p.11).

The importance of effective training is discussed, amongst others, by Hallowell et al. (1996), Howcroft (1993) and Mattsson (1994). In none of the cases, however, is training seen in isolation. Training is regarded as part of the wider concept of internal service provision, which is deemed to be necessary to foster employee job satisfaction and customer satisfaction. Henkoff (1994) argues that the interpersonal skills of front-line worker are of prime importance when recruiting staff and suggests that more specific taskrelated skills can be learned on training courses, at a later time. The overall service quality is, according to Mattsson (1994), determined by the organisation and the qualities of the staff. Hallowell et al. (1996) identify eight components necessary to provide quality internal services. These include, appropriate tools, relevant policies and procedures, 
teamwork, management support, goal alignment, effective training, communication, rewards and recognition. Their research suggests that "service organizations rarely have satisfied customers without having satisfied employees" (Hallowell et al., 1996, p.28).

Associated with this focus on satisfied staff is the work by Bailyn et al. (1997) and Bowen \& Lawler (1995). Bailyn et al. (1997) argue that it is necessary to consider more closely the link between the personal needs of employees and business goals. Their research suggests that by involving employees in identifying and changing work practices, both the employee and the organisation benefit. They do, however, caution that the link between personal lives and strategic business issues is not a one-off event. Instead it is

a process of continually looking at the intersection of work and personal lives and using the connection as a lever to challenge work practices on an ongoing basis (Bailyn et al., 1997, p.19).

Bowen \& Lawler (1995) believe that employee empowerment is crucial in the context of service management, as customers are instantly affected by employee decisions. Employees, therefore, need to be given the flexibility and discretion to deal with the situation as appropriately as possible. They regard empowerment as being directly associated with the internal structures and policies of the organisation, which is highlighted by their formula for empowerment.

Empowerment $=$ power $\mathrm{x}$ information $\mathrm{x}$ knowledge $\mathrm{x}$ rewards $\ldots$ The formula reminds managers to avoid the common error of giving employees more discretion (power) but not the necessary support to exercise that discretion wisely (Bowen \& Lawler, 1995, p.74).

This concept of empowerment is important in the context of this research, as it relates to the role of the Case Manager. Bowen \& Lawler (1995) indicate that empowerment is more suitable to certain organisations than others. They see this as being contingent on the basic business strategy, the tie to the customer, the technology, the business environment and the types of employees needed. The empowerment of employees lends itself:

- to a business strategy, which emphasises differentiation, as well as being customised and personalised in its service delivery;

- to customer ties which focus on relationships and may involve long time periods;

- to technology which is non-routine and complex;

- to a business environment which is unpredictable and holds many surprises; and 
- to types of people who have high growth and social needs, as well as strong interpersonal skills (Bowen \& Lawler, 1995).

All of these, apart from the technology contingency, are applicable to the ACC and its delivery of case management. The service is by its very nature customised and personalised, based on the individual needs of the clients. Case Managers need to build good relationships with clients if the long-term outcomes are to be beneficial to both the client and the ACC. Many of these relationships are long term, particularly when dealing with seriously injured people. As the ACC is a government organisation, it is strongly influenced by government policy, as was described in Chapter 2. Case Managers in general have high growth and social needs, and having strong interpersonal skills is vital in order to provide quality case management services. Despite their focus on empowerment, Bowen \& Lawler (1995) like Schneider \& Bowen (1995), warn of the 'human resources trap' and state that

effective service management requires the active management of both the empowerment process and the overall service delivery system. Management's responsibility is to coordinate all the elements, human and otherwise, that must be woven together to deliver the "seamless service" that customers value (Bowen \& Lawler, 1995, p.82).

Tapsell (1998) reported on one CEO who commented that in New Zealand everyone thinks they can do everything, and therefore managers neglect to implement a service delivery system, throughout the whole organisation. Instead they only focus on the frontline staff. Larkin \& Larkin (1996) indicate that in order to engender change in frontline staff, frontline supervisors need to be involved in the process from the outset. These serve as further examples to illustrate the importance of a holistic approach to service management within an organisation, which focuses on the people, the policies and the structures.

\section{Human Services}

According to Dickens (1996), the human services are associated with bringing about change in the consumers they interact with. In general, the human services are concerned with people's welfare and well being and therefore tend to be found in the social, health and education fields. There also tends to be a predominance of women in the direct service 
positions, with men holding the administrative and managerial positions (Dickens, 1996). The human services have similar characteristics to the service industry, in general, in that their products are generally intangible and heterogeneous, with the production and consumption of the service being inseparable. Dickens (1996) suggests that there are four additional factors, which make the human services distinctive - the influence of values, the sources of finance, their heterogeneity and the issue of choice. Skelcher (1992) considered the context for service within the public and private sector, and suggested that the differences between them lay in accountability, choice and purpose. He also identified a number of issues which constrained public services from focussing on customers, including, access, service delivery, performance indicators, as well as organisational structure and culture. Blois (1992) indicated that customer complaints associated with staff behaviour may be higher where an organisation cannot chose their market. He went further to suggest that due to the diverse customer base of human service organisations, the recruitment and training of customer service staff presents additional challenges. Some direct links can be made between the work of Blois, (1992), Dickens (1996) and Skelcher (1992) and the context of this research.

One of the roles of the ACC is to bring about change in its clients, a function primarily carried out by its Case Managers. The majority of the Case Managers are women, with the managerial positions, in most cases being held by men, particularly the senior level ones. For the ACC there may well be a role conflict when considering the influence of values on its operation. In the human services, there is generally a concern for people's welfare and development through the provision of care, with the predominant values of other service industries being the provision of customer service and making a profit (Dickens, 1996). The ACC is trying to fulfil all of these, and at least internally often sees expenditure as one of the key management performance indicators. As with many other human services, the ACC is funded directly from taxpayers money, which means that money never actually changes hands at the point of service delivery. The heterogeneity of the human services is also particularly pertinent to the ACC. The ACC has a wide range of staff coming from a variety of socio-economic, cultural and educational backgrounds, all of whom contribute to the service delivery process. This may contribute to different notions of service delivery and makes the consistency of service delivery more difficult to achieve. The issue of choice, 
or rather lack thereof, is often associated with the public provision of human services. People do not chose to use the ACC, their interaction with the organisation is usually associated with an accident, where they have little say in what happens. A Case Manager is allocated to people, rather than there being any level of choice involved. In other services, it is generally possible to choose the provider and if dissatisfied you chose to go somewhere else. Despite these issues, some public organisations in New Zealand, who have no obvious rivals and therefore hold a virtual monopoly position, are regarded as providing exemplary customer service, including Auckland International Airport and the Hamilton City Council (Gibson, 1996). Given the similar characteristics of the ACC and human service industries, it is argued that case management can be seen within this context, and will now be considered in more detail.

\section{Case Management}

Case management has existed since the early 18 th century and throughout the next 200 years was primarily associated with providing services for the sick and poor (Bushy, 1997; Conti, 1996; Reynolds \& Smeltzer, 1997). Case management was closely tied to social work in the early days with the services being mainly provided to immigrants arriving in the United States of America. The values often associated with case management today were developed in those early programmes, which focused on the worth of individuals and sought to provide individual assistance so that clients could become self-sufficient (Conti, 1996). Conti (1996, p.68) also suggests that these programmes "established the basis for today's case management standards that reflect the importance of trained staff'. Since then case management has been associated with a number of fields, originally mainly in the area of health, but in more recent times case management can be found in banking, insurance, unemployment and income support services (Diwan, Berger \& Ivy, 1996; Eardley, 1996; Fineman, 1996; Frossard, 1996; Ozanne, 1996; Phillips, V., 1996). Similarly, case management is part of both private and public service provision in many countries including the United States of America (Diwan, Berger \& Ivy, 1996), Canada (Fineman, 1996), France (Frossard, 1996), Australia (Ozanne, 1996) and the United Kingdom (Phillips, V., 1996). 
There have been numerous attempts to define the concept of case management. As is the case with many definitions there is often the tendency to see only one as the true version. The key concepts mentioned in most definitions involve the terms 'process' or 'method', 'service co-ordination' and the 'meeting of a client's needs'. Some of these are as follows:

Case management involves service co-ordination and individualised planning. The latter process involves determining individual's needs and how to meet them. It includes both clients and service providers and results in a written plan. As service co-ordinator or 'systems broker', the case manager puts the plan into action, links clients to services and monitors both the services and plan over time (Spitalnik, 1981 cited in Pilling, 1992, p.14).

... a process or method for ensuring that consumers are provided with whatever services they need in a co-ordinated, effective and efficient manner" (Intagliata, 1982 cited in Pilling, 1992, p.13).

... case management refers to any method of linking, managing or co-ordinating services to meet client's needs and typically includes client assessment, service co-ordination and follow-up (Zawadski \& Eng, 1988 cited in Pilling, 1992, p.14).

Case management is defined as a collaborative process which assesses, plans, implements, coordinates, monitors, and evaluates options and services to meet an individual's health needs through communication and available resources to promote quality, cost-effective outcomes (Case Management Association of America, 1995 cited in Aliotta, 1996, p.38-39).

Despite the similar themes running through the definitions, a number of different ways of carrying out case management in practice have emerged. Not only is there a difference in process but also in application, as mentioned above. Pilling (1992) suggests that within the British context case management has moved towards tailoring the services available to client needs rather than what was previously the case when the clients were fitted around existing services. This focus on meeting clients need has been reiterated in the literature by, for example, Aliotta (1996), Fineman (1996), Frossard (1996) and Ozanne (1996). Aliotta (1996), commenting on the United States of America, sees case management as enabling organisations to meet the health care needs of their clients, by providing a continuum of care from the acute stage through to clients becoming self-managing in the long term. She regards case management as being proactive rather than reactive. For her case management 
involves identifying at risk people before they require acute care. This is different to the manner in which the term is used in the New Zealand context within the ACC. Whilst the $\mathrm{ACC}$ does have an injury prevention role, the prime function of Case Managers is to provide a service to clients requiring immediate attention and potentially long term care.

Fineman (1996, p.159) refers to the Canadian situation where "case management is perceived as a means of increasing a system's ability to control its resources and facilitate decision making to enhance service delivery". In France, providers of case management services are increasingly being asked to verify that their services are indeed "cost-effective, efficient and of high quality" (Frossard, 1996, p.163). Frossard (1996) concludes that the real value of case management is in being able to adjust services to the individual needs of the client, rather than it being an issue of where the client is located - in their own home or within a care institution. The review by Ozanne (1996) suggests that case management has been an integral part in reforming social and medical service delivery systems in Australia. The importance of having culturally competent Case Managers, in providing quality customer service, is addressed by Rogers (1995). She argues that Case Mangers need to be culturally competent to be able to operate within all spheres of society and that

lack of knowledge and understanding leaves case managers feeling uncomfortable and inadequate and clients feeling dissatisfied and frustrated (Rogers, 1995, p.61).

Within the United States of America case management has been receiving much attention, as their health system has sought to contain cost whilst at the same time maintaining quality care (Aliotta, 1996; Bushy, 1997; Diwan et al., 1996; Owens, 1996; Stiller \& Brown, 1996). Owens (1996) suggests that case management results in a beneficial situation to both provider and client. The client is more involved in the decision making with regard to their situation and for the provider case management, provides cost-efficient service delivery. For many the answer to this can be achieved "by delivering the right services, at the right time, in the right place, by the right person" (Bushy, 1997, p.1) that is Case Managers. 
A similar situation is found within New Zealand, where in 1993 the health system was restructured to provide more transparent services, improve efficiency, reduce waiting lists and increase consumer choice (Ashton, 1995). As mentioned above, case management was introduced by the ACC in 1994 to improve customer service (ARCIC, 1994a). For them the benefits of case management were seen as:

- providing better staff/customer relationships,

- providing a 'seamless service',

- reaching positive outcomes,

- ensuring full entitlements,

- a check point, and

- reducing debt within the organisation.

Case management to the ACC means that a single person deals with the multiple needs of a client and mobilises a range of services from in-take until service goals are met. At the same time it also provides one access point into the system for the client facing multiple difficulties. However, caution in implementing case management is advocated by Aliotta (1996) and Stiller \& Brown (1996). These authors argue that a successful case management programme requires careful planning, sufficient resources and total commitment from the organisation. Increased costs are also to be expected at the outset, when staff training is required for the programme to be successful. This training, according to Diwan et al. (1996), should not only be confined to Case Managers. They suggest that supervision training for supervisors is essential for the quality of case management to be assured and maintained. The long-term benefits to the organisation in terms of cost savings will more than compensate for this initial investment (Aliotta, 1996; Stiller \& Brown, 1996).

Conti (1996) suggests that there is no consensus in the literature regarding the roles of a Case Manager. The roles vary considerably according to the setting and the nature of the work required (Aliotta, 1996; Conti, 1996; Hamill, 1995; Issel, 1997; Koch \& Rumrill Jr., 1998; Phillips, V., 1996; Rogers, 1995; Scott, 1996). The focus of the Case Managers role is seen as being able to build rapport with the client by working with them to meet their needs. The skill set associated with this is strongly linked to highly developed interpersonal skills together with the ability to conduct thorough needs assessments and 
provide recommendations as to how to proceed (Issel, 1997; Koch \& Rumrill Jr., 1998; Phillips, V., 1996; Rogers, 1995). The study by Issel (1997) based on Case Manager interviews, identified that Case Managers are often affected by different levels of management within an organisation placing varying expectations on them, making it difficult for the Case Managers to accomplish everything that is expected of them. This finding is akin to the pitfalls of case management identified by Aliotta (1996). These included role conflict, where Case Managers are expected to do both the processing and the case management work. Similarly, case managers may only be case managing, but have too many cases to work with. The third pitfall mentioned, was associated with confining the scope of the Case Manager activities, which in Aliotta's (1996) example consisted of Case Managers not being able identify high-risk clients at an early stage, because they were limited to certain disabilities. According to Hamill (1995, p.28), Case Managers "are wellorganised, are able to establish positive outcomes, have good people-development skills and ... provide cost-effective care".

Within the context of the ACC, the primary roles of the Case Manager were identified as assessing the needs of the client, developing an individual programme, organising resources and then monitoring the client's progress so that the amount of services can be adjusted to the client's level of functioning, as required. Associated with these roles, the following competencies were also regarded as necessary for ACC Case Managers.

- Problem solving

- Facilitation

- Negotiation

- Communication

- Challenge the status quo

- Visionary

- Analytical thinking

- Financial responsibility

- Decision making

- Team worker (ARCIC, 1996b) 
Rogers (1995) highlights five skills, which are required for culturally competent Case Managers. These include the ability to be self-aware, to identify difference as an issue, to accept others, to individualise and generalise and to advocate. The multi-cultural nature of New Zealand society would suggest that these skills would also be applicable and beneficial to ACC Case Managers.

Given the high degree of interaction and customisation required, and the high level of labour intensity involved, it could be argued that case management fits within the Professional Service Quadrant of Schmenner's (1986 cited in Schmenner, 1995) Service Process Matrix (see Figure 3.3), even though within the New Zealand context case management is not seen as a profession.

\begin{tabular}{|c|c|c|c|}
\hline \multirow{4}{*}{ 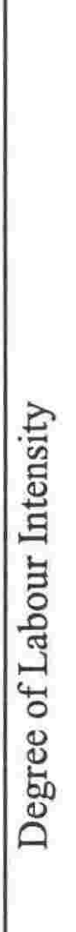 } & & \multicolumn{2}{|c|}{ Degree of Interaction \& Customisation } \\
\hline & & Low & High \\
\hline & Low & $\begin{array}{l}\text { Services Factory: } \\
\text { - Airlines } \\
\text { - Trucking } \\
\text { - Hotels } \\
\text { - Resort \& recreation }\end{array}$ & $\begin{array}{l}\text { Service Shop: } \\
\text { - Hospitals } \\
\text { - Auto repair } \\
\text { - Other repair services }\end{array}$ \\
\hline & High & $\begin{array}{l}\text { Mass Service: } \\
\text { - Retailing } \\
\text { - Wholesaling } \\
\text { - Schools } \\
\text { - Retail aspects of } \\
\text { commercial banking }\end{array}$ & $\begin{array}{l}\text { Professional Service: } \\
\text { - Doctors } \\
\text { - Lawyers } \\
\text { - Accountants } \\
\text { - Architects } \\
\text { - Case Managers }\end{array}$ \\
\hline
\end{tabular}

Figure 3.3: The Service Process Matrix (adapted from Schmenner, 1986 cited in Schmenner, 1995, p.35)

In an ideal environment case management may well achieve the objectives of high quality customer service and cost effectiveness. However, it should be noted that case management will only really work if the organisation in which it is introduced is ready to embrace it, as it is part of a service environment which is strongly related to fiscal and organisational 
realities (Austin, 1992). Furthermore, it should be noted that whilst case management aims to address individual client needs and co-ordinate service delivery, it cannot by itself redress the often fragmented and inadequate local service delivery networks. This is particularly the case in the more remote parts of New Zealand, where specialist services are often only available in major service centres. Case management, on its own, will not necessarily provide better staff/client relationships. It is the relationship that the Case Manager builds with the client that will determine service quality. Managing the 'moment of truth' well is what will determine better relationships. This in turn necessitates proper professional training and in-service training programmes, which will prepare Case Managers for the demands of their role.

Caution should also be exercised in assuming that case management will lead to cost reduction (Frossard, 1996; Haslanger, 1995; Stiller \& Brown, 1996), as is anticipated by the ACC 1994 Annual Report. Haslanger (1995, p.39) suggests that there is little empirical evidence to support the

contention that case management generates cost savings. . . One cost-related conclusion that does leap out from the literature is that case management is itself expensive. . . In case management you get what you pay for: a greater investment yields a higher-quality product.

She also suggests that there is little research on the link between case management and service quality. This is particularly the case when Case Managers are separate from service providers, as much of their service quality is dependent on the assistance of other people, after the initial assessment has been made. Given this situation it is imperative for Case Managers to be familiar with not only the services available in their area but also to have a sense of whether these other organisations provide a good service. Actually knowing the people that clients are referred to is an advantage, as it may be possible to match personalities.

Overall, Haslanger (1995) argues that for there to be a chance of saving on service provision, Case Managers "must have a caseload and catchment area small enough to facilitate real service planning as well as access to a substantial range of services" (p.41), 
and that for case management to improve service provision upfront investment is required which can then be capitalised on in time.

Not everyone agrees that case management works. Marshall (1996) suggests that there are two approaches to case management. The first he describes as 'standard' case management, "a low intensity approach in which case managers offer a largely "office based" service, brokering interventions from other agencies" (p.523). The second approach he terms 'assertive community treatment' is a "multidisciplinary team of mental health professionals" (p.523), who have a lot of face-to-face client contact, with individual team member's skills being used as required. He argues that within the British context of mental health services, 'standard' case management rather than 'assertive community treatment' has taken place since the late 1980s. The main reason for this has been a lack of funding, increased paperwork and an extension of the service to all psychiatric patients, rather than focusing on those most in need, as originally specified. Marshall (1996) suggests that case management continues because it is government policy, despite the problems he associates with the concept.

The importance of highly-skilled Case Managers, together with a well-thought out case management programme cannot be emphasised enough, if service delivery is to be one of the prime reasons for introducing the concept. A number of different approaches to case management training have been reviewed in the literature (Aliotta, 1996; Diwan et al., 1996; Fineman, 1996; Leutz, Sciegaj \& Capitman, 1997; Ozanne, 1996; Rogers, 1995). Most of these have focussed on the importance of Case Manager training in general, apart from Diwan et al. (1996) who emphasised the value of supervision training and Rogers (1995), who focussed on culturally competent case management practice. Rogers (1995, p.63) suggests that

effective teaching must go beyond simple descriptions of cultural differences to create greater selfawareness, insight and sensitivity.

and that

becoming culturally competent is a developmental process that involves considerable investment. It begins with self and requires a degree of self-scrutiny and reflection that may provoke strong 
emotions and reactions. . It is incumbent on the educational and training programs preparing case managers that they provide the content and learning environment conducive for acquiring the knowledge and skills for cultural competence (Rogers, 1995, p.65).

Achieving lasting personal development from training programmes is not always easy. One of the ways in which it can be achieved is by experiential learning, as it focuses on the learner, provides real-life experiences and encourages reflection as well as action. This process together with action learning will be discussed next.

\section{EXPERIENTIAL LEARNING AND ACTION LEARNING}

The literature concerning experiential and action learning will now be considered, together with the concept of 'the reflective practitioner' (Schön, 1983), as these are important to gaining an understanding of the philosophies underlying the VUW Diploma in Rehabilitation Studies. Experiential learning is introduced first as it provides the framework from which action learning develops. Action learning, however, is discussed in more detail because of its pertinence within the context of this research.

The concept of experiential learning is not new. A brief historical review could start with Socrates (470-399 BC) who challenged the existing norms by asking questions, rather than providing the answer with the question as was the convention of the time. He believed that students had something to offer rather than being merely receivers of knowledge. Furthermore, he regarded the process of becoming educated more important than arriving at some final state and with that was an advocate of lifelong learning. Plato who recorded much of Socrates' thoughts suggested that any learning of which we are capable is gained by reflection on our own beliefs and is best accomplished by critical discussion with others. As most of us do not like our own beliefs and assumptions challenged, Plato argued, actual learning maybe quite painful (Crosby, 1995). This is also echoed by authors such as Goldratt (1990).

In more recent times the work of Dewey (1938), Lewin (1951), Schön (1983) and Kolb (1984) has been influential in the development of experiential learning and education. As 
with so many other terms it is very difficult to define experiential learning (Chapman, McPhee \& Proudman, 1995), however it is possible to consider the characteristics. For Dewey (1938) the key point was that experience needed to be useable. By this he meant that experience is felt, rather than being something objective with no emotional attachment. He saw the goal of education as understanding and using experiences, which was achieved by developing thought processes with which to examine our experiences. In essence, he was talking about being able to reflect on what we experience. A number of models of experiential learning have been proposed, the most well-known of which is the four stage model introduced in 1975 by Kolb, Rubin and McIntyre (cited in Knapp, 1992, p.37). The four stages of the cycle are (see Figure 3.4):

immediate concrete experience as a basis for observation and reflection, which leads to the assimilation of observations into a theory consisting of abstract concepts and generalisations from which new implications or hypotheses are tested in new situations (Knapp, 1992, p.37).

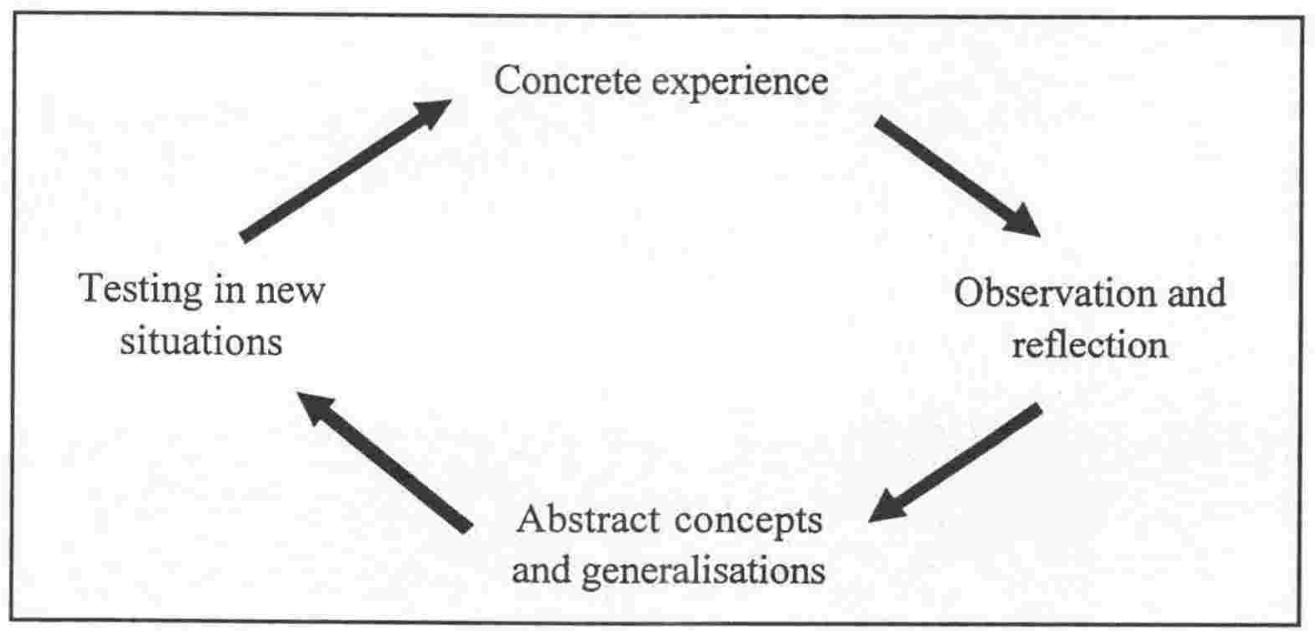

Figure 3.4: Kolb's (1984) Experiential Learning Cycle

There are also two models, which involve five stages. In 1979 Jones and Pfeiffer (cited in Knapp, 1992, p.37) described their experiential learning cycle as involving experiencing, publishing, processing, generalising and then applying the new learning or behaviour. Joplin (1981 cited in Knapp, 1992, p.36) identified the following five stages as being one full action-reflection cycle - focus, challenging action, debrief, feedback and support. Whilst there are differences in terminology within the cycles described, the common features are that an experience takes place - a direct first-hand learning opportunity - which is then reflected upon and the new learning and/or behaviour is then applied in a new situation, with the cycle, at that point, starting afresh. 
It is important to note that experiential learning is not restricted to the outdoors as some might claim. The term experiential education seems, for many people, to conjure up notions of kayaking down rivers, climbing walls and hanging off ropes. Experiential education is a process rather than being context specific; which means it can take place anywhere at any time. In the field of management education, experiential learning has taken place for a number of years, and may include, in addition to outdoor activities, the analysis of case studies, role-playing, taking part in business simulations or management games (Hussey \& Lowe, 1990; Mailick \& Stumpf, 1998; Mumford, 1991). Over time these experiential approaches to management development have been added to higher education management programmes, with a number of MBA courses across the world being either completely or partly experientially based (Hicks, 1996; Mailick \& Stumpf, 1998; Leberman \& Mellalieu, 1994; McEvoy \& Cragun, 1994). Given this variety, there is a need to identify some of the specific characteristics of experiential education. According to Flor (1991b) these include:

- a commitment to personal growth and development of the individual through the process of group dynamics;

- an adventure component, which need not necessarily be physical, involving some degree of uncertainty and risk-taking, some challenge and reflection, a co-operative group environment and consensual decision making, as well as a novel setting, dissonance and unique problem-solving initiatives;

- an array of "tools of the trade" including games, initiatives and activities;

- the use of metaphors and debriefs.

The role of metaphors, in facilitating both meaningful reflection for individuals and an understanding of the way they view the world, is discussed by Hovelynck (1998), Morgan (1986, 1988), Nadler (1995) Schön (1983) and Weick (1995). The consensus is that the metaphors have to be meaningful to the participants and that metaphor development is part of the experiential learning process. Morgan (1986, p.12) suggests that "theories and explanations of organizational life are based on metaphors that lead us to see and understand organizations in distinctive yet partial ways". This is especially relevant when considering experiential education in the context of management development programmes, and the transfer of individual learning back to the work place, as is further discussed below. 
The concept of metaphor development is seen as particularly important in enabling participants to move forward both personally and professionally (Schön, 1983). The key to experiential education is the reflection part - we all experience things in our daily lives, but all too often we just carry on and move on to the next thing rather than sitting back and taking stock of what just happened. The importance of reflection for learning is emphasised by a number of authors, particularly in the books edited by Boud, Keogh \& Walker (1985) and Boud, Cohen \& Walker (1993). Harris (1996) suggests that there is not much discussion of the actual nature of reflection and that if experiential learning were to be combined with Schön's (1983) concept of "reflection-in-action", a more useful approach to experiential learning would be available to, in her case, social work educators and practitioners. Her thesis is that for practitioners in the field of social work it is often impossible to simply apply theory to practice, due to the complex nature of the competencies required by social workers in the field and that therefore, practitioners often develop their own theories once working in the field. She suggests that

. . student evidence has shown that individuals learn from reflecting upon experience and engaging in active learning. . . that experiential learning theory characterises both an alternative epistemology and an alternative way of considering professional development in social work education. .. Instead of arising out of academic theory, there is a shift towards personal theorising and exploring constructs culled directly from students' experience (Harris, 1996, p. 44).

Case Managers like Social Workers derive much of their practical expertise from trial and error approaches to situations. As mentioned above, the service they provide is unique each time and requires a high level of interpersonal skill development, given the variety of people and circumstances they have to deal with in their daily practice. Given this situation it is often difficult to encapsulate in words exactly what a Case Manager actually does, but it can be demonstrated in practice. Essentially, this means that providing a set of competencies is fine, but their application in reality may vary considerably depending on the individual Case Manager's experience. Gould (1996, p.1) puts this very clearly when he says that

... reflective learning offers an approach to education which operates through an understanding of professional knowledge as primarily developed through practice and the systematic analysis of experience. This is sometimes referred to as a theory of experiential learning, ... 
The focus on individual learning, which is often emphasised in experiential education programmes, can usefully be extended to organisational learning by considering amongst others the work of Argyris (1982, 1994), Argyris \& Schön (1978), Kim (1993), Senge (1990) and Wyatt (1997). Argyris $(1982,1994)$ argues that learning takes place in two ways - single-loop and double-loop. Single-loop learning occurs when decisions are made, by individuals or organisations, without examining their underlying values. Argyris provides the analogy of a thermostat, which adjusts the temperature without questioning why it is set at a certain level. In essence, the reflection part of Kolb's model is avoided. Double-loop learning adds in the reflection part, by taking a more questioning approach, "not only about objective facts but also about the reasons and motives behind those facts" (Argyris, 1994, p.79). The concept of mental models (Argyris, 1982; Senge, 1990) is also important here as it deals with people's biases and pre-conceived notions - how people see the world. These mental models, in turn, influence the way people understand the world, how they perceive new experiences, interpret those experiences and then generalise from them (Wyatt, 1997). Wyatt (1997) suggests that reflection is the key to double-loop learning, and all of the participants in her study considered reflection as an integral part of an experiential programme. Four processes are identified by Wyatt (1997) as assisting in reflection, and encouraging people to move beyond their mental models. These include people learning to suspend judgement, identifying their assumptions, asking questions of themselves and listening with all their senses.

The paradox of organisational learning is that organisations learn through the experiences and actions of individuals. However, for the organisation as a whole to develop, more than individual learning needs to take place (Argyris \& Schön, 1978). Kim (1993) applied the concepts of single- and double-loop learning to organisations, and regarded "organisational learning as a metaphor derived from our understanding of individual learning" (1993, p.37). In his model, the mental models became shared and the learning organisational, rather than individual. The challenge here is understanding how the individual learning is transferred back to the organisation and how experiential programme designers working with organisations can facilitate this process. Wyatt (1997, p.84) suggests that 
the most important learning that an experiential program can transfer to an organisation is an understanding of the learning process that members experienced during the program.

In her case, this means the participant taking back the four processes of suspending judgement, identifying assumptions, asking questions and listening to the organisation. The difficulty in achieving this is in reality is highlighted by Argyris (1994). He provides a number of examples from organisations where employees have not asked questions of each other, even though they knew about double-loop learning and the importance of challenging mental models. The reasons he identifies for this not taking place are social and psychological. The social reason is linked to being considerate and positive with employees and not putting them on the spot, when the organisation is undergoing difficult changes. $\mathrm{He}$ sees this as managers not sharing the responsibility of bad news with employees. Argyris (1994) attributes the psychological reason for avoiding double-loop learning, to mental models developed early in life associated "with emotional or threatening issues" (1994, p.80). He goes further to suggest that

the purpose of this strategy is to avoid vulnerability, risk, embarrassment, and the appearance of incompetence (1997, p.80).

This means that even if employees have been on a training course, which challenges their mental models and they have developed an espoused theory of action, their actual theoryin-use on return to the workplace may well be very different (Argyris, 1994; Schön, 1983). In many cases this takes place because, once back in the workplace, responsibility for solving problems is taken away from employees and allocated to management. By not giving employees the opportunity to practise what they have learned, the status quo is perpetuated. This, Argyris (1994) argues prevents true staff empowerment and organisational learning to take place. Action learning, a process described next, seeks to bridge the gap between individual and organisational learning by linking individual learning very closely with the organisation and is a key aspect of this research. 


\section{Action Learning}

Action learning is a form of experiential learning which is most frequently used to meet the needs of people within a work environment, but has also been applied in increasingly diverse situations including helping unemployed people set up their own support networks and within educational institutions. It is also particularly applicable to adult learners, as it takes into account their previous experience and enables them to build on what they already know and develop in the areas which are pertinent to them individually, both on a personal and professional basis. In a sense action learning provides what Harris (1996) suggests, namely, experiential learning combined with Schön's (1983) concept of the 'reflective practitioner'.

\section{Evolution of action learning}

Reg Revans is recognised as being the founder of action learning - a term not used by him until the mid 1950s. Revans, originally a scientist working at Cambridge University, joined the National Coal Board as a training advisor in 1945 following a stint with the Education Department. It was here that he first used his ideas to develop people and organisations by using their own resources rather than bringing in external consultants to solve internal problems. He strongly believed that people were able to find solutions to their problems by asking, what he termed apposite questions (Q) and doing the necessary research of the literature, programmed knowledge $(\mathrm{P})$. These two amounted to learning which he represented by the formula $\mathrm{L}=\mathrm{P}+\mathrm{Q}$ (Inglis, 1994; Weinstein, 1995).

In addition to this belief, he demonstrated both at the coalface, and later (in 1955 he became Professor of Industrial Administration in Manchester) in the hospital area, that people working together in a so-called set, could learn even more. His work was not only confined to those in employment, but he also introduced action learning to unemployed people in Wolverhampton during the 1960 s. His work also involved taking managers out of familiar settings and putting them alongside managers in similar positions in different organisations. Despite the original lack of structure and high demands placed on organisations in terms of, for example, the trust and openness required, action learning slowly began to become more accepted, particularly in Britain. This was marked in 1977 with the foundation of the 
Action Learning Trust, which in the 1980s became the International Foundation for Action Learning. The first MBA offered using action learning methods was run by the International Management Centre in Buckingham (Inglis, 1994; Weinstein, 1995).

The essence of action learning to Revans (1982b, p.25) is

that those with responsible jobs to do, whether manager or not, learn best with and from each other when systematically brought together during the doing of those jobs.

The main characteristics of action learning for him are that:

- it is question rather than answer based,

- it be used to solve some present problem,

- it is a social process with the development of learning community,

- there is value in placing oneself in unfamiliar situations such as situations of ignorance, risk and confusion,

- action is taken.

Learning and taking action in the real world were seen as inextricably linked, whereby the learning gained from any experience would be dependent on the setting and the task of the action learning programme. This led Inglis (1994) to develop the following task/setting matrix (see Figure 3.5):

TASK

\begin{tabular}{|l|l|c|c|}
\cline { 2 - 3 } \multicolumn{1}{c|}{} & \multicolumn{1}{c|}{ Familiar } & Unfamiliar \\
\cline { 2 - 4 } \multicolumn{1}{c|}{ SETTiliar } & 1 & 2 \\
\cline { 2 - 4 } & Unfamiliar & 2 & 4 \\
\hline
\end{tabular}

Figure 3.5: Task/Setting Matrix (Inglis, 1994, p.12)

Here he argues, that people in 'box 4' may develop insights through skilful questioning that can be far-reaching, and the learning opportunities can be extensive. This 'box 4' type programme was used by Revans in the 1970s in the Fondation Industrie-Universite of Belgium, a joint venture set up by Belgian businessmen and the country's five leading 
universities. In this situation, "top managers from one industry worked full time in a different industry, looking into problems in areas where they had no expertise of their own" (Inglis, 1994, p.21).

\section{Characteristics of action learning}

Much has since been written (Boddy, 1981; Bunning, 1992; Dotlich \& Noel, 1998; Inglis, 1994; McGill \& Beaty, 1995; Mumford, 1991; Sutton, 1990; Weinstein, 1995) on action learning detailing its evolution, offering definitions and exploring its application in a wide variety of settings. It seems that there is difficulty in defining the concept of action learning as Revans himself never provided a single comprehensive statement (Mumford, 1991). Nevertheless, it is possible to identify the key characteristics of action learning. Following on from Revans's equation of $\mathrm{L}=\mathrm{P}+\mathrm{Q}$, there is the addition of action which is to be taken in the real world followed by reflection (R) on that action (A). Given this, the equation would be "expanded to read L $=\mathrm{P}+\mathrm{Q}+\mathrm{A}+\mathrm{R}$ " (Weinstein, 1995, p.49). Inglis (1994) had suggested extending the original equation to read $\mathrm{L}=\mathrm{P}+\mathrm{Q}+\mathrm{I}$, where I is implementation, similar to action. The action learning cycle can be represented as in Figure 3.6:

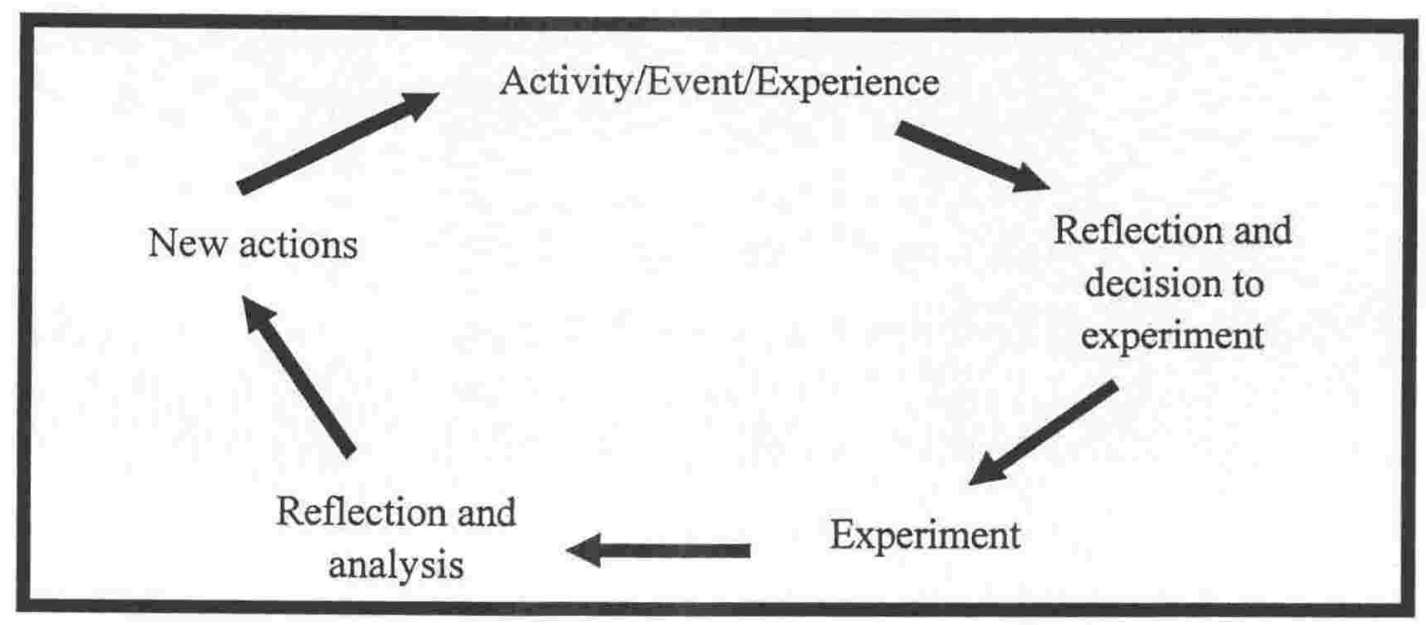

Figure 3.6: Revan's Action Learning Cycle (Weinstein, 1995, p. 51)

The role of action learning in higher education qualifications has been documented by a number of authors including Bourner \& Frost (1996), Henderson (1993), Leberman (1996); Leberman \& Mellalieu (1996), McGill \& Beaty (1995) and O'Hara, Webber \& Reeve (1996). O'Hara, Webber \& Reeve (1996) make a useful link between action learning and management education in terms of the expectations held by all the participants in the 
process. For the course participant, the expectation is a qualification and learning which will be beneficial to them once the course is finished. The organisation seeks a return on its investment in terms of improved organisational performance in specified areas. The higher education provider expects to contribute to "creating new and better ways of developing managers, contributing to business success, awarding qualifications and guarding standards of education" (O'Hara, Webber \& Reeve, 1996, p.17). In the case of this research similar expectations were made by the stakeholders - the Case Managers, the ACC in terms of improved service delivery to clients and the Department of Applied Social Sciences at Victoria University, as the course provider.

The action learning cycle is represented a number of times during the VUW Diploma in Rehabilitation Studies. The whole course contains at least one cycle based on the twelve weeks in Wellington where the students had the opportunity to reflect on their practice as Case Managers and gain new experiences. Within those twelve weeks, each module and study week consisted of another action learning cycle. During the practicum in their branches, there was a second cycle, when the students had the opportunity to experiment with their new learning as well as to reflect on the experience in Wellington. The third cycle was on their return to Wellington when the students presented their research findings and reflected back over the whole programme before returning to their branches full-time.

Another important characteristic is the view that action learning is a holistic approach, which focuses on the whole person, the personal and the professional development of an individual (Bourner \& Frost, 1996; Inglis, 1994; O’Hara, Webber \& Reeve, 1996; McGill \& Beaty, 1995; Mumford, 1991). Whilst much of the learning is done in groups - so-called sets - the learning is learner-driven and therefore based on the needs of the individual.

Other characteristics identified include:

- that it is a social process (Inglis, 1994; Mumford, 1991; O’Hara, Webber \& Reeve, 1996; Revans, 1982)

- the value of placing oneself in unfamiliar situations - task and/or setting (Revans, 1982)

- the focus on what can be learned rather than taught (Mumford, 1991; O'Hara, Webber \& Reeve, 1996) 
- that development takes time (Inglis, 1994; McGill \& Beaty, 1995)

- that there is a defined project (Inglis, 1994; Mumford, 1991)

It can be seen that there is both consistency and inconsistency amongst the literature. Some key points identified by various authors will illustrate this. Boddy (1981, p.18) suggests that "one of the basic ideas behind action learning is seeing its value as a way of helping people to develop their skills at coping with change, uncertainty and ambiguity". Dotlich \& Noel (1998, p.1) state that "on its most basic level, action learning is nothing more than learning by doing in a controlled environment".

Bunning (1995, p.3) sees the ultimate goal of action learning as developing "a way of functioning so that learning is a natural consequence of your taking action in the real world". He furthermore advocates action learning as a means of integrating knowing (what I know), doing (what I do) and being (who I am). It is an opportunity to become more aware of one's own behaviours and working towards a congruence between one's personal and professional life. By learning from your experiences, he argues, you will be empowered to manage your own learning, which will in turn mean you do not need to depend on experts to tell you how to do things. Bunning $(1992,1994,1995)$ sees action learning as being able to help people develop questioning insight and become reflective practitioners, with a capacity and commitment to life-long learning.

Emphasising the holistic approach, Mumford (1991, p.5) states that "action learning is holistic in its view of the person, the management process and learning. It is highly situational, flexibly treating elusive problems and combines a social process with individual needs". McGill \& Beaty (1995, p.30) make the link with experiential education when they state "belief in the power of the experiential learning cycle is at the heart of our investment in action learning as a method for personal and professional development". Inglis (1994) sees action learning as flexible and inventive, and whilst following some well-defined criteria, there is no one textbook methodology. He regards action learning as "a process which brings people together to find solutions to real, important organisational issues and problems and, in so doing, develops both the individual and the organisation" (p.3). 
Weinstein (1995, p.9), sees action learning as "a process underpinned by a belief in individual potential: a way of learning from our actions (and from what happens to us and around us) by taking the time to question and reflect on this in order to gain insights and consider how to act in the future". In addition, she considers two other elements to be important - that there is a group of people who work together on their doing and learning, and that there are regular and rigorous meetings of the group to allow space and time for this process of questioning and reflection.

She also identifies six elements, which she regards as critical for an action learning programme:

1. Small sets with regular meetings. A set is a small group of people - usually four to seven (McGill \& Beaty, 1995); five to six (Weinstein, 1995); five to eight (Inglis, 1994)

- who meet regularly and work together. Individual action and learning is the sets' raison d'être, rather than focusing on the group - unless team building is the objective of the group.

2. Observing airspace and questioning processes.

3. Project or task focus as a vehicle for learning.

4. Revisiting both action and learning with a set adviser until the set is able to work alone. The set adviser essentially is a facilitator of the process of action learning rather than necessarily being a subject expert. The aim is for the set adviser to become redundant in the medium to long term with the set becoming more and more independent, with individuals taking responsibility for their own learning.

5. A timeframe of no less than six months.

6. An emphasis on learning.

I would add the need to contribute to programmed knowledge in the field of study of the action learning programme.

It may be worth noting here that, when applied to the VUW Diploma in Rehabilitation Studies, all six elements identified by Weinstein (1995) were present during the students' time in Wellington and whilst on practicum back at their branch. The sets were the four regional groups and the set adviser the regional tutor, with the group becoming essentially autonomous by the time they left Wellington. Whilst the students were not necessarily 
physically in one place, support networks were set up via email and telephone, as well as regional get-togethers. There were a number of mini projects leading up to the main project completed during their time back in the branch. This main research project has led to a substantial increase in the programmed knowledge associated with the ACC and rehabilitation issues.

Raelin (1997, p.369) summarises the approach of action learning well when he states that

Action learning, . . . , as a form of management education, elicits managerial behaviour, not student behaviour. Students derive knowledge not about management but rather about their own capacities to take action.

\section{Outcomes of action learning}

There seems to be general consensus in the literature regarding the outcomes of action learning. These include:

- personal and professional development;

- increased confidence and self-esteem;

- increased self awareness;

- learning to relate to, and communicate with, others more effectively;

- increased readiness to take responsibility and initiative;

- a change in organisational behaviour;

- development of networks.

Bunning (1992) sees the cornerstones of action learning as networking, supporting and influencing. Weinstein (1995, p.293) states that action learning "helps people focus on the practicalities of their everyday working lives and gives them an opportunity to do something about the issues that concern them - and learn from that experience. It brings learning to the workplace, rather than separating the two".

Raelin (1997), in his study of part-time MBA students, concluded that action learning programmes appear to result in different behavioural outcomes than mainstream management development programmes. He found that the students tended to be more 
questioning in their approach to work and also were more familiar with their strengths and weaknesses. The research also suggested that there were links between the individual's character, situational characteristics and the outcomes. In his case the less confident students in his study seemed to do less well with an action learning approach. However, he did caution that without a control group it could not be categorically claimed that the action learning outcomes were different to traditional programmes.

Similar outcomes to action learning programmes have been reported by Bourner \& Frost (1996) and O'Hara, Webber \& Reeve (1996). The article by Bourner \& Frost (1996) is based on comments made by participants who have completed action learning courses within the higher education setting. Participants' feedback with respect to the role of the learning sets was summarised under the following headings - a personal think-tank, feelings, support and safety. When considering the process of action learning more generally, participants' talked about friendships, the challenging environment, the feedback provided, traction with respect to sustaining their motivation. The main areas of learning which participants indicated they had derived from the action learning courses included learning to give and take, that they had similar problems, the difference between solving and managing problems, learning to help, learning to question and be questioned, learning skills, learning self-awareness and learning about learning. Not all the participants were supportive of action learning, with the main criticisms being levelled at the management of the actual programme and learning set meetings. O'Hara, Webber \& Reeve (1996) regard the benefits of action learning programmes as extending beyond the usual outcomes of academic programmes as participants' learn to learn, become self-managing of their learning, increase their level of self-awareness and have an understanding of learning with and through others. All of these outcomes are important, given that management does not occur in a vacuum, but within the socio-political arena of organisations.

The action learning programmes described have, exclusively, taken place with adult learners. The question of whether action learning is only applicable to adult learners is one of the questions asked by Bourner, Beaty, Lawson \& O'Hara (1996), but remains to be answered. For this reason the following section considers some of the literature associated 
with adult learning and how it, in particular, ties in with the reflective aspect of both experiential and action learning.

\section{ADULT LEARNING}

The area of adult learning or andragogy is seen to be important to this research as it is associated with action learning and impacted on the course design of the VUW Diploma in Rehabilitation Studies. The distinction here is made between pedagogy, which means the teaching of children, and andragogy, which refers to the teaching of adults. Knowles (1990, 1996) is the name most commonly associated with andragogy, but his work has increasingly been questioned in terms of whether there is really a distinction between pedagogy and andragogy (Hanson, 1996) and whether providing characteristics of adult learning is helpful (Cranton, 1994). In essence, Hanson (1996) argues that the difference is not between pedagogy and andragogy, but that the differences are located in context, culture and power. Cranton (1994) divides adult learning into three different areas:

- subject-orientated learning (acquiring knowledge and skills);

- consumer-orientated learning (directly meeting the needs of the learner);

- emancipatory learning (engaging in critical self-reflection).

The focus on adult students is the key concept of andragogy. Weigand (1996) describes adult learners as ready to learn, who see time as a finite and increasingly precious resource, and have a more self-directed, problem-centred approach to learning, which builds on their previous experience. Along a similar vein, Milligan (1995, p.22) summarises the key elements of andragogy as the

facilitation of adult learning that can be best achieved through a student-centred approach that, in a developmental manner enhances the student's self concept, promotes autonomy, self-direction and critical thinking, reflects on experience and involves the learner in the diagnosis, planning, action and evaluation of their own learning needs.

Milligan (1995) goes further to suggest that there must be a link between the teaching philosophy and the educational subject. In his case the consistency between andragogy and nurse education is cited. This could also apply to case management, as it is necessary for the education to be congruent with and reflect the human services paradigm. In essence 
andragogy is a process, which in the context of this research is consistent with the education of Case Managers from the ACC.

Another important aspect of adult learning is that of transformative learning, which is associated with the writings of Mezirow (1990, 1996). His work focuses on how adult learners see the world, question what they see and then develop, personally and professionally, through critical self-reflection. There are two key concepts to his argument:

1. meaning perspective, which is essentially a person's Weltanschauung; and

2. meaning schemes, which are a person's perspectives deriving from their specific values, assumptions and beliefs.

The final outcome of this process is an empowered person who reflects on their actions. Links can be made here to Schön's (1983) concept of the reflective practitioner. Cranton (1994) summarises this process in Figure 3.7.

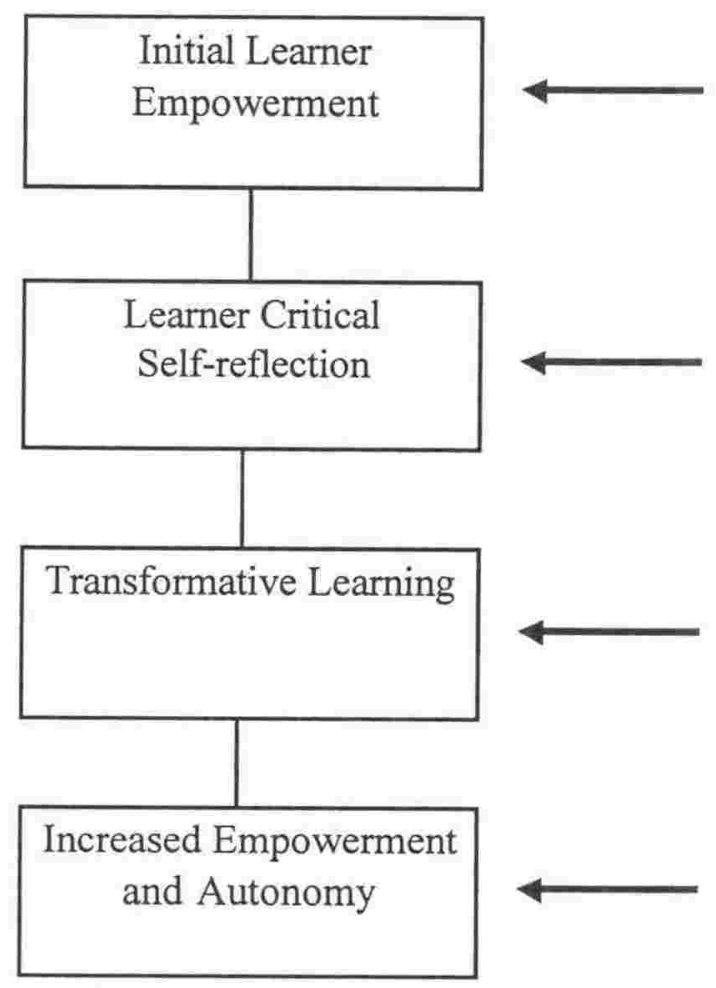

Freedom to participate

Comfort

Learner decision-making

Questioning assumptions

Consciousness-raising

Challenging assumptions

Revision of assumptions

Educator support

Learner networks

Action

Critical self-reflection

Transforming learning

Figure 3.7: Learner Empowerment through a Process of Transformative Learning (Cranton, 1994, p.143)

Mezirow (1996) suggests that adult education is emancipatory in the sense that it encourages reflection and discussion, with the educator being more of a facilitator and 
maybe even becoming a collahnrative learner. Thic develonment of a, naar, ralatinnahin 4.

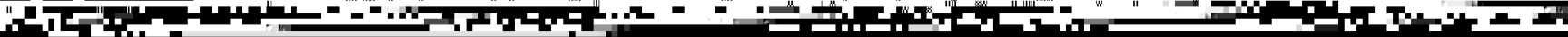

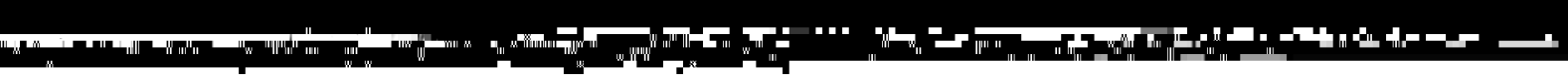

-

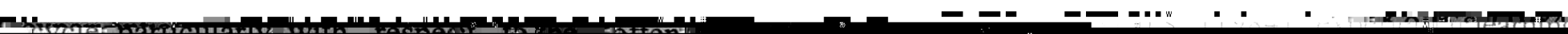

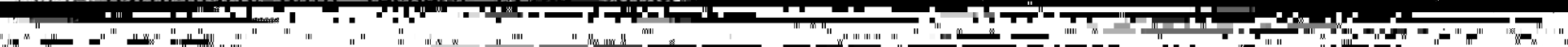
,

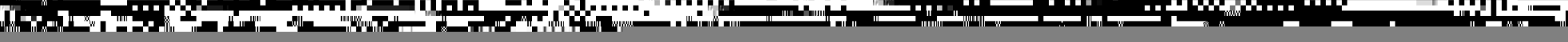


Managing is not a neutral or disinterested activity. The socially intrusive nature of managing means involvement in and having effects on the lives of others and on their future and the future conditions of wider society.

Reed \& Anthony (1992), when discussing the need to professionalise British management, made similar comments. They believed that management education should be concerned with the issues confronting mangers in the real world, which included the fact that managers need to make moral and ethical decisions. According to them,

any educational process must develop and encourage critical and sceptical responses and that a failure of management education to do so will contribute to its own redundancy (Reed \& Anthony, 1992, p.603).

These statements are very pertinent to the role of Case Managers with the ACC, as they have an effect on people and therefore society in their daily practice.

Reynolds (1998) also suggests that much experiential learning is removed from the sociopolitical and cultural context within which the participants will find themselves on return to work and regards this as one of the reasons why critical reflection is often lacking in the programmes. To remedy this situation he advocates "educational methods which lend themselves to a critical approach to content and process" and observes that "action learning offers considerable scope for critical reflection depending on how it is interpreted in practice" (Reynolds, 1998, p.195). Despite his support of a critical approach to management education, he does recognise the possible drawbacks, stating that

engaging in critical reflectivity can result in shared understandings being placed in doubt, undermining the basis of colleague ship, promoting conflict and cynicism, and even displacing individuals to the periphery of their professional group (Reynolds, 1998, p.197).

This comment leads to the subject transfer of learning and training, as it raises the question of how best to ensure, in Reynold's (1998) case critical reflection, is transferred from the educational setting back to the workplace and how to avoid the marginalisation of employees on their return from training. 


\section{TRANSFER OF LEARNING AND TRAINING}

This section will briefly outline the terminology, explain what transfer is and why it is important, before identifying the key issues in the area of transfer of training and detailing the thinking which has evolved from a historical perspective. The focus will be on the most recent literature and in particular, the literature which considers the different elements of the transfer process.

\section{Terminology}

The terms 'training' and 'learning' are often used synonymously, but they can also be taken to mean different things. Training elicits thoughts of working on particular skills and can appear very task-focused. Learning, however, seems a much broader term, encompassing not only specific skills, but also behavioural characteristics. Wills (1994) suggests that there are three types of managerial learning - cerebral, behavioural and transformational. Cerebral learning is associated with absorbing factual information and is largely skill-based, behavioural learning seeks to turn these skills into actual behaviours which are often situation-specific. Transformational learning is regarded as the development of the whole person, which is no longer situation-specific. This research is concerned with behavioural and transformational learning. Despite the terminology debate, Cormier \& Hagman (1987) argue that the term transfer of training equates to the term transfer of learning. Adopting this latter view, research on both transfer of learning and transfer of training will be reviewed and the terms used interchangeably, unless specified.

\section{What is transfer of learning?}

In general terms transfer of learning occurs when prior-learned knowledge and skills affect the way in which new knowledge and skills are learned and performed. Transfer is deemed to be positive if acquisition and performance are facilitated, and negative if they are impeded (Cormier \& Hagman, 1987; Marini \& Genereux, 1995). Seen in the specific context of transfer following an identified period of learning related to an individual's place of work, transfer is the process of applying skills, knowledge and attitudes acquired during a training programme to the work place. Their successful application leads to an 
improvement in job performance and has a lasting effect. McGeoch \& Irion (1952 cited in Cormier \& Hagman, 1987, p. XI) suggest that transfer of learning "is one of the most general phenomena of learning and, by means of its influence, almost all learned behaviour is interrelated in complex ways".

In the field of psychology there has been an interest in transfer of learning since the beginning of the century. However, it was not until the $1960 \mathrm{~s}$ and $1970 \mathrm{~s}$ that the methodology of transfer experiments were used in other areas of human learning. In the literature various types of transfer are identified. Apart from being 'positive' or 'negative', other terminology includes:

- 'near' and 'far' transfer i.e. similar or different situations (Laker, 1990 cited in Broad \& Newstrom, 1992)

- 'horizontal' and 'vertical' transfer i.e. similar or higher skill application (Foxon, 1987)

- 'specific' and 'non-specific' transfer (Brunner, 1960 cited in Gass, 1989)

- 'metaphorical' transfer (Bacon, 1983 cited in Gass, 1989; Priest, 1995)

Mmobuos's (1987) study on resolving re-entrants' problems in the transfer of management learning identified three models of transfer management. The first, based on Baumgartel \& Jeanpierre (1972 cited in Mmobuos, 1987), he called the "Pulpit Model" where the fault for the lack of transfer lies with the organisation, in that they should accept the new learning and the associated imported ideas, but often do not. Mmobuos named the second model, the "Linking-pin Model", based on work by Stiefel (1974 cited in Mmobuos, 1987). He argued that workgroups should all be trained on the same course. However, Mmobuos suggests that people exposed to the same situations do not always have the same perceptions of and attitudes towards what transpired. Thirdly, the "Leadership based Model" suggests that if the leader at the place of work is supportive transfer will happen. Mmobuos, then goes on to propose a new model which would involve all participants in the transfer process, throughout the different time phases of training i.e. pre, during and post training - he calls this the "Mutual Expectations Learning Transfer Model". The work of Broad \& Newstrom (1992) comes to a similar conclusion. 
Marini \& Genereux (1995) argue along similar lines from an educational perspective. They suggest, that in the past there has been a separation of the transfer process into task (stimulus-response psychologists such as Thorndike, 1913 and Cormier, 1987), learner

(Gestalt psychologists such as Katona, 1940; processing theorists such as Gick \& Holyoak, 1987; developmental theorists such as Case, 1992) and context (social-cultural environment such as Vygotsky, 1962,1978, Pea, 1987, Rogoff, 1990), rather than taking a holistic approach. They argue that in order to optimise transfer, it is necessary to teach about content/conceptual knowledge, procedural/strategic knowledge and appropriate dispositions.

A differing view of transfer is suggested by Bereiter (1995), who sees transfer as ability not as a process, with the potential for transfer lying with the learner, rather than in what has been learned. He argues that teaching should focus on character education, so that learners are able to think about situations rather than try and reproduce their learning. He supports the work of Lave \& Wenger (1991) who argue that people learn by entering ongoing 'communities of practice' and gradually working their way into full participation i.e. the social-cultural context is important.

Given the above discussion, transfer in the context of this research is regarded a process, which involves a number of participants, primarily the trainee, the trainer and the manager, who play different parts in the various phases of the transfer process - before, during and after training. However, the work of Bereiter (1995) is also supported where the learner is seen as playing a key role in the process.

\section{Why is it important?}

Training and development is considered an integral part of an organisation's investment. Good staff are particularly important in the human services industry and investment in them is seen as crucial (Blanchard \& Thacker, 1999). However, until recently this has not been reflected in the time and money spent on staff training and development (Blanchard \& Thacker, 1999; Hargreaves \& Jarvis, 1998). All too often training was seen as remote, a break from work and not necessarily applicable to the job at hand. One-day and week long 
courses were the favoured options as this meant staff were not away from the job for too much time.

Over the past few years it has been realised that more effort needs to be put into staff training, and tailor-made courses have become more common. For example, the August 1994 issue of Management, a New Zealand periodical aimed at professional managers, featured an account of the management education and development industry. It confirmed the availability of a wide range of training methods beyond traditional skills and university courses, including: consortium-style MBA programmes, customised training, competencybased programmes and the use by the Experiential Training Company, for example, of Senge's 'learning laboratories' (Mellalieu, Leberman, Bradbury \& Chu, 1994).

With this influx of management development training also came the question of how effective the training was, whether it actually transferred back to the workplace and the fade-out effects of the course. These questions are not new, with research in this area dating back to the 1950s. However, with training and development having become a multimillion dollar business, getting value for money is a primary concern for organisations, in the sense of being able to show a return on their investment, both in terms of time and money (Baldwin \& Ford, 1988; Broad \& Newstrom, 1992; Blanchard \& Thacker, 1999; Hargreaves \& Jarvis, 1998).

In the context of this research it is also important from a service management perspective. The ACC committed itself to the VUW Diploma in Rehabilitation Studies with the express aim of improving Case Manager service delivery to clients and regarded participants as potential 'change agents' on their return to work. This is akin to authors in the field of social work who have commented that training in social work organisations is not only of value to the individuals and the organisation itself, but also in terms of improving service delivery to clients (Cohen \& Deri, 1992; Hagen, 1988; Miller \& Dore, 1991; Rooney, 1988; Seipel, 1986). Gregoire, Propp \& Poertner (1998, p.2) suggest that

in a profession with ever increasing demand, including changes in policy, laws, and practice issues, training becomes a vehicle for the implementation of change. 


\section{Key Issues in Effective Transfer of Learning}

As stated above, the issue of transfer is not new, with the relevant literature in the area dating back to the 1950s. Mosel (1957 cited in Broad \& Newstrom, 1992) argued that three conditions must be present for effective transfer to take place. The training content must be applicable to the job, the trainee must learn the content and the trainee must then be motivated to change their job behaviour to apply that new learning. The emphasis was on the trainee, who was responsible for ensuring that transfer took place, assuming that the training was relevant and successful.

The role of support systems within the work place were discussed by Nadler (1971 cited in Broad \& Newstrom, 1992), who suggested that the trainee needed to be supported in order for transfer to take place. He argued that the level of management support was crucial and that the timing of training also played a part in ensuring successful transfer. Byham, Adams \& Kiggins (1976 cited in Broad \& Newstrom, 1992) in their study on supervisory skills, suggested that three factors support the transfer of training involving all the participants in the transfer process. Firstly, that trainees have acquired new skills - the trainer's responsibility. Secondly, that they have the confidence to try their new-found skills on the job - the trainee's responsibility. And thirdly, that the new skills are positively reinforced on the job - the manager's responsibility.

A review of some of the management, education and psychology literature since 1986, shows that the key factors discussed with respect to transfer of training are timing - before, during and after, and the people involved - the trainer/training deliverer, the trainee and the work organisation.

Baldwin \& Ford's 1988 review of the transfer of training literature provides a useful overview of the research done in the area to that date, as well as suggesting future directions for research. They provide a model of the transfer process, which considers three aspects of the transfer process - training inputs, training outputs and conditions of transfer. The training inputs are classified into trainee characteristics (ability, personality and motivation), training design (principles of learning, sequencing and training content) and work environment (support and opportunity to use). Training outputs are associated with 
learning and retention, whilst the conditions of transfer focus on the generalisation and maintenance of what was learned.

Two other key pieces of work exist in the transfer of training and learning literature - Broad \& Newstrom (1992) and Analoui (1993). The former coming from a North American perspective, the latter from a British view point.

\section{The transfer matrix}

Broad \& Newstrom (1992) argue for more consultation between trainer, trainee and manager and that the role of transfer manager should be taken on by human resource professionals. This concept of partnership is also emphasised by Minter (1996) in a study on safety training. Broad \& Newstrom (1992) focus on formal training that takes place in order to improve employee performance on the job. They define transfer of training as

the effective and continuing application by trainees to their jobs, of knowledge and skills gained in training - both on and off the job" and argue that full transfer of training has taken place when "...the level of skill with which that learning is applied will increase beyond the level demonstrated at the end of the training period (Broad \& Newstrom, 1992, p. 6).

\section{TIME PERIODS}

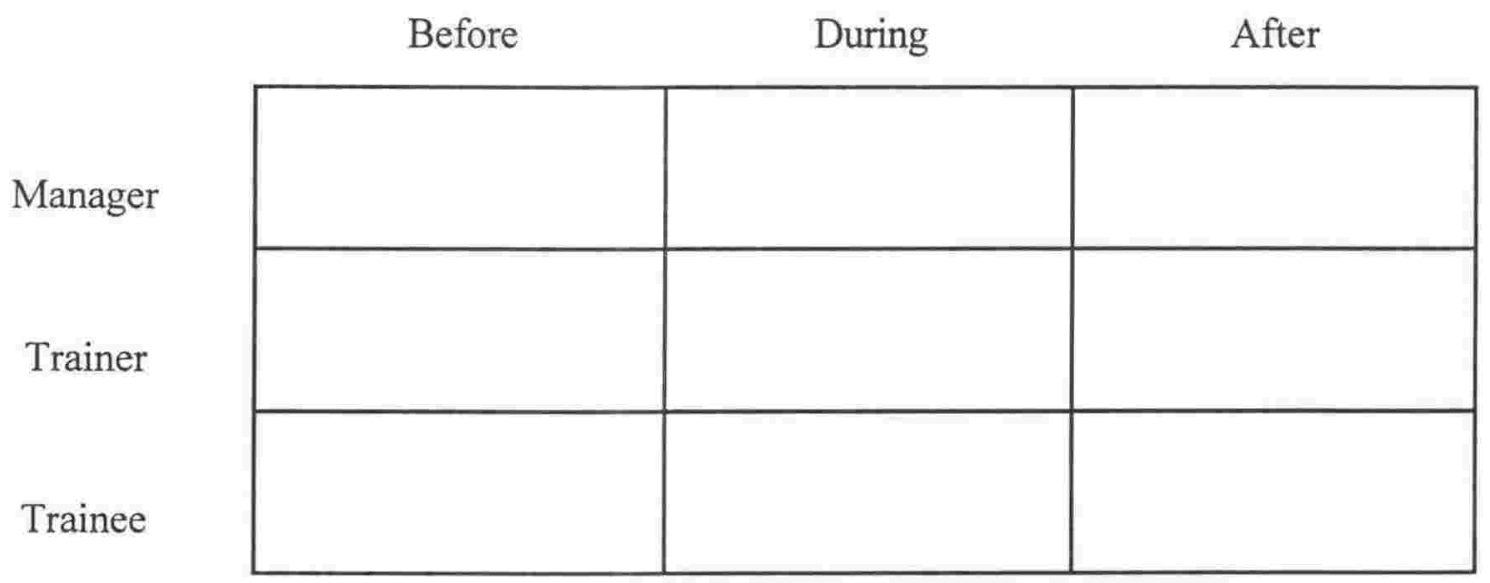

Figure 3.8: The Transfer Matrix (Broad \& Newstrom, 1992, p.52)

They have identified a number of strategies which can be carried out by the participants in the transfer process, in the before, during and after phases of training. Combining these two 
variables, they identified the Transfer Matrix which provides nine possible role/time combinations (see Figure 3.8).

Following on from this they were then able to identify who needed to do what at what stage to maximise the transfer of training. Much of their argument is built around Newstrom's (1986) research on the perceptions of trainers regarding barriers to transfer, which identified the key role that managers and trainers play in resolving the barriers to transfer. The three main barriers identified were lack of reinforcement on the job, interference from the immediate work environment and a non-supportive organisational culture. Reference is also made to the transfer barrier perceptions of executives from Kotter's (1988) study, which echoed the findings of Broad \& Newstrom. His findings suggest barriers to transfer often occur in organisations, particularly at the top management level, and that those barriers often inhibit change taking place in the work place after training. Whilst Broad and Newstrom accept that "trainees must be encouraged to take greater responsibility for their own development of new knowledge, skills and abilities; they are vitally important members of the Transfer Partnership" (Broad \& Newstrom, 1992, p.14), they also identify that the dominant sources of barriers to transfer come from the work organisation and management.

Broad \& Newstrom (1992) also draw on the work of Marx (1986) from the drug and alcohol rehabilitation area, to discuss the application of relapse prevention (return to pretraining behaviours) to the transfer area. They suggest that, assuming training has been successful, there are relapse indicators, which appear in the work place if trainees are not transferring their training. These include:

- a backlog of work or a lack of work resulting in boredom;

- unsupportive co-workers urging the trainee to revert to old behaviours;

- other pressures such as restructuring, multi-cultural differences or personal problems; which distract the trainee from focusing on applying their new learning;

- trainee doubts about using the new skills effectively;

- little or no management support to use new skills. 


\section{The socio-technical model}

Analoui (1993) argues for a socio-technical model of transfer where there is a move away from a focus on tasks, to an emphasis on the role of the socialisation in the work place. $\mathrm{He}$ sees training as including three aspects.

(1) Systematic processes which are concerned with some form of planned and controlled, rather than random learning experience;

(2) Changing the behaviour, skills and attitudes of people as individuals and as members of social work groups;

(3) Improvement of both the present and the following job performance (effective transfer) and enhancement of the effectiveness of the organisation in which the individual or group works (Analoui, 1993, p.5).

He also argues that

... the overall effectiveness of the trainees may not necessarily be related solely to the improved task performance but could also be due to their social competence skills (Analoui, 1993, p.5).

He discusses the location of training and the importance of social processes in the learning process, in particular "the socialisation processes which occur both during and after the training programme" (Analoui, 1993, p. 10). Analoui sees transfer as a complex process including the individual's experiences, expectations and ability, as well as the learning experience per se and the work environment provided by the organisation. This leads him to suggest the following working definition of transfer, where transfer is seen

as being a process which begins with the individual or group and concerns the ability and motivation to learn in a particular learning situation and which concerns the extent to which the learnt knowledge and acquired skills can be seen to materialise, (this includes suitable changes in behaviour and attitudes as well as more evident changes in performance), within the working environment and consequently contributes to the effectiveness of the individual concerned, the unit, department or organisation as a whole (Analoui, 1993, p. 13).

Analoui (1993) also suggests that as the process of transfer extends into the workplace it is difficult to "completely harness and bring under control" (p.20) other factors which may 
contribute to effective or ineffective transfer. To minimise the impact of these factors, Analoui advocates an experiential learning approach as it focuses on the learner, giving him or her a certain amount of autonomy. He also supports the use of learning contracts as it improves the transfer back to the workplace. Learning contracts were originally suggested by Knowles (1986) and are now widely used in the adult learning context. In most cases they consist of an individual contract between the learner and their direct supervisor, although a third party such as the training provider may also be involved. This contract identifies specific learning objectives that the individual contracts to work on over a set period of time. It also identifies the resources to be used in achieving the specified objectives and how their completion will be evaluated. The importance of action learning is also recognised by him and he comments on its increasing use.

One of his main assertions is that the low amount of transference experienced may be due to the traditional focus on task learning, which has ignored the social learning processes that takes place on training programmes. He suggests that "some of these social learning processes may have an undoing effect on the task-related learning and the process of transfer as a whole" (p.52-52). These social learning processes are not only related to the training environment, but also include social and cultural expectations of the work place and the interpersonal skills needed to remain effective as a member of the organisation after training.

The question of location of training is, according to Analoui, dependent on the nature and complexity of the job. In essence, this means that the more complex the job the further away from the work place the training should be. However, he argues that a combination of on-the-job and off-the-job training may be best in terms of transferring learning to the work place. He suggests that

managerial training is rated as the most difficult one since it involves changes in behaviour, attitude and values, which are troublesome to analyse, define and evaluate once the training is completed. There are 'no' correct ways of managing organisations (Analoui, 1993, p. 60).

Therefore, he argues that off-the-job training is for these more complex jobs and for those people who are to be 'change agents' on return to the work place. In addition, he suggests 
that in any off-the-job training there needs to be time set aside to prepare people for their return to work.

These arguments culminate in a taxonomy of the socio-technical model of transfer and types of training situations (see Figure 3.9). Analoui (1993, p.149) states:

In a way the parameters for the effectiveness of the socio-technical approach are determined by the utilising organisations, their training and development policies and the extent to which trainers and educators wish to include the above external and organisational factors. Components such as the availability of resources, supervision before, during and after the termination of training, the design, structure and content of a training programme, and the trainer's style of managing learning situations as opposed to maintaining them, are the main determinants of the scope and limitations of this approach to training.

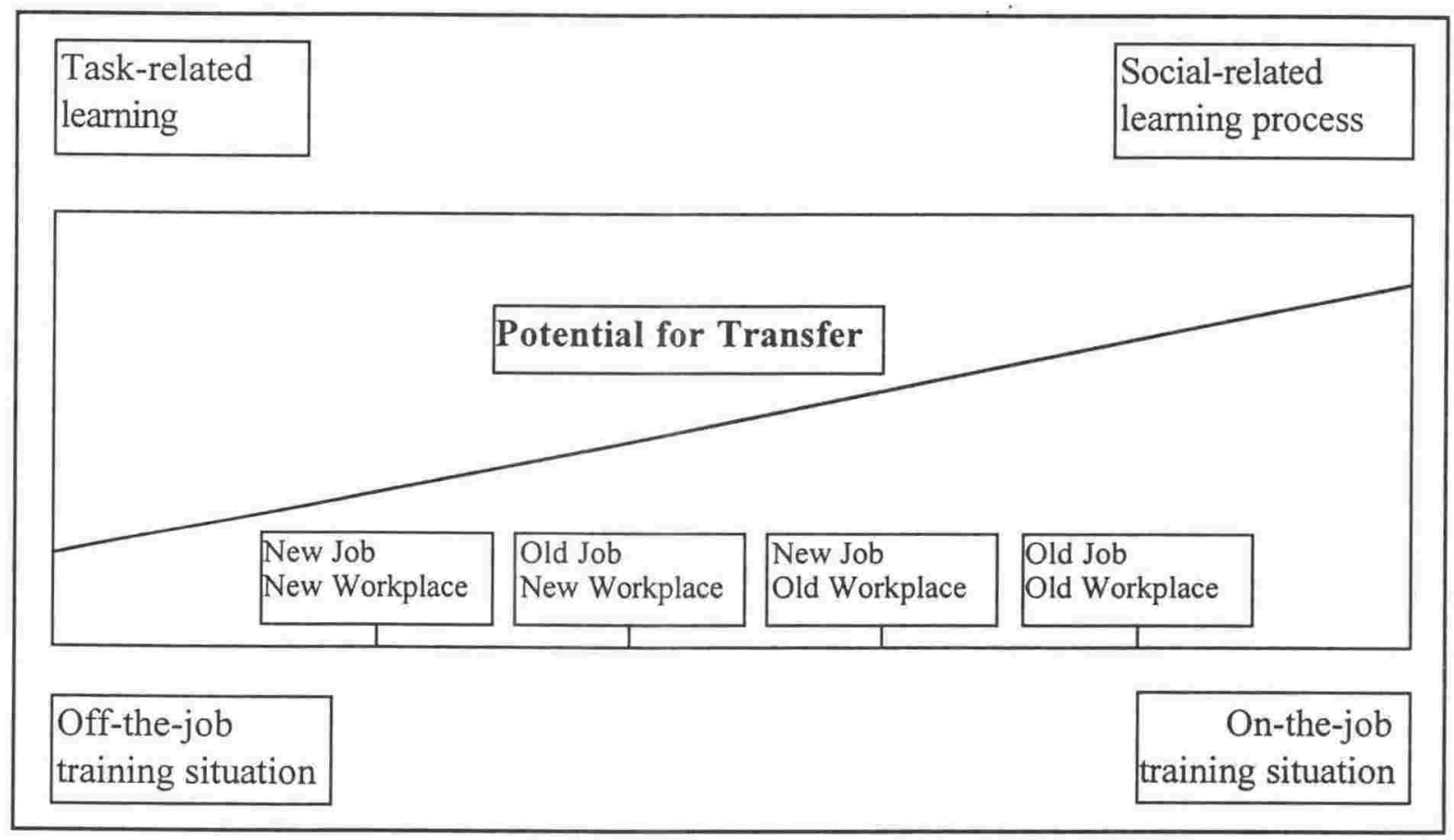

Figure 3.9: A Taxonomy of the Socio-technical Model of Transfer and Types of Training Situations (Analoui, 1993, p.123)

Figure 3.9 suggests that there is usually a combination of task and social learning processes present in training programmes. However, Analoui (1993) argues that the closer the training programme is to the actual workplace, the stronger the influence of social learning becomes and with that the potential for effective transfer is increased. The taxonomy shown in Figure 3.9, is divided further by considering where the trainee is going after the programme. 
This is seen as important in terms of the training methods adopted. For example, a trainee going to a new job in a new workplace, would according to this taxonomy benefit from an off-the-job training situation which focuses on task related learning.

\section{Associated literature}

Other general overviews of the subject are provided in three recent articles by Mbawo (1995), Holton (1996) and Gregoire et al. (1998). Mbawo (1995) identified five factors affecting the transfer of learning drawing on previous literature. These factors are individual/trainee characteristics, organisational climate, training design, learning styles and trainer strategies/facilitation style. She also interviewed six trainers from private, public and academic institutions to identify the methods used by them to enhance the transfer of learning. Her findings were grouped into the three time phases of the transfer process. The preparations before training involved manager/trainee interviews, trainee expectation assessments and thorough training needs assessments. During training, the use of experiential learning methods was prevalent, with case studies and story-telling being provided as examples. Voluntary participation was seen as important and learning contracts were also used. After training, feedback, both individual and collective is valued, and should be coupled with short-term and long-term action planning. Some trainers included on-the-job observation post-training and questionnaires to industry were also used. In spite of being able to provide a number of strategies to enhance the transfer of learning, there was still concern expressed by the trainers about the level of transfer actually taking place.

Holton (1996) approaches the transfer question from an evaluative perspective and argues for a new human resources development evaluation research and measurement model (see Figure 3.10). He suggests that the Four-Level Evaluation Model (Kirkpatrick, 1976 cited in Holton, 1996), together with its modifications by various other authors, has "received incomplete implementation and little empirical testing" (Holton, 1996, p.6). He states (p.8) that "there is a complex system of influences on training outcomes that must be measured if training is to be accurately evaluated". Following on from this statement, his model, 
therefore, considers the influences on learning, performance outcomes and organisational results.

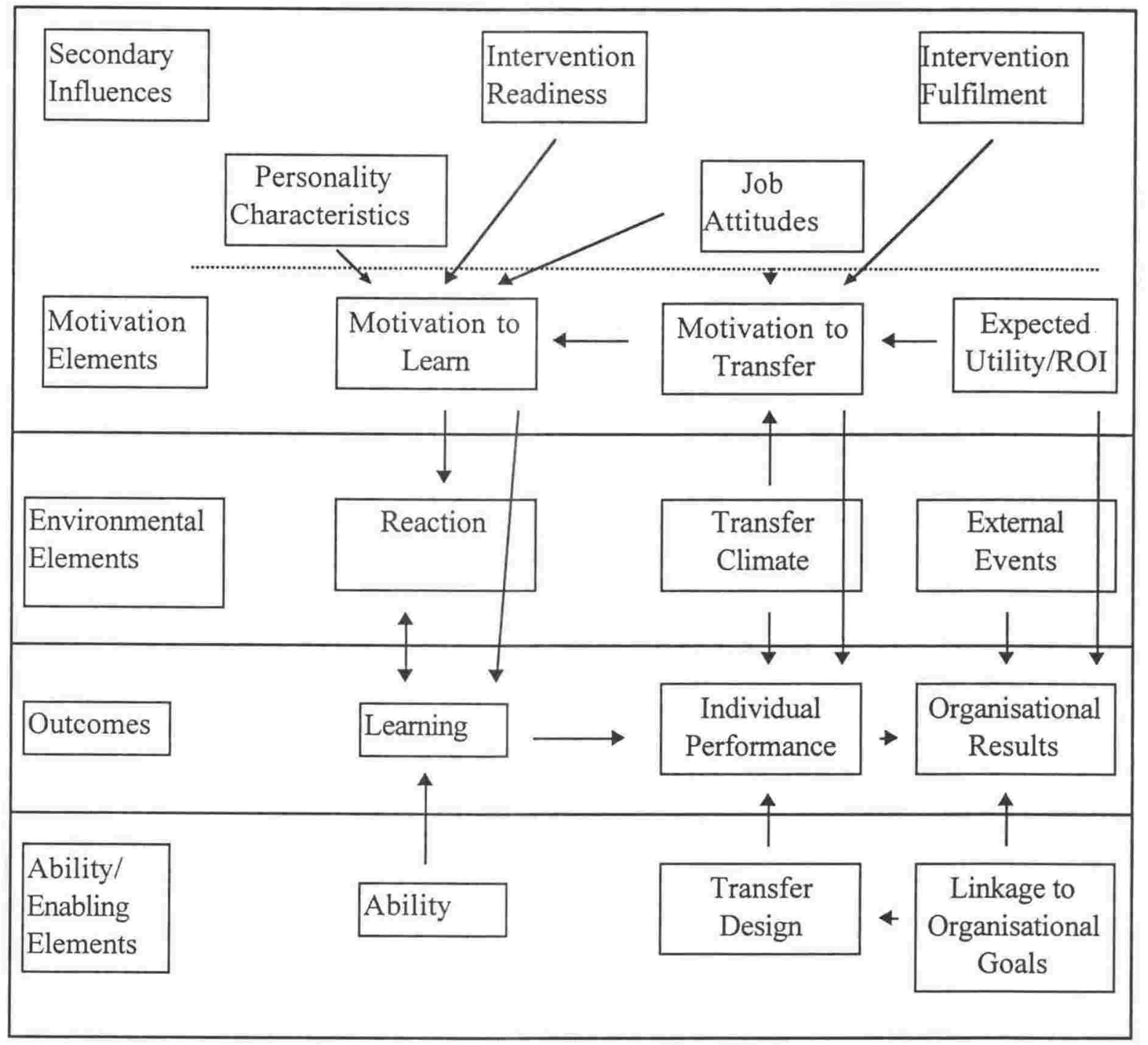

Figure 3.10: HRD Evaluation Research and Measurement Model (Holton, 1996, p.17)

Gregoire et al. (1998) approached the subject from a social work perspective and reviewed the literature associated with the transfer of training in the social work, educational and organisational psychology, management, and organisational behaviour areas. They concluded that there was little empirical literature available on the transfer of training back to the workplace. However, the literature reviewed indicated that individual attributes, the 
training curriculum and the work environment influenced the transfer process. These factors were summarised in the following figure:

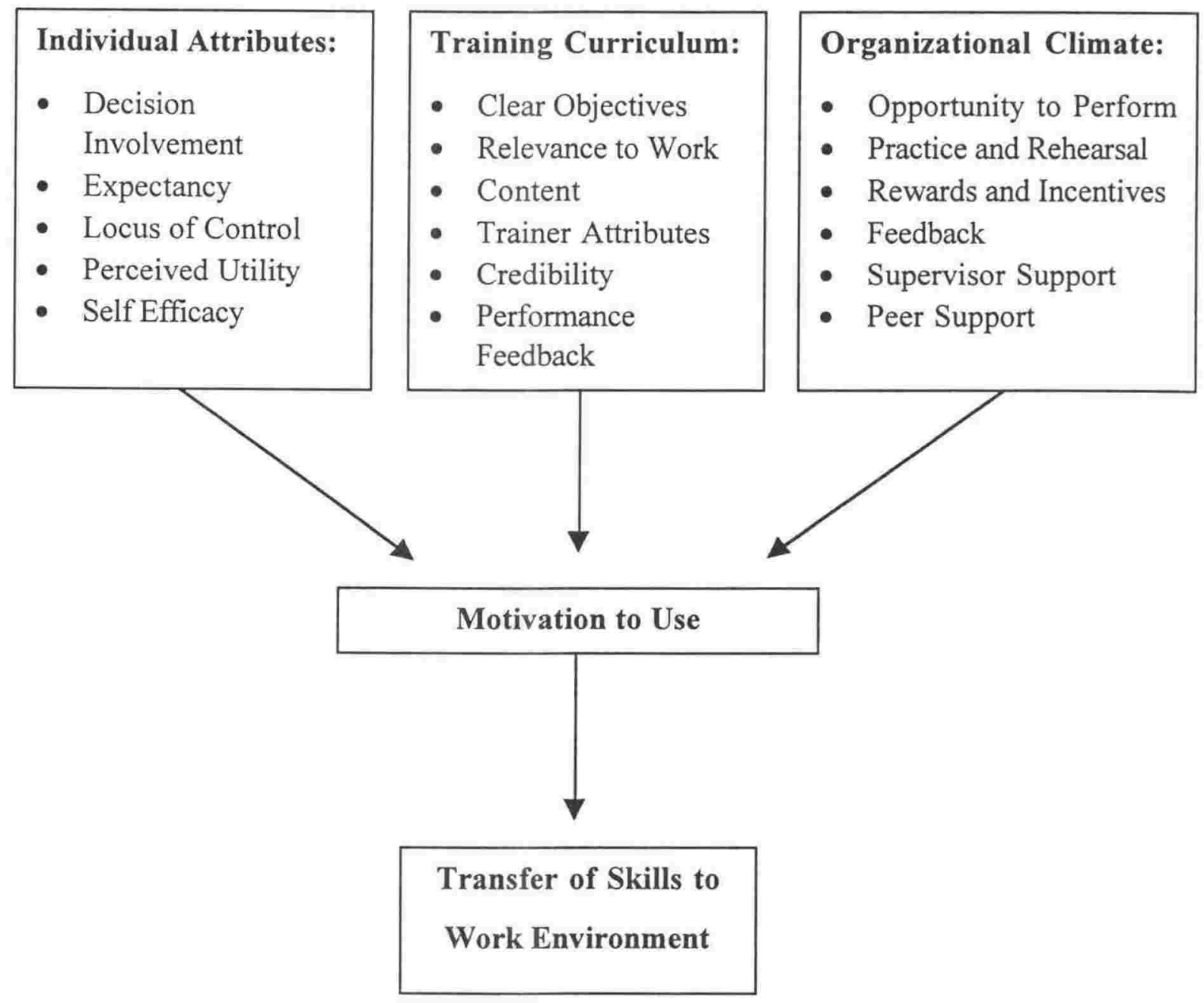

Figure 3.11: A Model of the Transfer of Training (Gregoire et al., 1998, p.4)

The focus of Gregoire et al.'s (1998) research was on the role of the supervisor in facilitating transfer back to the workplace. The findings suggested that course participants received little support from their supervisors once back at work. This lack of support is attributed to the low level of impact the training subsequently had on the workplace. These findings are not new, with Baldwin \& Ford (1988), Garavaglia (1993) and McSherry \& Taylor (1994) for example, coming to similar conclusions. One of the implications of these findings is aptly stated by Gregoire et al. (1998, p. 15).

In order to reap the benefits of training, organizations must be committed to, and take responsibility, for training. It is probably not sufficient to have a motivated supervisor. 
Ultimately, the agency's commitment to training emanates from upper management. The importance that upper administration places on training most certainly influences the supervisor's willingness and ability to enhance the benefit of training.

The remaining literature since 1986, essentially, falls under three headings: programme design, work environment and trainee characteristics (see Appendix 2 for a summary list of literature reviewed).

\section{Programme Design}

A large number of programme design elements have been highlighted in the literature as being important to facilitating transfer of learning.

The issue of training location is considered by a number of authors (Analoui, 1993; Billet, 1992 \& 1994; Buckley \& Caple, 1996; Lave \& Wenger, 1991). Billet (1992) argues that it is important to have training based in the workplace, so not to neglect the socio-cultural factors of the workplace. The basis for this argument is that new attitudes learned at offsite training, for example, may not be compatible with the actual workplace - so a degree of workplace reality needs to be introduced at some stage during the training course. Analoui (1993) supports this notion with his socio-technical model, but also argues that a combination of on- and off-the-job may be best in terms of transferring learning to the workplace.

The use of learning contracts or action plans to reinforce learning has been widely supported (Analoui, 1993; Foxon, 1987; Gist, Bavetta \& Stevens, 1990; Mbawo, 1995; Stuart, 1992) as being beneficial to the transfer of learning. The main reason for this is that it provides a point of reference for learners to work from and reminds them of where their focus should be.

Using an experiential learning approach, in particular action learning (Analoui, 1993), according to Foxon (1990) and Gass (1989) enables the use of an appropriate teaching methodology. Similarly, it is suggested (Gass, 1989; McGraw, 1993; Stuart, 1992; Wagner 
\& Campbell, 1994) that appropriate, but diverse, activities are designed. A mixture of assessment, to match the variety of learning styles (Analoui, 1993; McGraw, 1993; Stuart, 1992) represented in the students is also advocated. For example, the use of journal writing is supported in the experiential learning literature (Kruger \& May, 1986; Weinstein, 1995) as a form of assessment, conducive to developing skills in reflection. The use of an experiential methodology may also provide the opportunities for programme tutors to develop their own unique facilitation style, an aspect supported by Heron (1992 cited in Mbawo, 1995).

The benefit of non-physical risk-taking in experiential education programmes is supported by Gass (1989), Robinson (1992) and Wagner \& Campbell (1994). Traditionally, experiential education has been associated with outdoor management development programmes, where the use of perceived, as opposed to real, risk is seen as developing, amongst other things, self-confidence in the learner. Developing self-confidence and centring the locus of control within the student are also seen as important in the transfer literature. The work by Binder (1990), Robinson (1992) and Tziner, Haccoun \& Kadish (1991) are examples of this. It is also argued that the propensity for taking risks will be transferred back to the work environment (Bank, 1994; Krouwel \& Goodwill, 1994; Priest, 1995). This propensity for taking risks needs to be seen in the context of encouraging course participants to take calculated risks, which have been considered within a risk management framework.

Stuart (1992) suggests that it is of benefit to only train some of a work group at one time, as it enables a constant refresher to take place for those who have already completed the course. This overlap of students also enables informal mentoring (Stuart, 1992) to take place, with past students assisting those on the course. Stuart (1992) also suggested that peer support groups facilitate the transfer of learning, in the sense that they may provide some continuity to relationships established during training programmes.

The concept of a relapse prevention module is advocated by Tziner, Haccoun \& Kadish (1991). This module is set up to prepare course participants for their return to the work place. It seeks to identify some of the difficulties, which may arise on return to work and 
how to best deal with these situations. The effect of programme setting and duration has recently been investigated by Priest (1998) in the context of experiential corporate team development programmes. He concluded that the setting had no effect on the outcomes, but that several shorter programmes appeared to produce greater teamwork in the long term than one long programme.

\section{Workplace Characteristics}

The main workplace factors identified in the literature as facilitating transfer include direct supervisor support (Broad \& Newstrom, 1992; Brinkerhoff \& Montesino, 1995; Garavaglia, 1993; Gregoire et al., 1998; Mc Sherry \& Taylor, 1994; Mmobuos, 1987; Noel \& Dennehy, 1991; Xiao, 1996), socio-cultural factors (Analoui, 1993; Billet, 1992 \&1994; Buckley \& Caple, 1996; Lave \& Wenger, 1991), social support (McGraw, 1993; Tracey, Tannenbaum \& Kavanagh, 1995), continuous learning culture (Tracey, Tannenbaum \& Kavanagh, 1995) and transfer of training climate (McGraw, 1993; Tracey, Tannenbaum \& Kavanagh, 1995). The workplace plays an important part in the transfer process, as it is here that the learner is expected to demonstrate their new knowledge and skills. If no change is perceived to have taken place, transfer is deemed not to have happened. Given this situation a number of studies have tried to establish what particular factors in the workplace facilitate transfer.

Direct supervisor support is seen as crucial, since the supervisor often determines whether new learning can be implemented at the workplace. Noel \& Dennehy (1991) argue for a partnership to be formed with the learner's supervisor. This includes gaining the supervisor's input into the course, meeting with them and the learner prior to and after the course. In essence, the supervisor needs to be totally committed to the course or training programme, with their involvement being sought from the outset. Brinkerhoff \& Montesino (1995), Garavaglia (1993), Gregoire et al. (1998) and McGraw (1993) support this, but argue for wider management support, not just from the immediate supervisor. Their main reason for this is that the wider work environment may impact on the learner's opportunity to transfer their knowledge and skills. Mc Sherry \& Taylor (1994) suggested that running supervisor workshops, facilitated by the course deliverers should be held to 
facilitate the transfer process. The work environment may also be quite unpredictable, particularly when dealing with a government agency such as the ACC. Xiao (1996), in her study of the transfer of training in the electronics industry in Shenzhen, China, argues along similar lines, suggesting that supervision is the most crucial factor in the work environment for transfer to take place. She states (p.59) that "when training programmes improve the workers' potential, they also bring about changes in workers' expectations of themselves and of the organisation". In order to then realise this potential the organisation needs to be ready for these changes in expectations.

The importance of the socio-cultural factors of the work environment have been particularly emphasised by those writers who advocate for the training, or at least part of it, to take place in the work place. Analoui (1993), Billet $(1992,1994)$ and Lave \& Wenger (1991), for example, stress the importance of training being seen not merely as the acquisition of technical skills, but also see it as a social process. If the socialisation which takes place at training or on courses does not match that of the work place environment, then there is potential for difficulties to arise. By having the training on-site, this disparity is less likely to occur, and for new employees in particular, the opportunity to become acquainted with the social processes of the work environment, as well as gaining new skills and knowledge, is provided.

This notion ties in with the concepts of organisational culture and climate, which Tracey, Tannenbaum \& Kavanagh (1995) considered as important for transfer of learning to take place. In their study of supermarket managers, they were considering why training works. In particular, they considered the work environment, which they divided into transfer of training climate and continuous-learning culture. The "transfer of training climate refers to the perceptions about characteristics of the work environment that facilitate or inhibit the use of trained skills and behaviours" (p.242). This is seen to include, for example, managerial and peer support for training and development, and performance appraisal systems that account for behaviour and skills acquired in formal training programs. "A continuous-learning environment is one in which organisational members share perceptions and expectations that learning is an important part of everyday life" (p.241). 
McGraw (1993) also emphasises the importance of organisational culture in terms of trying to redress some of the re-entry problems encountered by training participants when returning to the workplace. His research findings whilst focusing on outdoor management development programmes also have wider applicability. He identifies three particular problems often associated with returning to work - the "return from space effect", the "hangover effect" and the "widows and orphans effect" (McGraw, 1993, pp.58-59). The 'return from space effect' takes place when the trainee has developed and changed but the workplace has not. This often means that it is difficult for trainees to re-integrate back into the work environment and there may be resistance from colleagues to suggested changes made by the trainee. Similarly, some training participants may be bored and understimulated on their return to the workplace, or they may have realised that they have the potential to achieve more than they had previously thought possible. These feelings are associated with the 'hangover effect'. In addition, training programmes often provide a supportive environment for participants to work and develop in, an environment, which may not be replicated in the workplace - the 'widows and orphans effect'. McGraw (1993) also stresses the importance of an in-depth organisational analysis prior to training and that the training programme needs to be complimentary to the culture of the sponsoring organisation for transfer to be successful.

\section{Trainee Characteristics}

The review of the transfer of training literature by Baldwin \& Ford (1988) divided trainee characteristics into three different areas, ability and aptitude, personality (which included a high need for achievement and an internal locus of control), and lastly motivation. Examples in the motivation category included confidence, high self-expectancies, high job involvement and a high belief in the value of training. More specific studies have covered some of the following areas:

- general ability of the learner (Bereiter, 1995; Rouiller \& Goldstein, 1993), including student background (Castaldi, 1989)

- motivation (Noe \& Schmitt, 1986 cited in Mbawo, 1995; Holton, 1996)

- self-efficacy (Gist \& Mitchell, 1992 cited in Mbawo, 1995) and self-esteem (Mink, Owen \& Mink, 1993) 
- the ability to take risks (Friedman, 1990; Robinson, 1992).

Bereiter (1995), as previously stated, sees transfer as an ability rather than a process. He argues that it is learned intelligent behaviour, which prohibits transfer from one situation to another taking place. In essence, they have not learned to think, but have learned to reproduce their knowledge, which necessarily limits its application to different contexts. Rouiller \& Goldstein (1993) suggest that the ability of the trainee to correctly determine the level of support they will receive on return to the workplace, affects their efforts to apply their newly learned behaviours.

Castaldi (1989) in her work with adult learners attending university, draws on the work of Freiere (1970) who suggested that it is important to learn about the backgrounds of the students you are working with prior to starting teaching. She states (p.18) that "students who are involved in academic pursuits for the first time or after a long hiatus will actively draw upon relevant experiences in order to construct a viable model which can be used to achieve immediate goals".

Holton (1996) sees the learner's motivation to learn in terms of readiness, job attitude and personality. He also identifies the motivation to transfer the learning as an influence on performance outcome. Noe \& Schmitt (1986 cited in Mbawo, 1995) suggest that the motivation to actually transfer the learning is largely dependent on the learner's confidence that the learning can be successfully performed. This last concept is also referred to as selfefficacy. In a sense it is akin to self-confidence, in that the learner has to believe that they can carry out a particular task or process, otherwise they will not even try. Gist \& Mitchell (1992 cited in Mbawo, 1995, p.7.30) suggest that

differences in self-efficacy are associated with differences in skill levels, that is it affects performance through behavioural choices such as effort and persistence.

Related to self-confidence is self-esteem. Mink, Owen \& Mink (1993) argue that there are four components of self-esteem - connectedness, a sense of uniqueness, a sense of personal power and a sense of purpose. The learner focuses on determining what is important and 
identifies meaningful connections, to him- or herself, from ideas, stimuli and learning opportunities.

The benefits of providing opportunities to take non-physical risks have been discussed in programme design. It is mentioned in this section again, as it is important that the learner is able to not only take risks during the programme, but is able to adapt the learning from those experiences to the work situation. Friedman's (1990) work focuses on the trainee, and amongst other things suggests that the trainee should take moderate risks. He states (p.18) that "these result in greater trainee growth and motivation than wild or conservative actions . . Trainees must identify projects that test their new skills, that have organisational benefits, and that have reasonable chances of success". The aims of Robinson's (1992) study were to consider how the risk recreation experience compares subjectively to everyday working experience in its potential to generate psychological wellbeing, as well as to provide some qualitative information on transferability of benefits to other life spheres. The study, whilst being based on mountaineers, raises some valuable issues with regard to risk taking in general. With particular importance to this study is his suggestion that a risk participant should be periodically required to accept often intense levels of fear and anxiety. Robinson quotes Csikszentmihalyi (p.17) who states:

The risk experience may even be generalised to whatever other situations the individual is forced into or chooses to enter, using the risk experience as a paradigm to which they refer situations from other realms of life for clarity and decision.

The findings of Robinson's study suggested that there was some perceived transfer of psychological benefits including, for example, self-confidence, commitment and perseverance and self-determination. He sees most of the transfer as having been nonspecific, in that they involved mainly principles and attitudes such as self-confidence.

Risk-taking in the managerial setting is also pertinent to this discussion. Within case management Case Managers are called upon to make decisions, often involving large sums of money, where the outcome is often uncertain. The important point here is that managers understand risk in order 
to enhance their ability to make and evaluate decisions in uncertain situations. If you understand the nature of risky decisions, you are more likely to evaluate these decisions based on the quality of the decision process rather than on the capriciousness of their outcomes (Bazerman, 1998, p.44).

This means that managers need to know about and understand the process of decision making involving risk, rather than try and avoid situations where risk is involved or alternatively being too overconfident where risk is an issue - in essence have a clear understanding of risk management principles. Similarly, Revans (1982b) saw the value of people being in situations involving risk, ignorance and confusion, as he regarded these as growing and learning opportunities.

All of the studies reviewed have used a largely quantitative approach involving pre- and post-training questionnaires to participants and/or work supervisors. Much of the analysis has been of a statistical nature involving t-tests and regression analysis. The timing of the post-training questionnaires has varied from one to twelve months.

There were some studies involving interviews which including Kruger \& May (1986), . Blomberg, Levy \& Anderson (1988), Rouiller \& Goldstein (1993) and Mbawo (1995). Kruger \& May (1986) conducted telephone interviews with management trainees eight to fifteen months after completing their course, in order to ascertain whether journal writing and peer support groups had assisted with transfer. Blomberg, Levy \& Anderson (1988) conducted interviews in conjunction with questionnaires in considering whether management development training at the Rochester Methodist Hospital had been successful. Rouiller \& Goldstein (1993) used exam results, questionnaires and focus groups when considering the relationship between organisational transfer climate and positive transfer of training. Mbawo (1995) conducted interviews with trainers to elicit their strategies for enhancing the transfer process.

Most of the studies have taken place in private corporations or organisations, with only a few involving government departments, and the latter were mainly divisions of the armed forces, for example the study by Tziner, Haccoun \& Kadish (1991) which focused on a training course with the Israeli army. 


\section{Funded Evaluation of the VUW Diploma in Rehabilitation Studies}

The evaluation study commissioned by the $\mathrm{ACC}$ to consider the transfer of training from the VUW Diploma in Rehabilitation Studies to the branches, up to six months after completion, was submitted to the ACC at the end of 1997 (Collinson \& Brook, 1997). Their research was conducted from a psychological perspective and was largely based on postal questionnaires. The sample for their research was drawn from the second, third and fourth cohorts of students on the VUW Diploma. The authors conclude that

the transference of the newly acquired knowledge, skills and abilities was achieved primarily through the personal attributes of the trainees. . . Support from others in the organisation was modest. . . However, the greatest dissatisfaction came from recognition from Head Office (Collinson \& Brook, 1997, p.50).

They identify the conflict between the realities of the workplace and the holistic approach to case management encouraged on the VUW Diploma in Rehabilitation Studies, as the key factor detracting from transfer taking place. Despite these difficulties they note that

the training was perceived by the trainees and the supervisors to have impacted favourable on the Corporation, colleagues and clients. For the Corporation, it was thought that better management of clients resulted in reduced costs. Also, the relationships between Case managers and their clients were improved through more professional case management. The training was perceived to have given credibility and professionalism to the role of Case manager (Collinson \& Brook, 1997, p.55).

The recommendations for the ACC were categorised into the training and the transfer phase. The training phase included conducting a thorough training needs analysis, a suitable time frame for participant selection and pre-course meetings to familiarise trainees and supervisors with the course processes. The recommendations for the transfer phase focussed on providing a more conducive work environment for transfer to take place after training, including providing extra support during the transition back to work, linking training to performance appraisals and encouraging trainees to use their newly acquired ideas. 


\section{Chapter Summary and Location of this Research}

Given the above review of the literature, it can be seen that this research makes an attempt at linking and integrating a diverse body of knowledge. There is the integration of case management into the service management area and the association of the transfer of learning as actually being part of improving service delivery, rather than standing as a separate entity. As can be seen the actual design and delivery of the VUW Diploma in Rehabilitation Studies integrated the area of experiential learning, focussing on action learning, with adult learning and the concept of the 'reflective practitioner'. By using a qualitative phenomenological paradigm concentrating on the participants' experiences, the research adds not only to the knowledge in the area of action learning and adult education, as advocated by Bourner \& Frost (1996), but also to the human services literature (Dickens, 1996; Mattsson, 1994). The research also makes a contribution to empirical studies in the area of transfer of learning, which according to Gregoire et al. (1998) are missing, as well as considering the link between service management and the transfer of learning. And finally, this study provides an extension of the psychological, predominantly quantitative transfer of training study completed by Collinson \& Brook (1997), with participants from the same programme. In this research, the experiences of the participants are considered in a purely qualitative manner at twelve, eighteen and twenty-four months after completing the VUW Diploma in Rehabilitation Studies. The details of the research methodology and methods used are discussed in the following chapter. 


\section{CHAPTER 4 MANAGING THE ENQUIRY: THE CHOICE OF METHODOLOGY}

In this chapter the choice of research paradigm and how it relates to the research topic will be discussed. This will be followed by explaining why certain research methodologies within the research paradigm were chosen. The methods of data collection and analysis, as well as a timeline indicating when the various stages of the research occurred will also be presented. Finally, reference will be made to the reliability and validity of the findings, as well as some of the inherent limitations associated with the research methodology.

\section{THE RESEARCH PARADIGM}

A phenomenological paradigm was adopted because of the underlying assumptions associated with it, my world view and the nature of the research.

\section{Assumptions}

The assumptions of this research paradigm include the focus on process, in addition to results; an interest in 'meaning' particularly the experiences of people; the researcher being seen as the main source of data collection and analysis; it involves fieldwork; is descriptive and is inductive. Furthermore, this approach encourages the use of multiple methods to establish different views of phenomena, as well as in-depth investigations over time (Denzin \& Lincoln, 1994; Easterby-Smith, Thorpe \& Lowe, 1994; Hussey \& Hussey, 1997; Miles \& Huberman, 1984; Rudestram \& Newton, 1992). The approach taken involves the gathering of information, the asking of questions, the forming of themes or categories, the search for patterns and finally the development of theory or the comparison of the patterns with other theories (Bryman \& Burgess, 1994; Cresswell, 1994; Denzin \& Lincoln, 1994; Easterby-Smith, Thorpe \& Lowe, 1994).

Stanley \& Wise (1993) argue that all research is socially constructed following Kuhn (1962 cited in Stanley \& Wise, 1993) who argued 
that there are no 'facts' which are 'paradigm-free', theory independent, because what we regard as 'fact' differs according to the world view or paradigm we live and work within. . . because of this talking about 'truth', in terms of social reality, makes no sense at all (p.154).

They go on to state that "our consciousness is always the medium through which research occurs" (p.157).

Following this concept of the researcher's consciousness, they argue that it is not possible to separate the individual from the researcher or the experiences from the research stating that, therefore

all research is 'grounded' in consciousness. . . the research experience itself, like all other experiences is necessarily subject to on-going 'theorising', on-going attempts to understand, explain, re-explain, what is going on (Stanley \& Wise, 1993, p.160).

They also suggest that the research process as experienced in reality is not often portrayed as such in the literature, which makes the whole process seem like very clinical linear experiences rather than the often diverse experiences that are usually involved in research. Stanley \& Wise (1993) attribute this to the fact that social scientists, in particular, seem to place more emphasis on theory than experiences, which means that much of the research reported tends to avoid the contradictions and ambiguities which arise because it is often easier to do so - in a sense it is less 'messy'. The researcher, as a thinking, feeling individual, becomes separated from the research for the purposes of detachment, truth and non-involvement, features generally associated as being important in the research process. However, they argue that the researcher as a person is central to the research and cannot be divorced from the process, just as its location in time, space and place cannot be left unconsidered.

Rose \& Webb (1998) argue that it is important for qualitative researchers to establish rigor throughout the research process, and particularly when analysing the data. They support Stanley \& Wises's (1993) notion of the researcher being inextricably linked to the research process, especially if a reflective approach is taken. The work of Seng (1998) suggests that as qualitative researchers

we do not really "discover" "truth" about the natural world; rather we glean facts and construct theories that contribute to socially situated, tentative, temporary understandings. Our 
understandings of social worlds are even more situated, tentative, and temporary since societies are quickly changing and there is even less that we can "test' and "prove" in theories about human phenomena (Seng, 1998, p.45).

She goes further to assert that once the complexity of human phenomena is recognised, the value of controlled experiments and experimental design is reduced, as these experiments may not be applicable to other groups and situations.

These assumptions of the phenomenological paradigm have been heeded throughout the research process, with the research process in this case being more circular than linear. During this research certain relationships were constantly present, but which varied in intensity according to the stage the research was at. Within the context of this research the phenomenological paradigm encompassed four components, with the relationships between theses components being shown in Figure 4.1.

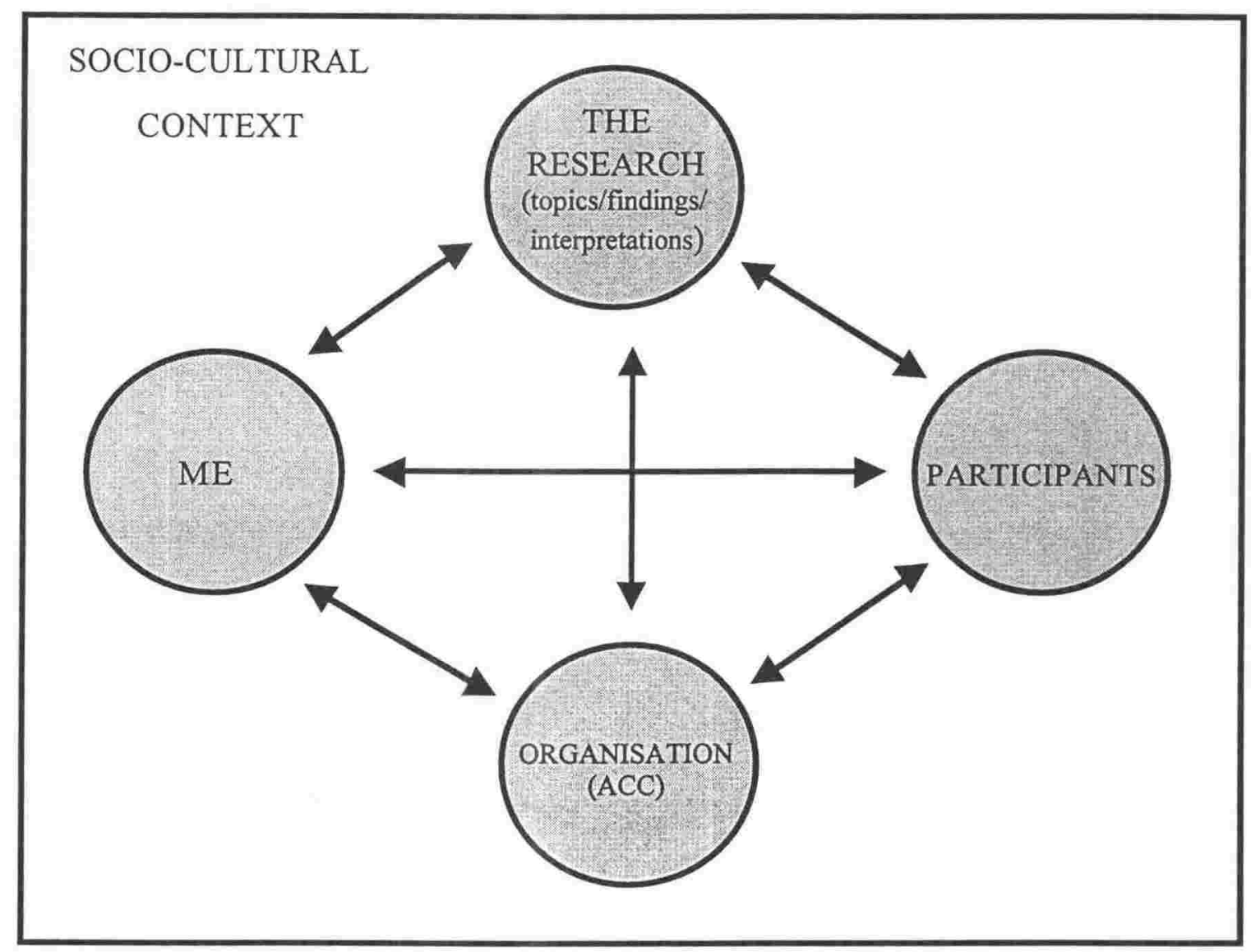

Figure 4.1: Relationships in Research (adapted from Schratz \& Walker, 1995, p.37) 


\section{My Choice of Research Paradigm and World View}

From 1984 to 1987 I was immersed in the culture of Cambridge University, England. Initially I struggled with the academic side of exams, but once I had learned to think rather than regurgitate I went from strength to strength. It was at Cambridge that I had my first real introduction to doing research. Between our second and third year we had to complete an original piece of research of 9000 words without the assistance of a supervisor. I am not really quite sure how I managed, as looking back I cannot recall any classes on research methodology, methods of inquiry or how to go about it. However, it must have all been there as I submitted my abstract which was accepted, was able to design a questionnaire, carry out the research, write it up and to my amazement receive a first class grade for it (Leberman, 1987). I was very worried about handing it in as it seemed much thinner than all the others and much more practical than theoretical. I really enjoyed the research as it was all my work with nobody telling me what to do, nor when to do it.

After leaving Cambridge and three and a half months in Asia, I started an applied postgraduate degree in New Zealand. The main attraction of coming to New Zealand, a country I knew nothing about, was that the course allowed much flexibility in design and above all there were no exams. My research for the Masters degree, again involved questionnaires, but also included participant observation (Leberman, 1989). This time I did have a supervisor which was very useful, despite my initial apprehension. At this stage I was still rather vague on all the different aspects of research, particularly the philosophical background. This meant that the research was again of a relatively practical and applied nature. I was interested in people's perceptions and experiences, but relied on questionnaires for this information.

Enrolling for this $\mathrm{PhD}$ was a big step as, again, the philosophical side loomed large on the horizon. However, at least I knew a little more than I did before and this time felt confident to find out about people's perceptions and feelings through interviews and focus groups adopting a qualitative methodology, with some quantitative baseline information available for use if required. I feel confident in this approach as it is my belief that people are shaped 
by the experiences they have had in their lives and that these very much determine how they approach new situations. Working with adults has shown me very clearly that we all come from different starting points and will reap different benefits from the same presentation, reading or encounter. So I have come from a very positivistic numerate background to now having a much more phenomenological approach to life and view of the world. I believe that people, myself included, are very much moulded by the background and experiences they have had and that determines the way they interpret the world around them (see Appendix 3 for Ethical Approval Form).

My exposure to action learning started in 1993 when I was involved in designing and delivering a third year management education programme, which focused on enabling students to put into practice the management theory they had learned to date. Topics covered included team building, leadership, risk management and project management. Initially, the philosophy of the course was mainly drawn from the outdoor experiential education field, but over time, evolved to focus more on action learning principles (Leberman \& Mellalieu, 1994, 1996). From 1995 to 1997 I was involved in the VUW Diploma in Rehabilitation Studies which was also based on an action learning approach (Leberman, 1996).

This focus on action learning during the VUW Diploma in Rehabilitation Studies led me to believe that adopting an action research approach to my $\mathrm{PhD}$ would be the logical next step. The reason for this was that both action learning and action research are based on the same learning cycle, which focuses on learning from experience with an action and a reflective phase (McGill \& Beaty, 1995). In addition, the purpose of action learning is to make improvements in the real world and to yield some private learning. Similarly, action research seeks improvement in the real world, but the learning resulting from the research needs to be of benefit to the wider community, rather than just contributing to individual learning (Bunning, 1994). So I focused on action research as they seemed to go together and my research was centred around an action learning course. But after much reading I realised that my research did not really fit with the action research methodology. Instead, I adopted a grounded theory approach, which will be discussed later in this chapter. 


\section{Nature of the Research}

My interest in the research first arose during the early stages of my involvement with the VUW Diploma in Rehabilitation Studies. What I wanted to know was whether what we were doing was actually going to be beneficial to the students and how it would compare to, say, a one-week outdoor management development programme, in terms of long term effect on the students and the organisation. The research was to focus on the students' experiences once back in the work place and to be over the long term. Patti Lather (1985 cited in Reinharz, 1992, p.185) argues that

the research process is a powerful place to go for praxis to the extent we can formulate research designs that change people by encouraging self-reflection and a deeper understanding of their situations in the world.

Seng (1998) develops the notion of praxis further by suggesting that it can provide a conceptual framework for participatory nursing research. She draws on the literature from a number of different disciplines, including feminist, critical theory, philosophy of science, methodology and health, to support research which is specific to particular situations, with the consequence that it can only be generalised in a limited manner to other populations and phenomena. The concept of praxis is important in the context of this research as it deals with the work of Case Managers and changes in their professional practice. Praxis is associated with integrating theory and practice, focusing on reflection and action, as well as working with people to cause change. In many ways it is similar to action learning, although its historical roots lie in the work of Marx and Freiere, and is more associated with wider social change (Seng, 1998).

I also wanted the participants to be part of the research process in terms of driving the direction of the research, with only the first interviews and focus groups having predetermined questions. The subsequent interviews and focus groups would be based on issues arising from the initial contact. In a sense the research started with some preconceived notions and then moved towards a more emergent approach as the research proceeded (Cocklin, 1996). This process mirrored my own development, as I became more 
confident in my research skills and did not feel the need to have a set agenda and was more prepared to go where the research took me, a key learning step for me.

The research itself was very time consuming, both in terms of keeping up with all the research participants across the country and the amount of data generated over the two year time period from interviews and focus groups. However, to balance this, it was

fulfilling to see how some people had developed since meeting them for the first time on the VUW Diploma in Rehabilitation Studies and also to maintain a sense of connection with people in whom I had vested a lot of time and energy.

\section{RESEARCH METHODOLOGIES}

Whilst the overriding paradigm is phenomenological, the specific approach taken was that of a longitudinal case study. A case study can be defined as:

an empirical inquiry that investigates a contemporary phenomenon within its real-life context, especially when the boundaries between phenomenon and context are not clearly evident. Furthermore the case study copes with the technically distinctive situation in which there will be many more variables of interest than data points, and as one result relies on multiple sources of evidence, with data needing to converge in a triangulating fashion (Yin, 1994, p.13).

Reinharz (1992) argues that case studies are written

to illustrate an idea, to explain the process of development over time, to show the limits of generalisations, to explore uncharted issues by starting with a limited case and to pose provocative questions (p.167).

Furthermore, she states that case studies defy

the social science convention of seeking generalisations by looking instead for specificity, exceptions and completeness (p.174).

Both of these statements, as well as the work of Rose \& Webb (1998), Sandelowski (1996) and Seng (1998), lend credence to the use of a case study in this research in which I have tried to illuminate the situation of a particular group of people over a specified timeframe. Sandelowski (1996) argues that whilst most of the literature on qualitative research claims that generalisation is limited from case studies, there are naturalistic generalisations which 
can "be made from and about cases" (Sandelowski, 1996, p.527). She also indicates that in some disciplines, such as law and nursing, cases make up a significant part of the knowledge in that particular area.

A further reason for choosing this approach was based on the fact that, when ethical approval for the research was sought, little, if anything had been written about the population involved in this research and the emerging picture would be based on their experiences and ideas. In fitting with the phenomenological paradigm, the majority of the data collected was qualitative apart from some of the baseline data, which was of a quantitative nature. Such a mixed method approach has become increasingly acceptable (Rossman \& Wilson, 1985; Lancy, 1993 both cited in Cresswell, 1994). Reinharz (1992) also lends support to the use of multiple methods in research as she suggests that it increases the likelihood that the

researchers will understand what they are studying, and that they will be able to persuade others of the veracity of their findings. Multiple methods work to enhance understanding both by adding layers of information and by using one type of data to validate or refine another (p.201).

In addition to this, I needed to choose research methodologies that would incorporate the concept of action learning, "a process which brings people together to find solutions to real, important organisational issues and problems and, in so doing, develops both the individuals and the organisation" (Inglis, 1994, p.3). Since the action learning approach is process orientated and functions in a cyclical manner, the theoretical underpinning needed to be dynamic, in the sense that at different stages of the research process new directions may have emerged. Given that action learning is focused on the individual, a qualitative methodology seemed most appropriate to the research, following a phenomenological approach. The two approaches both have a cyclical nature and are interlinked throughout their various stages. In addition to this, the use of qualitative methodologies in adult education has increased over the last two decades, in an endeavour to give credit to the experiences of adult learners and to be able to hear their 'voices' (Cocklin, 1996).

The nature of my research required a methodology that was change focused, empowered the people involved in the research process, could include action learning and andragogy, 
would lead to a change in practice, enable reflection on practice, give a voice to the experience of adult learners in professional education and would enable the triangulation of data. Many of these requirements could be met by action research (Bunning, 1994; Chisholm \& Elden, 1993; Eden \& Huxham, 1996; Robinson, 1993; Zuber-Skerritt, 1993). However, the research did not consist of a number of action research cycles which involve planning something, acting on it, observing what happened, reflecting on the experience and then moving on to a revised plan (see Figure 4.2).

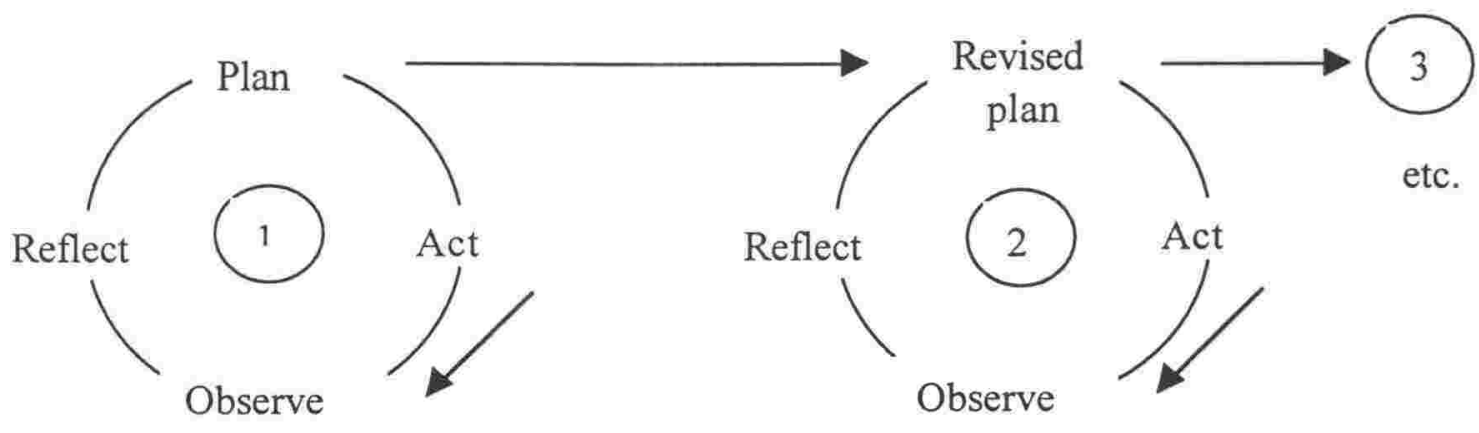

Figure 4.2: The Action Research Spiral (Zuber-Skerritt, 1993, p.47)

Essentially, my research was concerned with looking at the experiences of course participants and in so doing giving them the opportunity to reflect on their professional practice, as well as providing an insight into what factors facilitated transfer of learning from the VUW Diploma in Rehabilitation Studies to their place of work. It could be argued that this is a form of 'technical' action research, which aims to enhance the effectiveness of educational practice and professional development (Bunning, 1994). However, for me it was important that the research participants gained something from the experience and that the conclusions from the research would be beneficial to other people undertaking personal and professional training. I did not want the research to be done for research's sake but for the research to lead to change in the way that personal and professional training is often delivered. In this sense, it was important to me for the research to be shared as a process, as well as a final product (Henderson, 1993). Given that I was trying to address a number of issues and that action research did not quite fit my requirements, I ended up drawing more on the grounded theory methodology. 


\section{Grounded theory}

Grounded theory seeks to build a theory from the data collected, which is faithful to and illuminates the area under study (Strauss \& Corbin, 1990). The process involved is inductive in the sense that the concepts and themes emerge as the research progresses rather than starting with preconceived ideas of what is to be found (Maxwell, 1996). The idea is that the different stages of the research process - data collection, data analysis and reading - occur concurrently and inform each other. From these, concepts arise which are then linked to provide an account of what has happened in the area of study and finally, a framework for action.

The term grounded theory was originally developed by Bernie Glaser and Anslem Strauss and published in their 1967 book 'The Discovery of Grounded Theory'. Their work was based in the area of sociology focusing on the awareness of dying. Over time they have gone their separate ways with Glaser (1992) strongly criticising Strauss \& Corbin's (1990) book as not being true to their original work together. The key point of contention is that the data should be able to emerge from the research rather than be forced. Glaser (1992, p.16) argues that:

the grounded theory approach is a general methodology of analysis linked with data collection that uses a systematically applied set of methods to generate an inductive theory about a substantive area. The research product constitutes a theoretical formulation or integrated set of conceptual hypotheses about the substantive area under study.

At first I struggled with the concept of grounded theory, as it appeared so structured and formalised and quite opposite to what it claims to do which is to encourage the emergence of theory. This weakness has also been identified by Charmaz (1994a, p.73), when she says that there seems to be

... a premature commitment to a set of analytic categories, unnecessary jargon, and a lack of clarity about key terms such as theory, category and saturation.

However, she also suggests that a major strength of grounded theory is its openness and flexibility, because one can develop ideas throughout the analysis rather than only suggesting or alluding to them at the end. At the end of the research process, the validity of 
grounded theory will depend on how useful the theory generated is in terms of its 'fit' (that it comes from the data), that it is relevant to the participants and the practice group, and finally, that it explains what happened, can predict what may happen and can interpret what is happening (Baker, Wust \& Stern, 1995).

A book by Bryman \& Burgess (1994) drew together a number of authors to reflect on the process of not only conducting qualitative research, but in particular on the analysis of qualitative data. In their concluding reflections, they comment on the number of contributors who made reference to grounded theory, which however in their opinion was not employed in its entirety. Most contributors informed their research with grounded theory, as it applied to their situation. This is similar to my situation in this research. I would suggest that one of the reasons for this is the very prescriptive nature of grounded theory, which in many ways is contrary to the whole notion of qualitative research.

In my opinion there are a number of similarities between action research and grounded theory, particularly with respect to their emphasis on process and change. The main differences I perceive are associated with the criteria that need to be met for research to fall clearly into one or the other. In this research I have drawn on parts of both, as neither on its own seemed to fit what I needed.

\section{Other influences}

Whilst this research is not focused on women's experiences, I myself am a woman and feel that some of the feminist research literature supports a number of the experiences I had in carrying out this research. Following Reinharz (1992), I would suggest that it is difficult to define the term feminism or feminist. It has many different meanings reflecting the diversity, which exists amongst women. Reinharz (1992) sees these differences as good as it enables a degree of freedom of thought and action, and herself favours self-determination of the term feminism by women. She quotes Dale Spender (p.7) who states that

at the core of feminist ideas is the crucial insight that there is no one truth, no one authority, no one objective method which leads to the production of pure knowledge. 
She acknowledges that there is debate amongst feminists about whether or not there are specific methods that are feminists'. Her book offers some valuable insights, amongst other things, into feminist perspectives on interviewing, case studies and multiple methods research all pertinent to my research.

Reinharz (1992) argues that learning should occur at three levels in any research project - at the level of the person (herself); at the level of the problem (the subject matter) and at the level of the method (how to conduct research). All of these three levels have been pertinent to this research. I myself have grown as a person in terms of keeping focused on one thing at a time, whilst trying to juggle work commitments, $\mathrm{PhD}$ research and my private life. I have also become more confident in my ability to actually do research and meet the required standard. In terms of the subject matter, I have gained an in-depth knowledge about the area of transfer of training and learning, action learning and their association with, in particular service management, and about the ACC as the organisation with which I have worked closely over the past 4 years. The learning in terms of method has been mainly associated with the fact that I find it difficult to clearly locate the research within only one methodology. It clearly falls within the phenomenological paradigm, but the nature of the research has required my methodology to be informed by a number of different sources, which has added to the complexity of the research. What this has shown me, is that when you are studying people within an organisational context and you want those people to be seen as participants in the research process, rather than as subjects to be used, it is quite difficult to achieve all these requirements within the limitations of a single methodology.

With respect to interviewing, Reinharz (1992) argues that by using interviews, the researcher is able to tap into the ideas, thoughts and memories of the participants and can therefore use their words rather than her own. It also means that the researcher can develop a sense of 'connectedness' with the participants, rather than operating at a distance to gain information on a particular issue for research purposes (Reinharz, 1992). The debate about being a stranger or a friend to the people one is working with is not resolved, with individual writers strongly advocating each perspective. This leads on to interviews being dialogue involving researcher self-disclosure in terms of sharing information rather than the process being one-sided. She also suggests that 
multiple interviews are likely to be more accurate than single interviews because of the opportunity to ask additional questions and to get corrective feedback on previously obtained information. As time passes, the researcher also can see how thoughts are situated in particular circumstances (Reinharz, 1992, p.37).

I very much felt that in this research I was having conversations with people rather than interviews in the formal sense of the word. I already knew all the participants before the research started and had shared with them a number of key experiences during the VUW Diploma in Rehabilitation Studies, which meant that rapport was re-established rather than developed from new.

\section{RESEARCH METHODS}

In keeping with the qualitative approach, the methodologies for data collection included reflective notes of the researcher, interviews with students from the Southern Region and either focus groups or interviews with students from other parts of New Zealand. The use of a questionnaire instead of interviews would have probably been more cost effective. However, it was disregarded as a form of data collection because the aim of the research was to elicit opinions and beliefs, as well as to develop an understanding of the issues affecting the transfer of training and learning. This mix of data collection allowed not only for triangulation of the data, but also assisted in addressing the issues of validity and reliability.

I had also observed the coercive manner in which the data was collected for the formal evaluation of the programme and did not want to have my research tarnished in that way. Hence, I sought no financial support from the ACC and invited participants to take part in the research at their own discretion. Similarly, I was aware of some of the methodological difficulties associated with the Collinson \& Brook (1997) study and felt that an alternative methodology would be more suited to the research questions about transfer.

The information supplied by the students prior to and during the course in module and course evaluation questionnaires was used as base line information to inform the research. Whilst it is recognised that questionnaires are not always part of the qualitative approach, it is becoming more acceptable to incorporate quantitative methods of data collection in 
qualitative research and vice versa (Lancy, 1993 and Rossman \& Wilson, 1985; both cited in Cresswell, 1994; Reinharz, 1992).

\section{Data Collection Methods}

The qualitative methods chosen included reflective notes collected by the researcher both during practicum visits to the students whilst still on the course and during the research period, semi-structured and open-ended interviews and focus groups. The use of a research journal is widely supported (Blaxter, Hughes \& Tight, 1996; Rubin \& Rubin, 1995) in qualitative research, as it provides the researcher with a way of keeping track of their own development throughout the research process. For me it provided the opportunity to express my 'highs and lows', insights gained, my impressions of how interviews and focus groups went and issues that I was grappling with at particular points in time. Writing a research journal was not a daily task for me, but took place when I needed it and has been a learning process in itself, as I do not perceive writing to be my strength - I prefer talking things over with people.

Interviews in this context provided

... access to knowledge - a knowledge of meanings and interpretations that individuals give to their lives and events (Minichiello, Aroni, Timewell \& Alexander, 1996, p.1).

Individual participant interviews were to have been conducted six months, twelve months and eighteen months after having completed the VUW Diploma. Rubin \& Rubin (1995, p.140) suggest that

In focus groups, the goal is to let people spark off one another, suggesting dimensions and nuances of the original problem that any one might not have thought of.

Focus groups were to be held at the same time points to provide some internal validity for the individual interviews. In the event, the six month time point had to be abandoned, as approval to do the research was not granted by the ACC until November 1996, one month after the time when the first six month data with Cohort 2 should have been collected. This left only Cohort 3 with a six-month data collection time point, so to ensure consistency 
this data was also not collected, as the focus of the study is on the long term. This still allowed for data collection over three cohorts at twelve and eighteen months, with the research period extended to include a twenty-four month collection point.

Table 4.1 gives an indication of when interviews and focus groups were conducted:

\begin{tabular}{|c|c|c|c|}
\cline { 2 - 4 } \multicolumn{1}{c|}{} & \multicolumn{3}{c|}{ Time Post Diploma } \\
\cline { 2 - 4 } & 12 months & $\mathbf{1 8}$ months & 24 months \\
\hline Cohort 1 & November 1996 & May 1997 & November 1997 \\
\hline Cohort 2 & April 1997 & October 1997 & April 1998 \\
\hline Cohort 3 & August 1997 & February 1998 & August 1998 \\
\hline
\end{tabular}

Table 4.1: Interview and Focus Group Data Collection Time Points

\section{Participant Selection}

In October 1996, students from the Southern Region Cohorts 1, 2 and 3 were sent a letter outlining the aims and objectives of the research and seeking their participation in being interviewed on a six monthly basis over the next two years (see Appendix 4 for Participant Information and Consent Form). The remaining students from Cohorts 1,2 and 3 were also sent a letter outlining the aims and objectives of the research and seeking their interest in being involved with a focus group at six monthly intervals over the next two years (see Appendix 4 for Participant Information and Consent Form). These letters were followed up within two weeks by a reminder letter. Cohort 1 students were sent the participant information sheet and consent form in the initial mailing, due to the short time frame remaining, after permission to proceed with the research was given by the ACC. The students from Cohorts 2 and 3 agreeing to take part in the research were then sent a participant information sheet and a consent form. Phone calls were not made, as I believed this would influence the students' decision to take part in the research, rather than them deciding independently whether this was what they wanted to do. In the event there were no more than ten responses per Cohort to the focus group information letter, so that a random sample did not need to be selected to represent the rest of the country. 
The self-selected sample involved forty-seven Case Managers from a total population of one hundred and fifteen who completed one of the first three cohorts of the VUW Diploma in Rehabilitation Studies. Twenty-one of the Case Managers were from the Southern Region, the remaining twenty-six from the rest of New Zealand. All offices in the Southern Region had participants in the research, and thirteen of the remaining twenty-six branches represented on the VUW Diploma in Rehabilitation Studies had participants in the study. Over the research period two participants withdrew from the research, two participants resigned from the ACC and five participants did not respond to messages left for them to contact me in order to organise time for interviews or focus groups. I would leave three messages for each person, after which I assumed they did not wish to continue with the research. These changes resulted in a total of forty-one participants eighteen months post course and thirty-eight twenty-four months post course.

There was a high level of non-respondance to the request for participants. I did not follow up reasons for this, but would suggest that a number of factors could have contributed to this. First of all, a long time commitment was required on behalf of the participants, which may have discouraged some from taking part. Other reasons may have been no interest in the subject matter of the study, no interest in working with me, negative feelings about the course or simply not 'getting around' to sending back the forms. However, I did not want to 'force' the issue of participation and considered forty-seven participants to be sufficient for the purposes of this research. I, therefore, did not send out reminders to increase the number of participants.

\section{Issues arising}

An issue arose, in terms of the practicalities of getting participants from all over the North Island together at one time and in one place. The option of using video-teleconferencing was investigated, but the facilities required were only available in the main centres, thus excluding some of the respondents. Following this line of thinking, teleconferencing was investigated as an option, as this had been used in the past when people are geographically spread out and time is at a premium. (Stewart \& Shamdasani, 1990). However, the logistical requirements associated with organising large groups of people to be available 
simultaneously, even by phone, ruled out the notion of large focus groups. After discussion with my $\mathrm{PhD}$ supervisors, it was decided that it would be preferable to pursue smaller face-to-face focus groups in regional areas, where possible, rather than one large focus group over the telephone. For Cohort 1 this resulted in three small focus groups with two participants each. The fourth focus group was to have three people, but due to work commitments and sickness, it did not eventuate and the participants were followed up individually by telephone interview. This experience confirmed my rejection of one large focus group. There was one focus group of four people and one of two people for Cohort 2 , with three people being followed up individually by phone or face-to-face. With Cohort 3 , there were two focus groups of two people, the other fourteen participants being interviewed on the phone or face-to-face.

I fully support Rubin \& Rubin (1995) who state that telephone interviews are not the best way of conducting interviews because of the non-verbal cues which are missing. However, given the financial and time constraints of the research, there was at times no other option available to me. I would argue that because I already had a relationship with all of the participants that the task was easier for me, and I also did meet with each participant at least once during the research period on a face-to-face basis. Along a similar vein, I would suggest that I was able to make good use of the focus groups as I already knew the participants involved, which meant that it did not detract from the relationship building process.

\section{The Interview and Focus Group Process}

The interview schedule for the first data collection point of twelve months (see Appendix 5 for draft interview questions) was to be pre-tested on students from Cohorts 1,2 and 3 not taking part in the research and refined accordingly. In the event this was not possible due to the late approval to proceed with the research given by the ACC and the tight timeframe requiring virtually immediate conducting of the interviews and focus groups. It was also not possible to pilot the questions on Cohort 4 as they were not at the appropriate stage of their course to be able to respond to the questions. Consequently, the questions were tested on my colleagues for clarity and understanding. Considerable changes were made to 
the wording and to use language which would be more understandable to the majority of people (see Appendix 6 for the questions used). The schedule consisted mainly of open questions, with probes being used where possible, based on the responses to earlier questions. I had intended to start each interview by asking the participant to reflect back over the past six months and to recall the event or issue (work or non-work) that had taken centre stage in their life over that time. This procedure is related to the concept of using a critical incident to illuminate learning (Gonczi et al, 1990, cited by Sadique in Fook, 1996, p.25). In the event this technique was not used at the outset of the interview, but was incorporated in the interview with specific questions, particularly questions 3 and 4 (see Appendix 6 for wording of questions). Notes were taken by myself during the interviews and focus groups, which were then fed back to the participant(s) at the end of the interview or focus group to check that I had correctly noted and understood what had been said, thus enhancing validity and accuracy.

The interviews and focus groups were not taped, as I was concerned that people may feel inhibited and may not take part in the research. Another consideration was the amount of transcribing that would have been involved. For me personally it was also important to really focus on what people were saying during the interviews and focus groups, rather than just relying on the tape recording. I found that I was able to take down what people said without problem. Being able to feed back what I had written at the end of the interviews and focus groups also meant that I had an instant check on the validity of what had been said and that I had captured the participant's words not mine. It was not uncommon for participants to add in things when I fed back what they had said and occasionally delete things they had said. If I had gone away and had the tape transcribed and sent it out to the participants, I do not believe that I would have received as much feedback as I did. The process I adopted also meant that participants knew I was the only person involved with the information received, rather than being fearful of an outside person doing the transcribing.

During the interviews and focus groups I did not necessarily follow the order of the questions as laid out in the schedules. I tended to go with the flow of the conversation and talk about each issue as it arose, so that they were more guided conversations rather than 
formally structured interviews (Rubin \& Rubin, 1995). This process felt more comfortable to me, rather than always keeping to my predetermined order, and ensured that the participants could follow their thought processes through rather than be guided by mine.

The questions developed for the eighteen month data collection point (see Appendix 7 for questions used) arose from the information received during the twelve month data collection point, which is consistent with the grounded theory approach. In the event the same questions were used for all three cohorts, as the same issues, of outcomes and change, arose from the twelve-month data. The twenty-four month data collection approach was slightly different (see Appendix 7 for question used). Every participant was interviewed individually rather than having focus groups and only one question was used to start the interview. The purpose of this was to encourage participants to reflect back over the past two years and to consider the impact of the VUW Diploma in Rehabilitation Studies in the context of their work.

Once all three Cohorts had completed each time point, a summary of the analysed data was sent to each participant or, in the event of there being more than one person from an office taking part in the research, a copy was sent to the branch, in order to save paper.

\section{Issues arising}

Interviewing is rather like marriage: everybody knows what it is, an awful lot of people do it, and yet behind each closed front door there is a world of secrets (Oakley, 1993, p.229).

Common issues raised with regard to interviewing and running focus groups include obtaining trust, researcher bias and the relevance of the study to the participants. In the positivist research literature there is an emphasis on maintaining strict protocols when conducting interviews so as not to bias the information received. It is argued that if the interviewer maintains an objective position then the data received will be more reliable and valid. This approach to interviewing fits very much in the positivistic school of thought.

However, the reality in this case was that I already knew all the participants, some better than others, depending on whether they had been in my tutorial group or not. Before 
starting the interviews and focus groups there was time for us to catch up with each other, family and other Cohort members. All the interviews and focus groups started with me stating my position as a researcher rather than as their ex-tutor and encouraging the participant(s) to be as honest as possible so that the findings would be reliable and valid. Often the discussion after the interview/focus group focused on the ACC, branch issues and personal matters, which provided a closure to us meeting up again, rather than me simply leaving straight after I had "my" data.

One of the advantages I had with this research was that all the participants had themselves completed a research project and were therefore familiar with research protocol and had an understanding of the process they would be involved in. This is particularly relevant in terms of establishing a trusting relationship. Easterby-Smith et al., (1994, p.76) state:

Above all interviewers need to be able to listen, and to refrain from projecting their own opinions or feelings into the situation. This is more difficult than it sounds, since one of the ways of obtaining trust is to empathise with the respondent.

The issue of trust was not seen as a problem in this instance as the participants had known me for at least six months prior to the interviews commencing. I recognise that interviews are open to personal bias by myself as the interviewer. To address this issue I tried to mirror what the participant has just said and avoided using any leading probes. Feeding back a summary of their responses at the end of the interview also attempted to reduce the amount of bias.

Acknowledging my own biases was a vital part of this research, particularly due to my preconceived notions about the participants and my history with them. Rubin \& Rubin (1995, p.120) state that:

None of us is sufficiently self-aware to always know exactly how we are reacting to an interview or interviewee or interview situation.

There were times when I caught myself thinking "I knew he would say that" or "It doesn't surprise me that she thinks like that." Rather than trying to pretend that I did not experience these feelings I took note of them in my research journal and tried to 
acknowledge what I was thinking. I was not an objective part of the research process, but was subjectively involved particularly since I had shared many of the experiences that the participants were talking about. Two other issues are important to note. The first one concerns gender with respect to how men and women respond to questions, as well as how men may have perceived me as a woman in the role of researcher. The second issue is associated with class boundaries. Whilst I believe that this was not an issue for me in the research, it may well have been for the participants. However, I would hope that by virtue of the participants knowing me, neither of these points were causes for concern.

The quality of the data can also be affected if the participant sees no value in the research. This issue was addressed by seeking informed consent from the participants prior to starting the research. As well as this, the research topic was regarded as interesting to many of the participants, with comments such as "I'll be really interested to see what you find" not being unusual. Within the grounded research framework, it is argued that there should be some direct relevance to the participants and hopefully by taking part in this research it gave them an opportunity to reflect on their learning experience. For many, it was also seen as an opportunity to share other issues (both personal and professional) pertinent to them at the time, but not necessarily related to the research. One participant commented after an interview "Thank you! You have just saved me $\$ 60$ on a supervision session".

The points regarding establishing trust and the quality of the data are discussed by Cotterill (1992). She argues that interviews are often fluid encounters, both during and between interviews, and that the subjective experience of the researcher is important and must be acknowledged. Whilst her experiences are different to mine, they have highlighted how the relationship between researcher and participant may vary. You get to know some people better than others and often there is a break between the chat before and after the 'formal' interview or focus group. I tried to avoid this break as mentioned above, so that the interviews and focus groups were more like guided conversations, but this was not always achieved.

Cotterill (1992, p.600) also raises another important point when she says that 
no two interviews are the same. Forms of interaction between the researcher and the researched are highly individual, and it is impossible to predict levels of co-operation.

For me this was a very important issue. At first I thought that every interview had to be as similar as possible to provide for meaningful, reliable and valid data. However, I soon realised that different approaches were needed, depending on who I was talking to, what day of the week it was, the time of the day, where the interviews were held, and how busy the participant was at the time. I strongly believe that all these factors have had an influence on the information received. However, rather than devalue what this research shows, I think it demonstrates the reality, not only of conducting qualitative research, but also presents the voices of the participants under real life conditions. The same applies to myself, because however hard I tried to be the same in all situations, I too was not free from the effects of internal and external factors. For example, it always took a while for me to get back into the swing of the next round of interviews and focus groups. I liken it to warming up for a sport - once you get into the flow of things it gets easier. Rubin \& Rubin (1995, p.38) support this by saying that

an interview right after someone's mother died is likely to be quite different from an interview conducted a year later with the same person. Qualitative research is not looking for principles that are true all the time and in all conditions, ... the goal is understanding specific circumstances, how and why things actually happen in a complex world. Knowledge in qualitative interviewing is situational and conditional.

Interviewing in organisations carries its own distinct challenges. It is vital to have the interest of the participants at heart throughout the research process and I regarded this as one of my main obligations to the participants (Rubin \& Rubin, 1995). This for me, included not being funded by the ACC, ensuring total confidentiality between interviews and disguising where the responses came from in this written piece of work so that no trace can be made back to individuals. This last point was quite challenging to achieve as the ACC is a relatively small organisation and New Zealand itself is not that large, which means that it could be quite easy to trace some comments back to individual participants if care was not taken. Similarly, issues raised by the participants had to be presented accurately whilst at the same time maintaining their anonymity. This was particularly difficult where participants had changed positions within the organisation (applicable to 
fifteen of the participants) or left the ACC to take up a Case Manager role with another employer (applicable to five of the participants).

\section{Data Analysis Methods}

There are two main ways of analysing qualitative data - content analysis and grounded theory (Bryman \& Burgess, 1994; Denzin \& Lincoln, 1994; Easterby-Smith et al., 1994; Miles \& Huberman, 1984). Given the research design of this study, the more holistic and inductive approach of grounded theory was used. It seeks out themes and patterns from the data. The approach suggested by Easterby-Smith et al., (1994) involves the steps of familiarisation, reflection, conceptualisation, cataloguing concepts, recoding, linking and reevaluation.

Following the interviews and focus groups, the notes taken were written up in full. This enabled me to go over the interview or focus group again and note down any issues, which may have arisen. An advantage of conducting all the interviews and focus groups myself is my familiarity with the data and my ability to recall the comments in my head when rereading them. The responses were then entered onto the computer with the initial analysis being done manually in terms of grouping and coding participant responses, with the codes being based on participant responses. The subsequent analysis and coding was performed using HyperRESEARCH 1.56. HyperRESEARCH 1.56 is a qualitative data analysis package, which enables text to be coded and retrieved, as well as being used for theory building. It also allowed me to generate some descriptive statistics in terms of numbers and percentages, by easily retrieving the number of times a code had been mentioned by participants. Individual text files were created for each participant at each time point for Cohorts 1, 2 and 3 . This enabled me to consider the data on an individual basis, on a Cohort basis and between Cohorts.

Separate codes were generated for each time period. The codes were derived from what participants actually said rather than being predetermined. This was in line with the grounded theory approach, where themes emerge from the data rather than being imposed on it. At the twelve-month time point forty-nine codes were originally allocated, at 
eighteen months thirty-three codes and at twenty-four months forty-one codes (see Appendix 8 for Original Codes). Given the large number of codes I then sought to combine the codes, which related to the same theme for each time period. After this process I had thirteen codes at twelve months, eleven codes at eighteen months and twelve codes at twenty-four months (see Appendix 9 for Grouped Codes). This provided a more manageable set of codes, whilst at the same time maintaining the voices of the participants. I then thematically grouped the reduced number of codes for each time period by relating them back to the aims and objectives of the research. In the final analysis there were ten codes at twelve months, six at eighteen months and seven at twenty-four months (see Appendix 10 for Final Codes used). I then sought to identify a relationship between these themes, as well as provide descriptors to the themes in order to identify a pattern to the data. At first, I was only able to identify links between different codes. However, I then saw that the different codes seemed to group into different areas. I named these - the educational process, the individual, job specific processes and the organisation. These form the basis for the model presented in the discussion. A summary of the data is presented in Chapter 5 .

Further depth was added to the data analysis by using the hypothesis testing function in HyperRESEARCH 1.56. It was used to strengthen the interpretation I had attributed to the data and also to search for disconfirming evidence. This function enables the researcher to test any hypothesis about the meaning of the data in a consistent and logical fashion. In addition, the Hypothesis Tester enables revision of the parameters being tested and the fine-tuning of hypotheses. Other researchers are also able to replicate and verify the conclusions I have reached. In essence, the hypothesis testing function enabled me to determine whether or not the data supported the assumptions and inferences I had made about the data (Dupuis, 1994). It is important to note here that the hypothesis testing function provided by HyperRESEARCH 1.56 tests for relationships only and does not identify the nature of the relationships. The hypothesis testing function works by constructing a number of 'if' - 'then' statements arising from assumptions about the data, through my assumptions which I have inferred from these original assumptions, to the final goal of the hypothesis. 
For example, if I hypothesise that the educational process adopted by the VUW Diploma in Rehabilitation Studies is associated with the personal development of the participants, I am able to test this by using HyperRESEARCH 1.56. My statements would look something like this

'IF'

'THEN'

Learning Context and Personal Development

A

Practicum and Personal Development

B

Cultural Awareness and Personal Development

$\mathrm{C}$

Personal \& Professional Development Day and Personal Development

$\mathrm{D}$

$\mathrm{A}+\mathrm{B}+\mathrm{C}+\mathrm{D}$

GOAL REACHED

HyperRESEARCH 1.56 then looks through all the data and produces a report, which indicates for which participants the hypothesis holds true and for which it does not, either as a whole or in part. This means that for example, one participant may have associated their Personal Development with the Learning Context and the Practicum, but not Cultural Awareness and the Personal and Professional Development Day. In this case the report would indicate that $\mathrm{A}$ and $\mathrm{B}$ were present for that person, but the hypothesis as a whole would not be supported by that person.

This process was repeated for each hypothesis. I was able to identify whether the hypothesis was supported by individuals, by Cohort and then for all the participants. Appendix 12 provides the numerical detail for all the hypotheses tested by cohort and as a total figure. However, HyperRESEARCH 1.56 only tests for relationships, that is whether the codes are present, but not what the relationship between them is. Therefore, it was necessary for me to re-read the interview and focus group scripts for all the participants who supported the hypotheses, in order to identify whether there was a relationship between the codes or if the codes had only been mentioned.

\section{Issues arising}

I was surprised, and at times I despaired, at the depth and breadth of the data. My feelings are echoed by Cocklin (1996, p.93) who states 
While accounts can be found in the methodological literature ..., much of that reporting research gives the impression that concepts and theory simply 'emerge' from the data in 'full blown' form with little indication of the processes, let alone 'difficulties', involved in analysis.

This is illustrated by my attempts to analyse the twelve-month data once I had collected it from all three cohorts. I went through what participants had said and tried to identify common themes. In the end I came up with what I thought was a workable way of going about it and was pleased with what I had done, until I read some work on grounded theory which told me that I had to follow a strict procedure of conceptualising data, categorising it, naming a category and then developing properties and dimensions which would then provide me with a pattern representing specific properties of a phenomenon under a given set of conditions (Strauss \& Corbin, 1990). I had not used any of these terms nor in my opinion gone through this process. This is where having a supervisor proficient in qualitative research was very beneficial. I went to him with my dilemma and explained what I had done and what I had read and my perceived discrepancy and desire to 'do things right'. He assured me that I had done what was required, I had just used different terminology.

The final stage of the data analysis involved producing this final written piece of work, which is the result of my interpretation of the data and must be seen in the context of my Weltanschauung. Cheek (1996), Rose \& Webb (1998) and Weatherly \& Tansik (1993) all comment on the fact that the way researchers view data, interpret it and then present it is a reflection of who they are. Cheek $(1998$, p.493) states that "texts are not only conveyors of reality or research, they actually work to create, at least to some extent, our very understandings of that reality or research in the first instance". Weatherly \& Tansik (1993) in their research of how customer-contact workers perceived their positions, indicated that whilst the data from the participants was analysed to identify themes, their interpretations, as researchers, of what participants said and meant could not be avoided.

\section{Validity and Reliability}

Gummesson (1994) argued that there needed to be a link between basic research and practical application in the area of service management. Within this he called for relevance 
of the research to the real world and that it should contribute to changes in behaviour and a better understanding of reality. He also advocated validity, in the sense of trying to gain understanding and insight into phenomena. However, he cautioned that reliability is often used as a crutch for validity, where people from the same background as the researcher come up with the same results when they repeat the study and it is therefore considered reliable (Gummesson, 1994). This view challenges the conventional wisdom associated with validity and reliability of research, but is becoming increasingly accepted in some areas, for example, Rose \& Webb (1998).

Following Rose \& Webb (1998), I would suggest that the manner in which this research was conducted has been rigorous. The research process has been made explicit in this chapter, including an insight into my background, why the research topic was chosen, how the participants were involved, my relationship with them, the difficulties associated with selecting the methodology and using the methods, as well as a detailed outline of the process adopted for the data analysis and the issues involved in producing a final piece of written work. I, therefore, concur with Rose \& Webb (1998) when reflecting on her research experience one of the authors states:

In defending the way the data were analyzed, I therefore conceive of rigor as being able to demonstrate an understanding of what I did and why I did it, rather than the application of a set of rules. . The rigor of my analysis can therefore be defended by arguing that I am clear as to the academic traditions that have influenced me, that I attempted honestly to represent the process of data analysis, and that I admit that some of this process took place at a creative level that I am not able to translate entirely in terms of concrete language simply because it takes place at a level that is too abstract to be represented concretely (Rose \& Webb, 1998, p.561).

Having said this, I do believe that use of a qualitative data analysis package (HyperRESEARCH 1.56) has, despite my initial reservations, greatly enhanced the validity and reliability of the data. Before using HyperRESEARCH 1.56, I had thought certain things about the data. However, after entering the data in HyperRESEARCH 1.56, coding it and then looking at correlations, I was quite surprised to find that what I had vehemently thought was being said was actually not the case. A few more vocal participants did voice these opinions, but across the board my initial impressions did not 
hold true. This showed me how easy it is to interpret qualitative data, not necessarily, in the wrong way, but certainly not in a representative manner. There are also some possible biases of the research, which I feel need to be considered.

Bazerman (1998) associates these biases with heuristics. In my situation described above, the bias would emanate from the availability heuristic. The bias is ease of recall for which Bazerman (1998) offers the following description:

Individuals judge events that are more easily recalled from memory, based on vividness or recency, to be more numerous than events of equal frequency whose instances are less easily recalled (p.39).

The metaphor of a choir could be used here in that it is often the loud voices, which we hear most clearly, with the quieter ones being in the background. The choir, however, would not exist without all its members, as they all play a part in delivering the whole, even though we may remember most vividly the tenor or soprano. Similarly, if one person pronounces the vowels differently they will stand out from the rest of the choir. This illustrates how easy it is to be influenced by one person rather than necessarily doing justice to the whole.

Other biases particularly relevant to this research are those of presumed associations and the confirmation trap (Bazerman, 1998). The presumed associations bias is described by Bazerman (1998, p.39) as follows:

Individuals tend to overestimate the probability of two events co-occurring based on the number of similar associations that are easily recalled, whether from experience or social influence.

This was particularly pertinent when I was developing the transfer of learning model from the data (see Chapter 6). I had a tendency to infer relationships between variables for the majority of participants, before actually checking whether this was the case. This is where it was invaluable to have the HyperRESEARCH 1.56 data analysis package, but also the verbatim scripts from the interviews and focus groups. The latter enabled me to identify the relationships between variables mentioned by individual participants after HyperRESEARCH 1.56 had indicated that the variables were present within a particular participant's script. 
I also had to be very aware of the confirmation trap. This is where

individuals tend to seek confirmatory information for what they think is true and neglect the search for disconfirmatory evidence (Bazerman, 1998, p.40).

When considering the vast amount of qualitative data I had collected it was easier to pick out what I wanted to see in terms of confirming my impressions, rather than looking for the opposite. Again, HyperRESEARCH 1.56 was very useful in 'keeping me honest' by providing me with frequencies for codes, which assisted me in reaching my conclusions based on the data and not on what I thought the data was saying.

Internal validity was enhanced by triangulating the data between Cohorts and between regional groups within Cohorts. It is recognised that the extent of generalisation from the research is limited, but this is concordant with the nature of qualitative research, which seeks to form a unique interpretation of events rather than produce generalisations. It may, however, assist in the generating of hypotheses that can be further tested.

\section{Chapter Summary}

In this chapter the rationale behind choosing a methodological approach informed by grounded theory, and the reasons for the methods in this research have been discussed. The issues arising from my experience with the methods have also been identified. The role of HyperRESEARCH 1.56 in the data analysis has been highlighted, and concerns associated with the validity and reliability of the data have been addressed. In the following chapter a summary of the data collected during the research is presented. Each time period is considered separately, to enable the reader to gain an understanding of the similarities and differences between each time period. It is in this chapter that the voice of the participants comes through most clearly. The discussion of the data as a whole follows in Chapter 6. 


\section{CHAPTER 5 MANAGING THE DATA: A SUMMARY OF THE FINDINGS}

This chapter presents a summary of the data collected from the interviews and focus groups at each time interval. Each time interval is considered separately, starting with the final codes and a summary figure which groups the Final Codes into thematic areas. These summaries of the Final Codes are provided in Figure 5.1, Figure 5.2 and Figure 5.3, for twelve months, eighteen months and twenty-four months respectively. These are then followed by more detailed bar graphs within each time period. The heading of each bar graph represents the Final Code heading, with the bars of each graph representing the actual number of people who responded in the sub-code. The total number of respondents for the Final Code is indicated by the ' $n=$ ' value noted in the graph caption. The value above each bar represents the number of participants who mentioned factors associated with that subcode. As participants could have mentioned more than one sub-code the values are not given in percentages. These bar-graphs are supported by representative verbatim participant quotes. No comparison has been made between the findings from the Southern Region and Northern Region students as initially indicated to participants (see Appendix 4 ), because of the similarity of the findings between the two groups.

As has been discussed in the previous chapter, the data from this research has been analysed a number of times. The first step involved coding all the interview and focus group scripts, which generated a large number of codes at each time period (see Appendix 8 for Original Codes). These Original Codes were then grouped into common themes for each time period (see Appendix 9 for Grouped Codes). Following this process, the Grouped Codes were then considered for associations between them, which then became the Final Codes used (see Appendix 10 for Final Codes).

The data presented in this chapter is based on these Final Codes identified at each time period, and is descriptive in nature focussing on the voice of the participants. Chapter 6 will then consider, in detail, the relationships between the Final Codes and the emergent transfer of learning model. 


\section{DATA COLLECTED TWELVE MONTHS POST COURSE}

Below are the Final Codes (in bold) used for the twelve-month data with sub-codes identified in each box.

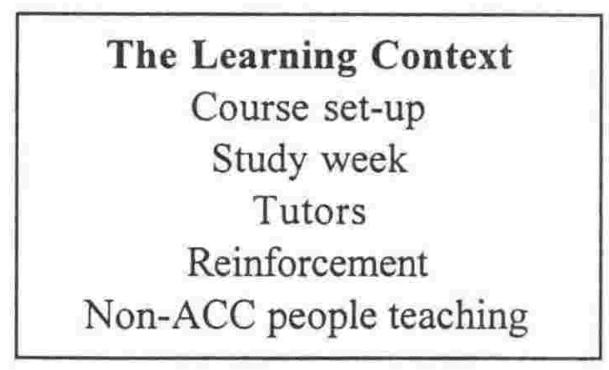

\begin{tabular}{|c|}
\hline Personal \& Professional Development \\
Day \\
Tuesdays or Wednesdays \\
Critical incidents \\
\hline
\end{tabular}

\section{Cultural Awareness \\ Noho marae \\ Importance of culture \\ Insiders/outsiders assignment}

\begin{tabular}{|c|}
\hline Personal Development \\
Increased confidence \\
Self knowledge \\
On my own \\
Attitude change \\
Less judgmental \\
Personal change \\
\hline
\end{tabular}

\begin{tabular}{|c|}
\hline Using a Holistic Approach \\
Needs assessment \\
Interviewing skills \\
Communication skills \\
Negotiating skills \\
Holistic approach \\
Importance of context \\
Seeing people as individuals \\
Working with clients \\
Outside networks \\
\hline
\end{tabular}

\section{Organisational Supports}

Branch support

Opportunity to do course

Finance

More time

\section{The Practicum}

Practicum

Research project

Learning contract

Supervision

\section{Praxis Development}

Stress management

Planning \& organisational skills

Risk taking

Presentation skills

Conflict management

Creativity

Future learning

Role change

Trying new ideas

Balanced life

\section{Changes in Practice}

Personal changes

Branch changes

ACC networks

Better outcomes

Consistency
Organisational Detractions

Head Office problems

Lack of branch support 


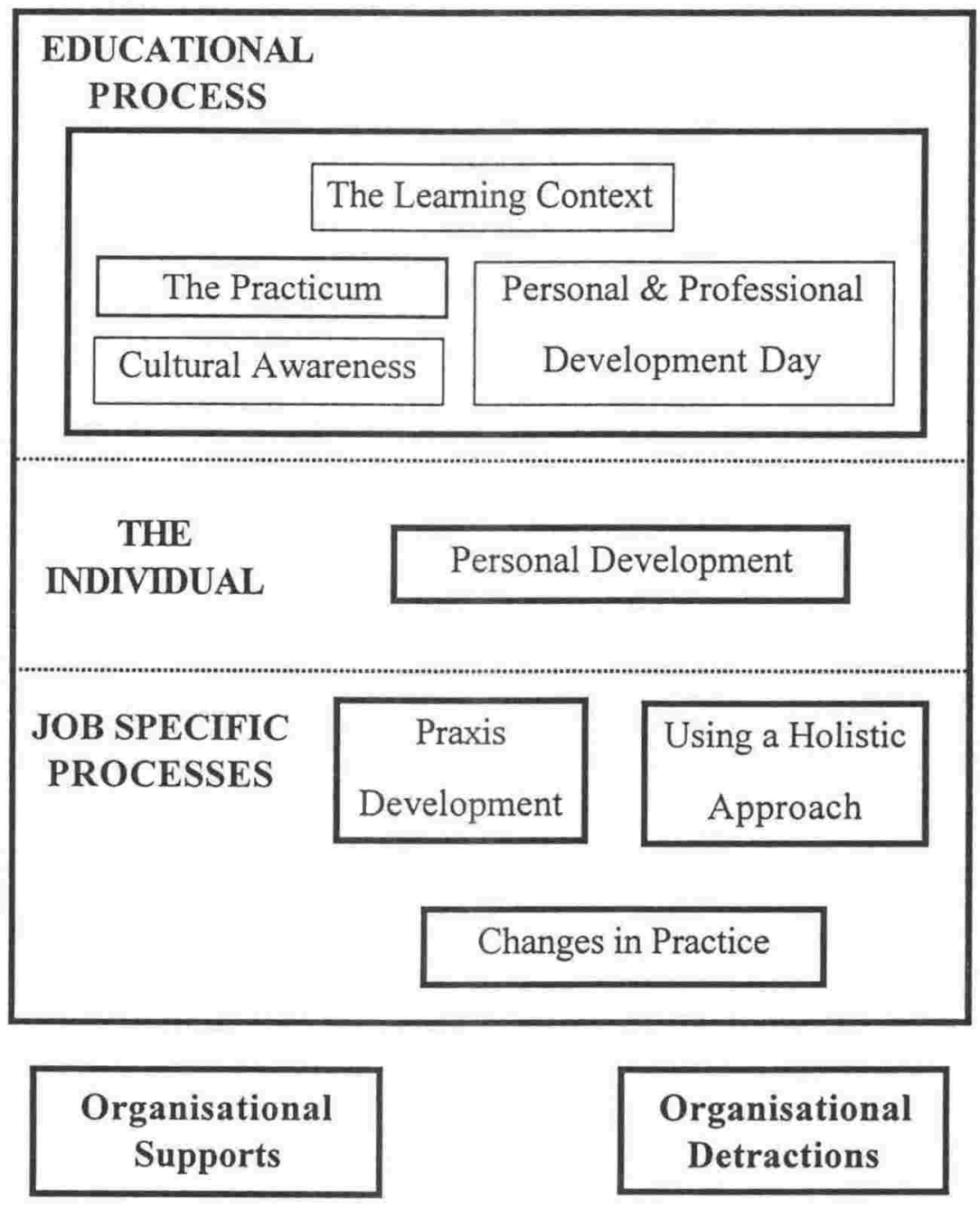

Figure 5.1: Summary of Final Codes at 12 months

Figure 5.1 presents a summary of the Final Codes which emerged twelve months post course. The identified codes have been derived from what participants said in response to questions asked in a semi-structured interview or focus group (see Appendix 6) and the subsequent coding of those responses. The association between the codes into Educational Process, The Individual, Job Specific Processes, Organisational Supports and Organisational Detractions was developed by myself in an attempt to link the codes in a meaningful manner.

The following bar graphs detail each of the codes and provide the reader with some indication of the coding protocol used in this analysis. The bar graphs are presented by starting at the top of Figure 5.1, with the learning context and culminating with changes in practice. The role of the organisation in this process is considered at the end. 
At the twelve month stage forty-seven participants took part in the research - fourteen from cohort 1, seventeen from cohort 2 and sixteen from cohort 3 . Overall there were twenty-one from the Southern Region and twenty-six participants from the rest of New Zealand. Thirty-one participants were female and sixteen male.

\section{Educational Process}

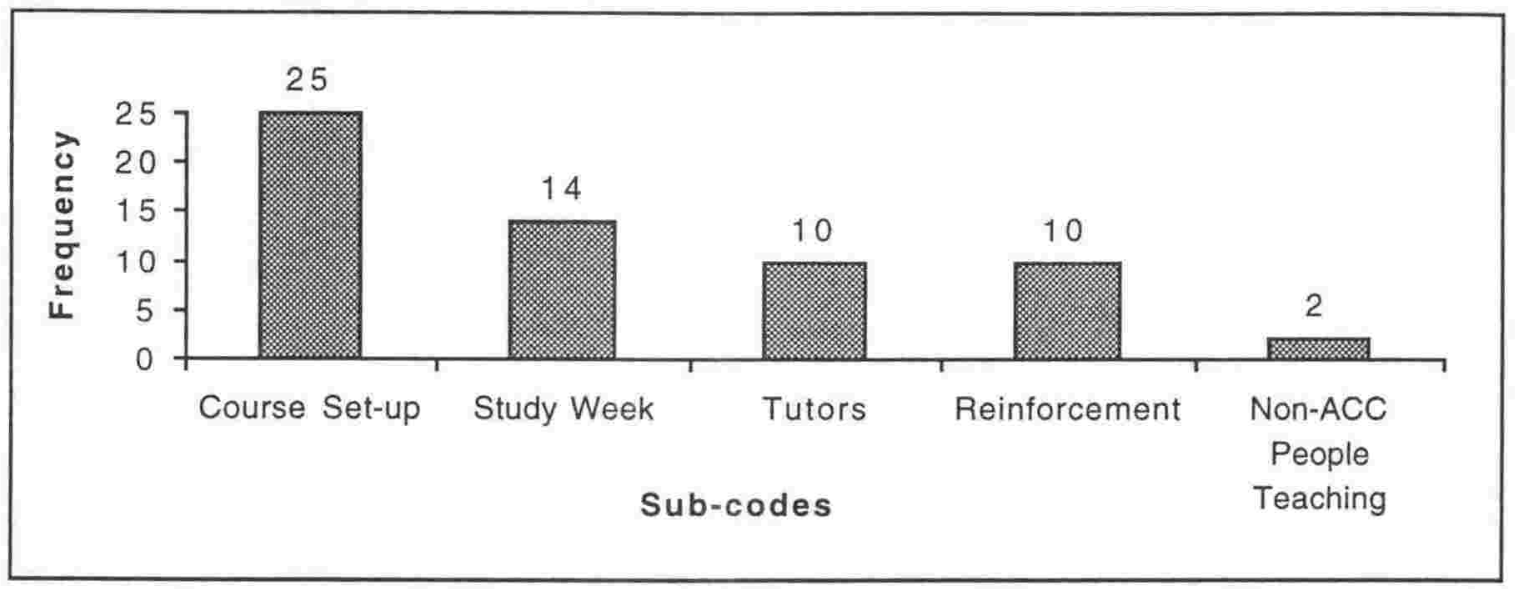

\section{Graph 5.1: The Learning Context at 12 months $(n=40)$}

As Graph 5.1 shows, the course set-up was mentioned by twenty-five participants as being important to the transfer of learning. These participants reported:

I liked the structure because it got one module out of the way before the next one was started, therefore you could concentrate on one area. Not cluttered with different subjects.

The combination of personal and professional worked because people are so important in the role of rehabilitation. You have to be part of peoples' lives, but must also be able to stand back.

Being able to put theory into practice. The way we learnt what we did. When I think about the best way I learn it is by discussion, by doing, working through ideas and then applying them to the situation, because it is easier to then transfer it back to what I was doing here. Also the discussions we had in the classroom and regional groups.

Learning how to learn. I now know how to find things. Getting my brain into the thinking mode.

If you are working in a supportive environment you can achieve and if this was mirrored in the organisation it would be great. 
I liked the format because it kept you moving along and really motivated. It was easier to immerse yourself in something than normal varsity. It was quite well structured, particularly for people who hadn't been to varsity before and the work was relatively structured.

The module with the study week was good, as there was lots of information in the module and the study week provided a breather and set time for yourself - it was a real good balance.

The course worked well. I liked the idea of theory and then the assignment, because it was still fresh in your mind.

My learning was better by being off-site because I didn't have to cope with family and other distractions.

The study week was emphasised by fourteen participants, as giving them time to reflect on the previous module, before moving on to something new. Two participants made this point very clearly:

Study weeks took the pressure off as I hadn't studied before.

The course was well set up. It was good to have the study week after the module because you could apply the learning straight away.

The importance of the tutors and the reinforcement of knowledge provided by the course were each highlighted by ten participants. The following comments draw attention to these influences:

The assistance from the tutors and the other students helped me get through it which was pretty good stuff. The tutors were like friends as well as there to do a job, therefore we were privileged.

The tutors were an excellent group of people

Just being on the course was a big eye-opener for me as I'd never done anything like that before . . , the tutors held it together.

I had a sense of the topic area but the course provided reinforcement.

The assessment process was not a new skill, but helped me recover issues and refresh my mind. 
I had the background knowledge to most things on the course, but it provided me with a structure of how to apply it.

Two participants made the point that it was good to have non-ACC people teaching on the course, as it provided a different perspective.

\section{Important course components}

Three separate components of the course were singled out by participants as being particularly important in the successful transfer of learning - the personal and professional development day, the module on culture, and the practicum.

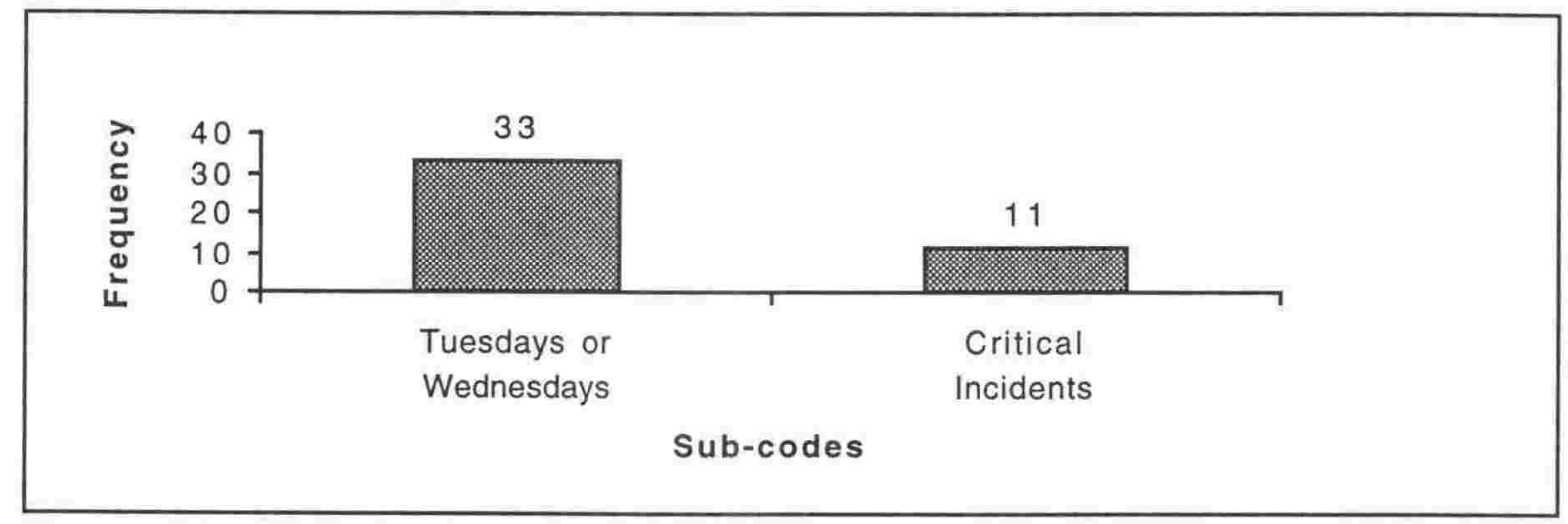

Graph 5.2: Personal \& Professional Development Day at 12 months $(\mathrm{n}=37)$

Graph 5.2 illustrates how thirty-three participants drew attention to the personal and professional day in general (referred to by the participants as Tuesdays or Wednesdays as these were the days they fell on depending on which Cohort), with the following comments being representative of the views expressed:

Tuesdays enabled you to see the diverse ways that people work and still achieve goals, because ACC generally gives only one model of doing things.

Tuesdays were the most valuable out of whole course as you figure out whether you should be in the job.

Tuesday sessions were really good. A lot of it was quite hard because you had to look at yourself. Look at how you perceive things, how you were like before and more conscious of it now.

Wednesdays, just in little ways. Looking at yourself a little closer and how you'd like to be treated. 
The critical incidents which were part of the personal and professional day were specifically emphasised by eleven participants, with examples including:

The critical incidents showed me that professionalism is important and that I need to think before I speak. Also that I can learn from my mistakes and that there is always something positive in a situation.

The critical incidents did a lot and were very useful. I've refined my own approach from them without realising it.

Now when I'm faced with ugly situations I reflect back to the critical incidents. How not to lose my cool and knowing that the result of the interview would set the scene for outcomes in the next six months. I also imagined the others were watching me.

The critical incidents were good for sitting back and looking at problems and trying things in different ways.

Within the participants who commented on the personal and professional days there was a minority who found these days unhelpful, as is noted in the following comments:

Some of Tuesdays was too touchy feely and it was hard to take the tutor seriously as I didn't think they meant it.

I'm sure personal development was useful, but I would have liked more on the professional side of things.

Tuesdays were too personal. The wrong place and at the wrong time. They were not appropriate to the group situation and not relevant to a professional course.

Graph 5.3 shows the breakdown of the cultural awareness code. The noho marae (see Glossary) was specifically mentioned by twenty-seven participants, whereas the importance of culture in a more general sense was seen as important by thirteen participants and the assignment associated with this module was highlighted by five participants. 


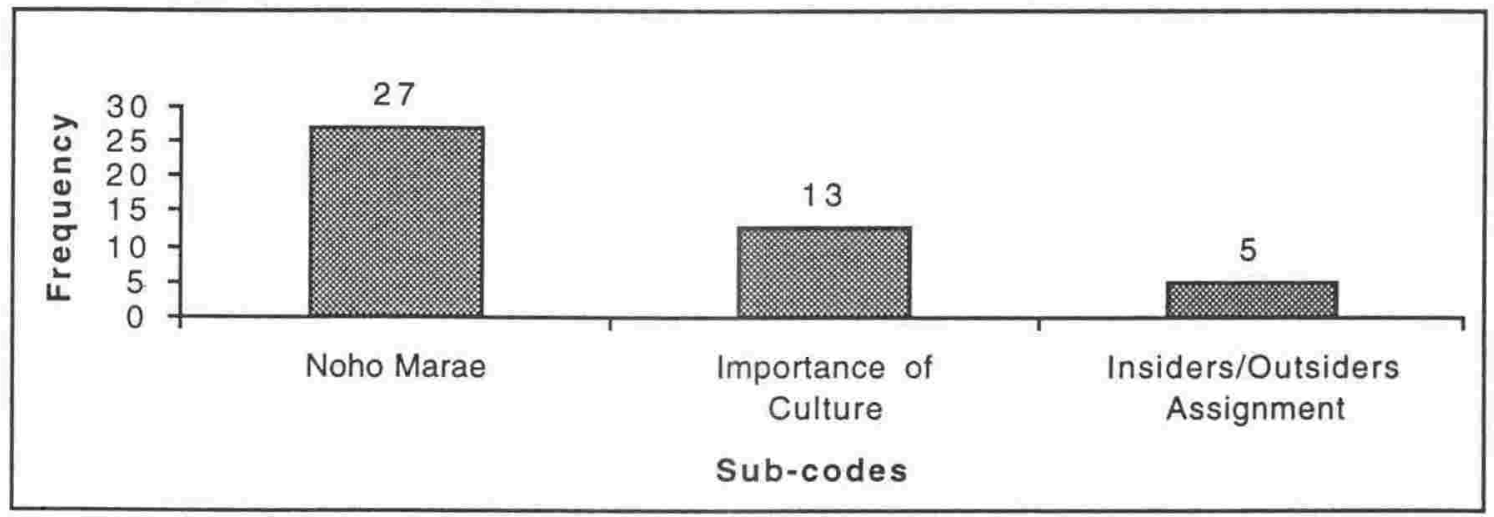

\section{Graph 5.3: Cultural Awareness at 12 months $(n=29)$}

The reasons for the noho marae being important to the transfer of learning in this context is reflected by the following responses.

The marae visit showed that ACC acknowledged that different cultures exist not just in staff but amongst claimants which is particularly relevant now with the new discretionary Homehelp regulations. It also shows that we honour the Treaty of Waitangi.

The marae visit changed a lot of my attitudes. I discovered how racist I was, not that I called people black bastards, but that I tended to categorise people. Now I have more insight.

I had never stayed on a marae before and it was good to live differently to how I normally live. It was also interesting to see how people adapt to different living arrangements and what value they place on those. It also made me recognise that when we deal with Maori there needs to be a balance between ACC values and their values. Also that things may not move as quickly as anticipated - the timeframe may be longer. They may also have medical treatment providers which may not fit in with their view, as they may have other psychological values and beliefs.

The marae visit helped me identify where I come from and why I'm like I am. Now I've accepted me as me and am happy with that. I'm not going to change to please other people.

I try and apply things personally first then professionally. It was like we learned on the marae where I learned that you need to know who you are first before you do anything else.

I've had on-site meetings with claimants about six at a time and established rapport. It got quite aggro once I was inside, but now they are aggro at the system not at me, as they are no longer dealing with a faceless organisation. I link it to going onto the marae and not knowing what would happen. I'm meeting with them on their terms, going to their factory, wearing a collar and tie (I put a jersey over the top) and meet in their smoko rooms. It was nerve racking but very worthwhile. 
The importance of culture in more general terms can be seen in the following comments.

The cultural aspect was very important to me as it has improved my judgement skills on how I view my clients.

Cultural part had quite a big impact, because you looked at different cultures and looked at yourself and why you are as you are. People are different because of different experiences - not everyone is the same as you.

I'm a lot more aware of other people's comments now ... I'd always thought of culture as race rather than sexuality or age, I'd never thought like that before.

The cultural side made me much more aware of not just different coloured skins. I now visit new claimants in the first seven days. I learn about their homes, find out about how they live, as you get used to white middle class living, but people live very differently. I now also dress more casually and am accepted more easily.

The insiders/outsiders assignment was seen as difficult, but at the same time useful. One participant stated that:

The insiders/outsiders essay was useful as it tied in with the critical incident and needs assessment and it enabled me to stand back and look at my own background and how mine ties in or conflicts with the clients or someone else.

Another participant said that:

The insiders/outsiders essay was really emotional, it was really bad news. It was really hard but good, because it was a growing and learning experience about your own identity, where you are and where you are going.

Not everyone felt the cultural module was useful. This was clearly voiced by one participant who said:

I learned nothing. I felt I was put down. It was a waste of time. If I'd been given the choice I would have gone into an Asian environment for example. You need to have a choice appropriate to personal background and working environment. 


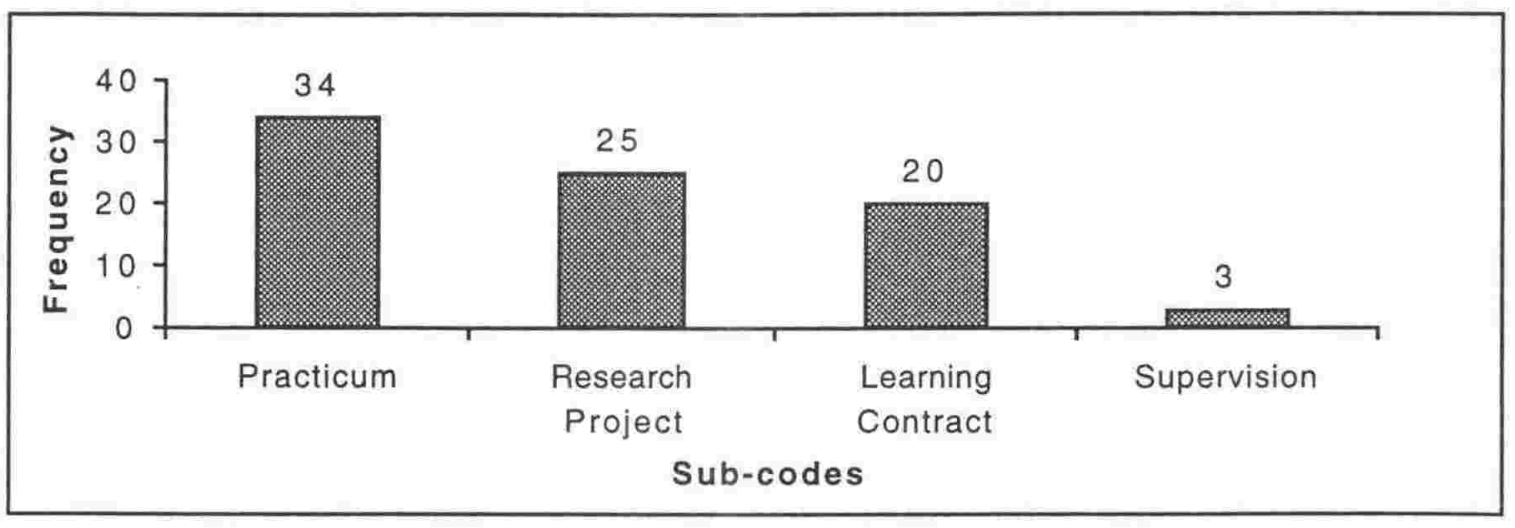

\section{Graph 5.4: The Practicum at 12 months $(n=45)$}

The importance of the supervised practicum in the transfer of learning is highlighted by the fact that forty-five out of forty-seven participants mentioned it either directly or indirectly by referring to specific components of the learning experience. These can be seen in Graph 5.4. There was a variety of opinion on the practicum which is reflected in the following comments:

The practicum was excellent, because I could apply knowledge without having to go straight back to work.

The most important thing for me from the course, and it goes without saying, has to be the practicum and learning objectives.

Having half the course based in the office was good and having, in my case, a definite rehab related project. The practicum and learning contract worked well together, particularly if you got them in sync with what you thought you needed to know.

The practicum was ghastly as there was no support from management on return to the branch. However, the concept of a practicum was good because you are on your own - a little out of your comfort zone. It was a good test, particularly the case study.

The practicum was good. It showed through in the transition case study where you were able to pull in the different aspects of the course such as interviewing and negotiation. At times the practicum was hard as you were quite alone back in the branch. But there was good networking and support from people who'd been through it. It was quite an adjusting period.

The practicum worked well for me because of the support I had so I started putting things into practice. I was very fired up. 
It was rather disjointed going from a supported learning environment to fend for yourself. In that sense the practicum wasn't great, but the research project was good. I like the concept of a practicum but it needs to be facilitated differently.

\section{The Individual}

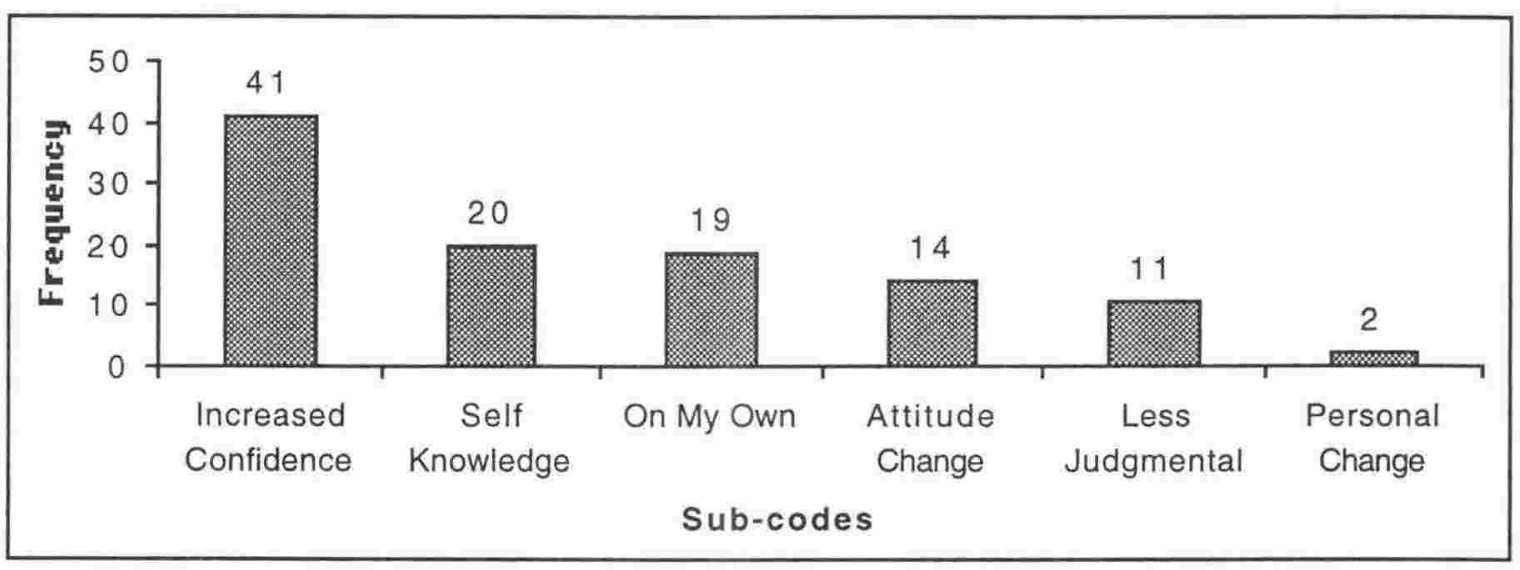

\section{Graph 5.5: Personal Development at 12 months $(n=45)$}

Forty-five participants indicated that personal development had taken place as a result of the course. The key themes associated with this are shown in Graph 5.5. Increased confidence was seen as the main outcome for forty-one of the participants, followed by increased self-knowledge and making things happen on their own. Responses highlighting these factors include:

I had a depressed school teacher, with whom I had heavy going interviews. Drinking and drugs had been mentioned before, but I'd never probed before. When I did it turned out the client had a dependency. I wouldn't have had the confidence to do this pre-course.

I wrote a memo to Bert [General Manager Operations]. I would have never done that before. It was a personal achievement for me. I've more guts now and it has led to office changes. My behaviour has rubbed off on others - they are now taking risks too. I've had the confidence to do this.

I took my increased confidence back to the office and after a couple of weeks I realised that I needed to make some changes regarding my workload. There was no support from team leaders so I went on my own initiative due to my increased self-confidence. I led by example. The mere fact that what I was doing was working meant that others followed suit, particularly with respect to working with employers. My positive attitude flowed on to other people.

For me it's being more sensitive, less judgmental and knowing that I have the ability to change things. 
My confidence has increased and also before the course I was very much a black and white person, now I'm much more creative. I'm more focused on needs assessment rather than the client fitting the legislation, I find a part of the legislation that fits them. Confidence and self-awareness were key factors in enabling me to apply for new positions. Knowing that if you set your mind to it you can do it - nothing is impossible. Just like the first assignment, I never thought I'd finish it.

Knowing why things happen has increased my confidence in dealing with tricky cases about one in ten. I now have a more holistic approach, for example I consider their cultural background and think about how they would like to be treated, which is something I wouldn't have done before.

It's increased my confidence, particularly in dealing with professionals in general. Before the course I'd never mixed with professor and university tutors. Now I'll give things a go and take a risk. For example, case conferencing, before I would have been too scared to ask, now I'm not because now I have to make people accountable. If people can't work I have to ask why. The same goes for the medical profession. My self-esteem has gone up for having done it and finished it.

I'm a little more assertive now. I had trouble dealing with people senior to me. Now that's fine, I have worked through the issues now. If I haven't got the answers, I will go back. It didn't happen straight away, but the practicum helped me work things through with my tutor.

The following comments referred to increased self-knowledge and doing things on their own.

Personal development - I think a lot more about myself and how my make up affects my performance.

I think on reflection, I know who I am now - maybe age thing or space I'm in - I definitely know who I am, has been quite good because before I plodded through life - more self-aware now.

My own motivations to experiment with new ideas promoted through the course from teaching and interactions with other Case Managers. These ideas developed into skills once proven.

Own desire to improve what I was doing - I changed, the job didn't so that's why the change and it is very, very challenging.

Fourteen participants mentioned that their attitude had changed as a result of the course and eleven felt that they were now less judgmental. This can be seen in the following observations. 
The course changed my attitude - this enabled it to be better; spent more time with clients.

My attitude has changed - not so demanding and uptight about things

. . . in particular being more sensitive; less judgmental; ability to change things, i.e. left my partner because he was insensitive and judgmental.

Understanding of people's choices - there is more to the picture than what I know- I'm less judgmental now.

\section{Job Specific Processes}

The data shown in Graph 5.6 and Graph 5.7 relate to the learning specific to the case manager's job, which participants gained from the course. It is important to note that out of the forty-seven participants, forty-five commented on their praxis development, and all, except for one participant, said that they used a holistic approach. Graph 5.8 indicates that forty-five of the participants were aware that changes in their practice had taken place.

The main areas of praxis development are shown in Graph 5.6. Within the area of praxis development, improved stress management and planning/organisational skills were seen as most important. These two skill areas were closely followed by an increase in risk taking, better presentation and conflict management skills. The following are some of the observations made by participants with respect to stress management and planning/organisational skills.

The stress management was useful as I use the skills in the work place and I have the handouts by my desk.

I'm much less stressed now because I've changed my attitude and basically don't put my energy into things I can't change.

Planning skills have been important for me. I now look at what I want out of things. Start at the end and work backwards. 
Graph 5.6: Praxis Development at 12 months $(n=45)$

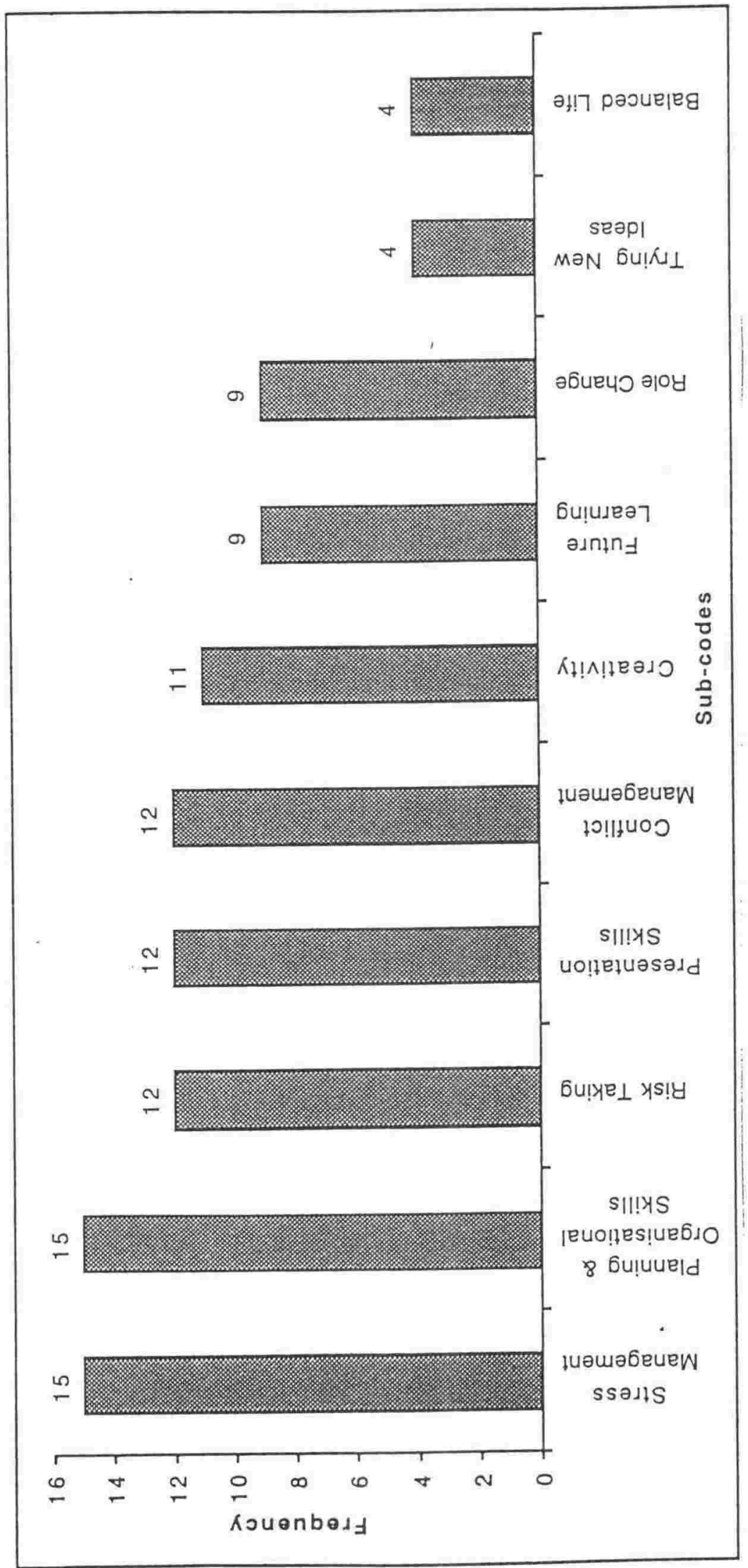


The importance of planning in terms of rehab. I'm now much more focused on being organised.

Being more organised and prepared has made things flow better and life easier.

Comments associated with risk taking, presentation skills and conflict management include:

I am now much more prepared to take calculated risks and try new things.

I'm not so worried now about taking risks because I met people who'd done different things, changed jobs and lived in different places.

For me having to do presentations was important as it boosted my confidence for speaking in front of a large number of people.

Giving presentations was important to me as you learned how to structure them and use the appropriate resources. I give a lot of presentations in the community and to the public - so it was very helpful.

Conflict management works and helps particularly with gnarly employers and grisly clients. I now stay calm and collected and we look at options.

Conflict management was really useful for me as I deal with it much better now. I never knew when to back off, but now I know how to facilitate the process and I'm often a mediator now.

Other remarks by participants related to increased creativity, the desire to continue learning and the fact that many had changed roles since the end of the course.

I now see my role as a case manager as working the system creatively to help the clients through the system.

For me the lateral thinking has been important. Trying to find another way to do it within the law. Looking at things more creatively.

The course has encouraged me to pursue other and further learning, because I've found that analysing situations and discussing things at work often carries over to my home life as well. 
There will be more study for me on the future, to keep my brain going. It's just a matter of finding the right course.

My change in role and return to the branch has been important as it enabled me to make changes as I had more time.

If I'd never had the opportunity to go on the course, I wouldn't have advanced. Even if I hadn't moved to .... the course has given me a much clearer concept of case management and I had been in case management since it started. The course was a catalyst to do something different.

The importance of using a holistic approach in case management was commented on by forty-six of the forty-seven participants and is shown in Graph 5.7. The most frequently mentioned process associated with taking a holistic approach was the importance of the needs assessment. The following are some of the participants comments:

I now have a plan for doing needs assessments. I determine what their needs are with the initial evaluation taken home by the client for them to complete from their perspective. We talk about their needs first and what they can and can't do.

I had a male client who had been on ACC for eight years, had lost motivation and made ACC a career. So on return from the course I asked him 'what is it that you really want to do?' he couldn't answer the question because he'd never been asked. We made another meeting when he came back with a list of options, from which we then determined realistic ones. The change in him was dramatic - he now desperately wanted to get of ACC. He is now off ACC. I never would have asked this question prior to the course.

$\mathrm{ACC}$ has been very entitlement based. But we must ask clients what they really need. 'What do you need?' is the one basic question to ask in order to assess their needs. I'm now more concerned about their whole life rather than just getting them back to work.

I had a lady with a back injury and major emotional problems who desperately wanted to be a pharmacist. So we put her through a course and she looked at options in hospital training. At first she started voluntarily now she is off the books. Giving her support and encouraging her to do something were the key, and I did the rest when needed. Prior to the course I thought they wouldn't let me do this, now I just ask 'what do you really want to do?'

Interviewing, communication and negotiating skills were also seen as important in the context of using a holistic approach to rehabilitation. Theses points are highlighted by the following responses. 
Interviewing skills are important in terms of asking the right questions at the right time, prompting and putting a process in place. I now use a planned approach with an interview schedule with all my clients.

Interviewing, particularly active participation in terms of listening to people, what was said and paraphrasing.

Being aware of listening in interviews and looking at whether what they say matches their body language.

Listening skills. Hearing what the client is saying rather than telling them.

I negotiate and communicate better with employers because meetings are better planned and I know what I want to discuss and the outcomes I want.

I worked with a person to get a cessation date, but it didn't go to plan. So I backed off and we renegotiated to get a win/win situation. If I'd stuck to the original date it may have led to a review situation.

Other statements in the remaining sub-codes included:

I have fine-tuned the concept of case management with respect to rehabilitation concentrating on a holistic approach and working towards solutions with the claimant.

I've made a difference to case management, because I offer a different point of view particularly in this branch, because the workforce here is quite stable. I work in partnership with the client taking into account everything in their life not just the injury and use a holistic approach. For example, there was a female nail technician who had had training denied because of her age and it wouldn't be good for the corporation. I looked at the situation differently gave her training and now she is off the books. I empower the clients. I say 'I hold the wallet, you have to convince me to open it.' This provides motivation for the client as it is their responsibility to find a job or decide on training they would like.

The idea of ACC's history and it's place in society is very important, particularly for staff because its understanding what ACC's role in society in terms of the social contract is and why people expect certain things from ACC.

I'm now more aware of peoples' circumstances and therefore the way I approach the job. I now see clients as individuals - that they are not all the same. 
Graph 5.7: Using a Holistic Approach at 12 months $(n=46)$

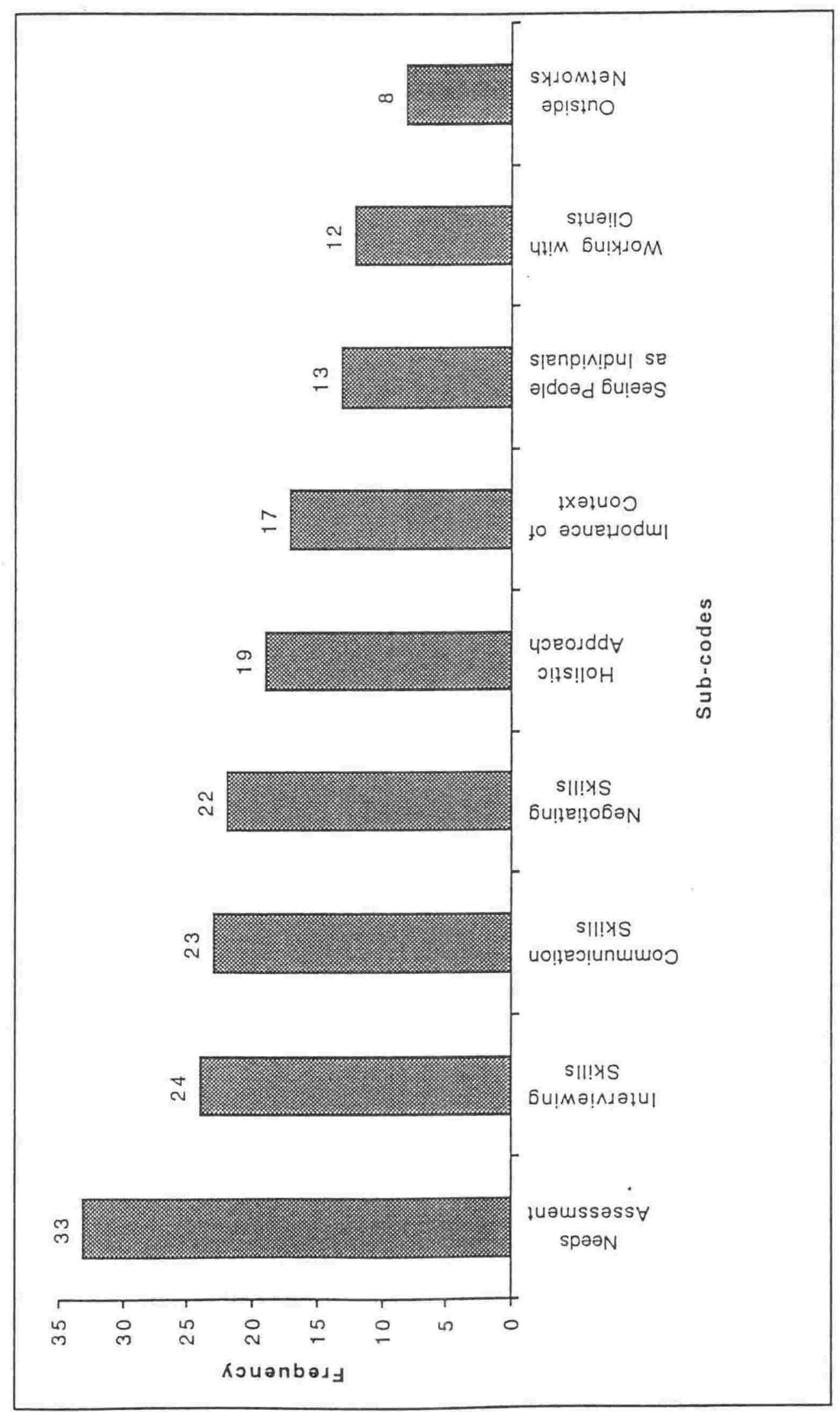


Three people were laid off and I did IRPs (see Glossary) for all of them stressing that they were in charge and the partnership aspect of it. I wouldn't have done this pre-course. I now see the case manager as the lesser of the two partners. It is the clients life. The case manager is there to support, to co-ordinate, not to tell or dictate to them what to do.

Community involvement has been important with lots of networking following on from the research. I've expanded the area I cover. I go out a lot and network, which I wouldn't have done prior to the course.

One participant did note, however, that whilst:

... the holistic thing was huge, it was also most frustrating because ACC doesn't want to know.

They are more interested in outcomes.

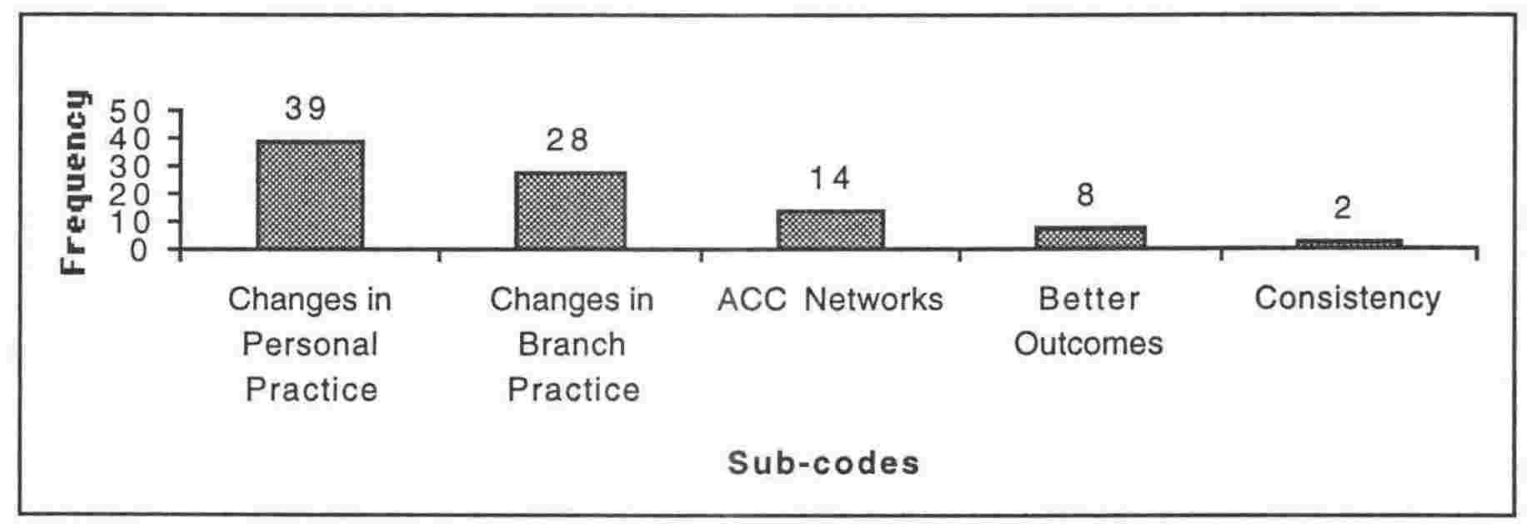

\section{Graph 5.8: Changes in Practice at 12 months $(n=45)$}

Changes in case management practice took place on an individual and branch level as can be seen in Graph 5.8. Thirty-nine of the participants indicated that their personal practice had changed as a result of the course. The following responses are representative of the comments made.

I use the skills I learned every day, particularly empathy and negotiation skills. I'm proactive rather than reactive and therefore not in crisis mode all the time and the clients get quality service. I've learned to say 'no' and only make promises I can honour. I also feel more responsible to my work.

I use something from the course everyday, particularly since the course has finished, as there was lots of pressure during the practicum. Now I'm able to make links to daily practice. I've also seen that these links from the course to daily practice remain strong amongst other students. 
There have been radical changes in the branch over the past twelve months with ideas coming from myself and others. The single most influential change has been instituting case conferencing. We've also reduced case loads from 257 to 128 per case manager, due to a change in the way we work. Each case manager focuses on five people per month, like we did for the case study during the practicum. This has led to making a real change in the community. Case managers make their choice based on professionalism. Working with post 52 week people or people at 13 weeks who might need more intensive work is encouraged. The staff were not overly keen on all the new ideas mainly due to their worrying about time. Now the people are happy with both case conferencing and supervision. They see the case conference as a learning opportunity. There is also more helping and sharing in the case management team. People will now ask for help due to the safe environment which has been created.

There have been subtle changes in the branch because it went with the whole new understanding. I helped give that to other people in the branch via training and handing out materials from the course. Also training people in how to do holistic IRPs.

For some, time has been a factor in being able to make personal changes, as was mentioned by this participant.

I think I'm in a position now to say yes, six months ago no way because of the branch. I think it's taken twelve months to consolidate what I've learned and put it into practice. It's sort of a gradual thing.

Twenty-eight participants indicated that personal change in practice had led to changes in branch practice (Please note that some branches were represented by more than one participant in the research). The following comments highlight this point.

I took what I learned back to the office with me and after a couple of weeks I realised that I needed to make some changes regarding my workload. There was no support from team leaders so I went on my own initiative due to my increased self-confidence. I led by example - the mere fact that what I was doing was working meant that others followed suit, particularly with respect to employers. My positive attitude flowed onto others.

There has been a change in the way I work. I was the first one to have a day out of the office to meet with people. Other case managers followed suit. I made it my business to meet with all GPs and service providers, which has made things much easier.

It is the example you set rather than what I do. My change encouraged other people rather than telling people how to do that ... I explained how I found it easier to do things, that you'll never get things perfect and to try not to get stressed out about things. I also offered encouragement to others. 
Change in practice was not always possible or easy. As one participant states:

The branch climate has not let us do this - not to the extent we'd been encouraged to. On my return I tried to encourage staff to focus on getting out rather than processing, but it wasn't realistic. My approach is now more client focused and I try to impact this with other staff. There is little opportunity to change the organisation. Few resources to achieve things, because to change the organisation you need resources and abilities to do things.

The networking which developed after the course was seen as beneficial to some participants. Their feedback included:

The networking particularly interoffice was helpful. I never did that prior to the course. It's useful because you can pick up good practices from other offices.

You got to know forty other people with their knowledge and different ideas. You realised you're not the only one with the problem.

Better outcomes were mostly linked to a change in personal practice. The following examples provided by participants demonstrate this.

I had a male client who had a work injury to his back in March 1995 and I worked with him to June 1996, with a work trail in January for three weeks. I was able to extend the work trail for three months. I had a good ally in the work site nurse. Even though the employer didn't want him, he's now back to full-time work which was due to my persistence and not wanting to give in.

I had this Maori guy in his 50s who had been talked to about going back to work. He complained about this and was allocated to me. We took it slowly so that he could build up trust in me which took time. At first he just said no to any suggestions of work but eventually he decided to go on a work trial. I tend to push a lot harder now and it's how you do it. He didn't want to go but after a few days he came back and was happy and smiling and now he's been back at work for six months.

The whole situation with regard to changes in practice and being change agents was summed up well by one participant who stated:

My understanding was that the course was to change the culture of ACC to being more rehab and people oriented. To question the way things were done so the whole group are change agents rather than just one person. By individually changing the way they work, this influences people around them, which I've been able to do, because of my role. 


\section{Organisational Factors}

The role of ACC as an organisation is considered in Graph 5.9 and Graph 5.10. The number of responses suggesting support offered by the organisation (thirty-six) is slightly more than those participants mentioning detracting factors (thirty-one).

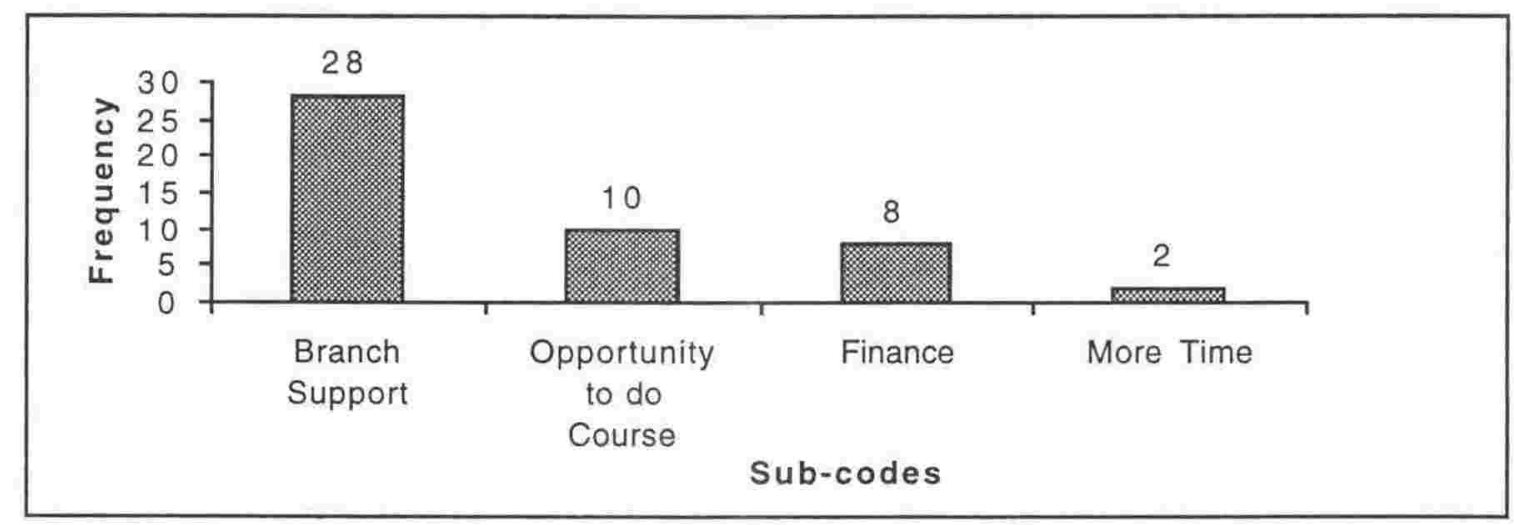

\section{Graph 5.9: Organisational Supports at 12 months $(n=36)$}

The main form of organisational support was offered via the branches as can be seen in Graph 5.9. The following responses illustrate this.

My PCM told me not to lose skills that I learned. I felt I was needed and that my PCM wanted me to lead by example.

The branch was very supportive and overall I found ACC supportive. You can't expect everything to be handed to you on a plate. Branch Manager and PCM support was always there.

People at the branch were interested, as I could teach them stuff from the course. The Team Leader and PCM were supportive.

Ten of the participants mentioned that having the opportunity to do the course was valued by them. Comments included:

The opportunity of doing the course was great as it was not an in-house course, it had a holistic overview, gave you the opportunity to explore and develop new ideas and knowledge as well as providing time to study.

I'm pleased I had the opportunity to do the course because of the qualification and I enjoy my job more now because I have more of a sense of what I'm doing and I have good support people in the DSOs. 
I found ACC more proactive and caring than I thought. I was quite surprised at the length they went to develop it rather than picking up an existing course. I certainly appreciated it.

The fact that ACC financially supported them was also important. This is well stated by a participant who said:

The cost was a big one for me, without ACC support I wouldn't have been able to do it.

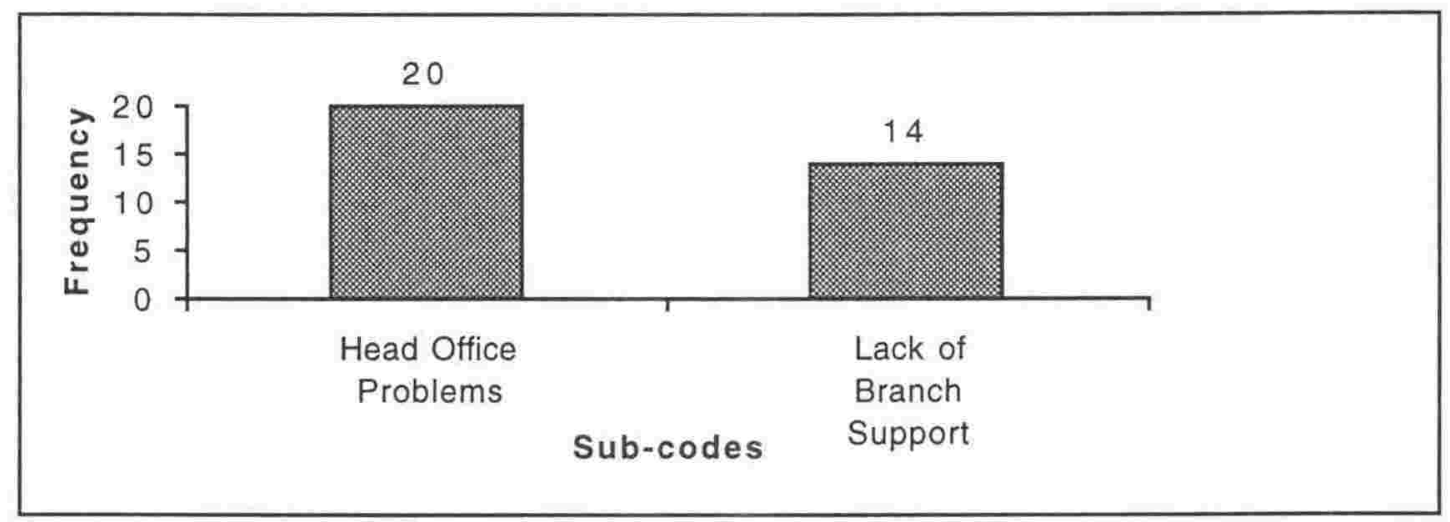

\section{Graph 5.10: Organisational Detractions at 12 months $(n=31)$}

Graph 5.10 shows that the main concerns regarding the organisation came from problems with Head Office, followed by a lack of support at the branch level. Observations made by participants included:

ACC Head Office lost an opportunity by not taking an active interest in students when they were in Wellington. I felt that the loyalty I offer to the organisation and my clients was not returned.

It's sad the way ACC is going. They spend a lot of money on restructuring which leads to more work. We've got to the stage when you can't see the future. I want to be proud of the organisation I work for. We're in more trouble than a lot of people realise, basically because bad wording of the legislation. They just don't seem to be getting it right. We could be a very good organisation.

I'm disappointed that I haven't been able to fully utilise the skills and knowledge because of the crazy and stressful environment we work in. In some respects it's quite a waste of time and energy.

The concerns regarding the lack of branch support were often quite strongly worded, reflecting how strongly participants felt about the issue.

You get back after the course and it's just like you've never been away, everything gets dumped on you. At first you're encouraged to go on the course and they'd be proud of you on your return. But I was 'shat on' and told to keep my ideas to myself. 
Back at work I was chucked straight back into it. Management didn't give a stuff about it. You're back at work so get to it. So I haven't really been given the opportunity to apply what I've learned. ... I'm disappointed at the lack of interest on my return. I grew throughout the course and felt I achieved something in the end. Those six months have gone unrecognised, not even in the performance review. The reason given was that it's not fair because others had no choice. I chose to go which they didn't. I'm really pissed off as other branches recognised this.

The feeling of not being supported is well summarised by one participant who commented: I think it's a waste of time by ACC, because it's no good encouraging people to be change agents if they are then not supported by the branch or Head Office on their return. 


\section{DATA COLLECTED EIGHTEEN MONTHS POST COURSE}

Below are the Final Codes (in bold) used for the eighteen-month data with sub-codes identified in each box.
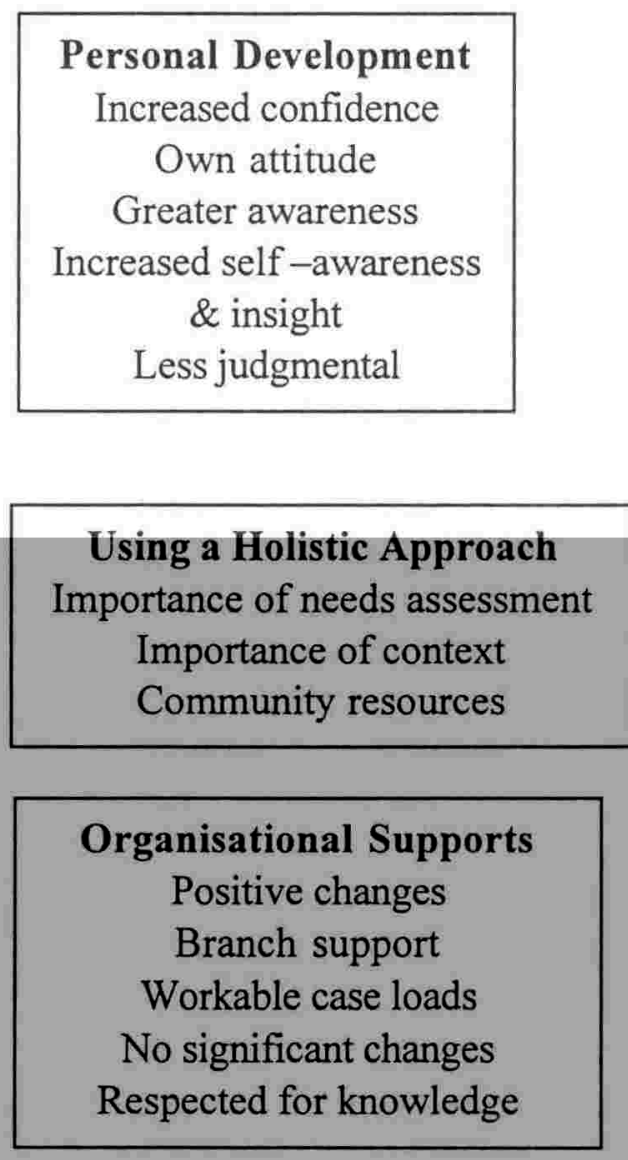

Praxis Development

New or seek new job

Future learning

Planning skills

Balanced life

Reflect more

Creativity

Risk taking

\section{Changes in Practice}

Good outcomes

Adapting learning to new situations

Has become second nature

Learning is working

Realistic approach

Changes made

\section{Organisational Detractions}

Negative changes

ACC not supportive

Conflict between own \& work

knowledge

Concerns about ACC future

Follow-up needed

Work constraints

The data at this stage of the research is based on semi-structured interviews and focus groups, where the focus was on outcomes achieved as a result of the course (see Appendix 7). There were forty-one participants at the eighteen month stage of the research - fourteen in Cohort 1, thirteen from Cohort 2 and fourteen from Cohort 3. All the initial participants from Cohort 1 took part in the research eighteen months after they had completed the course. Four participants from Cohort 2 were no longer part of the study - one chose to withdraw from the research, one participant took redundancy and the two others did not respond to messages left to arrange a meeting time with them. In Cohort 3 , two of the 
original participants left the research - one took redundancy and the other did not respond to messages left to arrange a meeting time with them. Participant numbers from both the Southern Region and the rest of the country reduced - to seventeen and twenty-four respectively. The number of female participants dropped to twenty-seven and to fourteen for the men.

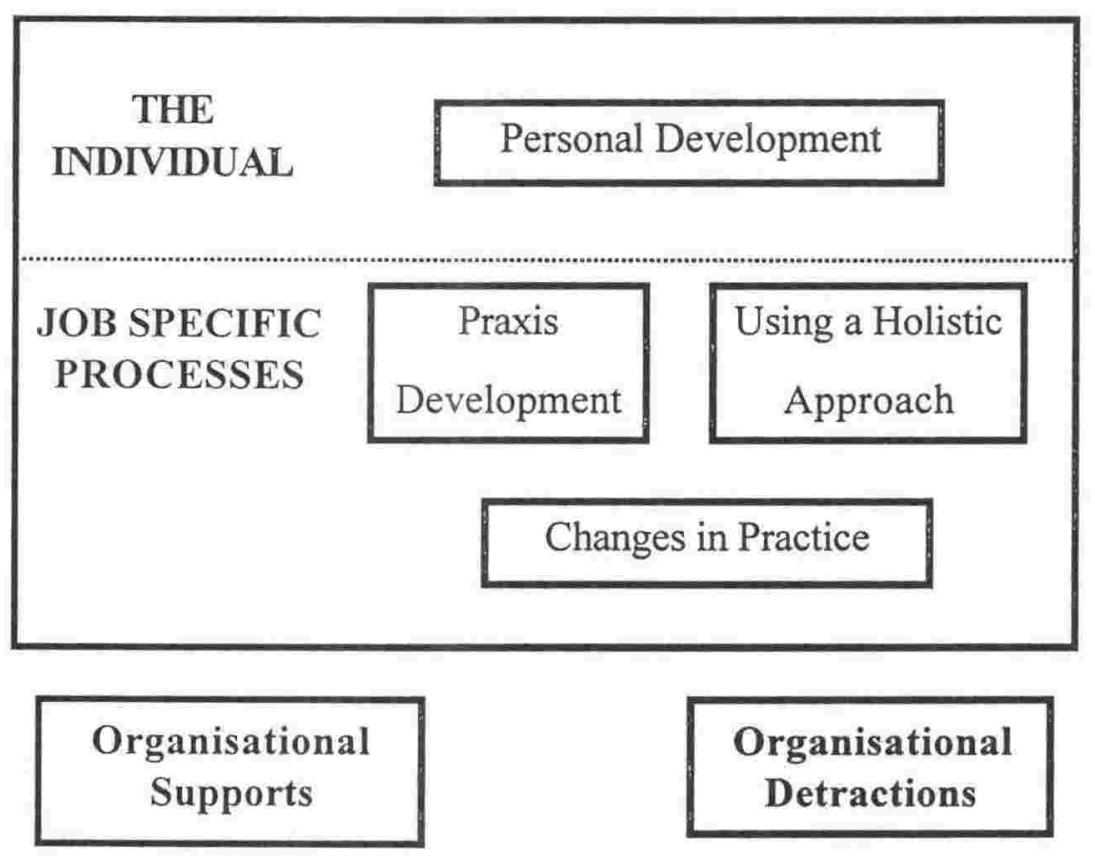

Figure 5.2: Summary of Final Codes at 18 months

As can be seen from Figure 5.2, similar Final Codes to the twelve month stage emerged from the data. Little reference, however, was made to the educational process in terms of course components or course design, so it did not merit a separate code, but is incorporated into other codes were appropriate. As with the twelve month data the following bar graphs detail the sub-codes for each of the Final Codes seen in Figure 5.2, starting with personal development and then working through to changes in practice, before finishing with organisational supports and detractions. 


\section{The Individual}

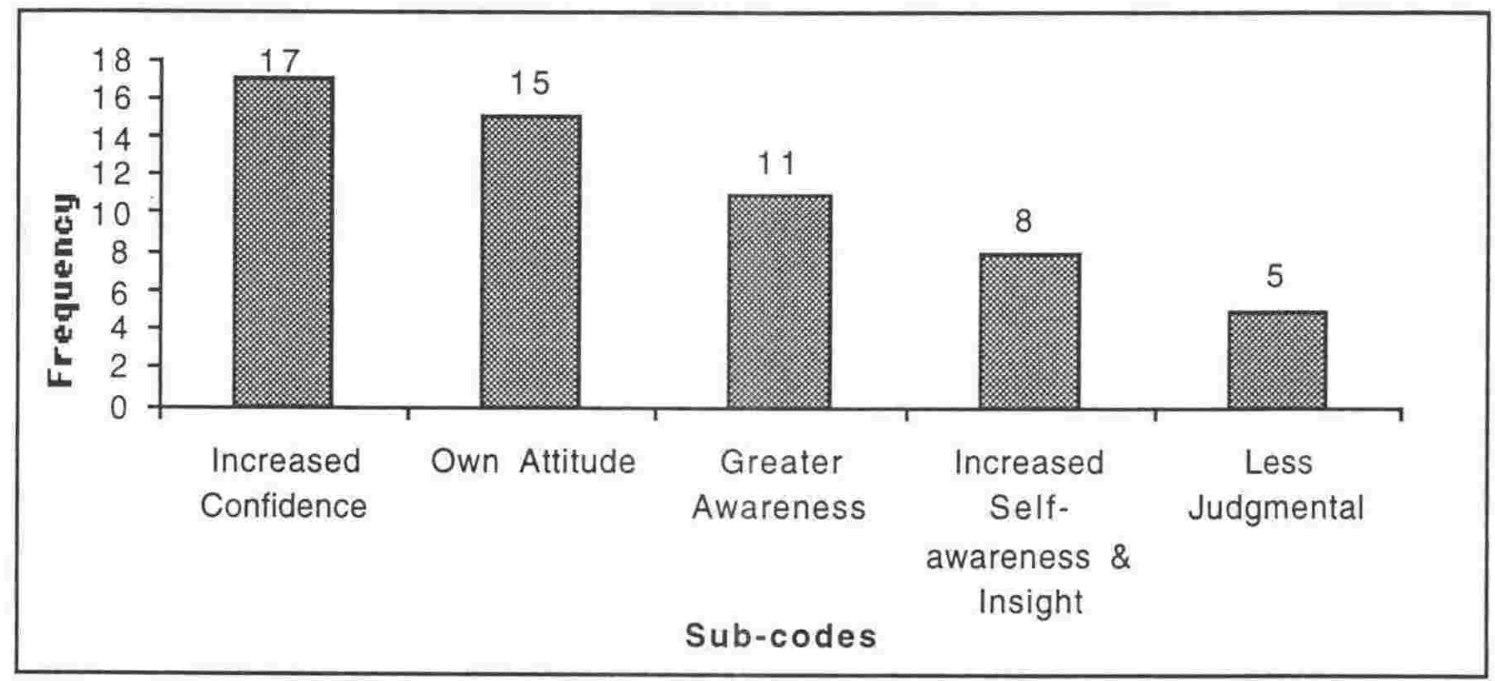

\section{Graph 5.11: Personal Development at 18 months $(n=31)$}

Thirty-one participants indicated that personal development, resulting from the course, was still important to them eighteen months after having finished the course. This was most clearly demonstrated by an increase in confidence and their own attitude, as can be seen in Graph 5.11. The following comments illustrate this.

I have far more confidence in what I'm doing, the more I do it. What I do now is have far more face-to-face interviews, as people react so differently. I request interviews by letter, and it's amazing how people suddenly perceive themselves to be more ready to return to work than they thought. Personal contact makes a huge difference and also provides better outcomes.

Self-confidence - it has taken me six months to figure out where I stand. Not many people know what I do and in the long term I want to get more into health and safety and injury prevention. Knowing that I'm a professional and that I have the right to challenge other professionals.

I've had the self-confidence to reorganise the Medfees system and the computer system. Being Acting Team Leader for two weeks was really good. It enabled me to work with the next level up such as organising cover for staff and dealing with difficult clients.

Outcomes with clients are due to me being more assertive and pushing for outcomes - I was out there. Also because I get so involved in my job and set targets for myself.

It's me listening and looking at all the other areas. I always see them at home and dress down and see them for who they are. I can get outcomes like this even if ACC doesn't like it, so I keep my jeans in the car and get changed away from the office. 
Issues associated with greater awareness in general and self-awareness, as well as insight, were mentioned by a number of the participants. Their observations included:

People who have come back from the course seemed to have got more respect from their colleagues. The blinkers have been taken off - they are not just ACC focused anymore. They seem more happy to take time to listen and have an increased awareness of their own abilities.

The research skills made you want to know more and why. It made you question more, as well as do more follow-up reading than before. The needs assessments I do are more thorough than they would have been. I find people who haven't done the course still don't focus on the client. It has given me a much greater awareness.

I learned a hell of a lot from the marae stay - it made me sit back and analyse why people are the way they are. It goes across everything you do - treating people as individuals and trying to recognise their point of view. I come across as genuine, because I am genuine. The whole needs assessment thing ties into the marae and insider-outsiders.

One thing about the course which has been good is the consciousness of the thought process - in what and why I'm doing things. I actually verbalise what the situation is and weigh up things so that the person I'm working with is hopefully also weighing up the issues.

Tied in with self-awareness is being less judgmental. One participant expressed this by saying:

Pre-course I got complaints from clients about being too black and white and that I had no empathy; now I listen and don't make a ruling on it. I'm not as judgmental as I was even though I might think things, I know what to say and to give the appearance that it's OK.

\section{Job Specific Processes}

The next two graphs (Graph 5.12 and Graph 5.13) illustrate the learning participants have taken from the course and applied to their work in the case management field. The final graph in this section (Graph 5.14) relates to the actual changes in case management practices which participants feel have taken place for them as a result of having completed the Diploma course. 


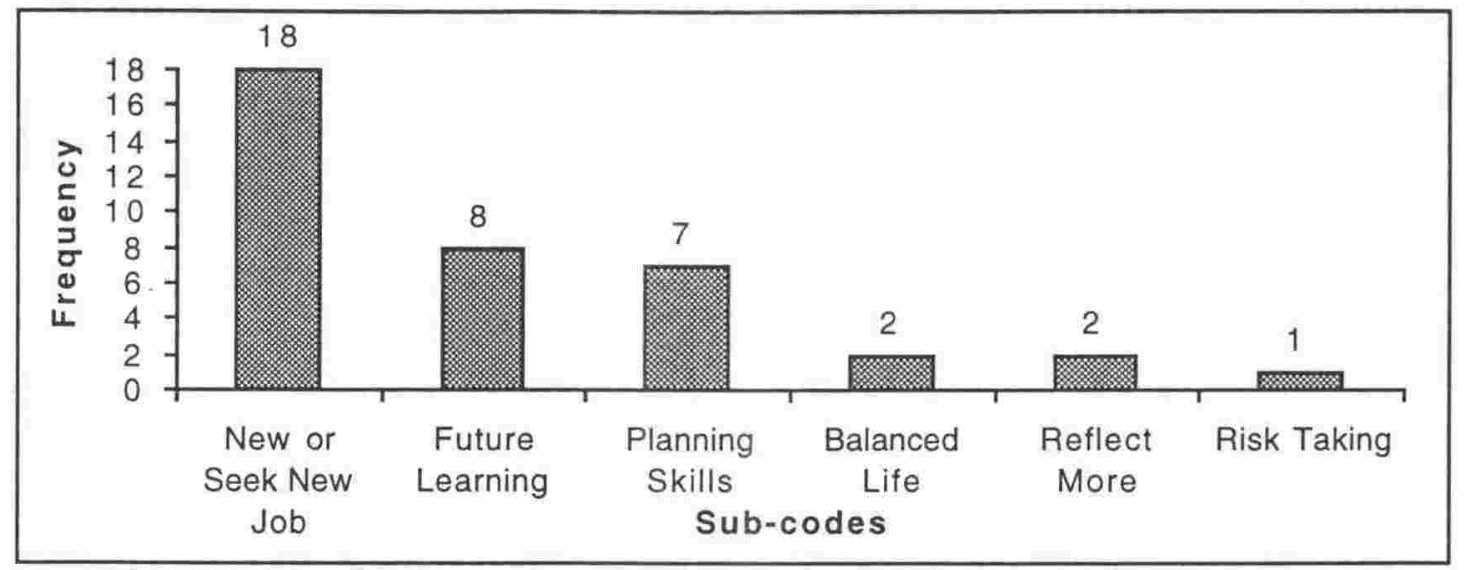

\section{Graph 5.12: Praxis Development at 18 months $(\mathrm{n}=31)$}

Two thirds of the participants indicated that praxis development had taken place. Of these participants, over half either had a new job or were actively seeking a new position. A number of reasons were given as can be seen by the following responses.

It's a struggle being professional when we're being overloaded - claimants are the ones who suffer as they deserve rehab. For me as income earner in my family it is causing me sleepless nights even though I know in my head they still need someone to do the job. After many years with ACC I'm now looking at the situations vacant.

My skills were not recognised which encouraged me to look elsewhere, but I feel the lack of my way of doing things will show up in the branch in the long term.

I've been training other people on ACC rules and regulations, as well as a bit of case management. The planning and interview sessions we did with Susan are good for that with the negotiation side coming as well. Otherwise definitely negotiation skills. I have a lot of discussions with business managers and my ideas don't always match their expectations. I'm also involved in a lot of case conferences which are quite valuable. I come from the ACC side of things, whereas the work site manager only looks at the company perspective - the costs - not the person involved. If we're trying to rehabilitate people or get them back to work we have to work with people. We're trying to be proactive in trying to keep people at work unless they have a severe injury, which involves upskilling them in other areas.

Graph 5.12 also shows that future learning and planning skills were seen as relevant by participants. Some of the comments included:

I had forgotten what it was like to have a passion for learning and it's amazing how many things I have done since the course. I've done what I wanted because it built up my confidence. I always 
think to myself how lucky I was to have had the opportunity of the course and I feel sad for those who don't see it that way. For me it has been the start of a whole new life, which has given me the ability to change both personally and professionally.

The course made me more aware of my weaknesses - so now I'm looking at other courses for further development in these areas.

I'm still very positive about the course because if you plan, set goals and everything and look at what you want out of the course - for me it worked because I knew where I wanted to be two years down the track. Maybe more guidance at the outset for others. I've used that principle of goal setting 22 times this week with my clients.

Planning, trying to look objectively at the situation and weighing up the options, cutting through 'the crap' in terms of seeing things clearly and then following through the path and being able to modify it if appropriate.

At eighteen months after the course the needs assessment process continues to be of importance, as can be seen in Graph 5.13. Twenty-seven of the forty-one participants indicated that the needs assessment was a key component in their practice as case managers.

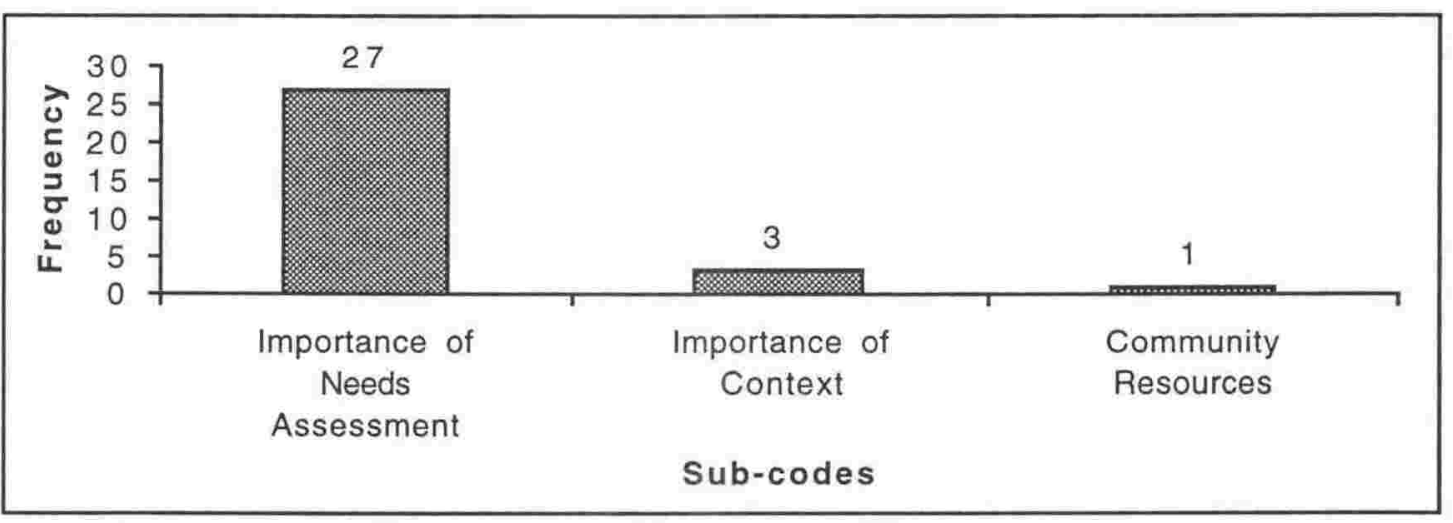

\section{Graph 5.13: Using a Holistic Approach at 18 months (n=27)}

The feedback received from participants included:

I get really good successes with +52 week clients averaging 2 off per month; that all came from skills learned on the course particularly interviewing, planning, listening, negotiation, understanding what working in partnership really meant (not dictating) - this is the main/best tool I've used. This average is more than the office average - it's all about listening to what the client wants, i.e. focussing on their needs. That's made a difference between being successful or not. At 
first I didn't think it would work, thought they'd ask for the sun - but in reality didn't happen. As long as you're open with them from the start it's OK, listen to them, build a rapport, develop mutual trust, i.e. you're not all blow and no go.

Probably more than anything listening and interviewing techniques. Outcomes have been based on focussing on the clients agenda and going with what is most suitable for them. For example, I had a totally unrealistic employer who caused a claimant to suffer emotional problems in addition to their physical injury, because the employer was totally unrealistic. The claimant ended up resigning from their position and has been looking for alternative work. After 12 months nothing has eventuated, but they now may be emotionally ready to look at the pre-injury employer again.

I had a woman with serious injuries who wasn't really compliant with her rehab and there were not a lot of options, but we needed to be realistic given her circumstances. Previously a goal was to get them back to work, now I break things down into steps. People say "thank God you listened at least you heard me". It's about people.

Graph 5.14 illustrates the changes in practice which participants identified as having taken place eighteen months after the course.

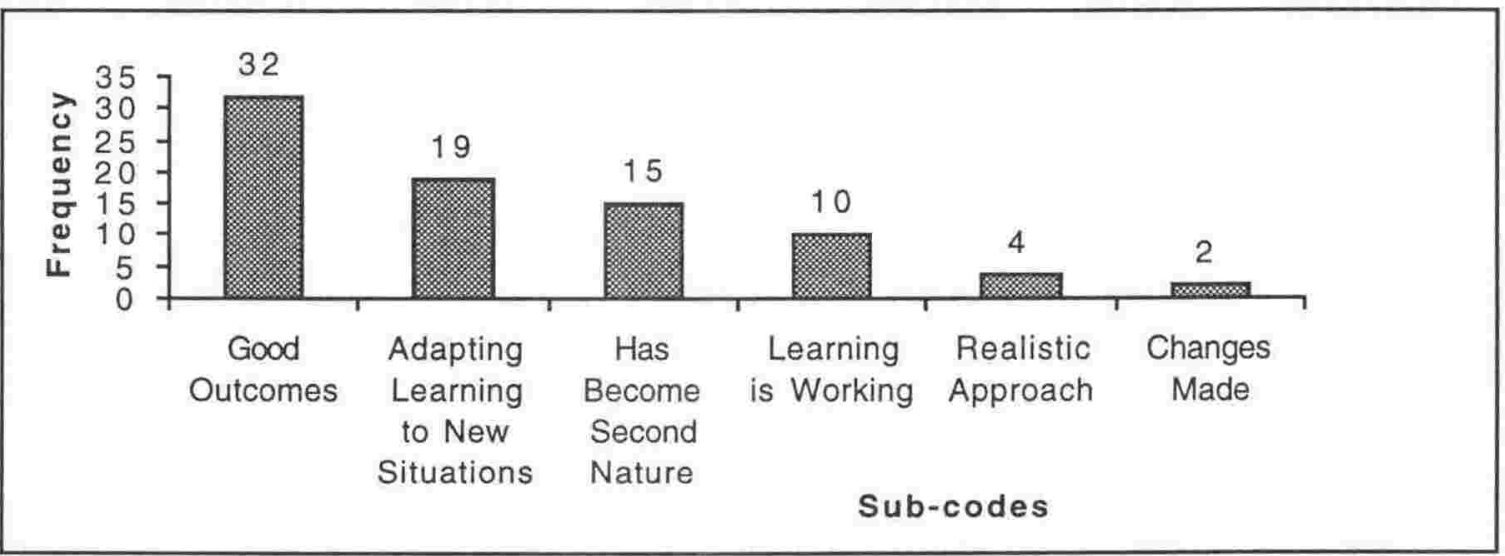

\section{Graph 5.14: Changes in Practice at 18 months $(n=39)$}

Two-thirds of the participants indicated that they were achieving good outcomes as a result of having done the course. Nineteen participants mentioned that they were able to adapt their learning to new situations and for fifteen their new way of working had become second nature. Ten participants stated that they felt the learning from the course was working for them.

There were many good outcomes mentioned by the participants. Here is a selection from the responses received. 
I've got about 55 files at the moment and am pretty autonomous and relaxed at the moment. I mainly work with RARLTC or Work Capacity and have got 40 people back to work since August so I'm nearly at the 2 million dollar savings mark and really pleased about it. Confidence is some of it, but the tool is also good and clever. RARLTC is not reviewable and is negotiated from the outset with a rehabilitation plan. For example, I had a guy the other week who had been on ACC for seven years and cost $\$ 300,000$, once I had outlined the options to him he had a job by the end of the afternoon. My interviewing skills have improved because prior to the course I was really only firefighting with my 300 files. I always remember whoever said, 'if you ask the right question'. The first proper interview I ever did was the one we did for the Case Study. I also had a chap in a rural area who had completed a one year course in horticultural training and so now has the skills to work in a nursery. So I paid for a gym programme with a physio to strengthen his back. He is now off $\mathrm{ACC}$ and the responsibility of the employment service.

I've had at least 20 good outcomes - two key ones are; a 42 year old shearer who was selfemployed and had a lower back and arm injuries and had been on ACC for 12 years and had had lots of retraining into self-employed ventures. So I sent him on a functional capacity assessment which then went on to an orthopaedic surgeon and it turned out that he was more able than he had indicated. He came in with a proposal which was unrealistic so I negotiated with him to go along the vocational rehabilitation line and now he is on a rehabilitation plan to become a self-employed dealer and we managed to cut back the quotes he had come up with by $\$ 2,500$. We offered him two months support plus the set up costs of his business and then he has to go off the scheme. If I'd put him on the Work Capacity Testing scheme he would have been very disgruntled, because he would have ended up with nothing. There was also a 52 year old brick labourer who was into drug dealing and a very shifty character. He wanted to do a deal where we gave him $\$ 10,000$ in cash and he would go off the scheme. He wanted to set up his own bricklaying business and employ locals. He still has it on top. So we told him he would have to get quotes and that we couldn't give him cash. It took 3-4 weeks to get him around and then he agreed to go on a rehabilitation plan which amongst other things stated that if he sold off the things we had financed he would have to pay us out. I got the manager involved just to check out that everything was above board. I mainly used my negotiation skills and tapped into community resources, as well as using other resources and being creative. I still stay within the legislation, but give them options and let them think they are in control.

Most of the clients I'm working with have been on the scheme for more than eight years. In terms of outcomes I've got three people into full-time work without RARLTC or Work Capacity Testing. One guy went on a six month computer course and has since become a tutor. I had a woman on OOS (see Glossary) who is now working for her husband and earning $\$ 33,000$ and only has five hours homehelp a week and will be completely off the scheme in five months. Another woman is 44 and has been on ACC since 1975 as a below the knee amputee with 24 hours of attendant care and 20 hours of homehelp a week. She is now working three jobs for 35 hours a week doing things like care plans and has reduced homehelp to six hours a week and 14 hours of attendant care. Basically I don't worry about things I can't do anything about and just 
focus on my injured workers - I don't call them clients anymore. I have got increased confidence to knock on GPs doors and am specific about what I want before going around the edges. They also know that I won't go away. Some people say that a little bit of knowledge is dangerous, but I now have a thirst for more knowledge. Oh, there's also this young paraplegic who was suicidal at Christmas and now is playing wheelchair rugby and going to Queensland with the team.

A number of the participants have moved into different roles and are not only doing case management. They have found that is was possible to adapt their learning from the course to new situations. This is highlighted by the following remarks:

I'm a floating Case Manager and in a training role so I don't usually do rehab plans. In the training role I have taken the needs assessment and teach that (only have a couple of hours) and have adapted the format for my needs. Prior to that I was using it in initial assessments particularly when a file had been transferred - so that I got to know them well.

I've used my negotiation skills and a lot of interviewing skills over the past six months, and also had to recruit 10 people. If I'd been offered the opportunity to do the job for a few months prior to the course I would have had a fit, but instead I though what could be the worst thing that could happen.

I've been involved in job search and placement over the past few months. In the team leader role it was a facilitation thing in trying to build cohesiveness, listening to everyone and resolving issues as a team particularly since it was a large team at 15 - I learned how to pull them together. In terms of rehabilitation I've taken the holistic approach and looked at diversity within the confines that we have. The most important thing is that claimants are heard. Dealing with complaints has meant using all my people skills. I have been able to promote a holistic approach particularly with OOS people, by looking at the psychological not just medical side. I've had my first case conference involving full Maori protocol which I felt very comfortable with. It was really good; prior to going on the course I would have been a bit nervy, but it was no worries.

A lot has been useful in my training role, and it fits with the course, particularly going back to branches having come from there. Mainly my negotiation and presentation skills have been useful in realising my outcomes.

Fifteen participants observed that their learning had become second nature to them in that they did not think about what they were doing anymore it just happened. Linked to this were the comments that the learning was actually working. The responses included:

Because it was an applied course learnings have become behaviours; the way of learning. 
The assessments are not as thorough as they could be, but are better than before the course. I respect the client and try to put the onus back on them and have also developed a more professional approach. It's really become second nature and has made a big difference in my life, so much so that I've decided to study part-time now.

I use it all the time - the marae stay in particular. I was talking to people from Ngai Tahu today and felt much more comfortable talking to them because I'd had the chance to get all my doubts out of my system and can see the benefits to the whole community, if they do well. I don't care what they've got, it's what they are entitled to. I'm a born optimist and everyone in rehab should be looking at things like that.

Initially I carried on the way I had been before the course. But then I realised that I had learned some good things on the course and after a while I put them into practice and now they have become second nature to me and I pass some of them on to my colleagues.

I love what I'm doing, really enjoy case management - go to see clients and enjoy listening to them and they are responding and the clients think I'm great and that's all come through from the course.

\section{Organisational Factors}

The role the organisation has had on facilitating the transfer of learning back to the work place is shown in Graph 5.15 and Graph 5.16. The main factors associated with organisational support were positive changes within the ACC and support offered by the branch.

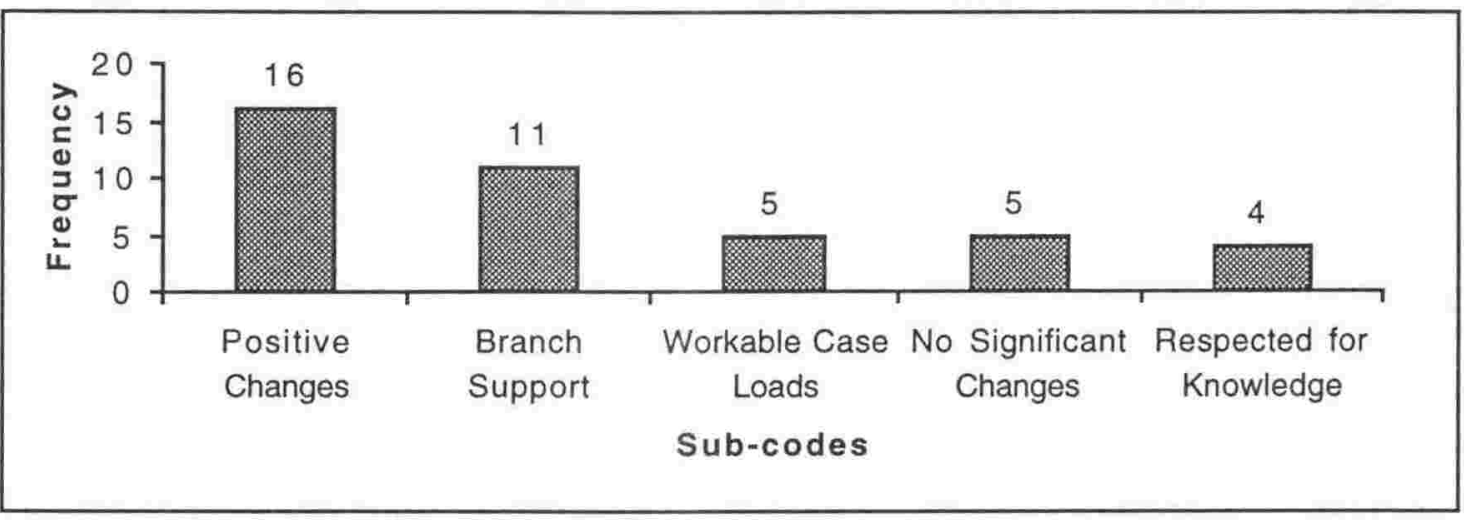

\section{Graph 5.15: Organisational Supports at 18 months $(n=25)$}


A number of positive changes were mentioned by participants. These are exemplified by the following responses:

The change in Homehelp is now legal even though we were doing it anyway. I liked that because it made a difference in managing peoples expectations. Everything that has happened has been for the better over the last 5 years. The emphasis has been on outcomes measurement. There is direction and you know where you are going and are part of it.

Objectives of ACC are becoming clearer. The message to stakeholders is clearer, with service providers and employers being part of the process.

With the Strategic Directions there has been a focus on the more seriously injured, which is starting to fall into place. With the segregation between Case Managers and Claims Managers which has been in place for about six months now the roles are much more clear. With the focus on employers Case Managers dealing the +52 week claimants are losing contact with employers, which is our new focus, which may not be so good and also it is possible that a claimant could have two Case Mangers if they moved from the -52 to the +52 week category.

The attempted change in culture over the last six months. There is now a more customer and business focus and more accountability, which has made it easier for me to do my job. It makes me focus on outcomes, so that people who have case loads are performance measured on their outcomes. People can chose to take my advice or not. My way works which is based on prioritising and following through and not using excuses like not having enough time.

Eleven participants mentioned the branch support they received. They stated:

When I returned from the course there was a very accepting environment in the branch and ACC to change - basically for the first year post course I was able to introduce a number of things, e.g. floating person to cover leave; discretion being legal; reducing case loads by half; support was there acknowledging skills and professionalism.

The change of the manager, office and system. The change in manager made a huge difference to me as I didn't have any confidence in the previous one. This one is very supportive and recognises people's skills and is willing to listen to zany ideas because she can see the cost effectiveness of them. . The new manager is also huge on projects like I'm looking into whether we are ready for self-management as in my PRS review developing leadership skills was identified. I'm also involved in cultural development and service quality. I'm certain I couldn't have done these projects without the course as they require research skills. The new manager also recognises what you do and makes you think rather than tells you what to do. 
A reduction in the size of caseloads, as well as being respected for their knowledge was remarked on by some participants. Five participants noted that they felt the changes within the ACC were not significant in terms of affecting their work. The following comments illustrate these points:

Being able to look outside the legislation and having the time to work with people, as I had a maximum of 50 files. This meant I could meet with people for 2-3 hours and provide a very personal service, as well as getting to know the people. For example, rather than sending them to a career adviser I would take them there and introduce them.

After the course I feel like I'm being treated as a professional and respected for my knowledge; before the course this only applied to people on the management team.

Quite frankly the changes are pretty insignificant because we are already doing what it says and its all coming from the course. Basically they are separating case management from claims management and making sure that people in jobs are right for the job, as well as getting rid of team leaders and PCMs. It won't change our practice.

There were slightly more participants who considered changes within the organisation as detracting rather than supportive eighteen months after the course - twenty-nine compared to twenty-five. Most of these comments related to negative changes in the organisation, followed by the ACC being unsupportive, conflict between their approach and the one wanted by the ACC, as well as concerns about the future of the ACC.

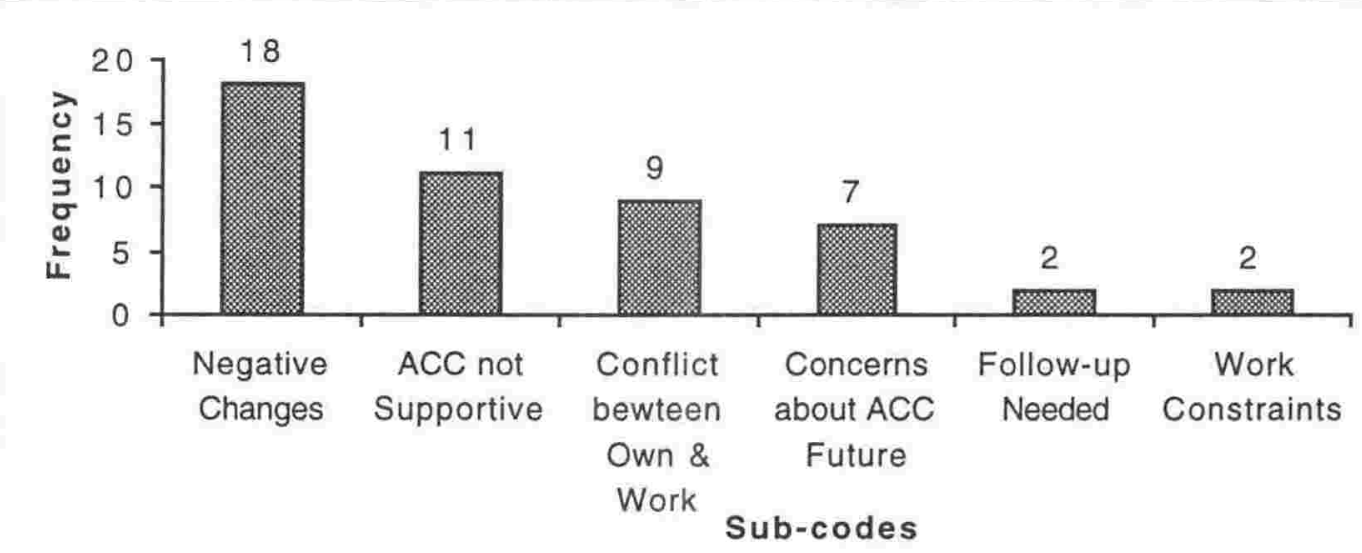

Graph 5.16: Organisational Detractions at 18 months $(n=29)$ 
Graph 5.16 shows that eighteen participants viewed the changes within the ACC as negative. The responses highlighting these concerns include:

All temporary contracts were cancelled and establishments frozen. This branch has the highest workload per staff member in the country. People cannot be productive when they are here evenings and weekends, as families fall apart. It's not healthy. There is more pressure in terms of KPIs and people are working 47 hours/week on average, when they are only paid 37.5 hours/week. Outsiders have commented on the 'busyness' of office. It's been worse over the last 6 months as Bert has been under pressure from the Board, therefore everyone else is under pressure. The KPIs are virtually impossible to achieve and you get penalised if you don't achieve the level and some things are out of peoples control.

KPIs are virtually impossible to achieve as some things are out of your control. The reality is that geographical locations are really important and if you are in a buoyant economy it is easier to get results. People are also off work longer due to the waiting lists with the limited number of specialists we have here. Long travel to see clients is also an issue for us here.

We have gone from a dictatorial/control environment to a self managing one, but there has been no training given on how to do this. We never get time to bed anything in - there is constant change. Nothing is ever given a chance or is evaluated to see whether something worked. A lot of the change is because they didn't evaluate in the first place. It takes time to build rapport and it's really demotivating. It's just like rehab it takes a few months to trust someone. It's like swimming a lap of a $50 \mathrm{~m}$ pool and you never get there either because you have to swim back or the distance has increased to $100 \mathrm{~m}$.

The feeling of not being supported by the ACC is expressed well by two participants.

Really interesting that me and my colleagues were encouraged to go on the course - they were supportive but now ACC is taking away the opportunity to implement these learnings, by the way they are treating their staff - particularly people who have been in the corporation for a long time and have done good work. People are not treated as individuals.

You're not credited for what you've done and I worked hard. Implicit are personal failures not system failures and problems. How can you show what you can do if you're not given the opportunity to case manage?

The conflict between what was learned and what is expected, as well as the concerns about the future of the ACC, can be seen in the following responses: 
Those of us who've been on the course, we put our clients first, we have a different mindset to others in the Corporation.

I've been trying to be holistic but it's not really been supported.

Office has had a change with some people having jobs that the rest of the branch doesn't support as they believe they are not qualified for the positions thus the morale in the office has declined and people are concerned about the future of the office because we need support in case management and rehab. 


\section{DATA COLLECTED TWENTY-FOUR MONTHS POST COURSE}

Below are the Final Codes (in bold) used for the twenty-four-month data with sub-codes identified in each box.

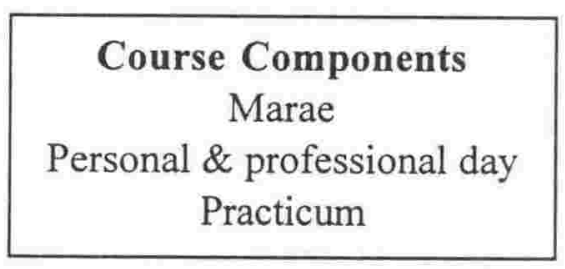

\begin{tabular}{|c|}
\hline Praxis Development \\
Continuing to learn \\
New job \\
Perspective \\
Goal setting \\
Risk taking \\
Communication skills \\
Negotiating skills \\
Helping other staff \\
More creative \\
Reflect more \\
Conflict resolution \\
Planning skills \\
Professionalism \\
\hline
\end{tabular}

Organisational Supports

Branch support

Professional supervision

Organisational Detractions

Lack of Head Office support

Lack of branch support

Change in ACC emphasis

ACC changes unsettling

Less networking

\section{Personal Development}

Confidence

Personal change

Self knowledge \& insight

More assertive

More forthcoming

More proactive

More motivated

Using a Holistic Approach

Importance of clients needs

Working holistically

Conceptual approach

\section{Changes in Practice}

Course pivot point

Better outcomes

Skills to other areas

Become second nature

Consistent approach

Changes yes practice difficult

Interview approach

Course varies in importance 


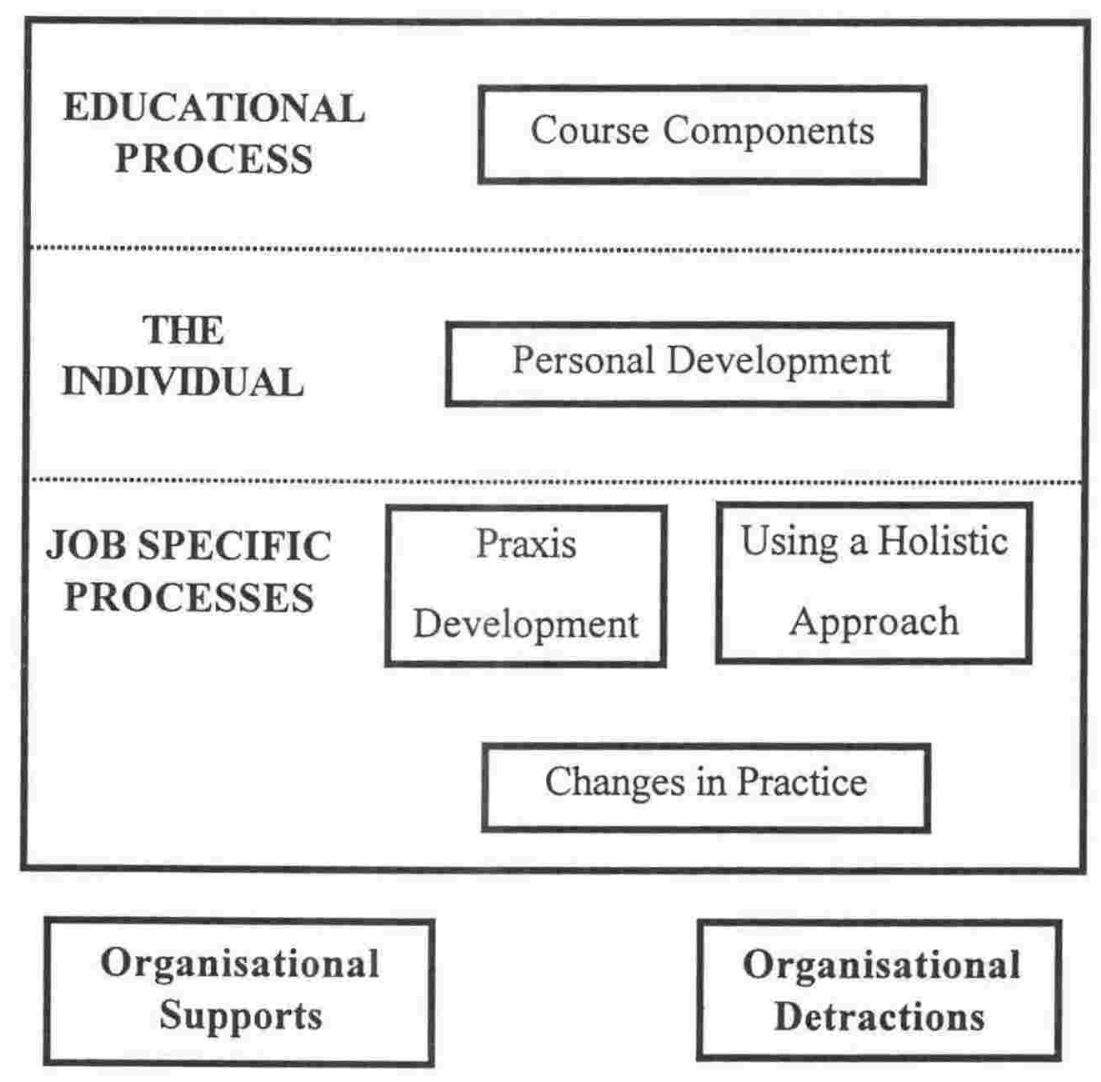

\section{Figure 5.3: Summary of Final Codes at 24 months}

The data for twenty-four months after the course are derived from open-ended interviews where the participants were asked to reflect on the past two years and comment on the relevance and impact of the course on them personally and professionally (see Appendix 7 for question). Figure 5.3 is a summary of the Final Codes which emerged at twenty-four months after the course. The course component code, comprises elements found at the twelve month stage (see Figure 5.1), but not at the eighteen month stage (see Figure 5.2). All the other Final Codes are represented at the twelve and eighteen month time points. The following bar graphs illustrate the sub-codes within the Final Codes, starting with the educational process and finishing with organisational factors.

There were thirty-eight participants at the twenty-four month stage of the research twelve in Cohort 1, thirteen from Cohort 2 and thirteen from Cohort 3. Two participants from cohort $1 \mathrm{did}$ not respond to messages left for them to arrange interview times. Cohort 2 still had the same number of participants as at eighteen months after the course. In Cohort 3 one participant withdrew from the research. At this final stage of data collection 
there were fifteen participants from the Southern Region, twenty-three from the rest of New Zealand; twenty-four women and fourteen men.

\section{Educational Process}

Only twelve participants made reference to course components during the twenty-four month interviews, with the marae visit being mentioned by six participants and the personal and professional day by five. One participant referred back to the practicum, as can be seen in Graph 5.17.

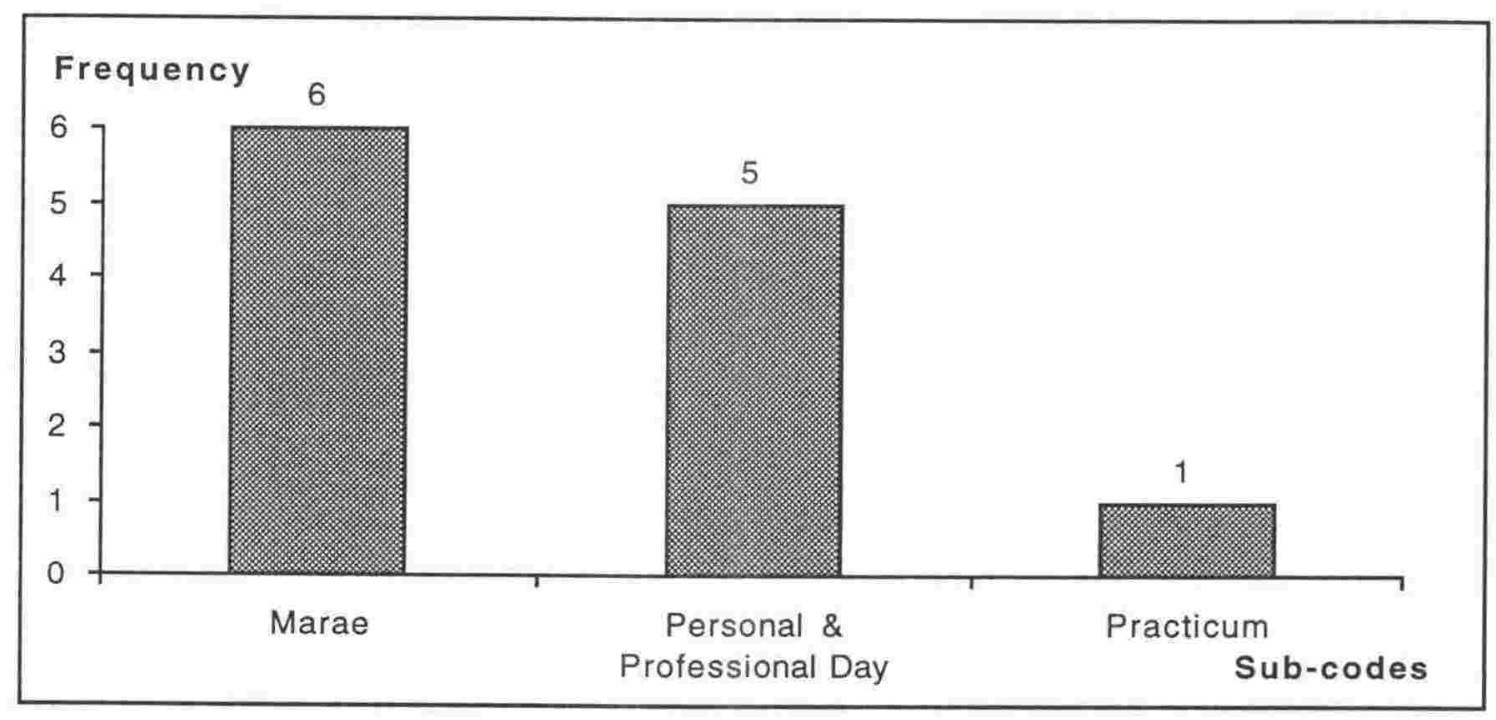

\section{Graph 5.17: Course Components at 24 months $(n=12)$}

Comments about the noho marae included:

I keep harping back to it but that marae visit was the most valuable part of the whole course. Maori people work slightly differently so I designed this training programme for one of my Maori clients in Business and Tourism which is linked in with his tribes needs. Pre-course I didn't fully realise Treaty of Waitangi issues and because of it I now deal better with Maori and don't go straight into a rehab plan, but let them talk about themselves and drop into the conversation about my stay at a marae. I don't judge people realising that everyone is different. I loved that marae visit.

There is also the culture thing when I've often thought about the week on the marae, in that some people might need a support person and someone who can speak their language.

The following are some of the remarks made by participants regarding the personal and professional day. 
I reckon it comes back to Tuesdays which started me thinking about who I am, what my prejudices are and how to start sorting them out

In the beginning I thought Tuesdays were funny days but they were a turning point for me as they have given me the confidence to give things a go and even if it doesn't work out I can say that I tried and try and find an alternative way to do things.

\section{The Individual}

Graph 5.18 shows that thirty-one of the thirty-eight participants mentioned factors associated with their personal development twenty-four months after the course had finished. Twenty-five participants commented that confidence had increased for them as a result of the course, with personal change and self-knowledge and insight being mentioned by eighteen and eight participants respectively.

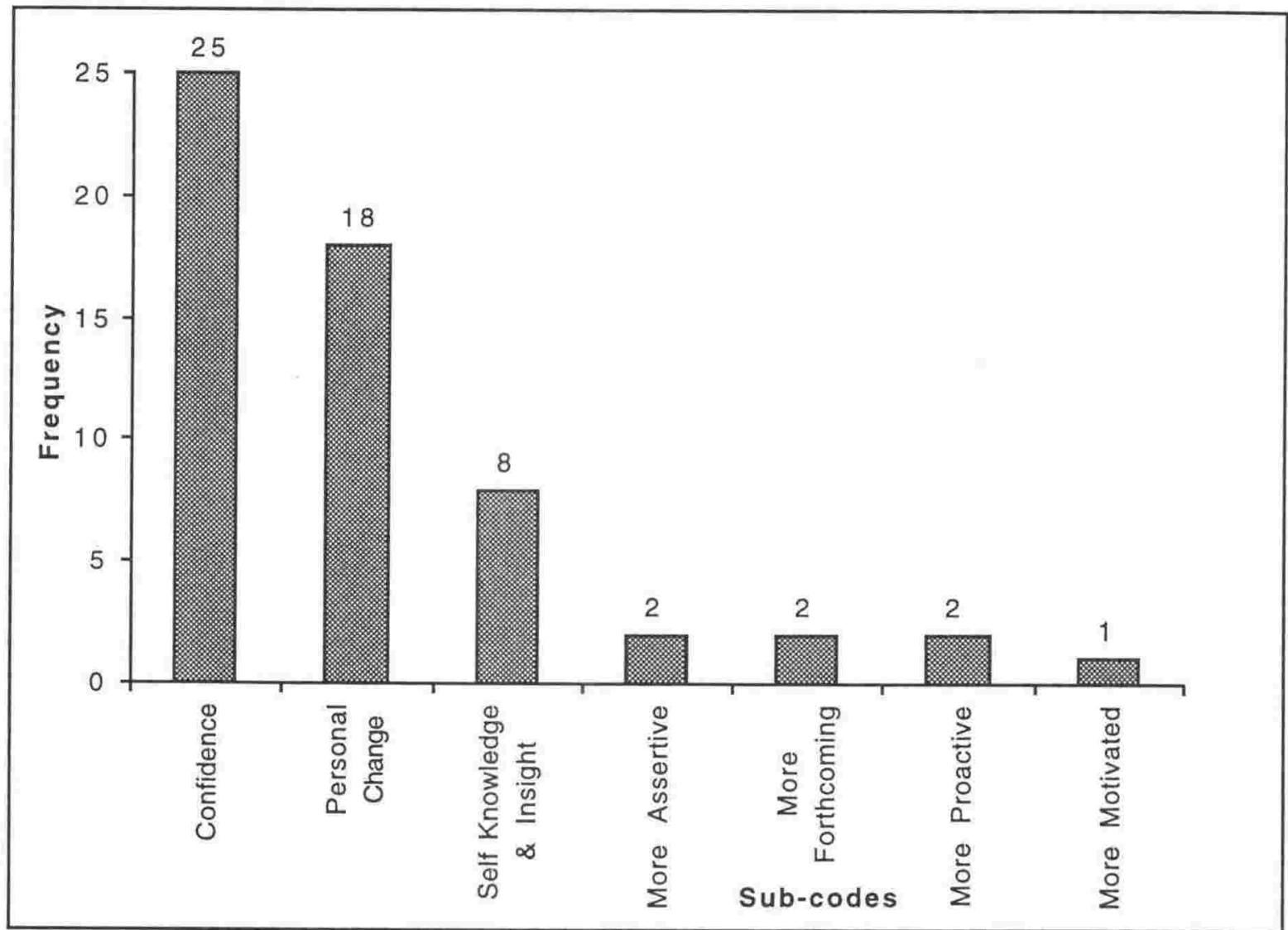

Graph 5.18: Personal Development at 24 months $(n=31)$

The importance of confidence to the participants is highlighted by the following responses.

I think overall the course has given me more confidence. Basically a lot more confidence in the knowledge I have and also in dealing with new information. I can now pick new things up quickly and run with them. 
The Diploma has given me the confidence . . . it's having the background of being more client centred the holistic stuff like the needs assessment. It has provided a grounding of where I'm coming from and I use it all the time.

What the course has done is open my eyes to opportunities and having done the course has increased my confidence that I can go out and do things. It's made me more confident as I'm quite a nervy person.

Observations about personal change included:

It's probably hard to think in how many ways I've changed - I'd changed on my return to the branch, not the branch. I had new ambition to do a lot more things and change ACC's world and to a degree that was successful. But ACC was not ready to change at the time - but it did make a difference.

There has also been personal growth. To be honest with you if I hadn't done the course I wouldn't be where I'm at now. The course gave me the experience and opportunity to reflect on what I was doing, and where I wanted to go.

The course has also had an effect in my personal life as the course gave me the impetus for much personal growth stuff when I got back and I'm doing a follow up in May.

The following statements were made by some of the participants regarding self-knowledge and insight:

The course provided insight and then me doing it enables me to do it more. The course has had quite a big impact in making me realise my own capabilities, what I could do and where I wanted to go.

It's certainly given me a thirst for more there's a little fire burning inside but there are barriers probably in me, as there is a bit of laziness creeping in and if I really wanted to do some more study I would. But now that I know the effort I put in, I would want to do the same and that means putting everything else on hold. Before the course I wouldn't have had the insight to realise I'm the barrier to this. 
Graph 5.19: Praxis Development at 24 months $(\mathrm{n}=28)$

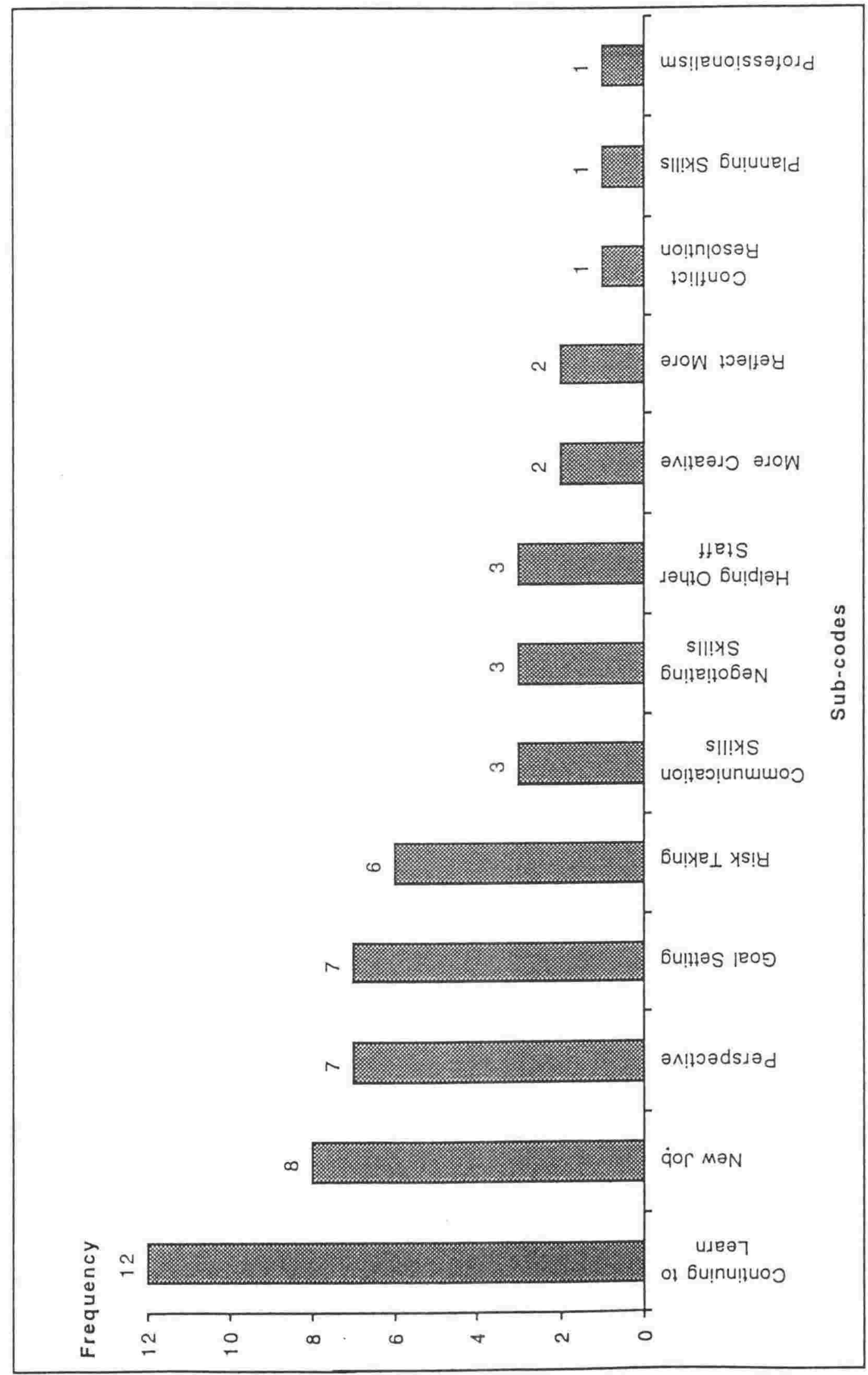




\section{Job Specific Processes}

Graph 5.19 illustrates the components mentioned by participants as having resulted from the course and which are associated with praxis development. The desire to continue learning was commented on by twelve participants, with eight participants having moved into new jobs. The importance of perspective, goal setting and risk taking was stated by seven, seven and six participants respectively. The following responses highlight these points.

It's had a great deal of importance to my work because it has encouraged me to learn more, increase my knowledge and look at everything rather than jumping in - doing research.

The course also gave me an increased desire to continue learning and to try new approaches. It has made me search for new and better ideas, it has opened up my mind much more.

I still do lots of reading and order in articles from Head Office - I now have 6 folders full. Precourse I wasn't even interested. Now I like to get something new out of every day and if I've learned something I can go to bed feeling good. I feel very disappointed when other people are not interested. It is interesting to read about ideas from overseas and decide what might be useful for me.

Some of the comments by the eight participants who have found new jobs included:

Originally I moved jobs to give my expertise as a Case Manager having learned what I learned. Case Managers weren't able to do their jobs because of the lack of support and the process - the structure wasn't there. I wanted to make a change and enable Case Managers to do their jobs. Two years down the track I feel I can say I've done this.

A lot of the course content is not so relevant now because I'm in a new role. But a lot of the things are applicable to day-to-day living and I've used a lot of the things here too. An awareness that other people have needs and things they want to say and even if you are ten steps ahead of them, that you need to listen to them because they are out there on the coalface - you need to listen to them.

The following observations are from participants who talked about perspective, goal setting and risk taking.

It's made me better at my job and made me feel better about my job because I don't look at things in isolation you have to look at the bigger picture as it gets a better result for the client and yourself. Money-wise for the organisation and the best result for the client. It's about not seeing 
things just from one perspective. For example, I bought a car for someone who wasn't off work to keep them at work as a Real Estate Agent as they couldn't drive a manual anymore. So I spent $\$ 10,000$ on an automatic as opposed to about $\$ 20,000$ per year for maybe ten years. I look for solutions and make them fit into the legislation.

Professionally the course had a great impact, probably most in my dealings with clients in that it gave me a broader perspective on things, which was more than just going out to see people. It enabled me to plan better and look at the bigger picture

It was really beneficial to have gone through the course, as I've done more goal setting and striving to achieve them.

I'm a cruiser, but after the course I realised that I can take control of what I'm doing and where I'm going, and that it doesn't necessarily come on a plate, but that I have to work for it. Where I'm now wasn't in the plan - but it will enable me to upskill further and provide new opportunities. I'm not actually a goal setter - but straight after the course I started doing this.

It was the Diploma which was the catalyst for me being here, if not I'd still be entrenched in branch life and probably wouldn't be there anymore. It was a wake-up call. I had a lot of skills dormant so needed to take some risks and going on the course was a risk with my family life and it was a risk coming here.

Twenty-six of the thirty-eight participants mentioned factors associated with using a holistic approach to case management twenty-four months after the course, as is demonstrated in Graph 5.20. Of these, twenty-two talked about the importance of clients needs and eleven used the term working holistically with claimants. Four participants regarded this as a conceptual approach which they were able to use in their work as case managers.

Responses concerning the importance of clients needs included:

The course still has a huge relevance to what I'm doing now. . The needs assessment in terms of asking the questions, starting to plan and focus on where you're heading is equally applicable to clients, colleagues and employers. It's more specific, you plan more and get more answers. I'd say this has had the most durable effect on me. It means I can identify the main problems and deal with them.

I'm also involved with career planning in terms of helping people plan for independence and work through barriers. For example, I had this man who had been on ACC for 5 years and was really 
negative. We looked at what 12 months of weekly compensation would come to and gave him the money to help him establish a business. There was also this other man who had a dominant hand injury and couldn't read and write. We paid for a shade house and a year worth of stock as well as four months of weekly compensation to get him started in his own business. If neither of these work out we will use Work Capacity Testing. I look at each case individually. The first example was a man who is close to retirement so making a living over the long term was not as vital as the other man who was much younger and has most of his working life ahead of him.

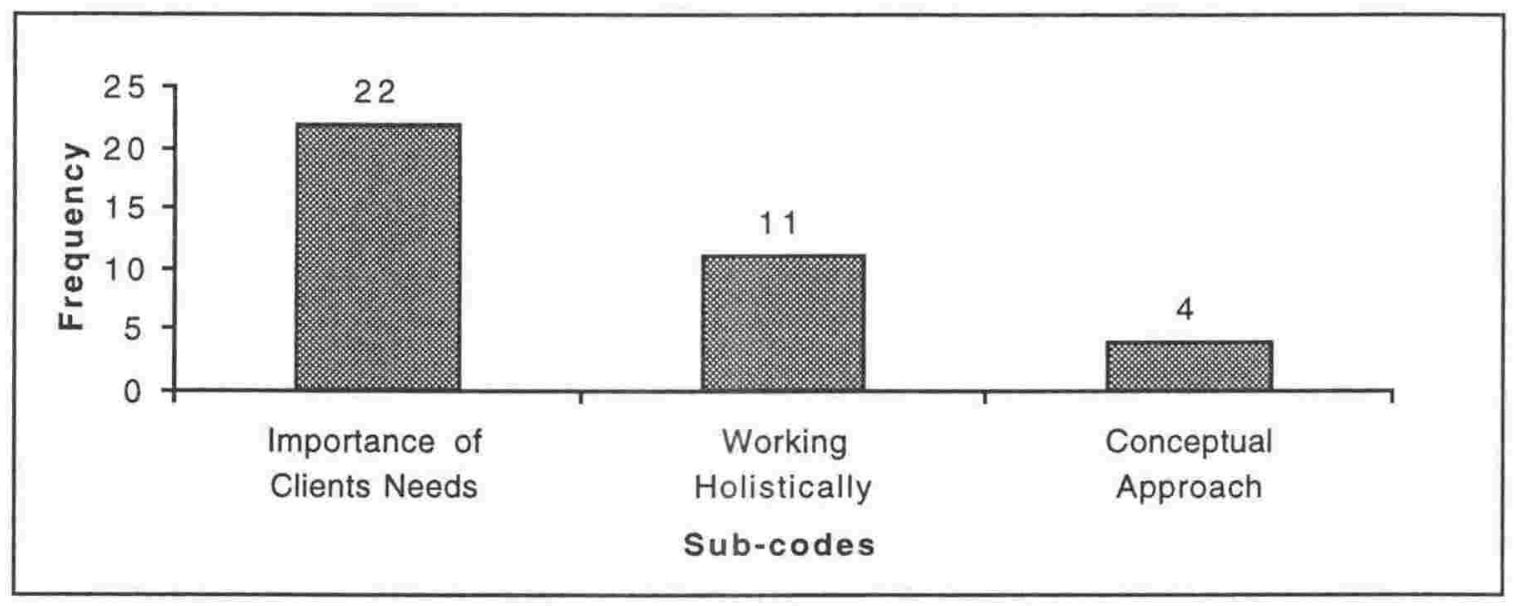

\section{Graph 5.20: Using a Holistic Approach at 24 months (n=26)}

The comments by participants on working holistically and seeing it as a conceptual approach are exemplified by the following:

I still apply the principles we were taught - what interventions, rehab and psychological issues the holistic approach is still there. For example, whether counselling is needed and for what.

I'm still working holistically because I find it works.

The main thing from the course has been the overall conceptual approach particularly negotiation skills, what end outcome you want to have, being more aware of what you say or do and finding ways to work around problems. 
Graph 5.21: Changes in Practice at 24 months $(n=35)$

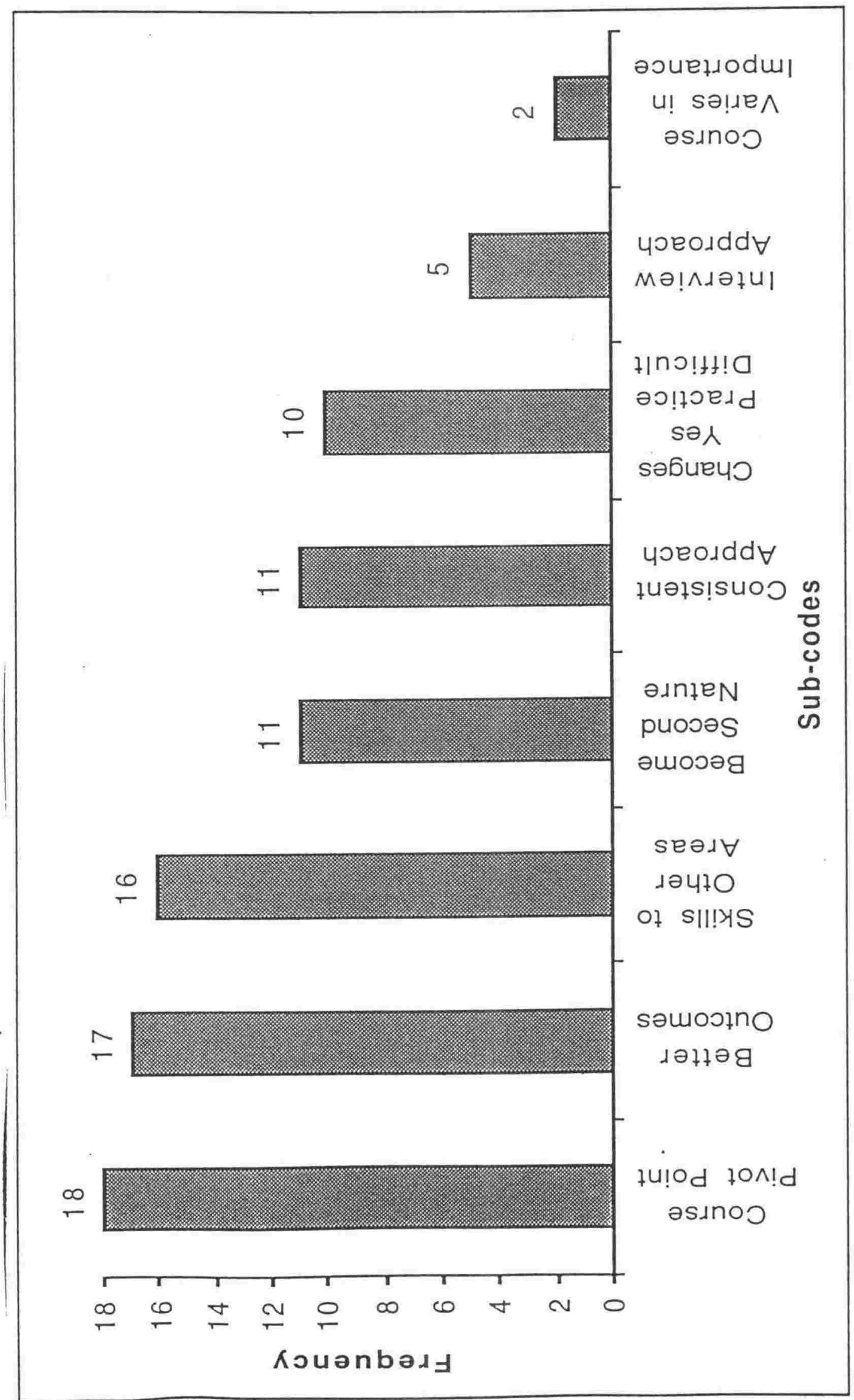


Graph 5.21 illustrates the components making up changes in practice, with thirty-five of the thirty-eight participants having observed a change in their practice. Key factors were the course being seen as a pivot point by eighteen participants, achieving better outcomes was mentioned by seventeen participants, as well as being able to apply skills learned to other areas, which was commented on by sixteen participants. The following responses are representative of these sub-codes.

The course has had a huge impact on the way I work and I keep saying this to everyone, not just you for your research.

The course has changed my whole way of thinking with respect to rehab - what I do now just happens. It was a bloody good course and I'd do it again.

I really think the course was a pivot in making a change in terms of looking from the outside in. It's been a permanent force to utilise in my personal and professional life.

I feel I'm getting better at outcomes because the clients are buying into it with input right from the start the client see the benefits and that leads to better outcomes. There was a woman who had severe burns but all she wanted was to have her own place which wasn't possible until she had completed here rehab and was able to complete certain tasks herself. So it was about her being able to understand the situation and working through the issues.

The long term claimants are shifting as what I'm doing is working, without the course I wouldn't be doing as well.

It was nice to receive an education in rehabilitation, even though it is a different approach to that of the manager. Because I get outcomes it's OK for me to do things my way. There are certain things we disagree on, mainly in terms of me looking at the long term whereas the branch tends to look only at the short term. For me cost-effectiveness is to look long-term with a win/win situation for all.

With respect to skills applying to other areas, participants' comments included:

Even being out of case management the course is still useful in terms of interviewing, communication and time management skills - the principles still apply and I was able to adapt these concepts to the new context. It was a combination of the way the course was done and me being able to apply it. It doesn't matter what you learn, if you can't apply it yourself it won't work. 
The course becomes the whole basis of your working life - it's just there - it influences everything you do, and you draw on that knowledge because it's still there. For example, when putting together an evaluation document I referred to the research stuff. I quite often pull out information that I've got sitting there. I even sometimes read my journal because it was an exciting and different time of learning and making new friends and the fun we had. It was a "time out of time". Because of the way we did it - it affects every part of your life - personally and professionally.

Eleven participants indicated that what they did had become second nature to them and using a consistent approach was also mentioned by eleven participants. These are some of their observations.

I've put into practice across the board what I learned on the course. All the skills that we covered involved all of those like interviewing skills and prioritising. They are now part of me and who I am - it comes naturally I don't have to think about it.

Things like conflict resolution and needs assessment have now become second nature. If I had to sit down and break down what I do it that has come form the course it would be hard to do.

Before the course I floundered a lot and after the course I had a more consistent method. I don't get a lot of complaints as many Case Managers get and I think that's because I'm up-front with the claimants from the outset. I explain where they stand in relation to the Act, so that they can see how I'm tied and explain that it is the law, and that we have to work with it the best we can. I use lots of open-ended questions.

Pre-course I was a good worker but after the course I had a co-ordinated approach to rehabilitation even my Branch Manager commented on this.

Although a large number of the participants felt that a change in their practice had taken place, ten of the participants remarked that it was not always easy to implement these. The following examples highlight this.

The course definitely did make a change, but the ability to put it into practice is difficult, so you go into survival mode and most of the work ends up being file administration, but what really counts is the rehabilitation as that gets the outcomes. In a sense I'm only doing half the Case Managers job, and not the other half. We're basically short staffed, so we have to do our own administration. 
I think I'm a better person for the course and I would like to be able to work holistically. The manager at the moment doesn't let me work like that. They want everyone off the scheme, there is no incentive to care about people anymore. Social rehab is not really acknowledged only those receiving weekly compensation are focused on. Money is the key issue and it is not really the scheme it was set up to be anymore.

\section{Organisational Factors}

At twenty-four months after the course the support received from the organisation, in terms of facilitating the transfer of learning back to the workplace, was confined to what was offered in the branch, as can be seen in 5.22 .

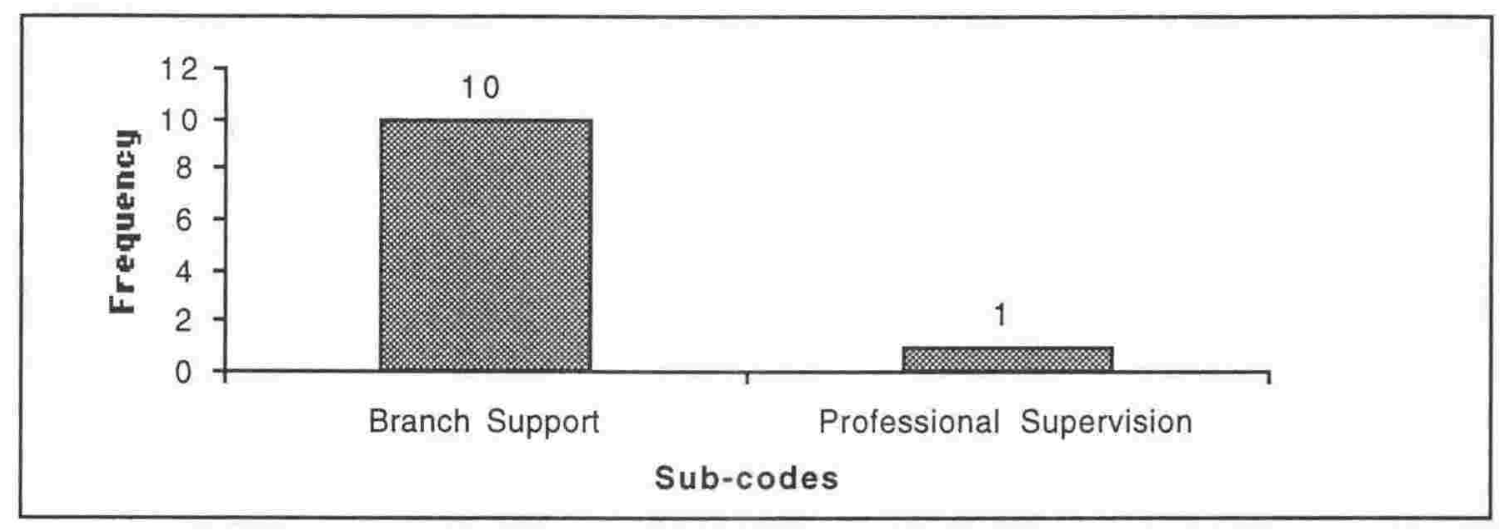

\section{Graph 5.22: Organisational Supports at 24 months $(n=11)$}

The responses included:

If I introduce ideas here that seem far fetched I am actually listened to. This has been the case since we've had our new branch manager - it's been great. We have a whole host of branch initiated projects going, some of which I took to our branch manager something I never would have done pre course.

Head Office doesn't care about us, but the people in our branch do. I can walk out at $5 \mathrm{pm}$ if I want to and in the branch they know that I've done my work so no one asks questions - we're cared for in our branch.

Graph 5.23 demonstrates that over twice as many participants (twenty-five) mentioned factors within the organisation which they considered unhelpful, compared with the eleven participants commenting on the support received. 


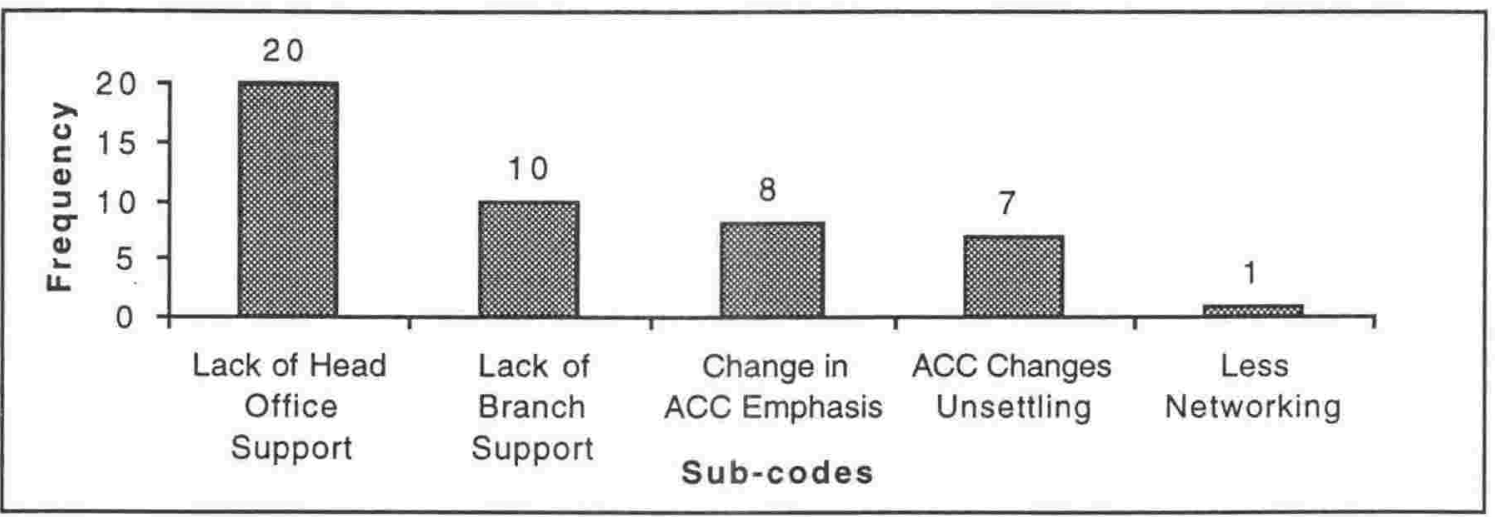

Graph 5.23: Organisational Detractions at 24 months $(n=25)$

The lack of Head Office support was identified as the key factor with statements including:

ACC essentially encourages people to leave rather than try and keep the knowledge in the organisation. It's strange because people could leave tomorrow and it doesn't seem to matter. There is a pay difference of about 20 grand between us and the private sector but somehow loyalty seems to come into it.

I still don't believe that ACC looks after its staff or values them in terms of seeing them as their most important asset - I'm speaking here from personal experience. If they can get staff onside and work as a team and get rid of the bureaucratic stuff like they have now said that flexitime is the exception not the norm, so you have to work 8.30 to 5.00 which is bullshit as it doesn't work.

There has been absolutely no input from the organisation and it seems that the Auckland course has had more value placed on it, because it is a qualification in case management not rehabilitation.

Ten participants mentioned that support in the branch was insufficient and eight participants were concerned with the change in the ACC's emphasis. This is exemplified by the following observations:

I'm getting the outcomes, but I don't feel that supported as there is no team work anymore. There is nobody to turn to anymore because people are too busy with their own stuff.

But there is a new huge change in the corporation with claimants no longer being the main focus, but the employer. This is something that it is hard for me to come to grips with. They seem to think that Case Managers aren't getting anywhere because we are doing too much for the claimants. Which isn't really true as all we do is facilitate. They feel that employers needs to take more responsibility with respect to the claimants. 
Seven participants regarded the changes within the ACC as unsettling, with responses including:

The changes within ACC are what bothers me. We're going around in circles changing names, but don't really address the workloads of staff. ACC has very hardworking people and the corporation doesn't really care - it's a faceless enterprise.

There have been too many changes in ACC and it's very unsettling and the legislation isn't tight enough.

\section{Chapter Summary}

This chapter has given a voice to the research participants and reflects the issues they regarded as important to them when considering their experiences of the VUW Diploma in Rehabilitation Studies and how it has subsequently affected their practice as Case Managers. The data suggests that the educational process has been important in developing the participants as people. Furthermore, there appears to be an indication that a change in personal practice has occurred, which has been associated with praxis development and the use of a holistic approach when working with clients. The role of the ACC in this process has also been elucidated. In the next chapter there is a move away from the purely descriptive data to considering in more detail, the implications of the data in terms of a managerially focussed model. It is here that the relationships between the data are developed and a transfer of learning model emerges from the data. 


\section{CHAPTER 6 MANAGING THE ANALYSIS OF THE FINDINGS: A DISCUSSION}

In this chapter the purpose for the research, the research aims and objectives will be restated, and an overview of the significant findings provided. These findings will then be considered in light of the existing research, before considering the relationships between the Final Codes using the HyperRESEARCH 1.56 hypothesis testing function. The emergent transfer of learning model will then be described and two other theoretical models presented. Findings, which are anomalous will also be examined, followed by a discussion of the limitations associated with this research.

\section{REASONS FOR THIS RESEARCH}

The specific aims of the research were to:

- identify the factors which facilitate the transfer of learning from an adult learning environment, using action learning methods of instruction, to the work place; and to

- develop a model which optimises the transfer of learning from the classroom to the workplace for adult learners.

The objectives of this research were to:

- consider the changes engendered in the individual and the organisation in the long term, as a result of having completed the VUW Diploma in Rehabilitation Studies;

- establish the role of partnerships between course providers (Victoria University) and the sponsoring organisation $(\mathrm{ACC})$;

- examine the methodological issues involved in measuring the transfer of learning from theory to practice; and to

- develop a transfer of learning model from the data collected.

The research questions included:

- What course design elements contribute to the transfer of learning for adult learners on an action learning course?

- What non-work characteristics facilitate the transfer of learning? 
- What organisational factors facilitate the transfer of learning?

- What elements of partnership are crucial for the transfer of learning to take place?

\section{OVERVIEW OF THE SIGNIFICANT FINDINGS}

The key findings of the research are highlighted below, as these relate to the research questions. These are then considered in light of the research literature discussed in Chapter 3.

\section{Course Design Elements}

Some elements of the course design had a more lasting impact than others. The mix of personal and professional development, as well as combining off and on-the-job components, were seen as important twelve months after the course. At the same time, participants also indicated that the course set-up was valued by them, particularly in terms of having time for reflection during the study week. The experiential components of the course, in particular the noho marae, personal and professional development days and the practicum, were referred to positively by participants up to twenty-four months after the course. This might suggest that the processes adopted in the course design - action and experiential learning - coupled with an androgogical approach in professional and vocational education, are more important than the content per se.

\section{Non-Work Characteristics}

The overall impact of the course appears to have been considerable with respect to personal development, resulting from the course design which was both experiential and combined professional with personal development. The findings would suggest that personal development is the key to enabling professional development to take place in human service organisations. Once people are centred in themselves they are much more able to provide a quality service to their clients, as they will feel less personally threatened by situations encountered in the course of their work. 
The key component of personal development for the participants was reported to be an increase in confidence. This was clearly identified at all three time periods. All, but six participants mentioned an increase in confidence, twelve months after the course. Only half of the participants referred to an increase in confidence eighteen months after the course. By twenty-four months reports of increased confidence had risen again to nearly twothirds of the participants.

Other personal development issues that remained prominent over all three time periods were a change in attitude and an increase in self-knowledge and insight. The responses suggest that changes in attitude became stronger as time went on. Twelve months after the course only a third of the participants, who commented on personal development, reported on how their attitudes had changed. By twenty-four months after the course, over half of the participants referred to attitudinal changes. Interestingly, the reverse appears to be true for self-knowledge and insight. Nearly half the respondents mentioned self-knowledge twelve months after the course but this dropped to a third by twenty-four months. This may be explained by participants not specifically mentioning self-knowledge and insight at twenty-four months, but incorporating this personal development issue when talking about personal changes in attitude. It also appears that the educational process adopted was beneficial to a heterogeneous group of people in terms of gender, age, culture and educational background.

\section{Job Specific Processes}

The fact that participants commented on changes in their practice at all three stages of the data collection, is an indication that the transfer of learning has been successful. Better outcomes were mentioned at all stages, with the ability to apply their learning to other areas and their new way of working having become second nature at eighteen and twentyfour months after the course. Twelve months after the course, all but eight participants reported that they had changed their personal practice with respect to case management. By twenty-four months the course itself was identified by nearly half of the participants as having had a pivotal influence on their work practices. 
A number of factors appear to have been important in achieving this. Understanding people's needs and carrying out thorough needs assessments came through strongly over all three time periods. Linked to this was using an holistic approach, which was specifically highlighted at the twelve and twenty-four month stages. Gaining an appreciation for the specific context of each claimant was also seen as important at twelve and eighteen months. Three themes carried through from twelve months to twenty-four months after the course with respect to praxis development. These were: (a) the propensity to take more risks; (b) the desire to continue learning; and (c) a change in role or new job. The relative importance of these changed, with risk taking being most important at twelve months, having or seeking a new job at eighteen months and the desire for continued learning being most important twenty-four months after the course.

\section{Organisational Factors}

The findings suggest that the organisation had only a limited influence on the transfer of learning in that participants appear to have transferred their learning despite a lack of support, particularly at the eighteen and twenty-four month intervals. Given this, it could be suggested that the transfer might have been even more successful, had support been more thoughtfully and strategically provided throughout the organisation.

The ACC was seen as being more supportive than detracting, twelve months after the course. Thereafter, the ACC was regarded as being more detracting than supportive when it came to fostering the participants' transfer of learning. Twenty-four months after the course over twice as many participants commented on factors that detracted from their transfer of learning. Branch organisation was highlighted as having played the primary supportive role within the organisation at all three intervals, although that too decreased. The main detractions appeared to have been associated with Head Office. However, the lack of Branch support was referred to at both the twelve-month and twenty-four month interviews and focus groups. Concern with organisational changes within the ACC also came through clearly during the last two time intervals. 
These findings raise questions concerning organisations, and in particular government organisations, which have a Head Office located in one place with Branch Offices geographically spread out around the country delivering services. These issues are particularly associated with communication between Head Office and Branch Offices, the nature of decision making on matters affecting the organisation as a whole, such as staff development, and the ability of Head Office decision-makers to canvas support for projects from throughout the organisation.

\section{Elements of Partnership}

The participants' responses would suggest that the partnership between the target organisation and the educational institution could have been improved, particularly for the students in Cohort 1 . This situation improved for subsequent cohorts, but a less rushed and pressurised timetable for the launching of such a major initiative would have been beneficial. Constant changes within the ACC made it difficult to maintain continuity with key people in that organisation, both at Head Office and in the Branches. This may indicate how working with large government organisations in the 1990's brought its own challenges, many of which may be quite different in private organisations.

Overall, it is interesting to note the longevity of the apparent transfer of learning. Whilst all the personal and professional development mentioned by participants cannot necessarily be attributed to the course, the findings would suggest that the course played a significant part in that development, even up to two years after the course. Some of this longevity of impact may be attributable to the structural components of the VUW Diploma. Of particular importance was the Practicum, which included the Learning Contract, the Practice Case Study and the Research project. All of these required the endorsement of the student, the Branch and the University. Whilst the level of support varied amongst Branches, the Practicum as a whole demanded an element of partnership between the ACC and the University. The actual length of the course may have also had an impact, as the VUW Diploma was much longer than most training courses which organisations send their staff on. 
These findings are now examined in light of the research literature discussed in Chapter 3.

\section{SERVICE AND CASE MANAGEMENT}

Grönroos (1990) considered that there should be three outcomes of service training programmes. These included gaining a holistic view of the organisation, acquiring task related skills, as well as developing communication and service skills. The findings would suggest that VUW Diploma in Rehabilitation Studies graduates were not only able to attain all these outcomes, but to go beyond these to develop personal traits such as increased selfconfidence, increased self-awareness and insight. It can be argued that such personal growth has enabled the participants to deal more effectively with the 'moments of truth' (Normann, 1984), which they encounter daily in the course of their practice as Case Managers. The reason for this is that these Case Managers are more confident in both their personal and professional capacities to deliver the service required at the time. The factors that impact on employees as reported in Chapter 3, Figure 3.1, are still relevant. However, these move into the background, once participants were clearer about why they were doing their job and what was required of them. The participants have been much more able to meet the customer's needs, as seen in the emphasis given to the needs assessment. This reinforces Schneider and Bowen's (1995) comments regarding the customer's need for security, esteem and justice. The importance of providing consistency within this context cannot be overstated, particularly in an organisation such as the ACC, which delivers services across a whole country. The Case Manager's task, in essence, is to provide a totally customised service, based on the needs of each individual. The importance of this was recognised by participants as highlighted in the following examples:

The needs assessment which includes the whole process like starting from where you actually meet the person, setting the scene and probing them for information.

Thinking more openly about people's rehab. Using different ideas rather than having a generic IRP and not putting people in boxes.

When I evaluate IRPs I look at things from a broader angle and try and work out why people are not on track. In the past it was more like I had to do an IRP and it was then left. Now I have more time and a better understanding and the IRP format has changed as well. 
I know what I'm here to do and can explain that clearly to my clients and manager. For example I was able to arrive at a point where a person had been on ACC for ages with chronic pain and in the end they ended up with nothing, but they felt that they had been heard and involved in the process. My approach to case management is that I can't be bothered playing games. I tell them what we can do and what we expect from them and I take each case on its individual merits.

In terms of rehabilitation I've taken the holistic approach and looked at the diversity within the confines that we have to work in. The most important thing is that claimants are heard. . . I have been able to promote a holistic approach particularly with OOS people, by looking at the psychological not just the medical side.

These responses also support the work of Issel (1997), Koch \& Rumrill Jr. (1998), Phillips, V. (1996) and Rogers (1995), who emphasised the need for Case Managers to have highly developed interpersonal skills, as well as being able to meet the needs of their clients, by using appropriate processes. Issel's (1997) research suggested that being a Case Manager is a diverse job, requiring a flexible approach, with a realistic number of cases and the ability to get out of the office and make home visits.

\section{Internal Service Management}

The relationship between work environment and employee performance has been the focus of much research in the service management area (Bailey, Fletcher \& Kolb, 1997; Bowen \& Lawler, 1995; Castellese, 1995; Hallowell, Schlessinger \& Zornitsky, 1996; Heskett, Sasser \& Schlessinger, 1997; Howcroft, 1993; Larkin \& Larkin, 1996; Macdonald, 1995; Mattsson, 1994; Redman \& Mathews, 1998; Reynoso \& Moores, 1995; Schneider, 1994; Schneider \& Bowen, 1995; Stauss, 1995; Tapsell, 1998; Varey, 1995), as well as case management (Aliotta, 1996; Stiller \& Brown, 1996). The issues which are particularly pertinent in this context are the link between internal and external service provision (Aliotta, 1996; Schneider, 1994; Schneider \& Bowen, 1995; Stiller \& Brown, 1996; Tapsell, 1998), employee empowerment (Bowen \& Lawler, 1995) and the importance of congruence between personal and organisational goals (Bailyn et al., 1997). The question of role conflict for service workers discussed by (Weatherly \& Tansik, 1993) also appears to be relevant for ACC Case Managers. Not only do they have to balance the dual service provision of rehabilitation and insurance, but according to Collinson \& Brook (1997), there 
are also conflicts between the realities of case management in the ACC and the holistic approach learned on the VUW Diploma.

The ACC's expectations of Case Managers in terms of assessing client needs, developing individual programmes and organising resources also appear to have been met over the long term. Similarly, many of the competencies seen as desirable attributes of Case Managers (ACC, 1996b), were mentioned by the participants. These included the ability to

- problem solve,

- facilitate the case management process,

- negotiate,

- communicate,

- think analytically,

- make decisions and

- challenge the status quo.

However, whilst desired by the ACC, the application of the last competency, was not always easily accepted by the organisation as evidenced in the following statements:

It's not been easy trying to do 'not normal things' in the sense of ACC thinking. For example, I had a woman who I wanted to put through an expensive training course and for that she would go off ACC, which is what she wanted. Both parties were benefiting from it, but I really had to fight for it.

Basically there are barriers in place detracting us from achieving outcomes. They paid for us to be highly motivated individuals and now they are trying to stop that. I'm generally pissed off.

Statements like these, illustrate the benefit of involving the whole organisation in issues of service delivery (Grönroos, 1994; Gummesson, 1994; Hallowell et al., 1996; Redman \& Mathews, 1998; Schneider, 1994; Schneider \& Bowen, 1995). The role of supervisors in this process is crucial both in terms of involving them at the outset (Larkin \& Larkin, 1996), in this case the PCMs, as well as providing relevant training which supports the training employees are completing (Diwan et al., 1996), in this case the Case Managers. 
Unfortunately, the Individual Development Plans instituted by ACC to assess Case Managers competencies, as outlined above, were abandoned in early 1998. As one participant mentioned:

At times there is a lack of direction at this Branch and a lack of rewards. We're not really acknowledged and nobody gives a stuff. There are no more Individual Development Plans. I get the feeling that the corporation is changing a lot. It is getting much harder in terms of getting people off and is giving very different messages than before.

This comment highlights the value of linking rewards to employee empowerment (Bowen \& Lawler, 1995) and seeking to integrate personal and organisational goals as advocated by Bailyn et al. (1997).

Overall, the findings suggest that service delivery through case management within the ACC has improved. The findings also suggest that the transfer of learning has had a lasting effect, to the extent that the new way of working has become second nature to a number of the participants. The following comments highlight this:

What you do on the course becomes part of your everyday life and is still very valuable.

The course is still useful, as I often think of it when I do things and realise that I did them like that because of the course.

Things like conflict resolution and needs assessment have now become second nature. If I had to sit down and break down what I do that has come from the course it would be hard to do.

The course still has a huge relevance to what I'm doing now. Listening skills and looking at rehab plans. Things come to me everyday and I don't even think about it. Things like stress management, negotiation skills, time management and other little things I do that remind me of the course. Having done the course affects my own work practice. It's sometimes hard to filter out what you're using and what you're not. The course has changed my whole way of thinking with respect to rehab - what I do now just happens. 


\section{EXPERIENTIAL LEARNING AND ACTION LEARNING}

The suggestion by Harris (1996) that practitioners tend to develop their own theories once in the field, would seem to hold true for the Case Managers involved in this research. By using an experiential learning approach and encouraging participants to reflect on how what they learned was pertinent for them, many of them were able to develop strategies which were appropriate for their situation. This also builds on Schön's (1983) notion of 'reflection-in-action' with Case Managers often adjusting to situations as they occur. These points are especially pertinent given the very diverse cultures represented in both the ACC Branches visited, and the geographical and socio-economic contexts within which they are located. An example of this is a form one of the participants developed to help them with their initial client contact, which can be seen in Appendix 11.

The link between experiential learning and organisational learning suggested by Argyris (1982, 1994), Argyris \& Schön (1978), Kim (1993), Senge (1990) and Wyatt (1997) appeared to be less clear in this research. The ACC was wanting Case Managers to return to their Branches and act as 'change agents', by sharing their new-found knowledge and skills with their colleagues. However, as indicated above the very ACC Case Manager competency of 'challenging the status quo' needed to achieve change, was in most cases not supported. Argyris (1994) suggested that this is not an unusual situation. It was his contention that the training may have indeed led to participants challenging their preconceived notions (mental models) and developing double-loop learning skills, but once back in the workplace they are not supported by the organisation to operate in this way. The reason for this, according to Argyris (1994) is a lack of true employee empowerment, with management wanting to remain in control.

The use of action learning, a form of experiential education, to achieve both individual and organisational learning has become more accepted (Bourner \& Frost, 1996; Bunning, 1992; Inglis, 1994; McGill \& Beaty, 1995; O'Hara et al., 1996; Raelin, 1997; Weinstein, 1995). Action learning aims to foster the personal development of people, enabling them to work more effectively within a variety of organisational cultures. This is an important skill when working as a Case Manager in the New Zealand context, as described above. Organisational 
cultures reflect a range management styles from empowerment to prescription, where it is expected that one way of doing something will work in all situations. Inglis's (1994) Task/Setting Matrix (see Chapter 3, Figure 3.5) provided a beginning framework for examining such issues. This model has been refined further as a result of the findings from this research, and will be discussed later in this chapter. Linked to influences on personal development is Raelin's (1997) assertion that action learning assists people to have an understanding of their own capacities to take action, to question more in work situations, and to become more aware of their own strengths and weaknesses. All of these points were mentioned by participants and are, in a sense, associated with increased confidence and self-awareness.

Raelin (1997) also suggested that in his experience, less confident people tended to perform less well on action learning programmes. This, however, does not appear to have been the case with the VUW Diploma in Rehabilitation Studies programme. From both the indication of the participants in terms of increased confidence, and from personal observation of individuals, the shy and less confident students performed much more confidently and assertively as a result of the course. In contrast, the confident and sometimes overbearing students, became more measured in their displays of confidence. This growth in self-confidence was definitely more striking and noticeable than the moderating behaviour, but it was nonetheless observable. The potential benefit to the organisation is that the individuals may become more similar in terms of confidence levels, which may translate into a more consistent approach to service delivery.

Given the findings, it would seem that the action learning approach has yielded the outcomes generally associated with the process (Inglis, 1994; McGill \& Beaty, 1995; Weinstein, 1995) and in particular when in the context of higher education (Bourner \& Frost, 1996; Bunning, 1992; O'Hara et al., 1996). There has been both personal and professional development amongst the participants. In the majority of cases, their confidence, self-esteem and self-awareness have increased. They have learned to relate to, and communicate with other people more effectively. There is also an indication that they have an increased readiness to take responsibility and initiative. Networks have been developed both within and outside the ACC, and there has been a limited amount of change 
in organisational behaviour. This last factor was very dependent on the Branch and this appears to be the least achieved outcome. There is no doubt in my mind that the learning has been taken back to the workplace - admittedly in varying degrees - with participants able to consider issues of relevance to their working lives, do something about these issues and learn from those experiences.

\section{ADULT LEARNING}

Cranton (1994) viewed androgogy as not only providing knowledge and skills, but also meeting the learner's needs, as well as engaging them in critical self-reflection. Critical selfreflection was also advocated by Mezirow $(1990,1996)$ in his notion of transformative learning, which aims at empowering people to reflect on their actions. The role of critical reflection was considered by Reed \& Anthony (1992) and Reynolds (1998), who suggested that being able to critically reflect is a key attribute of managers, as management decisions often have implications for specific groups in society. Case Managers have to make decisions in their daily practice which directly affect people's lives. Being able to reflect critically would, therefore, be a useful skill for ACC Case Managers to have. The findings, however, indicate that this has only been achieved to a limited degree. There are difficulties in ascertaining the degree to which people do critically reflect on situations, and it could be argued that the changes which have taken place in the case management practice of the participants indicates a move towards critical reflection.

\section{TRANSFER OF LEARNING AND TRAINING}

The role of training in improving organisational service delivery has been examined by a number of authors (Grönroos, 1990, 1994; Gummesson, 1994; Hallowell et al., 1996; Henkoff, 1994; Heskett et al., 1997; Howcroft, 1993; Mattsson, 1994; Schneider, 1994; Schneider \& Bowen, 1995). Heskett et al. (1997) viewed training as important in breaking the 'cycle of failure' within organisations, where the quality of the training rather than the quantity is the issue to be addressed. This means that the training must be of high quality and relevant to the participants. Although training is recognised as contributing strongly to improved service delivery, it must be integrated within the overall strategy of the organisation - not seen as the answer to the problem (Grönroos, 1990, 1994; Gummesson, 
1994; Hallowell et al., 1996; Henkoff, 1994; Heskett et al., 1997; Howcroft, 1993; Mattsson, 1994; Schneider, 1994; Schneider \& Bowen, 1995; Tapsell, 1998). The literature in the area of case management training supports this holistic approach to service delivery (Aliotta, 1996; Diwan et al., 1996; Fineman, 1996; Issel, 1997; Ozanne, 1996; Stiller \& Brown, 1996). The following discussion is couched within the context of these comments.

\section{Programme Design}

\section{Development of the course}

Chapter 2 indicated that the timeframe for the development of the course was very tight and involved only a small number of people from the ACC based at Head Office. As a result, the course was regarded very much as a Head Office initiative, as echoed by comments from the First Cohort of students.

I felt that PCMs should have been brought on line far sooner than they were.

$\mathrm{ACC}$ was paying for a course they didn't really understand what they were doing. The information was not clearly communicated to the Branches.

No input from staff who were actually doing the course - Head Office decision; nobody asked the Case Managers.

Management and PCMs think it's a waste of time because of the short time frame and social model, as against a medical model.

By the time Cohort 2 started, some of these issues had been addressed by the ACC and the course providers. However, the last point about the educational approach taken by the VUW course continued to be an issue within the Branches, which favoured the medical model of rehabilitation. This divergence of opinions was further exacerbated when the ACC supported a second course development at Auckland University, the Diploma of Case Management which was based on the medical model and had a contrasting educational philosophy to the VUW Diploma in Rehabilitation Studies. This would suggest that for the transfer of learning to be encouraged, the approach taken by the course needs to be 
supported throughout the organisation (Aliotta, 1996; Diwan et al., 1996; Fineman, 1996; Grönroos, 1990, 1994; Gummesson, 1994; Hallowell et al., 1996; Henkoff, 1994; Heskett et al., 1997; Howcroft, 1993; Issel, 1997; Mattsson, 1994; Ozanne, 1996; Schneider, 1994; Schneider \& Bowen, 1995; Stiller \& Brown, 1996; Tapsell, 1998). These findings would also support McGraw's (1993) assertion that thorough consultation with the organisation should take place prior to the provision of training. Similarly, it is advisable that where a variety of training options are offered to employees, they are not seen as competing, but as being complimentary in what they offer.

\section{Course philosophy}

The experiential nature of the course and in particular the action learning and reflective practitioner approaches, appear to have assisted in facilitating the transfer of learning. The focus on adult learning was particularly important given the diversity of backgrounds of the students. By adopting a learner-centred approach it was possible to meet the students' needs and enable them to draw on their individual personal and professional experiences.

\section{The actual course}

The VUW Diploma in Rehabilitation Studies (for details see Appendix 1) attempted to maintain a balance between the needs of the organisation and those of the students. It was a twenty-seven week professional course offered by Victoria University of Wellington, tailor-made to the needs of the ACC. Feedback from the students on their feelings about the course set-up combination, during their time in Wellington is summarised in the following statements:

It was really good as everything was relevant to Case Management.

The study week was valuable as I needed that time to reflect on the module and do my assignment.

I liked the structure because you got one module out of the way before starting the next one, therefore you could concentrate on one area and not get cluttered with different subjects. 
Taught you good research skills; networking; group co-operation; identifying people skills; time management and subconscious things.

It was good, excellent - I would never have coped with full-on study. The combination of personal and professional worked well because the personal part is so important in the role of rehabilitation. You have to be a part of people's lives, but must also be able to stand back. . . It's really important that there is a mix, as there is no set way to do rehabilitation because everyone is different.

A supervised fourteen week practicum followed the twelve week modular part of the VUW Diploma. The aims of the practicum were to provide an opportunity for students to practically apply the knowledge and skills developed during their twelve weeks in Wellington, which involved working on specified learning objectives and completing one practice case study, as well as providing fieldwork opportunities for completion of their research project. The learning contracts were then monitored and assessed throughout the contract period. Performance during the practicum period was assessed to determine whether there had been transfer of learning from the classroom, and whether enhanced performance outcomes were being achieved in practice. The following comments highlight some of the students' feelings regarding the practicum:

It was excellent.

The learning contract provided focus.

I learned most from the practicum, even though it was the hardest part of the course.

Learning contract and practicum useful - keeps you on track because personally responsible for them - I signed the contract - makes me do things.

Some of the participants did allude to the challenging nature of the practicum by stating:

The concept of the practicum was great, even though the pressure was on and I really enjoyed the research. 
The practicum was good, but managing varsity work and ACC work was stressful. Only had limited support with novice in my job therefore only really had 2 days in the office to manage a full case load.

It was quite intense, the practicum was a challenge in trying to balance work, family and study.

At the end of the practicum, students attended one further module in Wellington to review and evaluate their learning contracts, as well as to present their project findings. One participant summarised benefit of the course as follows:

The Victoria course makes an ordinary person a Case Manager. I had the skills to be doing administration and basic skills to interview people. The course said forget about entitlements and legislation and find out what the person needs and then work out how to manage the situation within the confines we have.

Given the above outline of the course and the comments made by the participants, it can be seen that many of the factors identified as being important for transfer to take place associated with programme design as highlighted in the literature, were incorporated in the VUW Diploma in Rehabilitation Studies programme. There was consultation with the ACC in the design and execution of the course before, during and after each group of students completing the course. Furthermore, the students on each cohort were asked to evaluate each module and the overall course, following which necessary changes were made. As acknowledged above, the consultation process with the individual ACC Branches could have been enhanced prior to the starting of the first Cohort. In spite of this, the consultation and feedback processes adopted would support the notion of a transfer partnership, as endorsed by Broad and Newstrom (1992), McGraw (1993), Minter (1996) and Stuart (1992).

The course itself consisted of both on- and off-the-job locations. Billet (1992) argued that it is important to have training based in the workplace, in order to incorporate the sociocultural factors of the workplace. The basis for this argument is that new attitudes learned at off-site training, for example, may not be compatible with the actual workplace - so a degree of workplace reality needs to be introduced at some stage during the course. Analoui (1993) supported this notion with his socio-technical model, but argued that a combination 
of on- and off-the-job may be best in terms of transferring learning to the workplace. The use of the practicum with the VUW Diploma in Rehabilitation Studies achieved this workplace reality, particularly since it was coupled with completing a learning contract, a research project and a practice case study - all of which built on the twelve weeks spent off-site in Wellington.

The use of learning contracts or action plans to reinforce learning has been widely supported (Analoui, 1993; Foxon, 1987; Gist, Bavetta \& Stevens, 1990; Mbawo, 1995; Stuart, 1992) as being beneficial to the transfer of learning. The main reason for this is that it provides a point of reference for learners to work from and reminds them of where their focus should be. The inclusion of a practice case study in the practicum merits extra comment. This piece of work, probably more than any other, provided the students with the opportunity to actually demonstrate what they had learned from the course and how they had applied their learning to the work situation. The practice case study involved selecting a client who had been receiving financial support from the ACC for more than fifty-two weeks and was in need of some intensive rehabilitation. The assessment of this piece of work was based on being able to demonstrate some progress over the fourteen weeks of the practicum. For some this involved an increase in motivation to look for work, for some a work trial and in some cases an actual return to work. Throughout the process the students needed to demonstrate a holistic approach to rehabilitation, involving a thorough needs assessment of the client and evidence of having linked theory to practice.

The use of an experiential learning approach, in particular action learning, enabled the use of an appropriate teaching methodology as advocated by Analoui (1993), Foxon (1990) and Gass (1989). Similarly, it was possible to design appropriate, but diverse, activities (Gass, 1989; McGraw, 1993; Stuart, 1992; Wagner \& Campbell, 1994) and forms of assessment to match the variety of learning styles (Analoui, 1993; Stuart, 1992) represented in the students. The use of journal writing is also supported in the experiential learning literature (Kruger \& May, 1986; Weinstein, 1995).

Gass (1989), Robinson (1992) and Wagner and Campbell (1994) have discussed the benefits of non-physical risk taking in experiential education programmes. Much of the 
literature focuses on outdoor management development where personal development is linked to moving individuals out of their comfort zones (Nadler, 1995) by engaging them in activities which contain a high degree of perceived risk, as opposed to real risk. Authors such as Bank (1994), Krouwel and Goodwill (1994) and Priest (1995) have argued that these risk taking skills will then also be transferred back to the workplace. It is also suggested (Binder, 1990; Robinson, 1992; Tziner, Haccoun \& Kadish, 1991) that transfer will be more likely if self-confidence is developed and the locus of control is centred within the student. In the VUW Diploma in Rehabilitation Studies, there were no perceived physical risks programmed for, but considerable perceived psychological risks. For many of these adult students this was their first time at University, their first time away from home and family, and their first time working intensively with their peers in a non-work setting.

Many of the situations the students had to deal with in the Personal and Professional Development Module, required them to look closely at themselves. For many, this was definitely a risk situation, particularly if major changes in their lives were seen as necessary. This process was associated with the need to challenge participants' mental models (Argyris, 1982; Senge, 1990), develop double-loop learning skills (Argyris, 1982, 1994) and encourage them to critically reflect on who they were (Cranton, 1994; Mezirow, 1990, 1996; Reed \& Anthony, 1992; Reynolds, 1998). The noho marae was probably the most 'risky' for many students, as it not only involved going into an environment which was alien to many, but also necessitated living in close quarters with near strangers for five days and four nights. The findings from this study show that increased confidence has not only taken place, but that learners have also been applying such learning to both work and personal situations. The following comments highlight some of these points.

I now have the confidence to stick up for what I believe is right.

Pre-course I would have steered clear of attempted sexual abuse victim clients, but now I am confident and able to talk with other professionals including lawyers and doctors.

Pre-course I wasn't confident negotiating with employers. The course gave me the confidence to successfully negotiate return-to-work trials. I can now see through all the game-playing authoritarian type employers. To have this is a major achievement. 
The role of the Personal and Professional Development Days also came through:

Tuesdays and other modules made me more confident in how I deal with my work and I am able to express myself better and say things more openly.

Similarly, the impact of the noho marae was also mentioned:

Marae stay had most effect on me personally. It developed my self-awareness and that of other people. It made me think a lot about me, where I am at, where I am going and gave me a definition of cultural safety, which was that I needed to know who I was first - not what Maori had for breakfast.

This personal and cultural development supports the research by Rogers (1995) which emphasises the importance of cultural competence in Case Managers.

The use of metaphors has been addressed in experiential learning by, for example, Hovelynck (1998) and Nadler (1995). In the management literature, Morgan (1986) and Schön (1983), for example, have also commented on the importance of metaphors in promoting personal and professional development. Although none of the participants specifically mentioned the use of metaphors during the course of this research, a number of them provided examples of metaphors during practicum visits carried out by the researcher. Two specific examples associated with the noho marae illustrate this very clearly. The first one related to the need for team-work in the Branch environment. The metaphor here was the experience of paddling the waka (Maori war canoe) during the noho marae of Cohort 1. It was impossible to reach the designated destination in the waka without all the paddlers working together in achieving this goal.

The second example is from Cohort 2 and relates to having an understanding of how many ACC clients feel when they have to deal with the organisation. Many of the course participants had never been to a marae, let alone spent a week living in a marae environment. The process of entering a marae follows a strict protocol, depending on the circumstances of the visit. This experience was quite daunting for some participants as the language was Maori and the surroundings unfamiliar. After the Cohort had been welcomed on to the marae, some students expressed how they were now able to better understand the 
feelings of their clients when visiting the ACC - an organisation with its own language and terminology, and unfamiliar surroundings.

Taking risks and the effect on participants' lives was also a feature:

I now take calculated risks, like that self-employment is now a viable option, more so than for any other office. Would never have done this before.

In my personal life there has been a willingness to take risks - we've done that as a family and it has paid off.

The use of peer support groups as suggested by Stuart (1992) was also incorporated, although this term has not been used. Each group of students was divided into regionally based tutor groups. The rationale for this split was threefold. Firstly, small groups were needed for working on interpersonal skills, particularly with respect to the Personal and Professional Development module. Secondly, it meant that one tutor could work intensively with ten students and establish networks within their respective regions and branches. It also made the logistics for the practicum visits more amenable. The third reason, was to provide regional peer support during the practicum, with many regional groups organising study weekends and casual get-togethers during that time. This did not preclude interregional groups forming, which they did, and many of these have remained post-course.

Only one or two people from a Branch completed the Wellington-based part of the course at any given time. There was some overlap with people being on practicum, whilst others were in Wellington. The reason for this was largely due to operational constraints within the individual Branches. Stuart (1992) suggested there is benefit in only training some of a work group at any one time, as it enables a constant refresher to take place for those who have already completed the course. Comments by the participants in this study suggest that this did happen to some degree, particularly where previous course members had taken on new roles within the organisation, either at Head Office or at Branch level. Such overlap of students also enabled informal mentoring (Stuart, 1992) to take place, with past students assisting those on the course and, in some cases, providing a strong mentoring role. 
The concept of a Relapse Prevention Module as advocated by Tziner, Haccoun and Kadish (1991), is mirrored by the Transition from Theory to Practice Module in the VUW Diploma in Rehabilitation Studies programme, designed to prepare students for returning to the workplace. In addition to drawing up their learning contracts, the module covered areas such as time-, stress- and conflict management. Sessions on creativity and negotiation skills were also included. These appear to have had a strong influence on a number of participants up to twelve months after the course, although negotiating skills, conflict management and creativity were also mentioned at twenty-four months.

\section{Trainee Characteristics}

The transfer literature identified a number of characteristics, considered important in facilitating the transfer of learning. These characteristics included ability and aptitude, personality and motivation. Motivation was seen to include confidence, high selfexpectancy, high job involvement and a high belief in the value of training (Baldwin \& Ford, 1988). A number of other studies have focused on single issues including the general ability of the learner (Bereiter, 1995; Rouiller \& Goldstein, 1993), student background (Castaldi, 1989), motivation (Noe \& Schmitt, 1986 cited in Mbawo, 1995; Holton, 1996), selfefficacy (Gist \& Mitchell, 1992 cited in Mbawo, 1995) and self-esteem (Mink, Owen \& Mink, 1993), as well as the ability to take risks (Friedman, 1990; Robinson, 1992).

The findings from this research support Bereiter's conclusions (1995) in the sense that the participants have learned to think and have therefore been able to apply their newly gained skills and knowledge to different contexts. This factor became evident in the participant responses eighteen and twenty-four months after the course and is highlighted in Chapter 5, Graphs 5.14 and 5.21. Eighteen months after the course nearly half (19/39) of the participants mentioned that they had adapted their learning to new situations. Sixteen out of thirty-five indicated that they applied new knowledge and skills to other areas after twenty-four months. 
Rouiller and Goldstein (1993) suggested that the ability of the trainee to correctly determine the level of support they will receive on return to the workplace, affects their efforts to apply newly learned behaviours. The findings do not provide a clear indication of whether this was the case for the research participants in this study. However, Cohorts 2 and 3 would have had a reasonable idea of how much support they were going to receive based on what had gone before. Cohort 1 had nothing to go by and hence would not have been able to determine this in advance. What the data does indicate, however, is that the level of Branch support declined over time, and that the relative lack of Branch support increased over time (see Chapter 5, Graphs 5.9, 5.10, 5.15, 5.16, 5.22 and 5.23). The level of Branch involvement is important in terms of the ACC's future training policies and practices.

Castaldi's (1989) concept of having an understanding of adult learners' backgrounds before starting teaching on university courses was acted upon with the VUW Diploma in Rehabilitation Studies building on the notion of "the reflective practitioner". The link here is that adult learners will tend to draw on their most relevant experiences as reference points for completing tasks at hand, in this case completing a university Diploma. It would appear that having this knowledge is helpful in understanding the perspective participants came from and provides an insight into issues that may arise for adult learners whilst studying. Admission to the VUW Diploma in Rehabilitation Studies required that a curriculum vitae be seen prior to student enrolment being completed. From Cohort 2 onwards, tutors generally met the students prior to coming on the course, whilst they were carrying out their practicum visits. The students on the VUW Diploma could be divided into three groups with respect to their criteria for gaining entry to the course:

- those with previous university experience and a first degree;

- those with a relevant professional qualification;

- those without university experience admitted to the Diploma after qualifying for admission to the university with special admission, which involved producing "evidence of extensive practical, professional or scholarly experience in social or rehabilitation services and have at least three years professional experience" (1997 VUW Calendar, p. 284 cited in Fulcher, Leberman, Paterson, Sutcliffe \& Walsh, 1997, p. 53). 
Within the first three cohorts, twenty-six students had previous university experience, twelve had relevant professional qualifications and seventy-seven gained access to the course with special admission. The sample in this research consisted of six students with previous university experience, seven with a relevant professional qualification and thirtyfour who received special admission to the VUW Diploma. The variety of entry requirements meant that the students on the VUW Diploma in Rehabilitation Studies were a very heterogeneous group in terms of their educational backgrounds, and therefore the need for having an understanding of where they came from was even greater, than may be on some other University courses.

Meeting the students before coming on the course was useful not only in terms of gaining insight into their backgrounds, but also in giving them a 'face' as prospective students. This is particularly important, as the majority of the students in this research had never been to university before, had a variety of perceptions of what it meant to be on a university course and what a university lecturer was. This pre-enrolment contact eased the way for many of the participants and provided a more supportive start to university study.

The learner's motivation to learn, in terms of readiness, job attitude and personality were identified by Holton (1996) as important factors affecting the transfer of learning. The selection process for the VUW Diploma adopted by the ACC addressed some of these issues. In general, the students applying for the course were ready for some training, many volunteered, although some were given no choice in the matter. It was however unclear what criteria were used to identify job attitude and personality. Therefore, the evidence supporting these factors has been more indirect, rather than being specifically identified during the course of the research. Holton (1996) also argued that the motivation to transfer the learning has an influence on performance outcomes. There is some evidence to indicate that this was the case for some participants in this study. As one student said

I'm more motivated since doing the course. I'm enjoying my job at the moment, dealing with a variety of people, doing voc rehab and visiting employers.

Associated with motivation is the importance of participant self-confidence and selfefficacy in transferring learning, as advocated by a number of writers including Noe and Schmitt (1986, cited in Mbawo, 1995), Gist and Mitchell (1992, cited in Mbawo, 1995) and Mink, Owen and Mink (1993). 
The importance of self-confidence and self-esteem came through very clearly from the participants. At each interval over half the participants commented on their increased confidence and how this enabled them to achieve things. Proportionately, more participants mentioned increased confidence at twelve and twenty-four months, compared with the eighteen-month follow-up (see Chapter 5, Graphs 5.5, 5.11 and 5.18). Some of the responses were as follows

I have more personal worth or self-worth as I now realise that I can make a difference in other people's lives.

My self-confidence has increased dramatically.

I learned about myself and how to deal with others.

I probe more when information is presented to me in difficult cases, I wouldn't have had the confidence to do this pre-course.

Increased self-confidence in both home and work life, enabling me to make changes.

I have more confidence to see GPs, which has had a great big spin-off because other clients see the same GPs and they contact me now when the clients are ready to work, which saves me a lot of time.

The findings would suggest that this increase in self-confidence has been a result of the programme design. This was facilitated through its experiential approach which included elements of psychological risk, where participants were moved out of their comfort zones, but always in a 'safe environment' (Friedman, 1990; Nadler, 1995; Robinson, 1992). The key factor here is that participants were able to transfer that learning to different situations and be prepared to continue challenging themselves, by taking 'calculated risks'. Most of the transfer outcomes in Robinson's (1992) study were non-specific, in that they involved mainly principles and attitudes such as self-confidence, rather than particular skills associated with risk recreation - in this case mountaineering. The findings from the VUW Diploma in Rehabilitation Studies research echo Robinson's findings, even though the risks 
were psychological or emotional rather than physical. In addition, there has been specific transfer of learning in terms of case management, as demonstrated by the use of an holistic approach, the development of praxis and actual changes in case management practice.

\section{Workplace Characteristics}

The importance of workplace characteristics in facilitating transfer of learning has been widely reported in the literature. These include direct supervisor support (Broad \& Newstrom, 1992; Brinkerhoff \& Montesino, 1995; Garavaglia, 1993; Gregoire et al., 1998; McSherry \& Taylor, 1994; Mmobuos, 1987; Noel \& Dennehy, 1991; Xiao, 1996), sociocultural factors (Analoui, 1993; Billet, 1992 \&1994; Buckley \& Caple, 1996; Lave \& Wenger, 1991), social support (McGraw, 1993; Tracey, Tannenbaum \& Kavanagh, 1995), continuous learning culture (Tracey, Tannenbaum \& Kavanagh, 1995) and transfer of training climate (Argyris, 1994; McGraw, 1993; Tracey, Tannenbaum \& Kavanagh, 1995). Similarly the service and case management literature has argued that the workplace plays a key role in ensuring improved service delivery takes place (Aliotta, 1996; Diwan et al., 1996; Fineman, 1996; Grönroos, 1990, 1994; Gummesson, 1994; Hallowell et al., 1996; Henkoff, 1994; Heskett et al., 1997; Howcroft, 1993; Issel, 1997; Mattsson, 1994; Ozanne, 1996; Schneider, 1994; Schneider \& Bowen, 1995; Stiller \& Brown, 1996; Tapsell, 1998). Given the wealth of literature from a number of disciplines, the importance of the

workplace cannot be neglected in studying the transfer of learning from the classroom to the workplace. Change in performance back at work is often regarded as the primary indicator of successful transfer.

The level of workplace support required for transfer to take place has been widely debated (Noel \& Dennehy, 1991; Brinkerhoff \& Montesino, 1995; Gregoire et al., 1998; McGraw, 1993; McSherry \& Taylor, 1994; Xiao, 1996). The support advocated ranges from the immediate supervisor through wider management to CEO level. The findings of this study indicate that support is required throughout the organisation not just at the local workplace level. Whilst specific reference was made of the Branches, more general organisational issues were also raised. When considering the organisational detractions, wider ACC problems were more prevalent than those associated with the Branches. This may be due 
to the fact that the ACC is a government organisation, very much at the whim of government, operating with a Branch structure over the whole of the geographically dispersed country, with a Head Office located in Wellington. Similar situations are found in many public service organisations, particularly those working in human service provision (Dickens, 1996; Skelcher, 1992). The following comments were made when participants talked about the level of workplace support. Those that were supported indicated:

I had a supportive Branch Manager.

PCM comes from a rehabilitation background, was supportive and receptive to new ideas.

Participants for whom the situation was more difficult observed:

Change wasn't easy as managers don't necessarily know where you are coming from.

The level of support required was not made clear to all Branches.

There hasn't been enough done to retain staff who have been on the course; there needed to be more opportunities provided.

Management didn't really support us on the return to the Branch. To become a change agent you need management support to do this.

Disappointed at the lack of interest on my return. I grew throughout the course and felt I had achieved something in the end. But the 6 months has gone unrecognised in the branch even in the performance review with the reason being that it wasn't fair to acknowledge it as others didn't have the choice which isn't right as I chose to go others didn't. I'm really pissed off as other Branches recognised this. It was not a waste of time - I'd do it again even though the Branch sees it as a waste.

Once again these participant comments highlight the importance of an holistic approach to improving service delivery, including all layers of the organisation, not just the customercontact workers. The comments also provide examples to support McGraw's (1993) 'return from space' and 'hangover' effects, which participants often experience when returning to the workplace after training. 
The findings support the notion that some of the training should take place in the workplace if transfer of learning is to take place (Analoui, 1993; Billet, 1992, 1994; Lave \& Wenger, 1991). The reason for this is that training not only involves acquiring technical skills but is also a social process. This can lead to potential problems when training environments are not matched by work environments. These socio-cultural factors are linked to the concepts of organisational culture and climate which Tracey, Tannenbaum \& Kavanagh (1995) argued were important in facilitating the transfer of learning. The main considerations within these concepts is that workers perceive that their work climate will encourage them to use their newly found skills and knowledge, and that learning is considered an integral part of their workplace. These concepts link in with the work of Bowen \& Lawler (1995) on employee empowerment and Bailyn et al's. (1997) research, which suggested more integration of personal and organisational goals. Some of the following comments illustrate these points. Participants who felt supported by the work environment stated:

Current policy of recruiting Case Managers with health backgrounds, because you can bounce ideas off each other.

Support of colleagues who have also been on the Victoria course.

People noticed changes, but more sceptical at first. However, then they became interested.

Good feedback from co-workers, which helps.

People at the branch are interested and I've loaned them stuff from the course

Environment I'm in now encourages the use of these skills, such as research and stress management, whereas this wasn't the case in the Branch. I haven't been explicitly been told to do this - it's more a feeling that it's OK.

However, where there was a lack of organisational support, participants indicated the following:

People in the branch labelled you as tall poppies - it would have been better if they'd had nothing to compare you to. 
On return from the course there was an anti-feeling to the course, but that has changed now that more people have been through the course. There are also more professionals in the branch so I don't stand out as much any more.

The branch climate has not let us be change agents - not to the extent we had been encouraged to. On return I tried to encourage staff to focus on getting out rather than processing - but it wasn't realistic. My approach is now more client focussed and I try to convey this to other staff. There has been little opportunity to change the organisation. Too few resources to achieve things.

It was very difficult settling again on return to the Branch, it took a long time assimilating back into the Branch; maybe my expectations were a little high - it was and is very frustrating as I can't do what I want to do. I have saved ACC $\$ 300,000$ whilst still doing mainly processing but focussing on vocational rehabilitation. If I had the time to do the real stuff it could be a million.

This discussion suggests that the distinct fields of study identified in Chapter 3 and used here as a guide, permeate across subject boundaries. Much of the literature from the service management area, particularly internal service management is highly relevant to the transfer of learning area, as has been demonstrated above. The literature in the areas of experiential/action learning and adult learning have similarities, which in turn are pertinent to the transfer of learning literature, particularly with respect to course design and trainee characteristics.

In the following section, the relationships between the codes at each time point will be presented using the hypothesis testing function available in HyperRESEARCH 1.56. The related codes were then analysed by the researcher to determine specific relationships (for a detailed explanation of the hypothesis testing function see Dupuis, 1994, pp.4.1-4.28). An emergent transfer of learning model is then suggested, followed by two other theoretical models. 


\section{RELATIONSHIPS BETWEEN THE CODES}

By considering the data in more detail and using the hypothesis testing function in HyperRESEARCH 1.56, it has been possible to say something more definite about relationships between different analytical themes (see p.113-114 for details of the process). For the purposes of this exercise, hypotheses were established and then tested at each time interval and for each cohort of participants. HyperRESEARCH 1.56 has the capacity to test hypotheses in terms of searching for specified relationships between codes within the complete data set. The hypothesis testing function produces a report listing the names of all the participants who support the hypothesis and those who do not support it. This enables the researcher to put frequencies to the hypothesis (see Appendix 12 for details of hypotheses, extract from a report and results) and by re-reading the relevant participant transcripts it is then possible to identify whether the participants perceived a positive relationship between the themes. The steps in the process adopted can be summarised as follows:

1. HyperRESEARCH 1.56 via its hypothesis testing function searched through all the data from participants and produced a report indicating those participants for whom the hypothesis held true and those for whom it did not. This identified the themes mentioned by each participant.

2. All the original transcripts of the participants for whom the hypothesis held true were then re-read by the researcher, to identify which participants' comments indicated a perceived positive relationship between the themes tested in the hypothesis.

\section{The Relationship between the Educational Process and Personal Development}

\section{Hypothesis 1 - Educational Process (Practicum and Learning Context) associated with Personal Development at 12 months}

Thirty-five (74\%) of the participants mentioned the educational process used in the VUW Diploma in Rehabilitation Studies and their personal development twelve months after completing the course. Of these thirty-five participants who mentioned the Practicum, the Learning Context and Personal Development, twenty-five (53\% of all participants) 
perceived a positive relationship between these themes. The following comments illustrate this relationship:

Initially I thought none of the course was particularly applicable, although my confidence had grown. In the long term I've realised the assessment and research were useful because they've allowed me to make negotiations. I learned a lot which I didn't like to admit. I enjoyed the practicum and grew from it. I learned a lot about the subject and it was good to put into practice what I'd learned and fulfil the learning contract.

The practicum was a good confidence thing in getting it finished and over-coming obstacles doing something a bit different, it really increased my confidence. The mixing of personal and professional was quite important and tied in well, particularly in terms of learning about the impact you have on others.

\section{Hypothesis 2 - Educational Process (Personal \& Professional Development Day and Cultural Awareness) associated with Personal Development at 12 months}

The combination of the Personal and Professional Development Day and Cultural Awareness being associated with Personal Development was mentioned by twenty (43\%) of the participants. All twenty perceived a positive relationship between these aspects of the Educational Process and Personal Development, with the following responses being characteristic of the comments made:

Tuesdays involved a lot of soul searching amongst yourself even though I didn't like it at the time it's made me see who I really am and what my strengths and weaknesses are. The marae environment was taken for granted by me but I realised this wasn't necessarily so for the next person. I now have a deeper appreciation of other people's interpretation of things - even life itself. I know better what people's comfort zones are and I now take people for who they are.

For me Tuesdays were most important because they made you look at yourself as a person. The marae was another example because you learned to centre yourself. I now know who I am - know my strengths and weaknesses and that unless I'm doing something I believe in I'm wasting my time.

After two years, the association between the Educational Process and The Individual was much weaker, with a positive relationship being perceived by only eleven $(29 \%)$ of the participants. 


\section{The Relationship between Personal Development, Praxis Development and Using an Holistic Approach}

\section{Hypothesis 3 - Personal Development associated with Changes at Work at 12 months, at 18 months and at 24 months}

The number of times Personal Development, Praxis Development and Using an Holistic Approach were associated by participants also diminished over time. After one year, the overall hypothesis held true for thirty-seven (79\%) of the participants, thirty-two $(68 \%$ of all participants) of whom suggested that there was a positive relationship between these themes. Eighteen months after the course, the overall hypothesis was only substantiated by fourteen (34\%) of the participants, eleven ( $27 \%$ of all participants) of whom perceived a positive relationship. Interestingly, however, the strength of this relationship improved two years after the course. The overall hypothesis was supported by eighteen (47\%) of the participants, with all these participants perceiving a positive relationship between the themes.

The following participant comments illustrate the positive relationship between Personal Development, subsequent Praxis Development and the use of an Holistic Approach.

Because I now believe in myself I can get out and do things. I also realise that there are different ways of achieving results and have picked up on other people's skills such as case conferencing. I now do these with a set agenda and the facilitation skills I learned are helping a lot with them. Having to do that final presentation has also given me more confidence and it now helps when I meet with employers. (12 months)

I approach things differently. Even things I'm really nervous about. I had this potential media situation, but took some breaths, went out to see the people and although I was shaking, they were happy with what we discussed. I've found a better way of being more diplomatic and also being a bit harder, but still being honest and negotiating with people. With clients I'm also upfront and set clear expectations at the outset. This has meant I've had no reviews of my decisions, no Ministerials and no claimant complaints to my Business Manager. (18 months)

I think the mere fact that I did succeed and achieve results gave me more confidence than I ever had. I like to think that the Diploma has laid a foundation for me as every risk I've taken has paid off - touch wood.... For me I needed to learn about listening as I wasn't a very good listener. I was judged by my peers in the Threes Exercise, so now in meetings I ask myself am I really listening to them and do I hear what they are saying? I am now able to run meetings and 
workshops and have good negotiation skills. I think I have more of an awareness that other people have needs and things they want to say and even if I'm ten steps ahead of them I need to listen to them. (24 months)

\section{The Relationship between Personal Development, Job Specific Processes and a Change in Practice}

\section{Hypothesis 4 - Personal Development associated with Job Specific Processes including a Change in Practice at 12 months, at 18 months and at 24 months}

When considering Personal Development and its relationship with Job Specific Processes and a Change in Practice, a similar trend was observed over time. At twelve months, the hypothesis that Personal Development via Praxis Development and Using a Holistic Approach is associated with a Change in Practice was substantiated by thirty-seven (79\%) of the participants. Thirty-two of the participants ( $68 \%$ of all participants) perceived the relationship to be positive. By eighteen months after the course this hypothesis was only supported by sixteen (39\%) of the participants, with twelve (29\% of all participants) perceiving a positive relationship between the themes. At twenty-four months after the course the hypothesis was still supported by sixteen $(42 \%)$ of the participants, all of whom indicated that there was a positive relationship between Personal Development, Job Specific Processes and a Change in Practice.

The following comments illustrate the strength of association for Hypothesis 4:

I feel I now have more empathy with clients and look at things from different angles. I also try to wipe out my personal issues before talking to clients so that I can focus on them. My personal growth from the course has affected my practice in terms of better interviewing and negotiating. The marae gave me more of a sense of trying to understand where clients are coming from. I've made changes in my practice and feel that it has been beneficial to the people, but not necessarily cost-efficient in terms of ACC. (12 months)

I have had a huge turnover in files - having the third most closures in the branch. I've had a lot of people who have done courses and then found work. It's hard to say I apply a particular skill from the course, but it's given me the confidence to apply everything. Like the needs assessment I apply it all the time, whereas prior to the course I didn't. I'd take short cuts because it's a numbers game, not really rehabilitation. . . . I have far more confidence in what I'm doing the 
more I do it. What I now do is have far more face-to-face interviews, as people react so much differently. . . Personal contact makes a huge difference and also provides better outcomes. (18 months)

The practicum was the key in bringing skills back to the work place because with the learning contract I set goals and for me the things I set out were my weaknesses, so it made me do it properly. Overall the course has had a lot of effect on how I work. My rehab side has increased tenfold. A lot of staff come to me to ask advice on IRPs and vocational stuff and I know that those areas were very new to me when I started as a Case Manager. My IRPs are now tight enough so that if they go to review we win. I put that down to a lot of the skills we learned on the course, like analysing skills. . . I've put into practice across the board what we learned on the course. They are now part of me and who I am - it comes naturally I don't have to think about it. . . . Prior to the course I didn't contribute as much. (24 months)

\section{The Relationship between Organisational Support and a Change in Practice}

Hypothesis 5 - Personal Development, Praxis Development and Organisational Support associated with a Change in Practice at 12 months, at 18 months and at 24 months

Hypothesis 6 - Personal Development, Using an Holistic Approach and Organisational Support associated with a Change in Practice at 12 months, at 18 months and at 24 months

The influence of the organisation on achieving a Change in Practice was also tested. Hypotheses 5 and 6 examined the link between Organisational Support and Job Specific Processes, suggesting that Organisational Support aided in achieving a Change in Practice. Twelve months after the course, the hypothesis was supported by twenty (43\%) of the participants when tested in association with Praxis Development and by twenty-four (51\%) of the participants when linked with Using an Holistic Approach. The relationship was perceived as being positive by fifteen $(32 \%)$ and sixteen $(34 \%)$ of all the participants, respectively. The following comment illustrates this positive relationship at twelve months: 
My self-confidence has improved dramatically and I also feel that I have a better understanding of rehabilitation, in terms of being more holistic, looking at the whole person and doing creative IRPs. I can also identify what people's needs are in interviews, due to my listening skills and that it's not what I thought they needed. The corporate environment has helped in terms of acknowledging my new skills and allowed me to use them, with the support being at both regional and Branch level.

A similar pattern was observed eighteen months after the course, when the hypothesis was substantiated by eleven (27\%) participants when associated with Praxis Development. Five of the participants (12\% of all participants) perceived a positive relationship. Similarly, when tested in association with Using an Holistic Approach the hypothesis was supported by thirteen (32\%) participants, seven (17\% of all participants) of whom perceived the relationship to be positive. Twenty-four months after the course, the overall hypothesis was unsupported by more participants than supported, with only two participants indicating that there was a positive relationship between the themes.

This positive relationship is exemplified by the following responses at eighteen and twenty-four months respectively:

For me more than anything listening and interviewing skills have been most important - listening to what the claimants want rather than imposing my expectations on them. Realising that there are barriers which prevent them from returning to work and looking at a person holistically. My outcomes have been based on focussing on the clients agenda and going with what is most suitable for them. ... The work environment has been better with restructuring and for me having a lower case load of between $40-60$ has been helpful.

Overall the course gave me much more confidence and made me look closely at who I am. ACC has also changed and given us a freer range. I look at each case individually and we can now put up a reason why we are doing something. I always document to the full and look at all the options and then pick the best one... The emphasis now is on the fact that the claimant can do a job, not just the financial outcome, so that in the long term a cost-effective outcome is achieved - so I use a lot of negotiation and evaluation. 


\title{
The Relationship between Organisational Detractions and a Change in Practice
}

\author{
Hypothesis 7 - Personal Development, Praxis Development and Organisational \\ Detractions associated with a Change in Practice at 12 months, at 18 months and at
} 24 months

\section{Hypothesis 8 - Personal Development, Using an Holistic Approach and Organisational Detractions associated with a Change in Practice at 12 months, at 18 months and at 24 months}

One year after the course the hypothesis was supported by twenty-eight $(60 \%)$ of the participants when associated with Praxis Development, twenty (43\% of all participants) of whom perceived the relationship to be positive. Thirty-one (66\%) participants substantiated the hypothesis when linked with Using an Holistic Approach. Twenty-two of the participants ( $47 \%$ of all participants) regarded the relationship between the themes as positive. By eighteen months after the course, the hypothesis linking Personal Development with Praxis Development was substantiated by fifteen (37\%) participants, with twelve participants ( $29 \%$ of all participants) perceiving the relationship to be positive. When linking Personal Development with Using an Holistic Approach fourteen (34\%) participants supported the hypothesis. Eight of the participants $(20 \%$ of all participants) suggested a positive relationship between the themes. After two years the percentage of participants supporting the hypotheses remained the same. However, the percentage of participants perceiving a positive relationship between the themes had increased to $32 \%$ when linked with Praxis Development and to $29 \%$ when linked with Using an Holistic Approach.

The strength of these positive relationships is illustrated in the following statements:

Personal development has been the key for me as I think a lot more about myself and how my make-up affects other people and also that there are lots of different ways of doing my job. I'm much more sensitive and professional in my approach now, whereas in the past I was too bureaucratic. I haven't been able to change as much as I would have liked to because there is a conflict of interest between insurance and rehabilitation. Also because of ACCs excessive workload and unstable work environment - there are changes every four to five months. I'd like to work really differently, so I'm 
trying to find a happy medium. There is an ongoing amount of change in ACC with a high level of staff turnover. (12 months)

The course has allowed me, if anything, to develop in my practice since the course - my skills have developed and been honed since the course. The course made me more aware of my weaknesses - so I'm now looking at other courses for further development in these areas. So for me my biggest outcome has been being able to reduce my file load of +52 week claims by over $50 \%$ in the last 12 months, because of my initial assessment, communication and listening skills. . Everything was pretty smooth until November when the recent changes started. The direction ACC is going in is positive but it hasn't been handled well. We had to indicate preferences for positions under the new structure, but there were/are no job descriptions, no pay scales, so how can you make a choice basically there is a lack of information. Outside consultants were brought in to do psychological, numerical and comprehension tests, but they didn't really know what our job entailed. And in the end individuals didn't really have any choice in the position they were given - there were already preconceived ideas about who would do what. I've had to change completely what I was doing. The change probably is a good thing but the process is demoralising for staff. (18 months)

It was really beneficial to have gone through the course, as I've done more goal setting and striving to achieve them. It's given me more confidence in my personal and work environment. I haven't used everything from the course, like the legislation, but I have used the analysis, documentation, communication and interviewing skills.... I now have more confidence and am not frightened to raise points or speak my mind, before the course I was quite shy. . . It was a combination of the way the course was done and me being able to apply it. . A ACC is very good at knocking your confidence. The course has made people stronger, as you tend not to develop your own skills because you are focussing on what ACC wants you to do. They underestimate you and don't let you strive and there is never any follow-up on courses throughout the organisation. (24 months)

\section{Summary of Perceived Positive Relationships}

Table 6.1 provides a summary of the hypotheses associated with the transfer of learning identified in this research and highlighted in the preceding discussion over the three time periods. Each time period is further divided into two columns. The first column indicates the percentage and number of participants who mentioned all the themes and for whom the hypothesis therefore held true (Hypothesis True - HT). The second column provides the percentage and number of participants who perceived a positive relationship between the themes tested in the hypothesis (Perceived Positive Relationship - PPR). Table 6.1 shows how the relationship between themes is strongest twelve months after the course, then there is a weakening in the relationships at eighteen months, followed by a strengthening of the relationships two years after the course. 


\begin{tabular}{|c|c|c|c|c|c|c|}
\hline & \multicolumn{2}{|c|}{$\begin{array}{l}12 \text { months } \\
(\mathrm{n}=47)\end{array}$} & \multicolumn{2}{|c|}{$\begin{array}{l}18 \text { months } \\
(\mathrm{n}=41)\end{array}$} & \multicolumn{2}{|c|}{$\begin{array}{c}24 \text { months } \\
(\mathrm{n}=38)\end{array}$} \\
\hline & HT & PPR & HT & PPR & HT & PPR \\
\hline $\begin{array}{c}\text { Hypothesis } 1 \\
\text { Educational Process } \\
\text { (Practicum and Learning } \\
\text { Context) related to Personal } \\
\text { Development }\end{array}$ & $\begin{array}{l}74 \% \\
(35)\end{array}$ & $\begin{array}{l}53 \% \\
(25)\end{array}$ & N/A & $\mathrm{N} / \mathrm{A}$ & N/A & N/A \\
\hline $\begin{array}{c}\text { Hypothesis 2 } \\
\text { Educational Process (Personal } \\
\text { \& Professional Development } \\
\text { Day and Cultural Awareness) } \\
\text { related to Personal } \\
\text { Development }\end{array}$ & $\begin{array}{l}43 \% \\
(20)\end{array}$ & $\begin{array}{l}43 \% \\
(20)\end{array}$ & N/A & N/A & N/A & N/A \\
\hline $\begin{array}{c}\text { Educational Process related to } \\
\text { Personal Development }\end{array}$ & N/A & N/A & N/A & $\mathrm{N} / \mathrm{A}$ & $\begin{array}{l}29 \% \\
(11) \\
\end{array}$ & $\begin{array}{l}29 \% \\
(11) \\
\end{array}$ \\
\hline $\begin{array}{c}\text { Hypothesis } 3 \\
\text { Personal Development } \\
\text { related to Changes at Work }\end{array}$ & $\begin{array}{l}79 \% \\
(37)\end{array}$ & $\begin{array}{l}68 \% \\
(32)\end{array}$ & $\begin{array}{l}34 \% \\
(14)\end{array}$ & $\begin{array}{l}27 \% \\
(11)\end{array}$ & $\begin{array}{l}47 \% \\
(18)\end{array}$ & $\begin{array}{l}47 \% \\
(18)\end{array}$ \\
\hline $\begin{array}{c}\text { Hypothesis } 4 \\
\text { Personal Development } \\
\text { related to Job Specific } \\
\text { Processes and a Change in } \\
\text { Practice } \\
\end{array}$ & $\begin{array}{l}79 \% \\
(37)\end{array}$ & $\begin{array}{l}68 \% \\
(32)\end{array}$ & $\begin{array}{l}39 \% \\
(16)\end{array}$ & $\begin{array}{l}29 \% \\
(12)\end{array}$ & $\begin{array}{l}42 \% \\
(16)\end{array}$ & $\begin{array}{l}42 \% \\
(16)\end{array}$ \\
\hline $\begin{array}{c}\text { Hypothesis 5 } \\
\text { Personal Development, Praxis } \\
\text { Development and ACC } \\
\text { Support related to a Change } \\
\text { in Practice } \\
\end{array}$ & $\begin{array}{l}43 \% \\
(20)\end{array}$ & $\begin{array}{l}32 \% \\
(15)\end{array}$ & $\begin{array}{l}27 \% \\
(11)\end{array}$ & $\begin{array}{l}12 \% \\
(5)\end{array}$ & $\begin{array}{l}5 \% \\
(2)\end{array}$ & $\mathrm{N} / \mathrm{A}$ \\
\hline $\begin{array}{c}\text { Hypothesis 6 } \\
\text { Personal Development, Using } \\
\text { an Holistic Approach and } \\
\text { ACC Support related to a } \\
\text { Change in Practice }\end{array}$ & $\begin{array}{l}51 \% \\
(24)\end{array}$ & $\begin{array}{l}34 \% \\
(16)\end{array}$ & $\begin{array}{l}32 \% \\
(13)\end{array}$ & $\begin{array}{l}17 \% \\
(7)\end{array}$ & $\begin{array}{l}8 \% \\
(3)\end{array}$ & $\begin{array}{l}5 \% \\
(2)\end{array}$ \\
\hline $\begin{array}{c}\text { Hypothesis } 7 \\
\text { Personal Development, Praxis } \\
\text { Development and ACC } \\
\text { Detractions related to a } \\
\text { Change in Practice } \\
\end{array}$ & $\begin{array}{l}60 \% \\
(28)\end{array}$ & $\begin{array}{l}43 \% \\
(20)\end{array}$ & $\begin{array}{l}37 \% \\
(15)\end{array}$ & $\begin{array}{l}29 \% \\
(12)\end{array}$ & $\begin{array}{l}37 \% \\
(14)\end{array}$ & $\begin{array}{l}32 \% \\
(12)\end{array}$ \\
\hline $\begin{array}{c}\text { Hypothesis 8 } \\
\text { Personal Development, Using } \\
\text { an Holistic Approach and } \\
\text { ACC Detractions related to a } \\
\text { Change in Practice }\end{array}$ & $\begin{array}{l}66 \% \\
(31)\end{array}$ & $\begin{array}{l}47 \% \\
(22)\end{array}$ & $\begin{array}{l}34 \% \\
(14)\end{array}$ & $\begin{array}{l}20 \% \\
(8)\end{array}$ & $\begin{array}{l}34 \% \\
(13)\end{array}$ & $\begin{array}{l}29 \% \\
(11)\end{array}$ \\
\hline
\end{tabular}

Table 6.1: Perceived Positive Relationships between Key Themes of the Transfer of Learning Process 


\section{Disconfirming Evidence}

In order to address the bias of the confirmation trap (Bazerman, 1998) and strengthen the conclusions drawn from this research, the hypothesis testing function of HyperRESEARCH 1.56 was used to search for disconfirming evidence. Hypotheses were constructed to indicate whether any of the participants mentioned elements of the Educational Process, but not Personal Development, and still commented on a Change in Practice. At both twelve and twenty-four months there was only one participant for whom this was true.

When considering whether Personal Development was associated with a Change in Practice, but not Praxis Development or Using an Holistic Approach, the disconfirming evidence was slightly stronger. The hypotheses involving no Praxis Development were supported by six participants at twelve months, nine participants at eighteen months and seven of the participants at twenty-four months. Those involving not Using an Holistic Approach were supported by one participant at twelve months and by eight participants at both eighteen months and twenty-four months.

The hypotheses testing whether participants mentioned a Change in Practice but not Personal Development, also revealed little disconfirming evidence - one participant at twelve months, nine participants at eighteen months and six participants at twenty-four months. From the hypotheses tested it would appear that the amount of disconfirming evidence is not extensive. Furthermore, the nature of the data collection may have had some influence on the amount of disconfirming evidence. The interviews and focus groups became progressively more unstructured during the data collection phases, with ten questions being asked at the twelve month phase and only one at twenty-four months. This means that there was the possibility of participants commenting on aspects which were pertinent to them at the time, and not mentioning other aspects which may have become part of their daily life without consciously linking them back to the VUW Diploma in Rehabilitation Studies. Because of this the number of participants highlighting certain points may understate reality. 


\section{ANOMALOUS FINDINGS}

There appear to be few anomalous findings as such. The nature of the questions asked may have unwittingly influenced participant responses. The interviews and focus groups became less structured over time, with only one question being asked two years after the course. At the eighteen-month stage the questions were focused on outcomes and the influence of organisational changes on case management practice (see Appendix 7), which may account for the apparent drop in perceived transfer.

It may also be possible that the findings at the eighteen-month stage reflect the state of change in which the target organisation was engaged at the time. There was much uncertainty for participants and this was reflected in the comments made. By twenty-four months after the course, the ACC had stabilised again and participants were more certain about where they stood in relation to their employing organisation. These changes are to be expected within organisations, particularly those, which are subject to the whim of government policy. This means that employees of government organisations need to be resilient and develop the ability to ride these 'waves of change' as indicated by Morgan (1988). The findings of this study suggest that the attitudes, values and 'mindsets' of Case Managers within the ACC have been developed as a result of completing the VUW Diploma in Rehabilitation Studies. This has enabled them, in turn, to deal better with the changing nature of their job and the political context within which it operates.

\section{THE EMERGENT TRANSFER OF LEARNING MODEL AND THEORETICAL MODELS}

It is acknowledged that all the participants on the VUW Diploma in Rehabilitation Studies were already on their own personal development trajectory (Bronfenbrenner, 1979) at the start of the course. The course, therefore, came at different points on that trajectory for individual participants. In this respect, the course must be regarded as one 'critical incident' in the personal development of each participant. 
The model in Figure 6.1 illustrates the interrelationships between the central themes highlighted by the research findings from this study that were tested for their strength of association in the hypotheses described above.

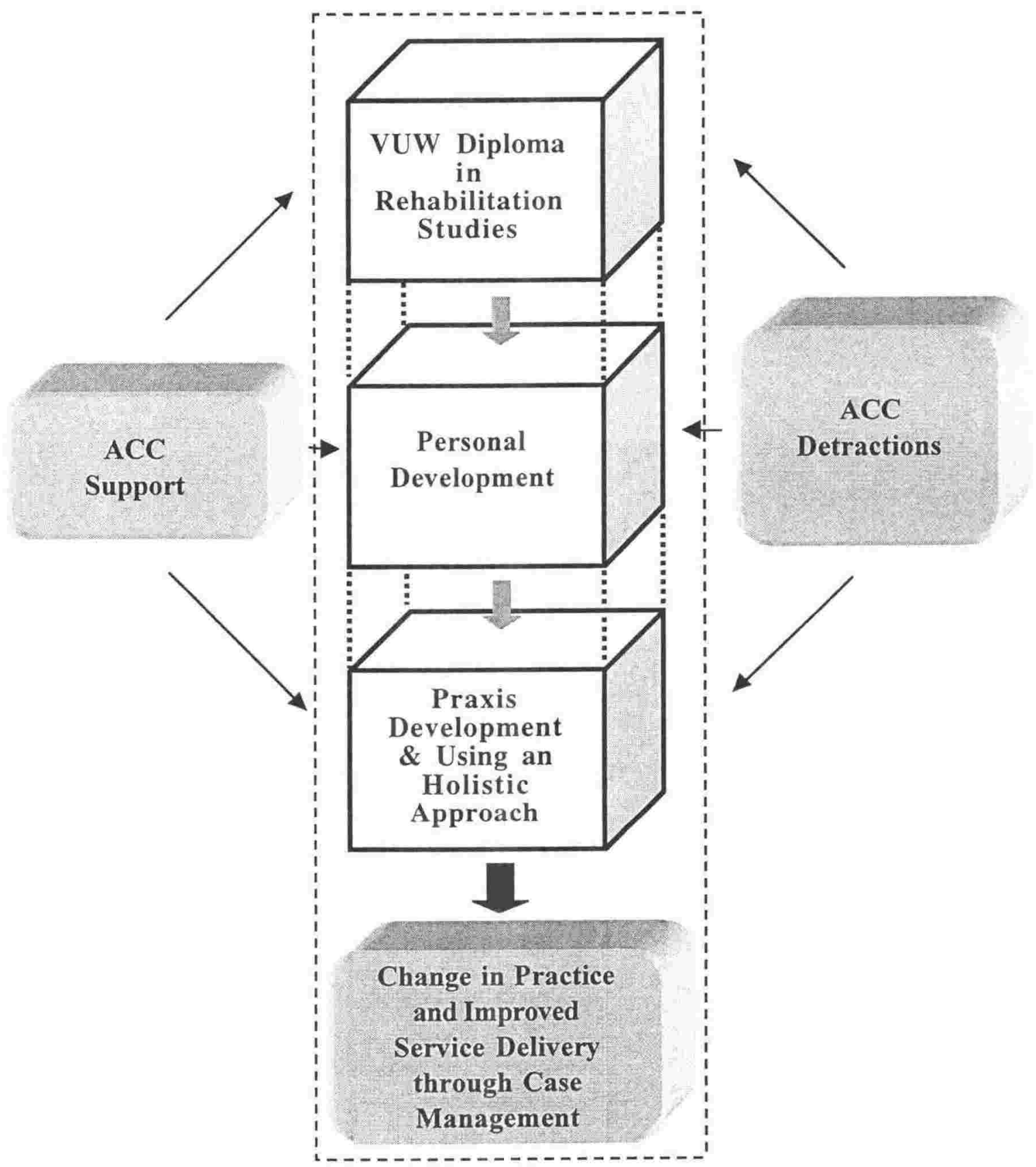

Figure 6.1: Transfer of Learning Model as representative of the data collected

Figure 6.1 suggests that the educational process adopted by the VUW Diploma is the key element on which everything else builds. The educational process accelerated and promoted the Personal Development of participants, which in turn enabled them to become more centred in themselves. Having achieved this, those participants who had experienced Personal Development were more able to develop their praxis and use an holistic approach with clients. This facilitated a change in the personal practice of Case Managers, which 
helped achieve the desired learning outcome of Improved Service Delivery through Case Management. The dotted lines between the three themes represent the fluidity between each and illustrate an interaction between all three. The dashed box around the VUW Diploma in Rehabilitation Studies, Personal Development, Praxis Development \& Using an Holistic Approach, as well as a Change in Practice and Improved Service Delivery through Case Management indicates how these have largely stood alone in this research. Similarly the smaller size of ACC Support compared to ACC Detractions is meant to represent the fact that participants perceived ACC support to only be greater than organisational detractions after one year. Thereafter, the organisational detractions throughout the ACC overshadowed organisational support.

\section{The Task/Setting/Risk Matrix}

Linked to the Transfer of Learning Model, and in particular the hypotheses relating the Educational Process to Personal Development, is the refinement of Inglis's (1994) Task/Setting Matrix shown in Chapter 3, Figure 3.5. Within the context of this research, various task/setting situations were selected for the students. The majority of students were engaged in an unfamiliar task in an unfamiliar setting ('box 4') during the twelve weeks of classroom teaching in Wellington. When they returned to their branches around the country, they moved to 'box 2 ' in that they were still completing an unfamiliar task, but were back in a familiar setting. In terms of the level of risk, particularly psychological risk, their time spent in Wellington was high risk, which as mentioned earlier, is a key component for experiential learning and personal and professional development (see Figure 6.2).

TASK

\begin{tabular}{c|l|c|c|}
\cline { 2 - 3 } \multicolumn{1}{c|}{ SETTING } & \multicolumn{1}{c|}{ Familiar } & Unfamiliar \\
\cline { 2 - 4 } & Familiar & 1 & 2 \\
\cline { 2 - 4 } & & \\
\hline
\end{tabular}

Figure 6.2: Task/Setting/Risk Matrix (adapted from Inglis, 1994) 
Figure 6.2 suggests that as people move away from familiar tasks and settings, the level of risk increases, with the highest level of risk being experienced when in an unfamiliar setting performing an unfamiliar task. This concept of moving people out of their 'comfort zone' is often used to justify taking people into the outdoors for personal development purposes, as well as team building and leadership development amongst corporate groups. The important point to note is that the risk, in order to be educational and lead to personal development, needs to be perceived risk rather than real. Real risks could, in the case of the outdoors, lead to serious injury or even death. The risk advocated in Figure 6.2 is mainly psychological, as compared with physical, which is the case in many outdoor programmes.

\section{The Setting/Task/Risk/Competence Model}

The Setting/Task/Risk/Competence Model incorporates the Task/Setting/Risk Matrix shown above with the concept of individual competence and the concept of 'flow' as developed by Csikszentmihalyi (1975 cited in Ewert, 1989). This scholar argued that the state of 'flow' is achieved when a person's ability is matched by the challenge they have been set. If the challenge is too easy, they will be bored. If the challenge is too difficult, their anxiety level rises. Both boredom and anxiety are generally not conducive to either having peak experiences or performing to one's best ability.

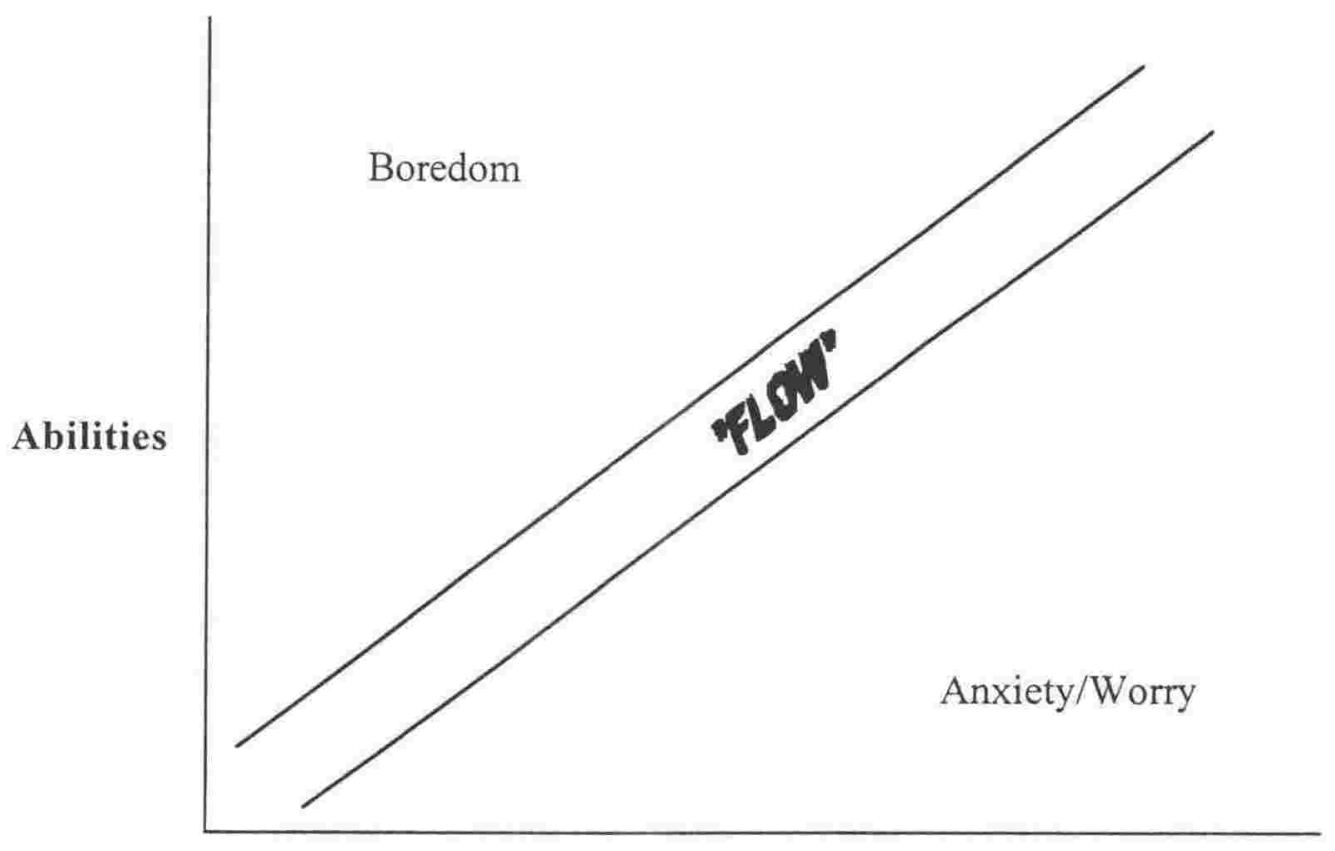

Challenges

Figure 6.3: "Flow" Model of Play (Csikszentmihalyi, 1975 cited in Ewert, 1989, p. 89) 


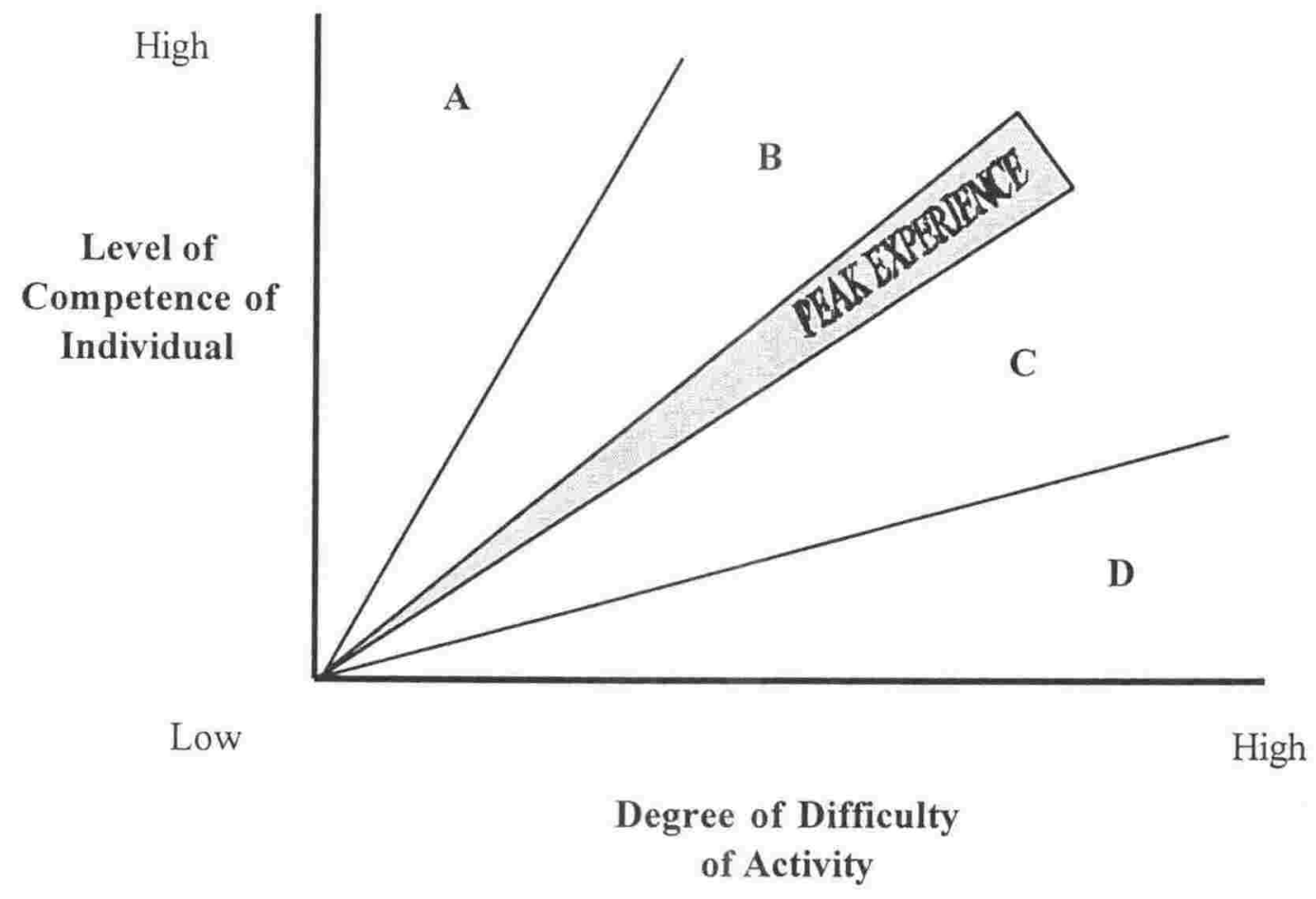

Figure 6.4: Competence/Difficulty Model for Adventure Activities (Davidson, 1992 cited in Haddock 1993, p.50)

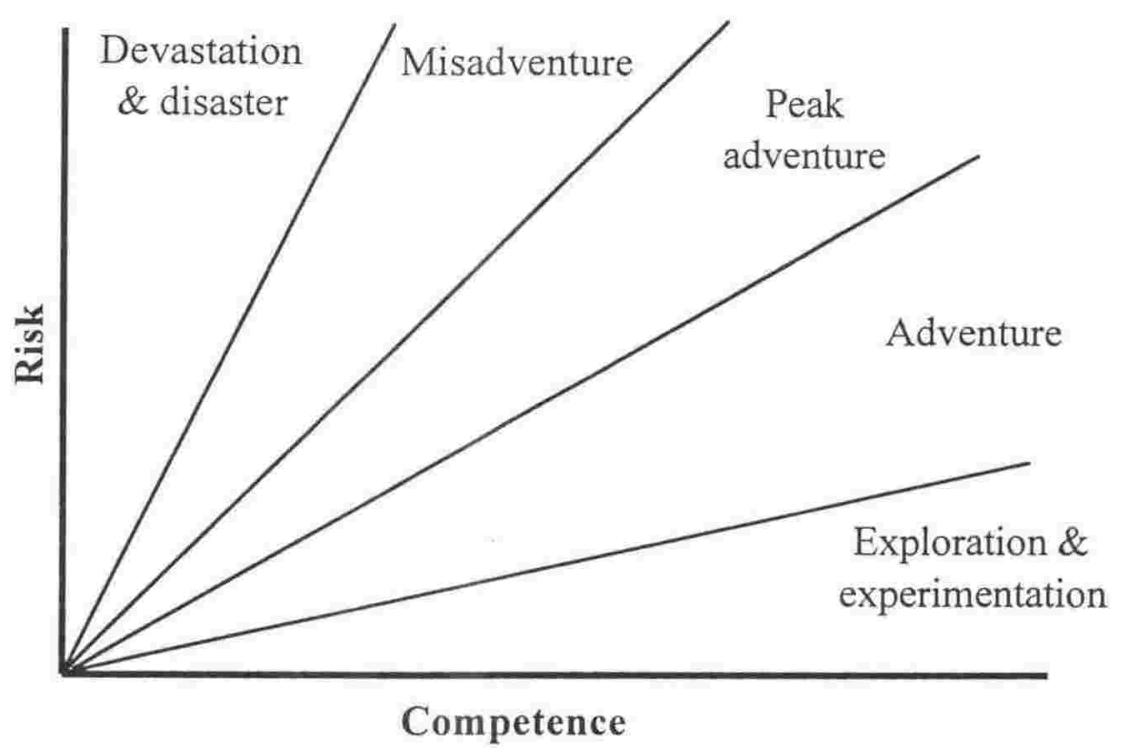

Figure 6.5: Risk/Competence Model (Priest \& Gass, 1997, p.46) 
The Competence/Difficulty Model (Davidson, 1992 cited in Haddock, 1993) and the Risk/Competence Model (Priest \& Gass, 1997) developed for outdoor adventure activities illustrate the relationships between competency and difficulty, and between competency and risk, as shown in Figures 6.4 and 6.5. The Setting/Task/Risk/Competence Model attempts to synthesise all of these concepts to provide a model that can assist managers in making decisions about staff development.

The Task/Setting/Risk matrix as shown in Figure 6.2 can be further developed to include the actual knowledge and skill level - competence - of the person involved. In the case of this research, the knowledge and skill level of Case Managers in the service industry. The flow, the competence/difficulty and the risk/competence models from the adventure education literature have provided a valuable framework from which the Setting/Task/Risk/Competence Model has been derived.

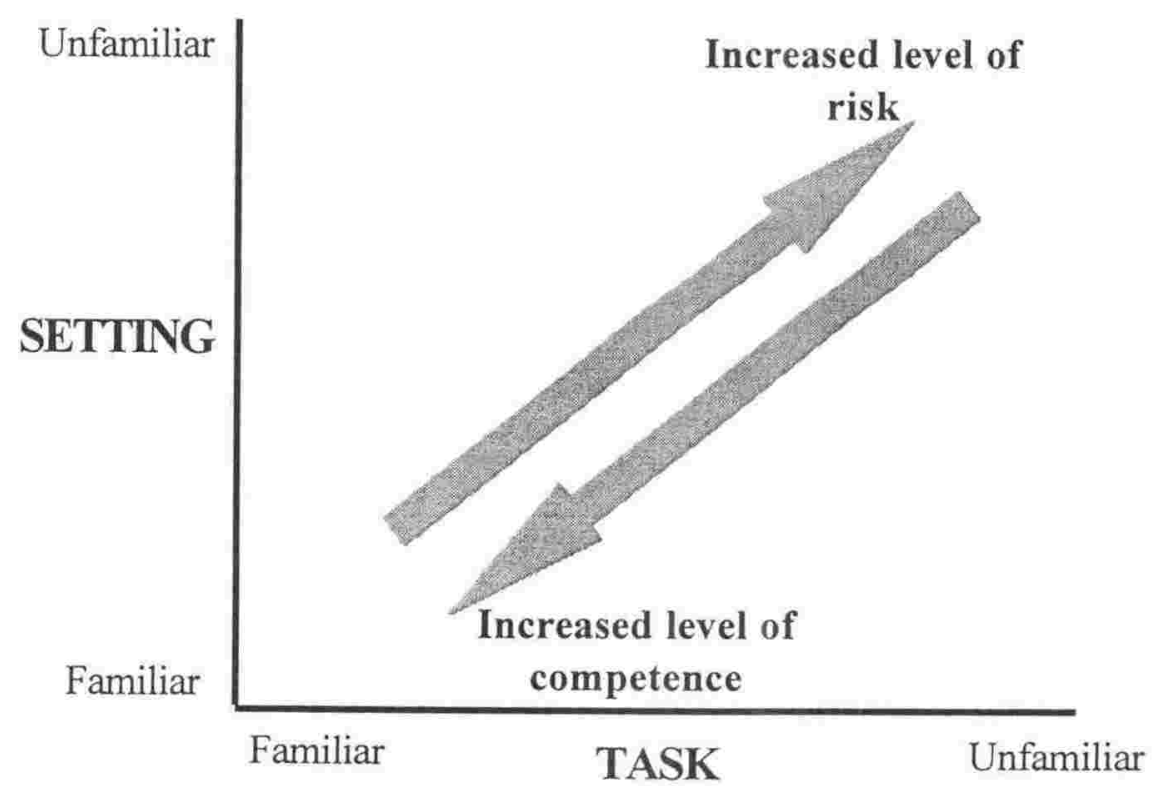

\section{Figure 6.6: Setting/Task/Risk/Competence Model}

The stylised model in Figure 6.6 suggests that the level of worker competence, in addition to familiarity with the task and setting, has an impact on the level of risk experienced by the individual. Where an employee is in the situation of an unfamiliar task and an unfamiliar setting the competence level is likely to be lower with a consequent increase in the level of risk. A situation where competence is high would indicate a lower level of risk. The importance of the level of risk lies in its association with the potential for personal 
development. The experiential literature suggests that an individual is likely to develop personally if moved out of their 'comfort zone' which often means being placed in a situation of perceived risk. The rationale for this is that an individual will rise to the challenge and learn from the experience. In the context of this research the course design sought to include a variety of settings and tasks which would extend participants in

different ways - both personally and professionally. Therefore, participants were out of their 'comfort zones' and in a situation of perceived risk at different times depending on their individual backgrounds. Their individual level of competence associated with the task at hand was also dependent on their perception of the risk level at the time.

The model presented in Figure 6.6 attempts to capture the interaction between the four variables in one model and therefore illustrates the relationship between the variables best at the extremes of each continuum. It is recognised however that most people will probably fall somewhere between the extremes. A person may find themselves in an unfamiliar setting with a reasonably familiar task with the result their competence is likely to be at a mid-point between high and low, and the risk factor not as high. This model may be useful for those making decisions about appropriate training opportunities, as well as considering the potential for personal and professional development in different situations. For example, if an employee is demonstrating high competence in a familiar setting and at a familiar task, it may be useful to provide opportunities for them in a different situation, so that the perceived level of risk for them increases and so, too, does the potential for both personal and professional development.

\section{LIMITATIONS}

As this research adopted a case study approach, the findings and the resulting model can only be generalised to a very limited degree until the model has been tested in other situations. Similarly, by only collecting data from individual participants about their perceptions and opinions, there is no data from supervisors to substantiate participants' statements. However, this approach is consistent with the phenomenological approach adopted. This approach has provided closer insight into participants' experiences of having 
completed the VUW Diploma in Rehabilitation Studies and their subsequent return to the work place.

It is also acknowledged that there was no pre- and post-study, nor control group against which to 'measure' my findings. Such a design is common place in psychological research. However, Bronfenbrenner (1979) challenged the notion of using control groups in his studies on the ecology of human development, where the emphasis was

not on the traditional psychological processes of perception, motivation, thinking, and learning, but on their content - what is perceived, desired, feared, thought about, or acquired as knowledge, and how the nature of this psychological material changes as a function of a person's exposure to and interaction with the environment (Bronfenbrenner, 1979, p.9).

In essence, Bronfenbrenner (1979) advocated that the environment or work place within which a person operates will determine their development. Therefore, to have a control group in a completely different environment offers little validity through comparison.

During the early stages of my research the ACC contracted the Department of Psychology at Massey University to evaluate the transfer of training of the VUW Diploma in Rehabilitation Studies to the corporate environment. The method adopted for that study was described as a

quasi-experimental research design, a longitudinal multiple cohort design, utilis[ing] four cohorts of trainees in a replication-type study to assess the transference of training and the associated facilitators and/or inhibitors of the transference process. The trainees' supervisors and a randomly selected no-training group of participants are also involved in the study to enable comparisons to be made (Collinson \& Brook, 1997, p.1-2).

Interestingly, the findings of the Massey University evaluation support the findings of this research, even though the timeframe was shorter - six months post-training - and the field of study and methodology completely different (see Chapter 3 for more details).

The longitudinal nature of this research means that many other factors could have influenced participants and their responses. This is one of the inherent difficulties associated with longitudinal research, as is the drop off in participant numbers. An attempt was made not to influence participants' responses at each time period, by sending out 
summary information only after interviews and focus groups had taken place with all cohorts. However, invariably participants will have talked to each other and in this respect may have influenced the individual responses given.

Finally, the identification of positive relationships between themes may have been strengthened by incorporating a second opinion.

\section{Chapter Summary}

This chapter has considered the findings in light of the research aims and objectives, and with reference to the pertinent literature. From the discussion of the literature, it is suggested that the various disciplines considered in this research could benefit from an inter-disciplinary approach to both service management and the transfer of learning. The research in each of these areas could assist in informing the other, in order to improve service delivery, by taking a more holistic view of the issue. A number of hypotheses were tested with the aid of the HyperRESEARCH 1.56 hypothesis testing function, to determine the relationships between the key themes at each time interval. The emergent transfer of learning model was presented, building on the relationships between themes as identified in this research. This was followed by a brief discussion around the disconfirming evidence and anomalous findings. Two other developments from this research were also presented. The adaptation of Inglis's (1994) Task/Setting Matrix to include the concept of risk was introduced and then a new model incorporating setting, task, risk and competence was suggested. Some of the limitations were discussed at the end of the chapter. Chapter 7

provides the conclusions from this research, a suggested transfer of learning model, implications for professional practice and recommendations for future research. 


\section{CHAPTER 7 MANAGING THE TRANSFER OF LEARNING}

FROM CLASSROOMS TO WORKPLACES: CONCLUSIONS AND IMPLICATIONS FOR MANAGEMENT PRACTICE

The aims of this research were to identify factors which facilitate the transfer of learning for adult learners from the classroom to the workplace; and to develop an explanatory model which optimises the process. The findings suggest that the key factor facilitating the transfer of learning from the classroom to the workplace for adult learners is the use of a course design that employs experiential/action learning, which incorporates both personal and professional development modules, as well as a work-based practicum. The emphasis needs to be on student-centred learning, which enables participants to reflect on and learn from their personal and professional experiences. At the same time it encourages the participants to move out of their 'comfort zone', which facilitates personal development. The importance of personal development for people working in the human services should not be underestimated, particularly for customer-contact workers. In the case of this research, it has been shown that confident and more self-aware Case Managers report that they are able to provide a better service to their clients, than was the case prior to having completed the VUW Diploma in Rehabilitation Studies.

\section{CONCLUSIONS}

The participants' perceptions of being able to provide an improved service to their clients as a result of the training they received, is important and provides an insight into why improved service delivery took place. However, managers need to know that this is actually happening. For the ACC this could be determined by an analysis of the number of cases handled, the percentage of claimants no longer funded by ACC or the amount of money saved by each Case Manager. These data were not specifically collected as part of this research, as the focus was on the experiences of the participants, even though many participants volunteered such data. The other option would be to conduct a customer service questionnaire to ascertain the level of client satisfaction, which was also beyond the scope of this research. 
As noted, some of the qualitative data collected in this study offered tangible indicators of improved service delivery, particularly with respect to reducing the number of claimants financially supported by the ACC and therefore saving the organisation money. The following comments illustrate this claim.

On average I've got off two of my +52 week claimants per month $\ldots$ all from the skills learned on the course.

My +52 week load has reduced by over $50 \%$ in the last 12 months because of my initial assessments.

I've had the third most closures in the branch.

The two of us working with the long term claimants have got 60 out of 80 off the scheme.

I've saved ACC $\$ 300000$ and it could be more if I had the time.

I've got 40 people back to work since August so I'm nearly at the \$2 million savings mark.

The number of participants who were either promoted, working with serious and complex injury cases or selected to work on the RARLTC scheme, suggests that the ACC valued their skills and knowledge. Overall twenty-nine participants were involved. Five participants were promoted to Head Office and ten to more senior positions in either their Branch or region. Seven participants were selected to work on the serious and more complex injury files, with one participant stating that "the more complex cases are given to Case Managers who've been through the course, although this may depend on the branch". A further seven participants focused on RARLTC which one participant directly attributed to the VUW Diploma in Rehabilitation Studies by saying "I was picked to do this because I'd done the course".

These research findings are supported by the Collinson \& Brook (1997) study, which reported how both the participants and supervisors indicated that the VUW Diploma in Rehabilitation Studies had led to improved claimant management due to a more professional approach and that this was associated with a subsequent reduction in costs to the ACC. 
Collinson \& Brook (1997) also highlighted how the participants had become role models for their colleagues, as well as being sources of information and advice. This may have had a positive effect on the service delivered by all employees, rather than only those who participated on the course.

Most organisations tend to focus their training activities on professional development, focussing on specific skills required for the job, but neglect to develop the person at the same time. This research indicates that once personal development has taken place, people are able to make use of job specific skills learned during training to provide, in this case, a better case management service to clients. In addition, the combination of personal and professional development has led to a change in personal case management practice. This signals a more long term benefit to the organisation as for many participants, their new way of being and working has become second nature.

The combination of off- and on-site training also appears to have been important. The use of a work-based practicum, following the University-based modules, enabled participants to transition back to the workplace in a gradual manner. During this time they were able to readjust to both the home and work environments, whilst still working on specific personalised learning objectives. These learning objectives, together with the Case Study and the Research Project provided specific opportunities for using newly acquired skills and knowledge. It meant that participants were not 'dropped' straight back into their workplace without provision for testing what they had learned.

The role the target organisation plays in facilitating the transfer of learning remains unclear. The findings imply that the desired organisational outcome of improved case management service was achieved in spite of numerous organisational detractions, which occurred during the research period. The service management and transfer literature, as well as common sense, would suggest that transfer will be more successful if the whole organisation was supportive of the training. This means that training needs to be an integral component of the organisation's service management strategy. It may well be that people are more able to ride the waves of change as a result of training that incorporates both personal and professional development. Constant change does not present opportunities to become 
complacent, where the expectation is that people will rise to the challenges as they occur. There were, however, a number of participants who either chose to leave the organisation, or were actively looking for new employment because of the unsupportive nature of the $\mathrm{ACC}$ and the constant changes they were experiencing. As a consequence the ACC has lost a number of valuable Case Managers, which impacts not only on their service delivery, but also provides little return to the organisation in terms of money and time invested in supporting staff through professional training. On balance, an organisation should provide more support than detractions in order to achieve higher levels of transfer of learning.

Collinson \& Brook (1997) also drew attention to ways in which organisational support was limited. Both participants and supervisors commented on this aspect. The supervisors indicated that contributing factors included limited resources, legislative restrictions, too little time and high case-loads.

\section{A GENERIC TRANSFER OF LEARNING MODEL}

The conclusions from the study have been incorporated into a generic transfer of learning model which, it is suggested, explains the preferred conditions for transfer of learning from the classroom to the workplace for adult learners, illustrated in Figure 7.1. This model is different from the one illustrated in Figure 6.1 in that it uses the key components highlighted by the participants in this research but represents them in more generic terms, so that the model can be tested in other situations. The model identifies three building blocks that are necessary for the transfer of learning to take place. These are: Educational Process, Personal Development and Job Specific Processes. The Educational Process is the foundation upon which everything else builds. The Educational Process encourages the personal and skill development of individual participants, which empowers participants to employ the Job Specific Processes needed to achieve desired outcomes. The fluidity and interaction between the three building blocks is represented by the dotted lines. The importance of organisational support has been discussed above. Organisational Support is, therefore, shown as larger than Organisational Detractions in Figure 7.1 because it is unrealistic to suggest there will be no detractions, particularly if this model is to be applicable to both government and private organisations. 


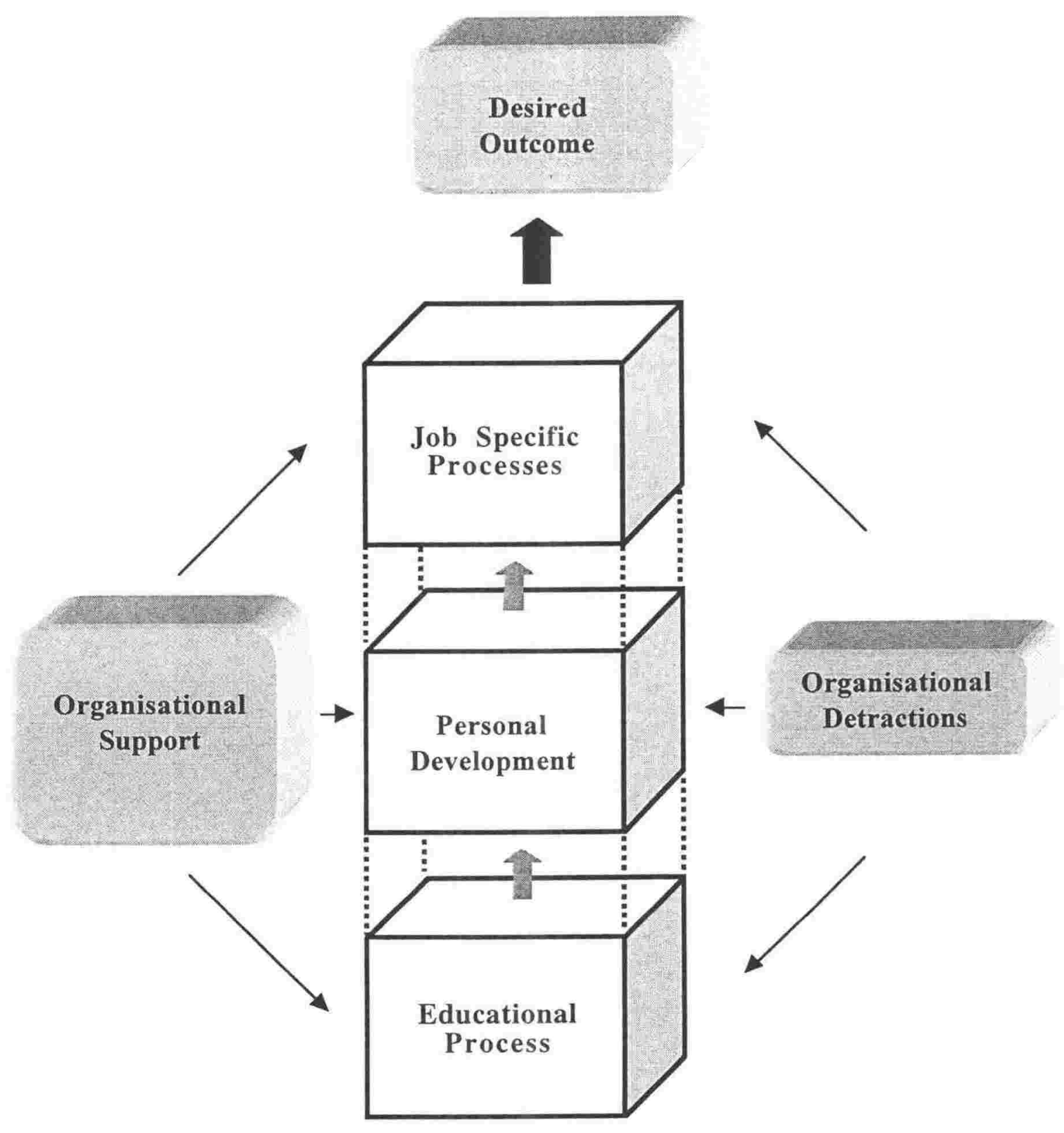

Figure 7.1: Recommended Transfer of Learning Model

This model contributes to the existing knowledge in the transfer of training/learning field as found in the service management and transfer literature (Analoui, 1993; Broad \& Newstrom, 1992; Gregoire et al., 1998; Holton, 1996). It integrates elements pertinent to this research into a wider theoretical model. The model has been derived from the experiences of course participants and focuses on the educational process, whereas existing 
models have been based on training provider and organisational perceptions, as well as reviews of the literature. The importance of the teaching methodology and the selection of appropriate learning activities have been highlighted in the literature (Analoui, 1993; Gass, 1989; McGraw, 1993). This model therefore endorses these observations from the participant's perspective. It is recognised that the elements of the Transfer of Learning Model suggested in Figure 7.1 do not interact in a vacuum, but are influenced by the social, cultural, economic and political environments, within which they operate. Depending on the situation, these environments may have a supportive or detracting influence on the various elements of the model.

\section{IMPLICATIONS FOR MANAGEMENT, PROFESSIONAL PRACTICE AND EDUCATIONAL PROVIDERS}

This research has a number of implications for human service organisations considering training and learning opportunities for front-line staff, which are detailed below.

\section{Implications for Management}

\section{Training and strategic goals.}

Management must consider how training and development programmes link into the overall strategic goals of the organisation. For maximum benefit, the training and development programmes should be aligned with the organisation's strategic directions. This may pose difficulties for large government service organisations like the ACC because of the constant changes in policies and/or government, to which they are subjected. It is important for the organisation to clearly identify the desired learning outcomes and then ensure that the organisation provides opportunities to implement the learning. In this research the target organisation's approach to case management changed part way through the research process. The original learning outcomes specified being able to adopt an holistic approach to case management so as to improve service delivery to ACC claimants. However, this emphasis on using an holistic approach changed with the formation of a new MMP-elected Government in October 1996. The focus throughout 1997 became that of saving money, a focus that was further emphasised with the appointment of a new CEO at the end of 1997. 
The aim was to reduce the number of long-term claimants as fast as possible, and not to look at each situation in an holistic manner. This complete change in emphasis resulted in many of the participants being compromised. They had been sent on a course to learn a certain approach, which they did. However, on return to their branch they were not encouraged to use this approach and found themselves in difficult situations.

\section{Adopting an inclusive approach.}

All levels of the organisation affected by training and development programmes should be involved in the planning stages. This will ensure that both participants and nonparticipants are aware of the programmes, what they aim to achieve and how the training process may affect the workplace. This is especially pertinent to immediate colleagues and their supervisors. The findings would suggest that the ACC was not particularly successful in communicating the educational process of the VUW Diploma in Rehabilitation Studies, the associated expectations placed on the PCMs and the workplace implications of the practicum. In order to facilitate the transfer of learning, organisations need to ensure that the appropriate structures and procedures are in place for participants to be supported throughout the training process. This is particularly important for large national service organisations, which may have a centralised Head Office with local branches delivering services to the community.

\section{Recognition of training and possibilities for advancement.}

Management needs to ensure that successful completion of training is recognised in performance appraisals and where appropriate rewarded in financial terms. It is also important to provide opportunities for training participants to extend themselves or progress in their careers on return to the workplace. Failure to do so may result in skilled employees leaving the organisation. This represents not only a skill and knowledge loss but also a financial loss in terms of the training time and money invested. Five participants in this research left the ACC for these very reasons. A number of other participants were actively seeking new positions outside the organisation, as they felt that their work was not recognised and there was a lack of opportunities for professional advancement. Staff need to be valued as a scarce resource and as real people who have a contribution to make. Training and development programmes which focus on both personal and professional 
development are more likely to have long-term effects, particularly when specific skills required of employees may change in a short period of time. If employees are selfconfident independent thinkers with a desire to learn, the change process may be much easier to achieve, and new skills or processes more readily adopted.

\section{Implications for Professional Practice}

\section{The time spent planning will pay off in the long run.}

Before developing training opportunities for staff it is important to clearly identify the desired outcome(s) of the training. This process should involve all the key stakeholders, including potential course participants and supervisors. Once this has been established, a training provider should be contracted who is able to work with the organisation to develop a tailor-made training programme. Time needs to be set aside for planning not only the course content in conjunction with the training provider, but also for ensuring operational details are organised, including transport, accommodation and cover for staff attending the training. These operational factors may appear trivial, but experience with the VUW Diploma in Rehabilitation Studies would suggest that students struggle to focus on the training when these primary needs are not met. It is also important to review each training opportunity involving the organisation, the training provider and the participants, so that improvements can be made to future training.

\section{Training courses need to be appropriate to the participants.}

When designing training courses it is important to carefully consider who the participants are going to be, as well as having an appreciation of their backgrounds. In general, there are a number of ways in which desired outcomes can be achieved, with the process used varying depending on the situation. This is where tailor-made training courses come to the fore. Delivering training courses to adult learners generally means that the participants come from a heterogeneous background, bringing with them a range of preferred learning styles and a myriad of experiences on which they can draw. It is, therefore, important that the educational process adopted is flexible enough to cater to the diverse needs of the participants, so that they all have the opportunity to develop, both personally and professionally, through the training. 


\section{The importance of experiential/action learning approaches with adult learners is not to}

\section{be underestimated.}

The experiential/action learning approach offers a process, which is flexible in terms of design and provides the capacity to meet the differing needs of different learners. The focus on action and reflection, as well as personal and professional development, provides a variety of learning opportunities for participants. Experiential learning encompasses numerous delivery options including indoor and outdoor, physical and non-physical. The key point to note is that the choice of delivery option needs to be suited to the participants and enable the desired outcome(s) to be achieved. Taking a group of people on a three-day outdoor management development programme may not be the best option for the participants nor will it necessarily achieve the desired outcome(s). The action learning approach falls within the options offered in experiential learning. It provides a specific tie-in with the organisation in terms of using work-based projects as the basis for personal and professional development, as well as using learning sets where members support each other in their development. Action learning aims to develop individuals to the point where they are independent of facilitators and seek their assistance only when required.

\section{There needs to be a focus on personal development, not just professional development.}

Training in the human services should always include a component of personal development associated with professional development. The findings from this research suggest that the development of self-confidence in the participants enabled them to actually adopt specific case management skills learned in the classroom and apply these back in the work place with improved service delivery to clients. It is unlikely that the same readiness to employ new skills would have been evident without the increased self-confidence. People working in the human services require not only job specific skills but also finely honed interpersonal communication skills for dealing with the wide variety of clients encountered in their daily practice. In order to provide a consistent quality service to each client, Case Managers need to be self-confident, know who they are, be self-aware and above all be centred in themselves - so they do not falter when a challenging situation presents itself. 


\section{All staff can develop and rise to the occasion, not just some.}

Much of the transfer literature advocates that only certain individuals are able to benefit from training and should be selected accordingly. The research findings from this study would imply that this is not necessarily the case. The participants represented a wide variety of backgrounds, in terms of gender, ethnicity, age and level of education. In spite of this diversity, all participants indicated that they had experienced some personal and/or professional development, which in varying degrees has transferred back to the work environment. The use of an experiential/action learning approach enabled participants to experience learning opportunities, which were pertinent to their situation and develop from these learning experiences.

\section{Transfer of training/learning is an integral component of service management.}

Service management is primarily seen as providing services to clients, mainly external, but also internal. It is also about being able to provide quality 'moments of truth'. The transfer of training/learning back to the workplace is discussed less often in the service management literature. This research considers the transfer of training/learning as part of internal and external service management. Providing training to staff should be considered as an integral component of internal service management. The transfer of that training back to the workplace is primarily of benefit to the client, in terms of improved external service delivery, but it also enhances the service image of the organisation.

\section{Implications for Educational Providers}

\section{Effective educational programmes.}

This research suggests that experiential education can produce positive results for adult learners, particularly with respect to personal development. The use of an action learning approach provided a workable framework for focussing on not only personal, but also professional development. The integration of a University-based and work-based phase of the VUW Diploma in Rehabilitation Studies also appears to have been beneficial to participants. The time away from work enabled participants to reflect on their personal and professional lives, as well as develop networks with fellow ACC Case Managers from 
throughout New Zealand. The supervised work-based practicum facilitated the transition back into full-time work and provided opportunities for participants to put into practice what they had learned, by working towards personalised learning objectives, completing a case study and completing a research project. The final call-back module at Victoria University in Wellington consolidated the programme with participants presenting the findings of their research project and reviewing the learning from their learning objectives with their Cohort colleagues as well as PCMs, Branch Managers, Regional Managers and representatives from Head Office.

\section{The limitations of different agendas.}

In an increasingly competitive, consumer and service environment, tertiary providers are seeking to meet the needs of industry by providing tailor-made education programmes. The VUW Diploma in Rehabilitation Studies was an example of this. The ACC originally commissioned Victoria University to develop an intensive programme of professional education and training for three cohorts of 40 adult learners employed as, or being recruited to become Case Managers within the ACC. In terms of Victoria University the proposed course matched the University's Vision of the time very closely. Amongst other things, the VUW Diploma in Rehabilitation Studies provided a memorable experience to participants, fostered a culture of innovation and creativity for both staff and participants, established community links throughout New Zealand, renewed the tradition of challenge and critical thinking, and implemented the University's Treaty of Waitangi obligations. The continuation of the programme was to take place if the ACC was satisfied with the transfer of learning back to the workplace of the first three cohorts. The programme was deemed successful by the ACC with the original contract being extended enabling a further two cohorts of 40 students to attend the VUW Diploma in Rehabilitation Studies. However, towards the end of the fourth Cohort it became evident that significant organisational changes were taking place in both the ACC and Victoria University. This resulted in the programme being discontinued, despite acknowledged benefits to the $\mathrm{ACC}$, measured through improved service delivery and Victoria University, measured in terms of substantial financial revenue. 


\section{RECOMMENDATIONS FOR FUTURE RESEARCH}

As with other research, additional issues have arisen during the course of this study, which would merit further investigation. These include research:

- It is recommended that the proposed transfer of learning model be tested in other human service organisations. The perceived positive relationships between key themes, in particular, need to be considered in different situations to determine their influences on the transfer of learning. The phenomenological approach adopted for this research has considered the experiences of a particular group of people over time. This provided a number of insights into the transfer of learning from the classroom to the workplace. The more positivistic psychological study undertaken by Collinson \& Brook (1997) examined similar issues with a larger sample of the same population but came to similar conclusions. The combined outcomes from these two pieces of research show that there is merit in testing the proposed transfer of learning model in other situations to enhance its validity and applicability to the human services in wider terms.

- It is recommended that the link between the transfer of learning and service management be investigated in other settings. This research suggests that the transfer of training/learning should be regarded as an integral component of an organisation's service management strategy. In order for this to eventuate it is necessary for the organisation to take a holistic approach to educational programmes. Consultation, communication and commitment, throughout the organisation, are vital for this approach to be successful. The challenge here is for government organisations, which often have little or no control over significant changes that are imposed on them.

- It is recommended that the impact of setting and duration of training on the transfer of learning be considered more closely. The combination of on- and offsite training appears to have been important in facilitating the transfer of learning for participants involved in this research. There was, however, little evidence to suggest whether the duration of the programme was significant or not. These factors are 
particularly important as they have direct financial implications for organisations considering training opportunities. Research identifying the impact of setting and duration would be particularly valuable if it was linked with the type of learning outcome desired by the organisation i.e. specific task development, personal development or a combination of the two. Priest (1998) has also advocated the merit of further research in this area.

- It is recommended that more research be conducted which focuses on the experiences of training participants. Most of the research on the transfer of learning has been based on the perceptions of training providers and workplace supervisors or managers. This research is one of few studies which has considered the impact of training on participants. There also appears to be a limited amount of research examining the long-term impact of participation in adult learning opportunities, which link people with their working lives, a recommendation also made by Benseman (1996). More research in the area of participants' experiences will assist in providing a more complete picture of the transfer of learning process. This will be particularly valuable if this is in the form of long-term longitudinal studies, as the majority of research on the transfer of learning only considers the period six months post training. Organisations, however, are increasingly interested in the long-term benefits they will derive from investing in training and development programmes.

\section{Concluding Reflections}

This research has considered the transfer of learning experiences of the ACC Case Managers, identified the key factors facilitating this process for them over a two-year period, and recommended a transfer of learning model, which focuses on the educational process. It has also provided a synthesis of the literature in the fields of service and case management, experiential/action learning, adult education and the transfer of training and learning. This study represents only one stage in seeking to better understand the complexities of the transfer of training and learning process, particularly in the longer term. In keeping with the action learning approach it is now necessary to reflect on this stage and 
to then put the learning into practice, from which new learning will come and a new action learning cycle will begin.

The process of carrying out this research has been a very challenging, rewarding, interesting and, at times, frustrating experience. I have learned the importance of flexibility. Not everything goes as planned where research is involved. This is an important researcher quality, particularly for someone like me who is a very organised person and prefers things to go to plan. Research for me is now very much a cyclical rather than a linear process, where each step seems to determine what to do next. Sometimes you have to go backwards or sideways before going forward, and then once you have reached a certain point you realise that rather than it being the final destination there is something new to consider. I have become very much aware that using a qualitative phenomenological approach is anything but easy. I was certainly not prepared for the vast amount of data I collected and the difficulties associated with analysis and interpretation. It was a challenge to try and accurately portray the participant's experiences, whilst at the same time condensing the information into manageable amounts to include in the thesis. Similarly, the choice of topic area provided its own challenge in terms of its interdisciplinary nature, requiring me to further develop my skills of synthesis. Accomplishing each phase required for this thesis, has in a sense been my educational process, which has led me to develop both personally and professionally. I have also acquired a number of valuable job specific skills, which will assist me in my work as a University lecturer. In completing this thesis I have achieved the desired outcome originally sought. However, I feel that I have gained so much more in terms of confidence with respect to the research process, a much clearer understanding of the challenges associated with research and an in-depth knowledge of the theoretical frameworks considered. 


\section{BIBLIOGRAPHY}

Accident Rehabilitation and Compensation Insurance Company. (1994a). Annual report. Wellington.

Accident Rehabilitation and Compensation Insurance Company. (1994b). Strategic directions 1994-1997. Wellington.

Accident Rehabilitation and Compensation Insurance Company. (1995a). Annual report. Wellington.

Accident Rehabilitation and Compensation Insurance Company. (1995b). Accident compensation 1995: A discussion document. (Discussion Document ). Wellington.

Accident Rehabilitation and Compensation Insurance Company. (1996a). Annual report. Wellington.

Accident Rehabilitation and Compensation Insurance Company. (1996b). Competencies for case managers. Wellington.

Accident Rehabilitation and Compensation Insurance Corporation. (1997a). Annual report. Wellington.

Accident Rehabilitation and Compensation Insurance Corporation. (1997b). Strategic Directions 1997-2000. Wellington.

Alexander, C. B. (1993). Soft systems methodology: Theory and practice. Unpublished Research Report, Massey University, Palmerston North.

Aliotta, S. L. (1996). Components of a successful case management program. Managed Care Quarterly, 4(2), 38-45. 
Allen, P. (1995). Evaluating quality. In D. Pilling \& G. Watson (Eds.), Evaluating quality in services for disabled and older people., (pp. 107 - 113). London: Jessica Kingsley Publishers.

Analoui, F. (1993). Training and transfer of learning. Aldershot: Avebury.

Argyris, C. (1994). Good communication that blocks learning. Harvard Business Review, 72(4), 77-85.

Argyris, C. (1997). Learning and teaching: A theory of action perspective. Journal of Management Education, 21(1), 9-26.

Argyris, C., \& Schön, D. A. (1978). Organisational learning: A theory of action perspective. Reading, MA: Addison-Wesley Publishing Company.

Ashton, D. (1988). Are business schools good learning organisations? - Institutional values and their effects in management education. Personnel Review, 4(17), 9 - 14.

Ashton, T. (1995). From evolution to revolution: Restructuring the New Zealand health system. In D. Seedhouse (Ed.), Reforming health care: The philosophy and practice of international health reform., (pp. 85-94). Chichester: John Wiley \& Sons.

Austin, C. D. (1992). Have we oversold case management as a "quick fix" for our long-term-care system? Journal of Case Management, I(2), 61-65.

Bailyn, L., Fletcher, J. K., \& Kolb, D. (1997). Unexpected connections: Considering employees' personal lives can revitalize your business. Sloan Management Review (Summer), 11-19.

Baker, C., Wust, J., \& Stern, P. N. (1995). Method slurring: The grounded theory/phenomenology example. In B. G. Glaser (Ed.), Grounded theory 1984-1994. Volume one., (pp. 41-52). Mill Valley, CA: Sociology Press. 
Baldwin, T. T., \& Ford, J. K. (1988). Transfer of training: A review and directions for future research. Personnel Psychology, 41, 63-105.

Balfour, D. L., \& Marini, F. (1991). Child and adult, X and Y: Reflections on the process of public administration education. Public Administration Review, 51(6), 478-485.

Bank, J. (1994). Outdoor development for managers. (2 ed.). Aldershot: Gower.

Basch, C. E. (1987). Focus group interview: An underutilised research technique for improving theory and practice in health education. Health Education Quarterly, 14(4), 411448.

Bazerman, M. H. (1998). Judgement in managerial decision making. (4 ed.). New York: John Wiley \& Sons Inc.

Becker, P. H. (1995). Pearls, pith and provocation: Common pitfalls in published grounded theory research. In B. G. Glaser (Ed.), Grounded theory 1984-1994. Volume one., (pp. 135-140). Mill Valley, CA: Sociology Press.

Bell, C. R., \& Sims, F. C. (1996). Customer service training. In R. L. Craig (Ed.), The ASTD training and development handbook: A guide to human resource development., (4 ed., pp. 900-914). New York: McGraw-Hill.

Bennett, N. (1997). Analysing management for personal development: Theory and practice. In L. Kydd, M. Crawford, \& C. R. Riches (Eds.), Professional development for educational management., (pp. 60-73). Buckingham: Open University Press.

Benseman, J. (1996). Continuing professional education. In J. Benseman, B. Findsen, \& M. Scott (Eds.), The fourth sector: Adult and community education in Aotearoa/New Zealand., (pp. 234-246). Palmerston North: Dunmore Press Limited.

Bereiter, C. (1995). A dispositional view of transfer. In A. McKeough, J. Lupart, \& A. Marini (Eds.), Teaching for transfer: Fostering generalization in learning., (pp. 21-34). Mahwah, NJ: Lawrence Erlbaum Associates. 
Bergman, B., \& Klefsjö, B. (1994). Quality from customer needs to customer satisfaction. London: McGraw-Hill Book Company.

Billet, S. (1992). Towards a theory of workplace learning. Studies in Continuing Education, 14(2), 143-155.

Billet, S. (1994). Searching for authenticity: A socio-cultural perspective of vocational skill development. Vocational Aspects of Education, 46(1), 3-16.

Binder, C. (1990). Closing the confidence gap. Training, (September), 49-56.

Blaikie, N. (1993). Approaches to social enquiry. Cambridge: Polity Press.

Blanchard, P. N., \& Thacker, J. W. (1999). Effective training: Systems, strategies, and practices. Upper Saddle River, NJ: Prentice-Hall, Inc.

Blaxter, L., Hughes, C., \& Tight, M. (1996). How to research. Buckingham: Open University Press.

Blois, K. J. (1992). Carlzon's moments of truth - a critical appraisal. International Journal of Service Industry Management, 3(3), 5-17.

Blomberg, R., Levy, E., \& Anderson, A. (1988). Assessing the value of employee training. Health Care Management Review, 13(1), 63-70.

Boddy, D. (1981). Putting action learning into action. Journal of European Industrial Training, 5(5), 1-20.

Booth, A. (1998). Fast \& easy research. Sydney: Prentice Hall.

Borg, I., \& Mohler, P. P. (Eds.). (1994). Trends and perspectives in empirical social research. New York: W. de Guyter. 
Boud, D., Cohen, R., \& Walker, D. (Eds.). (1993). Using experience for learning. Buckingham: Open University Press.

Boud, D., Keogh, R., \& Walker, D. (Eds.). (1985). Reflection: Turning experience into learning. London: Kogan Page.

Boud, D., \& Knights, S. (1996). Course design for reflective practice. In N. Gould \& I. Taylor (Eds.), Reflective learning for social work: Research, theory and practice., (pp. 23-34). Aldershot: Arena Ashgate Publishing Limited.

Boud, D., \& Walker, D. (1991). Experience and learning: Reflection at work. Geelong: Deakin University Press.

Boud, D., \& Walker, D. (1998). Promoting reflection in professional courses: The challenge of context. Studies in Higher Education, 23(2), 191-206.

Bourner, T., Beaty, L., Lawson, J., \& O'Hara, S. (1996). Action learning comes of age: Questioning action learning. Education \& Training, 38(8), 32-35.

Bourner, T., \& Frost, P. (1996). In their own words: The experience of action learning in higher education. Education \& Training, 38(8), 22-31.

Bowen, D. E., \& Lawler III, E. E. (1995). Empowering service employees. Sloan Management Review (Summer), 73-84.

Bramley, P. (1991). Evaluating training effectiveness: Translating theory into practice. London: McGraw-Hill Book Company.

Brew, A. (1995). Directions in staff development. Buckingham: SHRE \& Open University Press.

Bright, B. (1996). Reflecting on 'reflective practice'. Studies in the Education of Adults, $28(2), 162-184$. 
Brinkerhoff, R. O., \& Montesino, M. U. (1995). Partnerships for training transfer: Lessons from corporate study. Human Resource Development Quarterly, 6(3), 263-274.

Broad, M. L., \& Newstrom, J. W. (1992). Transfer of training: Action-packed strategies to ensure high payoff from training investments. Reading, MA: Addison-Wesley Publishing Company.

Bronfenbrenner, U. (1979). The ecology of human development: Experiments by nature and design. Cambridge, MA: Harvard University Press.

Brook, J., \& Collinson, C. (1995). A study of the transfer of training: From the tertiary setting to the corporate environment. Phase 1. (Unpublished ). Palmerston North: Massey University.

Brook, J., \& Collinson, C. (1996). A Study of the transfer of training: From the tertiary setting to the corporate environment. Phase $2 \& 3$. (Unpublished ). Palmerston North: Massey University.

Brunner, J. (1960). The process of education. New York: Vintage Books.

Bryman, A., \& Burgess, R. G. (Eds.). (1994). Analyzing qualitative data. London: Routledge.

Buckley, R., \& Caple, J. (1996). One-to-one training and coaching skills. London: Kogan Page.

Bunning, C. (1992). The reflective practitioner: A case study. Journal of Management Development, 11(1), 25-38.

Bunning, C. (1994). Action research: An emerging paradigm. (Occasional Papers Series 4). Brisbane: The Tertiary Institute, The University of Queensland.

Bunning, C. (1995). An introduction to action learning. Handout from Action Learning Seminar held by Cliff Bunning, 8 March 1995, Massey University, Palmerston North. 
Burford, G., \& Fulcher, L. C. (1995). Images video series. Wellington: Department of Applied Social Sciences, Victoria University of Wellington.

Burnard, P. (1991). Experiential learning in action. Aldershot: Avebury.

Bushy, A. (1997). Case management: Considerations for coordinating quality services in rural communities. Journal of Nursing Care Quality, 12(1), 26-36.

Cameron-Jones, M., \& O'Hara, P. (1997). Challenge and support for work-based learning. Studies in the Education of Adults, 29(2), 169-178.

Campbell, I. B. (1996). Compensation for personal injury in New Zealand: Its rise and fall. Auckland: Auckland University Press.

Carlzon, J. (1987). Moments of truth. Sydney: Harper \& Row.

Castaldi, T. M. (1989). Adult learning: Transferring skills from the workplace to the classroom. Lifelong Learning, 12(6), 17-19.

Castellese, G. J. (1995). Customer service . . building a winning team. Supervision (January), 9-13.

Chapman, S., McPhee, P., \& Proudman, B. (1995). What is experiential education? In K. Warren, M. Sakofs, \& J. S. J. Hunt (Eds.), The theory of experiential education., (3 ed., pp. 235-248). Dubuque, Iowa: Kendall/Hunt Publishing Company.

Charmaz, K. (1994a). Discovering chronic illness: Using grounded theory. In B. G. Glaser (Ed.), More grounded theory methodology: A reader., (pp. 65-94). Mill Valley, CA: Sociology Press.

Charmaz, K. (1994b). The grounded theory method: An explication and interpretation. In B. G. Glaser (Ed.), More grounded theory methodology: A reader, (pp. 95-115). Mill Valley, CA: Sociology Press. 
Checkland, P. (1981). Systems thinking, systems practice. Chichester: John Wiley \& Sons.

Cheek, J. (1996). Taking a view: Qualitative research as representation. Qualitative Health Research, 6(4), 492-505.

Cheeseman, J. (1994). How managers can help: Transferring accident investigation training to the workplace. Professional Safety (October), 22-27.

Cherrington, R., \& Van Ments, M. (1994). Pinning down experiential learning. Studies in the Education Of Adults, 26(1), 15-30.

Chisholm, R., F., \& Elden, M. (1993). Features of emerging action research. Human Relations, 46(2), 275-298.

Cocklin, B. (1996). Applying qualitative research to adult education: Reflections upon analytic processes. Studies in the Education of Adults, 28(1), 88-116.

Cohen, M. B., \& Deri, R. (1992). The dilemma of 'grandparenting' in state licensure: Confronting the training needs of nondegreed workers. Social Work, 37(2), 155-157.

Collinson, C., \& Brook, J. (1997). Transfer of training: An evaluation of transfer from the tertiary setting to the corporate environment. Palmerston North: Department of Psychology, Massey University.

Coloquhoun, D., \& Kellehear, A. (Eds.). (1993). Health research in practice: Political, ethical and methodological issues. London: Chapman Hall.

Conti, R. M. (1996). Nurse case manager roles: Implications for practice and education. Nursing Administration Quarterly, 21(1), 67-81.

Cook, S. C., \& Yanow, D. (1993). Culture and organisational learning. Journal of Management Inquiry, 2(4), 373-390. 
Coopey, J. (1995). The learning organisation, power, politics and ideology. Management Learning, 26(2), 193-213.

Cormier, S. M., \& Hagman, J. D. (Eds.). (1987). Transfer of learning: Contemporary research and applications. San Diego: Academic Press Inc.

Cotterill, P. (1992). Interviewing women: Issues of friendship, vulnerability, and power. Women's Studies International Forum, 5(15), 593-606.

Cranton, P. (1994). Understanding and promoting transformative learning: A guide for educators of adults. San Francisco: Jossey-Bass Publishers.

Cresswell, J. W. (1994). Research design - qualitative and quantitative approaches. Thousand Oaks, CA: Sage Publications.

Crosby, A. (1995). A critical look: The philosophical foundations of experiential education. In K. Warren, M. Sakofs, \& J. S. J. Hunt (Eds.), The theory of experiential education., (3 ed., pp. 3-14). Dubuque, Iowa: Kendall/Hunt Publishing Company.

Csikszentmihalyi, M., \& Csikszentmihalyi, I. S. (Eds.). (1988). Optimal experience: Psychological studies of flow in consciousness. Cambridge: Cambridge University Press.

Curry, D. H., Caplan, P., \& Knuppel, J. (1994). Transfer of training and adult learning (TOTAL). Journal of Continuing Social Work Education, 6(1), 8-14.

Cusins, P. (1995). Action learning revisited. Industrial \& Commercial Training, 27(4), 3-10.

Davenport, T. H., \& Prusak, L. (1998). Working knowledge: How organizations manage what they know. Boston, MA: Harvard Business School Press.

Davey, J., Laing, P., Neale, J., Opie, A., Pearson, D., \& Toynbee, C. (1994). Doing social research in New Zealand: Methods, reflections and sources. (Occasional Paper in Sociology and Social Work 9). Wellington: Victoria University of Wellington. 
DeLay, R. (1996). Forming knowledge: Constructivist learning and experiential education. The Journal of Experiential Education, 19(2), 76-81.

Denzin, N. K., \& Lincoln, Y. S. (Eds.). (1994). Handbook of qualitative research. Thousand Oaks, CA: Sage Publications.

Detterman, D. K., \& Sternberg, R. J. (Eds.). (1993). Transfer on trial: Intelligence, cognition and instruction. Norwood, NJ: Alex Publishing Corporation.

Dewey, J. (1938). Experience and education. New York: Collier.

Dey, I. (1993). Qualitative data analysis: A user-friendly guide for social scientists. London: Routledge.

Dickens, P. (1996). Human services as service industries. The Service Industries Journal, 16(1), 82-91.

Diwan, S., Berger, C., \& Ivy, C. (1996). Supervision and quality assurance in longterm-care case management. Journal of Case Management, 5(2), 65-71.

Dixon, K. (1994). Accounting in hospital organisations in New Zealand: A qualitative study in the reform context of 1984 - 1994. Unpublished $\mathrm{PhD}$, Massey University, Palmerston North.

Dotlich, D. L., \& Noel, J. L. (1998). Action learning: How the world's top companies are re-creating their leaders and themselves. San Francisco: Jossey-Bass Publishers.

Driessen, B. (1997). New environment for ACC operations network: Information for staff. . Wellington: Accident Rehabilitation and Compensation Insurance Corporation.

Dupuis, P. R. (1994). HyperRESEARCH (Version 1.56). Randolph, MA: ResearchWare Inc. 
Eardley, T. (1996). Case management for the unemployed. Does it work? Social Policy Research Centre Newsletter, 63, November (SPRC, University of NSW, Sydney, Australia).

Easterby-Smith, M., Thorpe, R., \& Lowe, A. (1994). Management research: An introduction. London: McGraw-Hill Book Company.

Ecclestone, K. (1996). The reflective practitioner: Mantra or a model for emancipation? Studies in the Education of Adults, 28(2), 146-161.

Eden, C., \& Huxham, C. (1996). Action research for management research. British Journal of Management, 7, 75-86.

Enderby, J. E., \& Phelan, D. R. (1994, February). Action learning groups as the foundation for cultural change. The Quality Magazine, 42-49.

Eraut, M. (1997). Developing expertise in school management and teaching. In L. Kydd, M. Crawford, \& C. R. Riches (Eds.), Professional development for educational management., (pp. 37-49). Buckingham: Open University Press.

Ewert, A. W. (1989). Outdoor adventure pursuits: Foundations, models, and theories. Columbus, Ohio: Publishing Horizons, Inc.

Fineman, L. (1996). Developing a formal educational program for case managers: One Canadian experience. Journal of Case Management, 5(4), 158-161.

Finley, D. L., Sanders, M. G., \& Ryan, A. J. (1996). Application of training transfer principles in developing the high transfer training (HITT) methodology. Innovations in Education and Training International, 33(4), 232-239.

Flett, R., Biggs, H., \& Alpass, F. (1994). The effects of professional training on occupational stress and personal affect in rehabilitation practitioners. The Journal of Rehabilitation, 60(3), 39-46. 
Flor, R. (1991a). An introduction to research and evaluation practice. The Journal of Experiential Education, 14(1), 36-39.

Flor, R. (1991b). Building bridges between organization development and experiential/adventure education. The Journal of Experiential Education, 14(3), 27-34.

Fogarty, R., Perkins, D., \& Barell, J. (1992). How to teach for transfer. Cheltenham, Vic.: Hawker Brownlow Education.

Fook, J. (Ed.). (1996). The reflective researcher: Social workers' theories of practice research. St Leonards, NSW: Allen \& Unwin.

Foxon, M. (1987). Transfer of training - a practical application. Journal of European Industrial Training, 11(3), 17-20.

Foxon, M. (1990). Using simulations to enhance technical training. Journal of European Industrial Training, 14(4), 17-20.

Freiere, P. (1970). Pedagogy of the oppressed. London: Penguin.

Friedman, B. A. (1990). Six ways to make it work at work. Training \& Development Journal, December, 17-19.

Frossard, M. (1996). Case management in France: An economic perspective. Journal of Case Management, 5(4), 162-167.

Fulcher, L.C., Leberman, S.I., Peterson, D., Sutcliffe, S. \& Walsh, C. (1997). Diploma in Rehabilitation Studies 1995-1997. Academic Review Report 1997. Department of Applied Social Sciences, Victoria University of Wellington, Wellington.

Gadrey, J., \& Gallouj, F. (1998). The provider-customer interface in business and professional services. The Service Industries Journal, 18(2), 1-15. 
Gallivan, M. J. (1997). Value in triangulation: A comparison of two approaches for combining qualitative and quantitative methods. In A. S. Lee, J. Liebenau, \& J. I. DeGross (Eds.), Information systems and qualitative research., (pp. 417-443). London: Chapman \& Hall.

Garavaglia, P. L. (1993). How to ensure transfer of training. Training \& Development, October(63-68).

Gass, M. A. (1989). Transfer of learning in adventure education. In J. C. Miles \& S. Priest (Eds.), Adventure education., (pp. 199-208). State College, PA: Venture Publishing Inc.

Georges, J. C. (1996). The myth of soft-skills training. Training, 33(1), 48-54.

Gibson, L. (1996, July). Serving up the best: Inside our most customer-conscious companies. Management, 43, 22-35.

Gist, M. E., Bavetta, A. G., \& Stevens, C. K. (1990). Transfer training method: Its influence on skill generalization, skill repetition and performance level. Personnel Psychology, 43, 501-523.

Glaser, B., \& Strauss, A. (1967). The discovery of grounded theory. Chicago: Aldine.

Glaser, B. G. (1992). Basics of grounded theory analysis. Mill Valley, CA: Sociology Press.

Goldratt, E. M. (1990). What is this thing called theory of constraints and how should it be implemented? Croton-on-Hudson, NY: North River Press.

Goldratt, E. M. (1994). It's not luck. Great Barrington, MA: The North River Press.

Gould, N. (1996). Introduction: Social work education and the 'crisis of the professions'. In N. Gould \& I. Taylor (Eds.), Reflective learning for social work: Research, theory and practice., (pp. 1-10). Aldershot: Arena Ashgate Publishing Limited. 
Gregoire, T. K., Propp, J., \& Poertner, J. (1998). The supervisor's role in the transfer of training. Administration in Social Work, 22(1), 1-18.

Gregory, M. (1994). Accrediting work-based learning: Action learning - a model for empowerment. Journal of Management Development, 13(4), 41-52.

Grönroos, C. (1990). Service management and marketing: Managing the moments of truth in service competition. Lexington, MA: Maxwell Macmillan Int. Editions, Lexington Books.

Grönroos, C. (1994). From scientific management to service management: A management perspective for the age of service competition. International Journal of Service Industry Management, 5(1), 5-20.

Gummesson, E. (1991). Qualitative methods in management research. Newbury Park, CA: Sage Publications.

Gummesson, E. (1994). Service management: An evaluation and the future. International Journal of Service Industry Management, 5(1), 77-96.

Haddock, C. (1993). Managing risks in outdoor activities. Wellington, New Zealand: New Zealand Mountain Safety Council Inc.

Hagen, J. (1990). Training income maintenance workers: A look at the empirical evidence. Journal of Continuing Social Work Education, 5(2), 3-8.

Hallowell, R., Schlessinger, L. A., \& Zornitsky, J. (1996). Internal service quality, customer and job satisfaction: Linkages and implications for management. Human Resource Planning, 19(2), 20-29.

Hamill, C. T. (1995). Case management. Independent Living Provider, 10(3), 28-29.

Hamilton, R. T., \& Dakin, S. R. (1992). Perspectives on management development in New Zealand companies. Journal of Management Development, 11(7), 30-36. 
Hanson, E. (1996). The search for a separate theory of adult learning: Does anyone really need androgogy? In R. Edwards, A. Hanson, \& P. Raggatt (Eds.), Boundaries of adult education., (pp. 99-108). London: Routledge.

Hargreaves, P., \& Jarvis, P. (1998). The human resource development handbook. London: Kogan Page.

Harris, A. (1996). Learning from experience and reflection in social work education. In N. Gould \& I. Taylor (Eds.), Reflective learning for social work: Research, theory and practice., (pp. 35-46). Aldershot: Arena Ashgate Publishing Limited.

Haslanger, K. D. (1995). Is case management of any value? What is the evidence? Journal of Long-Term Home Health Care, 14(2), 37-43.

Hayden, J. L. (1995). The training of front line personnel at the McDonald's Drive Thru restaurant in Palmerston North: A study of actual and perceived differences. (Research Report). Palmerston North: Massey University.

Hayes, B. L. (1996). Training in quality. In R. L. Craig (Ed.), The ASTD training and development handbook: A guide to human resource development., (4 ed., pp. 725-746). New York: McGraw-Hill.

Haywood-Farmer, J., \& Nollet, J. (1994). Professional service firms and total quality management: A good fit? International Journal of Service Industry Management, 5(3), 5-13.

Henderson, I. (1993). Action learning: A missing link in management development? Personnel Review, 22(6), 14-24.

Henderson, K. A. (1993). The changer and the changed: Leisure research in the 1990s. Journal of Applied Recreation Research, 1(18), 3-18.

Henkoff, R. (1994, October 3). Finding, training and keeping the best service workers. Fortune, 66-72. 
Heskett, J. L., Sasser, W. E., \& Schlessinger, L. E. (1997). The service profit chain. New York: The Free Press.

Hicks, R. E. (1996). Experiential learning in a postgraduate project management programme. Education \& Training, 38(3), 28-38.

Holding, D. H. (1991). Transfer of training. In J. E. Morrison (Ed.), Training for performance: Principles of applied human learning., (pp. 93-125). Chichester: John Wiley \& Sons.

Holton, E. F. I. (1996). The flawed four-level evaluation model. Human Resource Development Quarterly, 7(1), 5-21.

Houle, C. O. (1984). Patterns of learning: New perspectives on lifespan education. London: Jossey-Bass Ltd.

Hovelynck, J. (1998). Facilitating experiential learning as a process of metaphor development. The Journal of Experiential Education, 21(1), 6-13.

Howcroft, B. (1993). Staff perceptions of service quality in a UK clearing bank: Some empirical findings. International Journal of Service Industry Management, 4(4), 5-24.

Huggins, D., \& Moore, C. (1994). Taking customer service beyond satisfaction. The Case Manager (Oct/Nov/Dec), 71-82.

Hussey, D., \& Lowe, P. (Eds.). (1990). Key issues in management training. London, UK: Kogan Page.

Hussey, J., \& Hussey, R. (1997). Business research: A practical guide for undergraduate and postgraduate students. London: Macmillan Press Ltd.

Huxley, P. (1993). Case management and care management in community care. British Journal of Social Work, 23, 365-381. 
Inglis, S. (1994). Making the most of action learning. Aldershot: Gower.

Irons, K. (1997). The world of superservice: Creating profit through a passion for customer service. Harlow: Addison-Wesley.

Issel, L. M. (1997). Comprehensive case management: Implications for program managers. Health Care Supervisor, 15(3), 39-50.

Ivanoff, P., \& Prentice, E. (1994, September). Management development best practice: An enterprise perspective. HR Monthly, 8-13.

Jago, A. (1982). The transfer of learning to the workplace: A practical study. Journal of European Industrial Training. 7(6), 21-24.

Jarvis, P. (1997). Learning practical knowledge. In L. Kydd, M. Crawford, \& C. R. Riches (Eds.), Professional development for educational management., (pp. 26-36). Buckingham: Open University Press.

Jones, A. (1995). A learning organisation model. In D. C. A. Bradshaw (Ed.), Bringing learning to life: The learning revolution, the economy and the individual., (pp. 111-130). London: The Falmer press.

Kakabadse, M. T. (Ed.). (1982). People and organisations: The practitioner's view. Aldershot: Gower.

Keeton, M. T. (1994, November 9-12). Perspectives on experiential learning. Prelude to a global conversation about learning. Paper presented at The Experiential Learning Conference., Washington, DC.

Kim, D. H. (1993). The link between individual and organizational learning. Sloan Management Review, 35(1), 37-50. 
Kirby, S., \& McKenna, K. (1989). Experience, research, social change: Methods from the margins. Toronto: Garamond Press.

Kirkpatrick, D. L. (1996). Evaluation. In R. L. Craig (Ed.), The ASTD training and development handbook: A guide to human resource development., (4 ed., pp. 294-312). New York: McGraw-Hill.

Kirschenbaum, H., \& Henderson, V. L. (1989). The Carl Rogers reader. New York: Houghton Miffin Company.

Knapp, C. E. (1992). Lasting lessons: A teacher's guide to reflecting on experience. Charleston: ERIC Clearinghouse on Rural Education and Small Schools.

Knowles, M. (1990). The adult learner: A neglected species. Houston: Gulf Publishing Company.

Knowles, M. (1996). Androgogy: An emerging technology for adult learning. In R. Edwards, A. Hanson, \& P. Raggatt (Eds.), Boundaries of adult learning., (pp. 82-98). London: Routledge.

Knowles, M. S. (1986). Using learning contracts: Practical approaches to individualising and structuring learning. San Francisco: Jossey Bass.

Koch, L. C., \& Rumrill Jr., P. D. (1998). The working alliance: An interdisciplinary case management strategy for health professionals. WORK, 10, 55-62.

Kolb, D. A. (1984). Experiential learning: Experience as the source of learning and development. New York: Prentice Hall.

Kolb, D. G. (1991). Meaningful methods: Evaluation without the crunch. The Journal of Experiential Education, 14(1), 40-44.

Kolb, D. G. (1992). The practicality of theory. The Journal of Experiential Education, 2(15), 24-28. 
Kotter, J. P. (1988). The leadership factor. New York: Free Press.

Kreider, J. (1996). The ultimate in case management opportunities: All lines case management coverage. TCM (July/August), 47-52.

Kreps, G. L., Herndon, S. L., \& Arneson, P. (1995). Introduction: The power of qualitative research to address organisational issues. In S. L. Herndon \& G. L. Kreps (Eds.), Qualitative research: Applications in organisational communication., Cresskill, NJ: Hampton Press.

Krouwel, B., \& Goodwill, S. (1994). Management development outdoors: A practical guide to getting the best results. London: Kogan Page.

Kruger, M. J., \& May, G., D. (1986). Transfer of learning in management training: Building the payoff into the instructional design. Performance and Instruction, 25(3), 3-6.

Kurtin, S., Bohnenkamp, S., \& Palmer, J. S. (1994). Professional nursing practice. In M. L. Parsons \& C. L. Murdaugh (Eds.), Patient-centered care: A model for restructuring., (pp. 140-159). Gaithersburg, MD: Aspen Publishers Inc.

Larkin, T. J., \& Larkin, S. (1996). Reaching and changing frontline employees. Harvard Business Review (May/June), 95-104.

Latham, G. P., \& Crandall, S. R. (1991). Organisational and social factors. In J. E. Morrison (Ed.), Training for performance: Principles of applied human learning., (pp. 259285). Chichester: John Wiley \& Sons.

Lave, J., \& Wenger, E. (1991). Situated learning: Legitimate peripheral participation. Cambridge: Cambridge University Press.

Layder, D. (1993). New strategies in social research: An introduction and guide. Cambridge: Polity Press. 
Leberman, S. I. (1987). The relative merits of three different strategies of managing the visitors to the Aletschwald nature reserve. Unpublished BA (Hons) Dissertation, Cambridge University, Cambridge, UK.

Leberman, S. I. (1989). The Outdoor Pursuit Centre of New Zealand: Its role and effectiveness in generating a change in students' image of the outdoors and conservation. Unpublished MA (Applied), Victoria University of Wellington, Wellington, NZ.

Leberman, S. I. (1996, September 26-29). The Diploma in Rehabilitation Studies - the birth of a new form of industry-driven learning. Paper presented at the Spawning New Ideas: A Cycle of Discovery. Association for Experiential Education. 24th Annual International Conference., Spokane, WA.

Leberman, S. I., \& Mellalieu, P. J. (1994, December 14-17). Creating outdoor experiential educators: Launching the learners' expedition. Paper presented at the 3rd International Organisational Behaviour Teaching Conference, University of Otago, Dunedin, New Zealand.

Leberman, S. I., \& Mellalieu, P. J. (1996, 7-9 December). A Trojan horse for moving from mystery to mastery: ALP-DevCo and the Action Learning Programme. Paper presented at the From Mystery to Mastery - Mai I Te Ao Ngaro Ki Te Ao Marama. Outdoor Education Conference., Sir Edmund Hillary Outdoor Pursuits Centre of New Zealand, Turangi, New Zealand.

Leutz, W., Sciegaj, M., \& Capitman, J. (1997). Client-centered case management. Journal of Case Management, 6(1), 18-24.

Lewin, K. (1951). Field theory in social sciences. New York: Harper and Row.

Lincoln, Y. S., \& Guba, E. G. (1985). Naturalistic inquiry. Beverly Hills, CA: Sage Publications. 
Lynn, M. R., \& Kelley, B. (1997). Effects of case management on the nursing context Perceived quality of care, work satisfaction and control over practice. Image: Journal of Nursing Scholarship, 29(3), 237-241.

Macdonald, J. (1994). Primary vehicles of change. Personnel Review, 23(2), 38-43.

Macdonald, J. (1995). Customer care is not good enough. The TQM Magazine, 7(4), 58.

Maier, H. W. (1994). Some thoughts in preparation for effective teaching ventures. (Unpublished Essay). Seattle, WA: University of Washington.

Mailick, S., \& Stumpf, S. A. (1998). Learning theory in the practice of management development: Evolution and applications. Westport, CT: Quorum Books.

Marini, A., \& Genereux, R. (1995). The challenge of teaching for transfer. In A. McKeough, J. Lupart, \& A. Marini (Eds.), Teaching for transfer: Fostering generalization in learning., (pp. 1-20). Mahwah, NJ: Lawrence Erlbaum Associates.

Marshall, M. (1996). Case management: A dubious practice. British Medical Journal, $312(7030), 523-524$.

Martin, K. J. (1995). Workers' compensation: Case management strategies. Association of American Occupational Health Nurses Journal, 43(5), 245-250.

Martin, V. (1998). Developing managers in the 1990's public services: New requirements in public service management development. Total Quality Management, 9(2/3), 279-288.

Marx, R.D. (1986). Self-managed skill retention. Training and Development Journal, (January), 54-57.

Mason, J. (1996). Qualitative researching. London: Sage Publications. 
Mattsson, J. (1994). Improving service quality in person-to-person encounters: Integrating findings from a multi-disciplinary review. The Service Industries Journal, 14(1), 45-61.

Maxwell, J. A. (1996). Qualitative research design: An interactive approach. (Vol. 41). Thousand Oaks: Sage Publications.

Maykut, P., \& Morehouse, R. (1994). Beginning qualitative research: A philosophic and practical guide. London: The Falmer Press.

Mbawo, E. (1995). Strategies for enhancing transfer of training in the workplace. Training and Management Development Methods, 9(5), 729-744.

McEvoy, G., \& Cragun, J. (1994, December 14-17). Teaching organizational behavior in an outdoor setting to students of different nationalities: Observations and implications. Paper presented at the 3rd International Organisational Behaviour Teaching Conference., University of Otago, Dunedin, New Zealand.

McGill, I., \& Beaty, L. (1995). Action learning: A guide for professional development, management and educational development. (2nd ed.). London: Kogan Page.

McGraw, P. (1993). Back from the mountain: Outdoor management development programmes and how to ensure the transfer of skills to the workplace. Asia Pacific Journal of Human Resources, 3(31), 52-61.

McKeough, A., Lupart, J., \& Marini, A. (Eds.). (1995). Teaching for transfer: Fostering generalization in learning. Mahwah, NJ: Lawrence Erlbaum Associates.

McSherry, M., \& Taylor, P. (1994). Supervisory support for the transfer of teambuilding training. The International Journal of Human Resource Management, 5(1), 107-119.

Mellalieu, P. J., Leberman, S. I., Bradbury, T., \& Chu, M. (1994). Opening the black box: Beyond adventure-based management education programmes. (Department of Management Systems Discussion Paper 7). Palmerston North: Massey University. 
Mellander, K. (1993). The power of learning: Fostering employee growth. Alexandria, VA: ASTD.

Mels, G., Boshoff, C., \& Nel, D. (1997). The dimensions of service quality: The original European perspective revisited. The Service Industries Journal, 17(1), 173-189.

Mezirow, J. (1996). Contemporary paradigms of learning. Adult Education Quarterly, $46(3), 158-173$.

Mezirow, J., \& Associates. (1990). Fostering critical reflection in adulthood: A guide to transformative and emancipatory learning. San Francisco: Jossey-Bass Inc.

Miles, M. B., \& Huberman, M. (1984). Qualitative data analysis: A guide to qualitative observation and analysis. Beverly Hills, CA: Sage Publications.

Millar, S., \& Dreyer, W. (1996). Managing human resources in New Zealand. Auckland: Addison Wesley Longman.

Miller, J. \& Dore, M.M. (1991). Innovations in child protective services inservice training: Commitment to excellence. Child Welfare, 65(4), 437-449.

Milligan, F. (1995). In defence of andragogy. Nurse Education Today, 15, 22-27.

Mills, C. (1996). The experience of adult learning. In J. Benseman, B. Findsen, \& M. Scott (Eds.), The fourth sector: Adult and community education in Aotearoa/New Zealand, (pp. 285-296). Palmerston North: Dunmore Press.

Minichiello, V., Aroni, R., Timewell, E., \& Alexander, L. (1995). In-depth interviewing. (2nd ed.). Melbourne: Longman.

Mink, O. G., Owen, K. Q., \& Mink, B. P. (1993). Developing high performance people - the art of coaching. Reading, MA: Addison-Wesley Publishing Company. 
Minter, S. G. (1996). Safety training that sticks. Occupational Hazards (July), 33-36.

Mmobuos, I. A. (1987). Resolving re-entrants' problems in the transfer of management learning. Journal of European Industrial Training, 1(11), 13-16.

Mol, A. J., \& Vermeulen, L. P. (1988). Is management development worth the effort? Human Resources Management Australia, 3(26), 18-29.

Morgan, G. (1986). Images of an organization. Newbury Park, CA: Sage Publications.

Morgan, G. (1988). Riding the waves of change: Developing managerial competencies for a turbulent world. San Francisco, CA: Jossey-Bass Publishers.

Morgan, G., \& Ramirez, R. (1983). Action learning: A holographic metaphor for guiding social change. Human Relations, 37(1), 1-28.

Morris, L. E. (1995). Development strategies for the knowledge era. In S. Chawla \& J. Renesch (Eds.), Learning organisations: Developing cultures for tomorrow's workplace., (pp. 323-335). Portland, OR: Productivity Press.

Mullen, P. D. (1994). The potential for grounded theory for health education research: Linking theory to practice. In B. G. Glaser (Ed.), More grounded theory methodology: A reader., (pp. 127-145). Mill Valley, CA: Sociology Press.

Mumford, A. (Ed.). (1991). Gower handbook of management development. (3 ed.). Aldershot, UK: Gower Publishing Company Limited.

Mumford, A. (1991, October). Learning in action. Newsletter of International Management centres, 37, 1-6.

Munto, J. (1995). Who's that in my bed?: The strange bedfellows made by the politics of applied qualitative research. In S. L. Herndon \& G. L. Kreps (Eds.), Qualitative research: Applications in organisational communication., (pp. 19-28). Cresskill, NJ: Hampton Press Inc. 
Nadler, R. S. (1995). Edgework: Stretching boundaries and generalizing experiences. The Journal of Experiential Education, 18(1), 52-55.

Newstrom, J. W. (1986). Leveraging management development through the management of transfer. Journal of Management Development, 5(5), 33-45.

Newton, R., \& Wilkinson, M. S. (1994). When the talking is over: Using action learning. Management Development Review, 2(7), 9-15.

Noel, J. L., \& Dennehy, R. F. (1991). The learner's manager: The bridge from classroom to workplace. Journal of European Industrial Training, 15(6), 17-18.

Normann, R. (1984). Service management. New York: John Wiley \& Sons Ltd.

Norris, S. P. (Ed.). (1992). The generalizability of critical thinking: Multiple perspectives on an educational ideal. New York: Teachers College Press.

O'Hara, S., Webber, T., \& Reeve, S. (1996). Action learning in management education. Education \& Training, 38(8), 16-21.

Oakley, A. (1993). Essays on women, medicine and health. Edinburgh: Edinburgh University Press.

Orna, E., \& Stevens, G. (1997). Managing information for research. Buckingham: Open University Press.

Owens, C. (1996). The glue of managed health care. TCM (July/August), 75-80.

Ozanne, E. (1996). Case management applications in Australia. Journal of Case Management, 5(4), 153-157.

Packer, T., Race, K. E. H., \& Hotch, D. F. (1994). Focus groups: A tool for consumerbased program evaluation in rehabilitation agency settings. The Journal of Rehabilitation, $60(3), 30-36$. 
Perrie, D. A., \& Miller, J. M. (1992). Brooker's accident compensation in New Zealand. Wellington: Brookers.

Phillips, J. J. (1996). Measuring the results of training. In R. L. Craig (Ed.), The ASTD training and development handbook: A guide to human resource development., (4 ed., pp. 313-341). New York: McGraw-Hill.

Phillips, K., \& Shaw, P. (1998). A consultancy approach for trainers and developers. Aldershot: Gower Publishing Limited.

Phillips, V. L. (1996). The role of case managers in a United Kingdom experiment with self-directed care. Journal of Case Management, 5(4), 142-145.

Pilling, D. (1992). Approaches to case management for people with disabilities. London: Jessica Kingsley Publishers.

Priest, S. (1998). The effect of program setting and duration on corporate team development. The Journal of Experiential Education, 21(2), 111-112.

Priest, S., \& Gass, M. A. (1997). Effective leadership in adventure programming. Champaign, IL: Human Kinetics.

Priest, S. J. (1995). Corporate adventure training in a suspicious marketplace! (Unpublished Paper ). Turangi: Sir Edmund Hillary Outdoor Pursuits Centre.

Priest, S. J., Attarian, A., \& Schubert, S. (1993). Conducting research in experiencebased training and development programs: Pass keys to locked doors. The Journal of Experiential Education, 2(16), 11-20.

Queeney, D. S. (1996). Continuing professional education. In R. L. Craig (Ed.), The ASTD training and development handbook: A guide to human resource development., (4 ed., pp. 698-724). New York: McGraw-Hill. 
Raelin, J. A. (1995). Reformulating management education: Professional education, action learning and beyond. Selections (Autumn), 20-30.

Raelin, J. A. (1997). Individual and situational precursors of successful action learning. Journal of Management Education, 21(3), 368-394.

Redman, T., \& Mathews, B. P. (1998). Service quality and human resource management: A review and research agenda. Personnel Review, 27(1), 57-77.

Reed, M., \& Anthony, P. (1992). Professionalizing management and managing professionalization: British management in the 1980s. Journal of Management Studies, 29(5), 591-613.

Reid, M. A., Barrington, H., \& Kenney, J. (1992). Training interventions: Managing employee development. (3 ed.). London: Institute of Personnel Management.

Reinharz, S. (1992). Feminist methods in social research. Oxford: Oxford University Press.

Revans, R. W. (1982a). Origins and growth of action learning. Bromley: Chartwell Bratt.

Revans, R. W. (1982b). What is action learning? Journal of Management Development, 3(1), 15-26.

Reynolds, C., \& Smeltzer, C. H. (1997). Case management: Past, present, future - the drivers for change. Journal of Nursing Care Quality, 12(1), 9-20.

Reynolds, M. (1998). Reflection and critical reflection in management learning. Management Learning, 29(2), 183-200.

Reynoso, J., \& Moores, B. (1995). Towards the measurement of internal service quality. International Journal of Service Industry Management, 6(3), 64-83. 
Roat, J. (1988). The effects of continuing education on staff performance. Journal of Continuing Social Work Education, 4(4), 26-30.

Robertson, D. L. (1996). Facilitating transformative learning: Attending to the dynamics of the educational helping relationship. Adult Education Quarterly, 47(1), 41-53.

Robinson, D. G., \& Robinson, J. C. (1989). Training for impact: How to link training to business needs and measure the results. London: Jossey-Bass Publishing.

Robinson, D. W. (1992). The risk recreation experience: Subjective state dimensions and the transferability of benefits. Journal of Applied Recreation Research, 1(17), 12-36.

Robinson, V. M. J. (1993). Current controversies in action research. Public Administration Quarterly, 17(3), 263-290.

Roessler, R. T., \& Rubin, S. E. (1992). Case management and rehabilitation counselling: Procedures and techniques. (2 ed.). Austin, TX: Pro-Ed.

Rogers, C. R. (1961). On becoming a person: A therapists view of psychotherapy. London: Constable.

Rogers, G. (1995). Educating case managers for culturally competent practice. Journal of Case Management, 4(2), 60-65.

Roland, C. C., Wagner, R. J., \& Weigand, R. J. (Eds.). (1995). Do it . . and understand! The bottom line on corporate experiential learning. Dubuque: Kendall/Hunt Publishing Company.

Rooney, R. H. (1988). Measuring task-centred training effects on practice: Results of an audiotape study in a public agency. Journal of Continuing Social Work Education, 4(4), 27.

Rose, K., \& Webb, C. (1998). Analyzing data: Maintaining rigor in a qualitative study. Qualitative Health Research, 8(4), 556-562. 
Roskin, R. (1984). Choosing experiential based learning designs for management development. Journal of Management Development, 3(2), 17-33.

Rouiller, J. Z., \& Goldstein, I. L. (1993). The relationship between organisational transfer climate and positive transfer of training. Human Resource Quarterly, 4(4), 377-390.

Rubin, H. J., \& Rubin, I. S. (1995). Qualitative interviewing: The art of hearing data. Thousand Oaks: Sage Publications.

Rudestram, K. E., \& Newton, R. R. (1992). Surviving your dissertation: A comprehensive guide to content and process. London: Sage Publications.

Rylatt, A. (1994). Learning unlimited: Practical strategies and techniques for transforming learning in the workplace. Sydney: Business \& Professional Publishing.

Sandelowski, M. (1996). One is the liveliest number: The case orientation of qualitative research. Research in Nursing \& Health, 19(6), 525-529.

Schmenner, R. W. (1995). Service operations management. Englewood Cliffs, NJ: Prentice Hall Inc.

Schneider, B. (1994). HRM - A service perspective: Towards a customer-focused HRM. International Journal of Service Industry Management, 5(1), 64-76.

Schneider, B., \& Bowen, D. E. (1995). Winning the service game. Boston, MA: Harvard Business School Press.

Schön, D. A. (1983). The reflective practitioner: How professionals think in action. New York: Basic Books Inc.

Schratz, M. (Ed.). (1993). Qualitative voices in educational research. London: The Falmer Press. 
Schratz, M., \& Walker, R. (1995). Research as social change: New opportunities for qualitative research. London: Routledge.

Scott, K. (1996). Case management: A quality process. Topics in Health Information Management, 16(3), 58-64.

Seipel, M. M. (1986). Staff training policies in public welfare agencies: A quest for rationality. Journal of Continuing Social Work Education, 4(1), 25-29.

Seng, J. S. (1998). Praxis as a conceptual framework for participatory research in nursing. Advances in Nursing Science, 20(4), 37-48.

Senge, P. M. (1990). The fifth discipline: The art and practice of the learning organisation. New York: Doubleday Currency.

Senge, P. M., Kleiner, A., Roberts, C., Ross, R. B., \& Smith, B. J. (1994). The fifth discipline fieldbook: Strategies and tools for building a learning organization. New York: Doubleday.

Silverman, D. (1994). Interpreting qualitative data: Methods for analysing talk, text and interaction. London: Sage Publications.

Skelcher, C. (1992). Improving the quality of local public services. The Service Industries Journal, 12(4), 463-477.

Slovic, P., Fishhoff, B., \& Lichtenstein, S. (1984). Fact versus fears: Understanding perceived risk. In D. Kahneman, P. Slovic, \& A. Tversky (Eds.), Judgment under uncertainty: Heuristics and biases., (pp. 463-489). Cambridge: Cambridge University Press.

Smith, A. (1990). Evaluation of management training - subjectivity and the individual. Journal of European Industrial Training, 14(1), 14-15.

Smith, A. (1993). Management development evaluation and effectiveness. Journal of Management Development, 12(1), 20-32. 
Smith, A. J., \& Piper, J. A. (1990). The tailor-made training maze: A practitioner's guide to evaluation. Journal of European Industrial Training. Special Issue, 8(14).

Stamps, D. (1997). Learning is social. Training is irrelevant? Training, February, 3542.

Stanley, L., \& Wise, S. (1993). Breaking out again: Feminist ontology and epistemology. (2 ed.). London: Routledge.

Stauss, B. (1995). Internal services: Classification and quality management. International Journal of Service Industry Management, 6(2), 62-78.

Stewart, D. W., \& Shamdasani, P. N. (1990). Focus groups: Theory and practice. (Vol. 20). London: Sage Publications.

Stiller, A. L., \& Brown, H. N. (1996). Case management: Implementing the vision. NURSING ECONOMIC\$, 14(1), 9-13.

Strauss, A., \& Corbin, J. (1990). Basics of qualitative research: Grounded theory procedures and techniques. London: Sage Publications.

Stuart, P. (1992). New directions in training individuals. Personnel Journal (September), 86-101.

Sutton, D. (1990). Action learning: In search of P. Industrial and Commercial Training, 1(22), 9-12.

Swinburne, P. (1995). Management with a personal touch. People Management, April, 38-39.

Tapsell, S. (1998, October). Are you being served? Management, 45, 68-72. 
Thorne, S. (1998). Ethical and representational issues in qualitative secondary analysis. Qualitative Health Research, 8(4), 547-555.

Tracey, J. B., Tannenbaum, S. I., \& Kavanagh, M. J. (1995). Applying trained skills on the job: The importance of the work environment. Journal of Applied Psychology, 80(2), 239252.

Trauth, E. M. (1997). Achieving the research goal with qualitative methods: Lessons learned along the way. In A. S. Lee, J. Liebenau, \& J. I. DeGross (Eds.), Information systems and qualitative research., (pp. 225-245). London: Chapman \& Hall.

Tziner, A., Haccoun, R. R., \& Kadish, A. (1991). Personal and situational characteristics influencing the effectiveness of transfer of training improvement strategies. Journal of Occupational Psychology, 64(2), 167-177.

Usher, R. (1992). Experience in adult education: A post-modern critique. Journal of Philosophy of Education, 26(2), 201-214.

Vaill, P. B. (1996). Learning as a way of being: Strategies for survival in a world of permanent white water. San Francisco: Jossey-Bass Publishers.

van Reenen, J. A. (1996). The transfer of learning from continuing education to the job: An evaluation of the impact of total quality management courses on health sciences librarians. Bulletin Medical Librarian Association, 84(2), 257-260.

Varey, R. (1995). Internal marketing: A review and some interdisciplinary research challenges. International Journal of Service Industry Management, 6(1), 40-63.

Voigt, E. E. (1995). Learning out of context. In S. Chawla \& J. Renesch (Eds.), Learning organisations: Developing cultures for tomorrow's workplace., (pp. 293-303). Portland, OR: Productivity Press.

Wagner, R. J., \& Campbell, J. (1994). Outdoor-based experiential training: Improving transfer using virtual reality. Journal of Management Development, 13(4), 4-11. 
Warren, K., Sakofs, M., \& Hunt, J. S. (Eds.). (1995). The theory of experiential education. (3 ed.). Dubuque, Iowa: Kendall Hunt Publishing Company.

Weatherly, K. A., \& Tansik, D. A. (1993). Tactics used by customer-contact workers: Effects of role stress, boundary spanning and control. International Journal of Service Industry Management, 4(3), 4-17.

Weick, K. (1995). Sensemaking in organizations. Thousand Oaks: Sage Publications.

Weigand, D. E. (1996). Continuing education: A reminder about andragogy. Journal of Education for Library and Information Science., 37(1), 79-80.

Weil, S. W., \& McGill, I. (Eds.). (1989). Making sense of experiential learning: Diversity in theory and practice. Buckingham: Open University Press.

Weinstein, K. (1995). Action learning: A journey in discovery and development. London: Harper Collins Publishers.

Weintraub, R. (1995). Transforming mental models through formal and informal learning: A guide for workplace educators. In S. Chawla \& J. Renesch (Eds.), Learning organisations: Developing cultures for tomorrow's workplace., (pp. 417-429). Portland, OR: Productivity Press.

Whitaker, P. (1997). Changes in professional development: The personal dimension. In 1. Kydd, M. Crawford, \& C. R. Riches (Eds.), Professional development for educational management., (pp. 11-25). Buckingham: Open University Press.

Wick, C. W., \& Leon, L. S. (1993). The learning edge: How smart managers and smart companies stay ahead. New York: McGraw-Hill.

Wiggenhorn, A. W. (1996). Organisation and management of training. In R. L. Craig (Ed.), The ASTD training and development handbook: A guide to human resource development., (4 ed., pp. 19-47). New York: McGraw-Hill. 
Williamson, A. (1997). Reflection in adult learning with particular reference to learning-in-action. Australian Journal of Adult and Community Education, 37(2), 93-99.

Wills, S. (1994). 2001: A research odyssey - teaching different types of learning. Journal of Management Development, 13(1), 60-72.

Wyatt, S. (1997). Dialogue, reflection, and community. The Journal of Experiential Education, 20(2), 80-85.

Xiao, J. (1996). The relationship between organisational factors and the transfer of training in the electronics industry in Shenzhen, China. Human Resource Development Quarterly, 7(1), 55-73.

Yin, R. K. (1994). Case study research: Design and methods. (2 ed.). (Vol. 5). London: Sage Publications.

Zuber-Skerritt, O. (1993). Improving learning and teaching through action learning and action research. Higher Education Research and Development, 12(1), 45-58. 


\section{APPENDIX 1 - PROGRAMME DETAILS}

Students were enrolled in 5 papers: REHB 801 - Rehabilitation Policy in Practice; REHB 802 - Principles and Practices of Rehabilitation; REHB 803 - Applied Social Research: Culture, Gender, Class, Age and Ability; REHB 804 - Rehabilitation Studies Project and REHB 805 - Rehabilitation Practicum. They were offered learning opportunities that combine personal reflection and enquiry, formal presentations involving practice specialists and researchers from the health and rehabilitation field, small group tasks, activity-based learning in video and computing skills laboratories, personal and professional skill development, and directed study. Every alternate week, students were expected to use computing and skills laboratory facilities to carry out research, complete assignments and extend practice skills in the use of new technology and interpersonal communication being introduced into work environments across the human services.

Week 1 Module 1 - (REHB 801A) Rehabilitation Policy in Practice

An examination of social and economic policy reforms in New Zealand between 1984 and 1994, related demographic and labour market trends, and ways in which these have impacted on the development of health and rehabilitation services, and the work of ACC Case Managers in particular. Normalisation as a policy and practice ideology of international significance were explored in terms of its growing insistence on maintaining a consumer perspective in the delivery of services. Students evaluated justifications for changes to the legal mandate for services, increased accountability for service outcomes, and changing expectations about the nature of professional practice. Consideration was also given to the introduction of purchase of service contracting (POSC) as a contemporary funding mechanism that finds popularity in the provision of human services, where case management is introduced to ensure fiscal and quality-control in the production of human services. A Field Trip to a local Rehabilitation Resource Centre was linked to this module. 
This Personal and Professional Development module used directed study, information technology, audio and video recording equipment, and specialist library holdings available at Victoria University and other collections held in the greater Wellington Region to review, evaluate and extend professional knowledge and skills as a practitioner working in their own specialist sphere of the rehabilitation field. Students also used on-line computer access to the Internet system of electronic information exchange to seek information on rehabilitation services in other countries and retrieve information from specialist libraries in other countries for use in completing course assignments. Personal and Professional Development Plans were used to identify specific learning objectives that students contracted to achieve through directed study, extending these into Learning Contracts for use during the Practicum. At least one day per week was spent in small group learning exercises working in a skills laboratory where students explored their use of professional power in helping relationships through the use of video and computer-assisted media.

A review of professional practice knowledge and skills associated with study, assessment and intervention planning as required of professional practice with people in receipt of rehabilitation services. Principles of crisis intervention, task-centred casework, family/whanau decision-making and partnerships in professional helping were examined with particular reference to case management practices in New Zealand. The idea was emphasised throughout that assessment is a process of continuous review and evaluation carried out in partnership with the client and their family. The contemporary notion of "best practice" was also introduced and explored. 
Personal and Professional Development Module with directed study, and at least one day of the week working in Regional Groups with a Practice Tutor undertaking prescribed learning tasks in a professional skills laboratory. Gender, Class, Age and Ability

This module used a noho marae format during which students were invited to spend five days and four nights living at Ruamata Marae in Rotorua participating in the daily rituals of encounter from a cultural perspective that is likely to be different from that to which they are normally accustomed. During the course of this module, students were introduced to the notion of social enquiry and evaluation from a Maori perspective, looking at how the wharenui can be viewed as a research storehouse, and about how whakapapa and traditions of oral history have a well established place in the traditions of Applied Social Research. Cultural expectations associated with gender, class, age and ability were also explored. Ethical decision-making was examined as it related to questions of assessment and ethical practice as a Case Manager working with people from different cultures presenting for ACC services in their part of the country. Throughout the week, students were invited to personally explore the meaning of cultural safety as it might apply in their own lives and work.

Week 6 Module 2 Continues - (REHB 802A) Principles and Practices of Rehabilitation

Personal and Professional Development Module with directed study, and at least one day of the week working in Regional Groups with a Practice Tutor undertaking prescribed learning tasks in a professional skills laboratory. 
Module 5 - (REHB 803B) Applied Social Research: Culture, Gender, Class, Age and Ability

Examination of social research knowledge and skills that can be applied to the tasks of service evaluation by an ACC Case Manager. Formal instruction on research design and methodology were given to assist each student plan a small survey of service providers or consumers of ACC services, develop a resource kit on information available about a particular service or services for a particular clientele, or some other related Project approved by the University and the ACC. Students also received instruction on how to prepare a Project Proposal that would enable them to investigate a particular aspect of ACC service delivery and case management practice through their local Branch.

Week 8

Module 2 Continues - (REHB 802A) Principles and Practices of Rehabilitation

Personal and Professional Development Module with directed study, and at least one day of the week working in Regional Groups with a Practice Tutor undertaking prescribed learning tasks in a professional skills laboratory.

Week 9 Module 6 - (REHB 805A) Transition from Theory to Practice: Developing a Practicum Learning Contract

Each student was invited to review and evaluate the learning objectives identified in their Personal and Professional Development Plan developed since the start of the course. Working with their Practice Tutor and Practicum Supervisor, students constructed a Learning Contract that gained the endorsement of their Branch Manager as an agreed programme of workbased study during the Rehabilitation Practicum. Students were encouraged to begin discussions with their Branch Manager prior to the start of their 
course about how their Practicum might be used. The Learning Contract detailed a plan for weekly telephone or on-site supervision with the Practicum Supervisor to discuss learning and to review progress with their Rehabilitation Studies Project. A timetable for completion of one Practice Studies and a written summative evaluation of learning from the Practicum as a whole was also detailed in the Learning Contract. With approval of the Rehabilitation Project Protocol by the VUW Human Ethics Committee and endorsement of the Learning Contract by all four parties involved in the Practicum, students could formally begin their Rehabilitation Studies Practicum. The areas of negotiation, stress and time management and conflict management were introduced and explored.

Week 10

Module 2 Continues - (REHB 802A) Principles and Practices of Rehabilitation

Personal and Professional Development Module with directed study, and at least one day of the week working in Regional Groups with a Practice Tutor undertaking prescribed learning tasks in a professional skills laboratory.

Week $11 \quad$ Examination Period

Completion of assessment requirements for 3 papers (REHB 801, 802 and 803), endorsement of the Learning Contract for the Rehabilitation Studies Practicum (REHB 805) and completion of requirements for Ethical Approval of the REHB 804 Project Proposal.

$\underline{\text { Week } 12}$ Module 7 - (REHB 801B) Rehabilitation Policy in Practice

A review of key rehabilitation policy and practice issues, focusing on vocational assessment, job placement, public relations, head injury, spinal cord injury and lower back injury. In each of these areas of examination, students reviewed the impact of legislation, regulation and ACC policy and 
implications that arise for the case management function and role. An assignment was set in which groups of three to four students researched, wrote and presented a report on a topic of interest to those working in a specialist area of the rehabilitation field and ACC Case Managers with a specialist brief within their Branch Office. A Field Trip to a National Rehabilitation Resource Centre was linked to this module.

14 Weeks (REHB 805B) - Practicum

A 14-week (70 days) supervised practicum was undertaken in the Case Manager's work place using the Learning Contract endorsed by the student's Branch Manager as the basis for applied learning. The Practicum was assessed using formative evaluation (Practice Studies) and summative evaluation of the Learning Contract (Practice Evaluation Report) at the end of the Practicum. Each student was visited twice by their Practice Tutor during the Practicum, providing for an early review of learning and opportunity for review at the end of the Practicum. The student, their Practice Tutor from the University and their Practicum Supervisor, a designated Principal Case Manager, shared responsibility for reviewing practicum learning, making a qualitative assessment of, and giving feedback on the two Practice Studies, and preparing the Final Evaluation Report on performance during the REHB 805 Practicum with a recommendation of PASS or FAIL for the paper.

Week 27 Module 8 - (REHB 804) Rehabilitation Project: Review of Learning and Oral Presentation of Project Findings

A review and evaluation of learning from the Rehabilitation Studies Practicum and presentation of findings from the Rehabilitation Project carried out during the Practicum. Students were invited to compare and contrast learning experiences from different parts of the country, highlighting challenges facing those working in the rehabilitation field in New 
Zealand in the late 1990s. Aspirations and opportunities for on-going research, continuing education and professional learning were identified and discussed, along with findings relating to quality assurance in the delivery of rehabilitation services.

\section{Attendance and Assessment}

Modules 1, 3, 4, 5, 6, 7 and 8 involved block attendance for a whole week, from 9:30 am Monday morning until lunch time Friday. Module 2 - Principles and Practices of Rehabilitation A - involved directed study on the theme of Personal and Professional Development. Module 2 required that students spend at least one day per week working in Practice Tutorial Groups that worked closely together throughout the whole of the course. Module 2 was designed to integrate learning from all the other papers and to help students extend that learning towards skill enhancement in the workplace. The teaching programme normally followed the pattern of $3 \times 90$ minute sessions on a Monday, 4 x 90 minute sessions Tuesday to Thursday: 9 am to $5 \mathrm{pm}$, and $2 \times 90$ minute sessions on Friday: 9 am to lunchtime. Module 2 involved directed study and the use of university computing and library facilities, plus one day per week, 9 am to $5 \mathrm{pm}$, working in an interpersonal skills laboratory with video and computer technology.

Students were required to complete 10 pieces of formally assessed work during this intensive programme of postgraduate, professional study. Formal assessment involved both oral and written assignments as well as requiring individual work and group work. All assignments focused on the development of professional knowledge and skills, and the professional application of learning for practice in the rehabilitation field. With prior approval, work could be completed for assessment in a language other than English. All assessed work was recommended to a Board of External Examiners who moderated a sample of work for each assignment and for each candidate for the Diploma. Final confirmation of results was made at a meeting of the Examinations Board that met at the end of each Course of Study. 


\section{APPENDIX 2 - TRANSFER OF LEARNING LITERATURE REVIEWED}

Aspects of programme design which have been highlighted as important for transfer to take place include the following:

- location i.e. on or off-the-job (Analoui, 1993; Billet, 1992 \& 1994; Buckley \& Caple, 1996; Lave \& Wenger, 1991)

- importance of socio-cultural factors (Analoui, 1993; Billet, 1992 \& 1994; Lave \& Wenger, 1991)

- developing self-confidence/locus of control in trainee (Binder, 1990; Robinson, 1992; Tziner, Haccoun \& Kadish, 1991)

- non-physical risk taking (Gass, 1989; Robinson, 1992; Wagner \& Campbell, 1994)

- teaching methodology (Foxon, 1990; Gass, 1989)

- experiential learning/learning styles (Analoui, 1993; Foxon, 1990; Gass, 1989; Stuart, 1992; Wagner \& Campbell, 1994)

- action plans/learning contracts (Analoui, 1993; Foxon, 1987; Gist, Bavetta \& Stevens, 1990; Mbawo, 1995; Stuart, 1992)

- appropriate activities/content (Gass, 1989; Stuart, 1992; Wagner \& Campbell, 1994)

- journal writing (Kruger \& May, 1986)

- peer support groups (Kruger \& May, 1986)

- consultation in design and execution/transfer partnership (McGraw, 1993; Minter, 1996; Newstrom, 1986; Stuart, 1992)

- mentors (Stuart, 1992)

- only train some of work group at one time (Stuart, 1992)

- relapse prevention model (Tziner, Haccoun \& Kadish, 1991)

- trainer strategies/facilitation style (Heron, 1992 cited in Mbawo, 1995)

Workplace characteristics seen as facilitating transfer include:

- socio-cultural factors (Analoui, 1993; Billet, 1992 \&1994; Buckley \& Caple, 1996; Lave \& Wenger, 1991)

- direct supervisor support (Brinkerhoff \& Montesino, 1995; Garavaglia, 1993; Gregoire et al., 1998; Mc Sherry \& Taylor, 1994; Mmobuos, 1987; Noel \& Dennehy, 1991; Xiao, 1996) 
- social support (McGraw, 1993; Tracey, Tannenbaum \& Kavanagh, 1995)

- continuous learning culture (Tracey, Tannenbaum \& Kavanagh, 1995)

- transfer of training climate (McGraw, 1993; Tracey, Tannenbaum \& Kavanagh, 1995)

Trainee factors include:

- student background (Castaldi, 1989)

- ability to take risks (Friedman, 1990; Robinson, 1992)

- abilities in general (Baldwin \& Ford, 1988; Bereiter, 1995; Rouiller \& Goldstein, 1993)

- motivation (Noe \& Schmitt, 1986 cited in Mbawo, 1995; Holton, 1996)

- self-efficacy (Gist \& Mitchell, 1992 cited in Mbawo, 1995)

- development of self-esteem (Mink, Owen \& Mink, 1993) 


\title{
APPENDIX 3 - ETHICAL APPROVAL FORM
}

\section{VICTORIA UNIVERSITY OF WELLINGTON \\ Te Whare Wananga o te L"poko o te Ika a Maui}

\author{
HUMLAN ETHICS COMMITTEE \\ Application for Approval \\ Applied Social Sciences
}

\section{Proposed Project for: \\ Doctor of Philosophy}

Project title:

The Transfer of Learning from the Classroom to the Workplace: A New Zealand Case Study

Researcher:

Sarah Leberman

Professional Code of Ethics (Name):

The Association of Social Science Researchers. (ASSR)

Proposed Supervisor (if known):

Professor Leon Fulcher

Proposed Starting Date:

Following ethical approval

\section{Proposed Date of Completion:}

November 1998

Proposed Source of Funding:

(Comment on independence of the research if relevant)

Initially the Department of Applied Social Sciences will fund the research. Applications for funding will be initiated.

\section{Briefly Outline:}

(a) The Objectives of the Project -

The overall aims are:

1. To identify factors which facilitate the transfer of learning from an adult learning environment using action learning methods of instruction.

2. To identify a particular design to optimise transfer of learning in adult learners using an action learning methodology. 
The objectives are:

1. To evaluate the transfer of learning back to ACC branch offices where students are/were employed as Case Managers.

2. To identify influences on personal and professional development of Case Managers from the Southern Region three cohorts of the Diploma in Rehabilitation Studies.

3. To consider the potential application of action learning based modular courses in the recreation and leisure industry.

(b) Method of Data Collection-

Reflective notes of the researcher, interviews with students from the Southern Region and focus groups based on regional groups of students from other parts of New

Zealand. As well as this baseline information already collected will be used.

(c) The Benefits and Scientific Value of the Project -

The research will be of value to any organisation contemplating training programme for its staff. In particular, it is seen as being of vahue to organisations within the service industry.

(d) Characteristics of the Subjects (Participants) -

Students from cohorts 1, 2 and 3 of the Diploma in Rehabilitation Studies.

(e) Method of Recruitment -

Students will be invited to participate in the research. Those from the Southern region in the interviews and the remaining students in the focus groups. In the event that more than 10 students wish to participate in the focus groups, a random seleciion will take place.

(f) Payments that are to be Made/Expenses to be Reimbursed to Subjects Nil.

(g) Other Assistance (e.g. meals, transport) that is to be given to Subjects There will be no cost to those participants associated with the interviews.

The participants of the focus groups will be assisted with transport if required.

(h) Special hazards and/or inconvenience (including deception) that subjects will encounter:

Nil.

(i) How informed consent is to be obtained (Include a copy of any consent form and information sheet that is to be used.) (See Paragraph 4.3.1(g) of the guidelines):

If participants agree to take part in the research a consent form and participant information sheet will be sent to each participant. This will be further discussegtprior to the interview or focus group. 
(j) How issues of anonymity of subjects are to be dealt with if the research is to be conducted on an anonymous basis. (See paragraph 4.3.1(e) of the guidelines):

Information recorded on interview schedules at time of interview will be numbered and there will be no reference to any names or any factors that could identify the participant.

(k) Procedure for the storage of access to and destruction of data, both during and at the conclusion of the research. (See paragraph 7 of the guidelines):

Consent forms and interview schedules will be stored in a locked filing cabinet accessible only by the researcher. At the completion of the research all data will be destroyed.

(I) Feedback Procedures:

An executive summary will be available to the participants at the end of the research.

(m) Reporting and Publication of Results:

A thesis in fulfilment of the $\mathrm{PhD}$ will be submitted. In addition, a report will be made available to the Accident Rehabilitation Compensation and Insurance Corporation.

Signature of Researcher

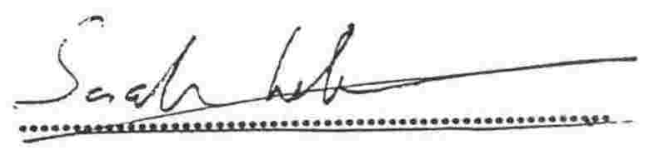

Date: $29 / 4 / 96$
Signature of Supervisor

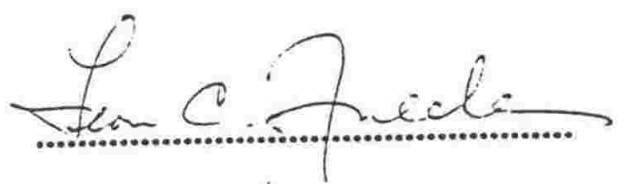

Date: $29 / 4 / 96$

Signature of Convenor of Ethics Committee

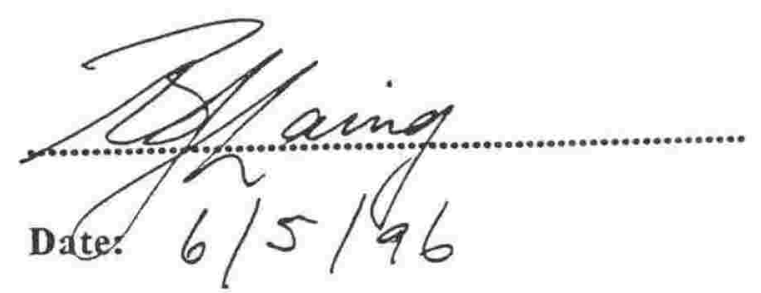

Approved subject to an

inclusion in the Information Sheer stating that a reset will be mede to $A C C$ at the conclusion of the research.

278 


\section{APPENDIX 4 - INTERVIEW AND FOCUS GROUP LETTERS, INFORMATION SHEET AND CONSENT FORMS}

\section{SAMPLE INTERVIEW LETTER TO SOUTHERN REGION STUDENTS - Cohort 1}

Dear

Now that you have finished the Diploma in Rehabilitation Studies I would like to invite you to be part of a longitudinal study focusing on the methodological issues involved in measuring transfer of theory to practice and changes engendered in the individual and the organisation in the longer term. The Diploma in Rehabilitation Studies, a course developed in partnership between Victoria University and the ACC will be used as a case study for this.

The title of my $\mathrm{PhD}$ research is: "The Transfer of Learning from the Classroom to the Workplace: A New Zealand Case Study".

As you were one of the students in my tutor group and I feel that I have been able to develop a rapport with you, I would value your participation in the study. Your commitment would involve being available for 2 interviews at 6 monthly intervals. The first one would take place between Wednesday 11 December and Thursday 19 December 1996 (or in November if you are available at such short notice) and the second one in May 1997. The interviews would last about one hour and would be held either at your place of work or at your home - whatever you prefer.

To ensure confidentiality for you and the information you share with me, all information recorded will be identified by number rather than name. It will be kept in a locked filing cabinet and will not be seen by any other person.

If you would like to be part of this research could you please let me know by returning the enclosed consent form by Tuesday November 19 or ring me to let me know you are willing to take part and I can collect the form at the interview. If you have any further questions, please do not hesitate to contact me. I apologise for the short notice, but it was unavoidable due to an ACC Head Office misunderstanding.

Regards,

Sarah Leberman

Phone: 04 - 4966585 (wk)

06 - $3591793(\mathrm{hm})$

Pager: 021 - 102449

Fax: $04-4966563$ 


\section{SAMPLE INTERVIEW LETTER TO SOUTHERN REGION STUDENTS - Cohorts 2 \& 3}

Dear

Now that you have finished the Diploma in Rehabilitation Studies I would like to invite you to be part of a longitudinal study focusing on the methodological issues involved in measuring transfer of theory to practice and changes engendered in the individual and the organisation in the longer term. The Diploma in Rehabilitation Studies, a course developed in partnership between Victoria University and the ACC will be used as a case study for this.

The title of my $\mathrm{PhD}$ research is: "The Transfer of Learning from the Classroom to the Workplace: A New Zealand Case Study".

As you were one of the students in my tutor group and I feel that I have been able to develop a rapport with you, I would value your participation in the study. Your commitment would involve being available for 2 interviews at 6 monthly intervals. These would be held during XXXXX and XXXXX, with times to be arranged closer to the time. The interviews would last about one hour and would be held either at your place of work or at your home - whatever you prefer.

To ensure confidentiality for you and the information you share with me, all information recorded will be identified by number rather than name. It will be kept in a locked filing cabinet and will not be seen by any other person.

If you would like to be part of this research could you please let me know by Friday 6 December 1996, so that I can send you a participant information form and a consent form. If you have any further questions, please do not hesitate to contact me.

Regards,

Sarah Leberman

Phone: 04 - 4966585 (wk)

Pager: 021 - 102449

Fax: $04-4966563$ 


\section{SAMPLE FOCUS GROUP LETTER TO NON-SOUTHERN REGION STUDENTS - Cohort 1}

Dear

Now that you have finished the Diploma in Rehabilitation Studies I would like to invite you to be part of a longitudinal study focusing on the methodological issues involved in measuring transfer of theory to practice and changes engendered in the individual and the organisation in the longer term. The Diploma in Rehabilitation Studies, a course developed in partnership between Victoria University and the ACC will be used as a case study for this.

The title of my $\mathrm{PhD}$ research is: "The Transfer of Learning from the Classroom to the Workplace: A New Zealand Case Study".

I would value your participation in the study as you will be able to substantiate or refute the findings I will receive from the Southern region. Your commitment would involve being available for 2 focus groups at 6 monthly intervals. The first one would take place between Wednesday 11 December and Thursday 19 December 1996 and the second one in May 1997. The focus groups would last about one and a half hours. Depending on who responds will depend on how the focus group is run. If the group is very geographically spread a teleconference may need to take place - or a focus group with those who are close together, and then communicating with the others by phone.

To ensure confidentiality for you and the information you share with me, all information recorded will be identified by number rather than name. It will be kept in a locked filing cabinet and will not be seen by any other person.

If you would like to be part of this research could you please let me know by returning the enclosed consent form by Tuesday November 19 or ring me to let me know you are willing to take part and I can collect the form at the focus group. If you have any further questions, please do not hesitate to contact me. I apologise for the short notice, but it was unavoidable due to an ACC Head Office misunderstanding.

Regards,

Sarah Leberman

Phone: 04 - 4966585 (wk)

$06-3591793(\mathrm{hm})$

Pager: $021-102449$

Fax: $04-4966563$ 


\section{SAMPLE FOCUS GROUP LETTER TO NON-SOUTHERN REGION STUDENTS - Cohorts $2 \& 3$}

Dear

Now that you have finished the Diploma in Rehabilitation Studies I would like to invite you to be part of a longitudinal study focusing on the methodological issues involved in measuring transfer of theory to practice and changes engendered in the individual and the organisation in the longer term. The Diploma in Rehabilitation Studies, a course developed in partnership between Victoria University and the ACC will be used as a case study for this.

The title of my $\mathrm{PhD}$ research is: "The Transfer of Learning from the Classroom to the Workplace: A New Zealand Case Study".

I would value your participation in the study as you will be able to substantiate or refute the findings I will receive from the Southern region. Your commitment would involve being available for a maximum of 2 focus groups at 6 monthly intervals. These would be held during XXXXX and XXXXX, with times to be arranged closer to the time. The focus groups would last about one and a half hours. The location will be decided closer to the time.

To ensure confidentiality for you and the information you share with me, all information recorded will be identified by number rather than name. It will be kept in a locked filing cabinet and will not be seen by any other person.

If you would like to be part of this research could you please let me know by Friday 6 December 1996, so that I can send you a participant information form and a consent form. If you have any further questions, please do not hesitate to contact me.

Regards,

Sarah Leberman

Phone: 04 - 4966585 (wk)

Pager: 021 - 102449

Fax: $04-4966563$ 


\section{RESEARCH PARTICIPANT INFORMATION SHEET}

The following information is aimed to give you more details about the research and enable you to make an informed choice about your participation in the study before you sign the attached consent form.

\section{Research Title:}

"The Transfer of Learning from the Classroom to the Workplace: A New Zealand Case Study".

\section{Research Questions:}

What course design elements contribute to the transfer of learning for adult learners on an action learning course?

What non-work characteristics facilitate the transfer of learning?

What organisational factors facilitate the transfer of learning?

What elements of partnership were crucial for the transfer of learning to take place?

\section{The research aims are:}

1. To identify factors which facilitate the transfer of learning from an adult learning environment using action learning methods of instruction.

2. To identify a particular design to optimise transfer of learning in adult learners using an action learning methodology.

\section{The research objectives are:}

1. To evaluate the transfer of learning back to ACC branch offices where students are/were employed as Case Managers.

2. To identify influences on personal and professional development of Case Managers from the Southern Region three cohorts of the Diploma in Rehabilitation Studies.

3. To consider the potential application of action learning based modular courses in the recreation and leisure industry.

As previously mentioned all information will be confidential and will not be used for any other purpose other than the research. All information received from you will be kept in a locked filing cabinet and will be destroyed at the end of the study.

You are free to withdraw from the research at any time and are free to choose not to answer any specified questions during the interview or focus group meeting.

At the end of the research you will be sent an executive summary of the results and ACC will receive a report on the findings. 
I,

(name in block letters)

have read the

Research Participant Information Sheet

for the project entitled

The Transfer of Learning from the Classroom to the Workplace: A New Zealand Case Study

I understand that I will be involved in a maximum of 3 interviews. I also understand that I am able to withdraw from the research at any time.

I agree to participate in this research.

(signature)

/ /1996

This consent form will be kept locked in a filing cabinet and will not be connected to the file name used for your contributions through the interview.

Thank you for your co-operation.

Please return this form to Sarah Leberman. 


\section{CONSENT FORM - FOCUS GROUP PARTICIPANT}

(name in block letters)

have read the

Research Participant Information Sheet

for the project entitled

The Transfer of Learning from the Classroom to the Workplace: A New Zealand Case Study

I understand that I will be involved in a maximum of 3 focus group meetings. I also understand that I am able to withdraw from the research at any time.

I agree to participate in this research.

(signature)

/ / 1996

This consent form will be kept locked in a filing cabinet and will not be connected to the file name used for your contributions through the focus group meetings.

Thank you for your co-operation.

Please return this form to Sarah Leberman. 


\section{APPENDIX 5 - DRAFT 12 MONTH INTERVIEW AND FOCUS GROUP QUESTIONS}

- Please describe the major event in your life during the last 6 months? This can be work or non-work.

- Can you think of a critical incident which occurred in the early return-to-work phase?

What competencies did you employ?

Did having been on the course have any effect on this?

- Thinking back to the course -

What parts of it do you consider most applicable to your work at the moment?

What parts of it do you consider have had the most effect on you personally?

- Were these specific skills - such as interviewing?

- Were these non-specific skills - such as taking responsibility?

- Were these metaphoric - such as the waka trip being linked to the importance of team work?

- What factors do you believe have facilitated the transfer of training for you?

Organisational?

Non-work?

- What effect do you think that the partnership agreement between the University and ACC has had for you with regard to the transfer of training? 


\section{APPENDIX 6 - FINAL 12 MONTH INTERVIEW AND FOCUS GROUP QUESTIONS}

1. What major skills/knowledge do you think you picked up on the course?

2. Do you feel that you were able to bring any of these skills/knowledge back to work? Which ones?

3. Can you think of a couple of major work related incidents which have occurred since you have returned to work fulltime?

What skills/knowledge did you use?

Did having been on the course have any effect on this?

4. What things do you think have helped you in using these skills/knowledge back at work?

5. Have you been able to put any of the skills/knowledge to use in your personal life? How and why has this happened?

6. Thinking back to the course -

What parts of it do you consider most helpful to your work at the moment?

What parts of the course do you consider have had the most effect on you personally?

7. What did you feel about the set-up of the course i.e. modules plus study week, the combination of personal and professional development?

8. As you are probably aware the course was tailor-made for the ACC. What do you think were the advantages and disadvantages of this?

9. Examples of being a 'Change Agent"?

10. Anything else you would like to mention? 


\section{APPENDIX 7 - 18 MONTH \& 24 MONTH INTERVIEW AND FOCUS GROUP QUESTIONS}

\section{Month Questions}

1. Could you please identify some outcomes that you feel good about related to the knowledge and skills you have been encouraged to develop since the course. Please be specific about outcomes and the knowledge and skills used.

2. Having described the outcomes, could you identify what factors have been instrumental in enabling you to achieve these.

3. Could you please comment on the changes that have taken place within ACC since you started the Diploma course and how these may have affected working towards your desired outcomes.

4. Specifically, could you please comment on the impact of the latest round of ACC restructuring and its effect on your practice as a Case Manager.

5. Is there anything else you would like to mention.

\section{Month Question}

Could you please reflect back over the past two years and consider the impact the Diploma has had on you, both personally and professionally? 


\section{APPENDIX 8 - ORIGINAL CODES}

\section{2 months}

\author{
ACC networks \\ attitude change \\ better outcomes \\ branch changes \\ communication skills \\ consistency \\ creativity \\ finance \\ holistic approach \\ increased confidence \\ lack of branch support \\ learning contract \\ marae \& related \\ needs assessment \\ non-ACC people teaching \\ opportunity to do course \\ people as individuals \\ personal change \\ practicum \\ reinforcement of knowledge \\ risk taking \\ self-knowledge \\ study week \\ trying new ideas \\ working with clients
}

\author{
ACC problems \\ balanced life \\ branch support \\ change in personal practice \\ conflict management \\ course credibility \\ critical incidents \\ future learning \\ importance of context \\ interviewing \\ learning context \\ less judgmental \\ more time \\ negotiating \\ on my own \\ outside networks \\ personal/professional day \\ planning/organisational skills \\ presentation skills \\ research \\ role change \\ stress management \\ supervision \\ tutors
}

Highest frequencies $(n=47)$

increased confidence 41

practicum 34

needs assessment 33

branch support 28

learning context 25

interviewing 24 change in personal practice 39 personal/professional day 33

marae \& related 29

branch changes 28

research 25

communication skills 23 


\section{8 months}

ACC changes not significant adapting learning to new situations become second nature changes positive changes negative concern about ACC future conflict between own and work knowledge further learning good outcomes importance of context learning is working new or seek new job own attitude realistic approach respected for knowledge self-awareness/insight workable case loads
ACC future

balanced life branch support Changes made community resources confidence increased follow-up needed good course greater awareness importance of needs assessment less judgmental no ACC support planning reflect more risk taking work constraints

\section{Highest frequencies $(n=41)$}

good outcomes 32

adapting learning to new situations 19

new or seek new job 18

changes positive 16

own attitude 15 importance of needs assessment 26 changes negative 18 confidence increased 17 become second nature 15 


\section{4 months}

ACC changes unsettling better outcomes

change yes practice difficult

conceptual approach

communication skills

consistent approach

course important at different times

goal setting

importance of practicum

lack of Head Office support

marae unit

more creative

more motivated

needs assessment

now helping other staff

personal/professional day

planning more

professionalism

risk taking

self knowledge/ insight

working holistically approach interview

branch support

change in ACC emphasis

confidence increased

conflict resolution

continuing to learn

course pivot point

importance of clients needs

lack of branch support

less networking

more assertive

more forthcoming

more proactive

new job

personal change

perspective

professional supervision useful

reflect more

second nature

skills to other areas

\section{Highest frequencies $(\mathbf{n}=38)$}

confidence increased 25

lack of Head Office support 20

better outcomes 17 importance of client needs 20

personal change 18

skills to other areas 16 


\section{APPENDIX 9 - GROUPED CODES}

\section{2 months}

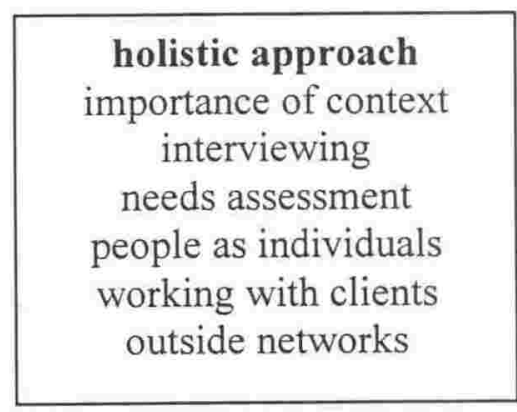

\begin{tabular}{|c|}
\hline generic skills \\
communication skills \\
conflict management \\
negotiating \\
planning/organisational \\
skills \\
presentation skills \\
stress management \\
\hline
\end{tabular}

\section{personal/professional day critical incidents}

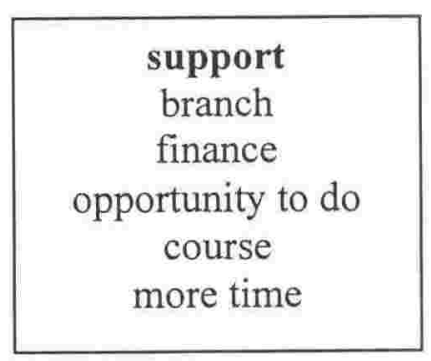

\begin{tabular}{|c|}
\hline outcomes \\
creativity \\
risk taking \\
trying new ideas \\
balanced life \\
future learning \\
\hline
\end{tabular}

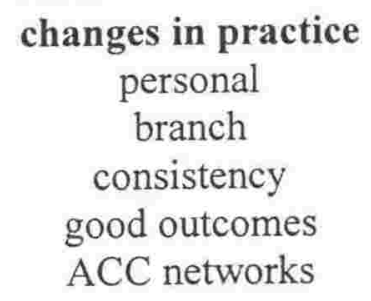

\section{learning context}

study week interesting course non-ACC people teaching tutors

reinforcement of knowledge

\begin{tabular}{|c|}
\hline practicum \\
learning contract \\
research \\
supervision \\
\hline
\end{tabular}

personal change
attitude change
increased
confidence
less judgmental
self knowledge
on my own

lack of support branch ACC problems

\section{other}

course credibility marae \& related role change 
18 months

\begin{tabular}{|c|}
\hline holistic approach \\
importance of needs \\
assessment \\
importance of context \\
community resources
\end{tabular}

changes in practice

become second

nature

personal

realistic approach

good outcomes

\begin{tabular}{|c|}
\hline lack of support \\
ACC \\
follow up needed \\
work constraints \\
conflict between own and \\
work knowledge \\
\hline
\end{tabular}
personal change
confidence
greater awareness
less judgmental
own attitude
self

awareness/insight

\begin{tabular}{|c|}
\hline other \\
adapting learning to \\
new situations \\
learning is working \\
new or seek new \\
job \\
good course \\
\hline
\end{tabular}

changes

positive

negative

not significant

ACC future \&

concerns

workable case loads

\section{outcomes}

balanced life

future learning

reflect more

generic skills

planning

support

branch risk taking 

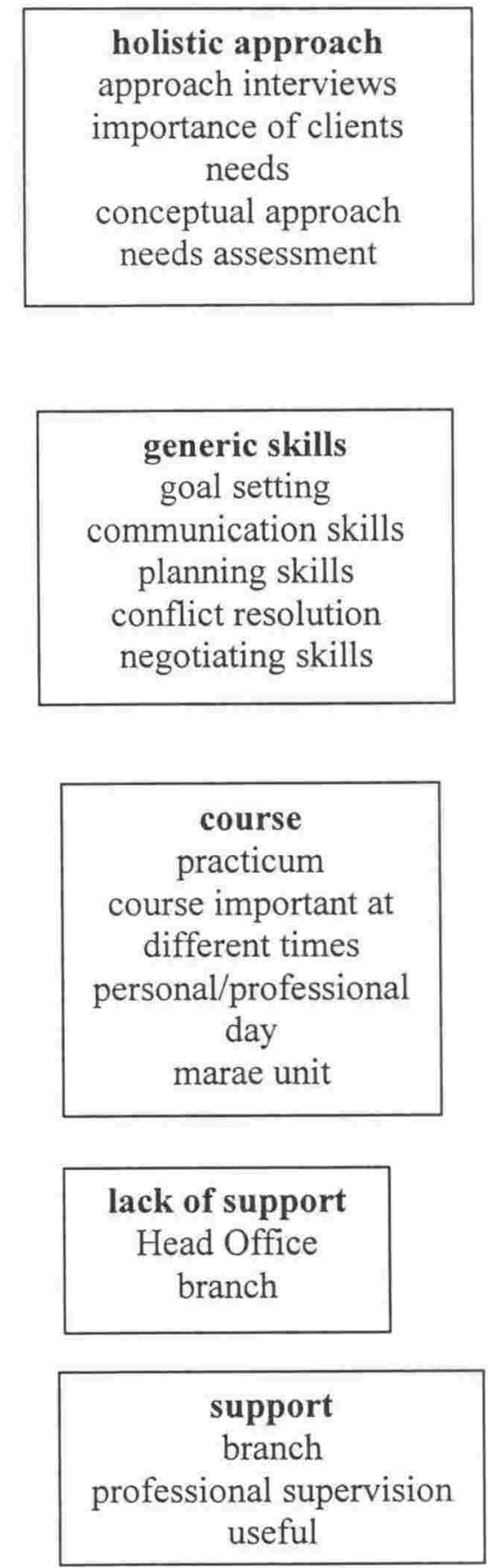

changes in practice

become second nature

better outcomes

consistent approach

now helping other staff

changes yes practice

difficult

course pivot point

more creative

professionalism

\begin{tabular}{|c|}
\hline personal change \\
confidence \\
more forthcoming \\
perspective \\
self knowledge/insight \\
more assertive \\
more motivated more \\
proactive
\end{tabular}

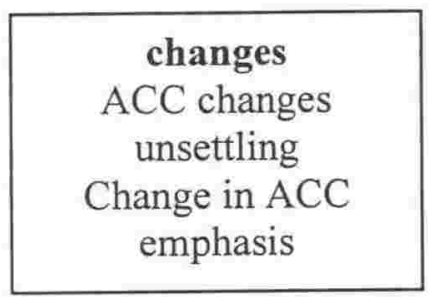

\begin{tabular}{|c|}
\hline outcomes \\
continuing to \\
learn \\
reflect more \\
risk taking \\
new job \\
\hline
\end{tabular}

other

skills to other areas

less networking 


\section{APPENDIX 10 - FINAL CODES USED}

12 months

The Learning Context

Course set-up

Study week

Tutors

Reinforcement

Non-ACC people teaching

\section{Personal \& Professional Development}

Day

Tuesdays or Wednesdays

Critical incidents

\section{Cultural Awareness}

Noho marae

Importance of culture

Insiders/outsiders assignment

\section{Personal Development}

Increased confidence

Self knowledge

On my own

Attitude change

Less judgmental

Personal change

\section{Using a Holistic Approach}

Needs assessment

Interviewing skills

Communication skills

Negotiating skills

Holistic approach

Importance of context

Seeing people as individuals

Working with clients

Outside networks

\begin{tabular}{c}
\hline Praxis Development \\
Stress management \\
Planning \& organisational skills \\
Risk taking \\
Presentation skills \\
Conflict management \\
Creativity \\
Future learning \\
Role change \\
Trying new ideas \\
Balanced life
\end{tabular}

The Practicum

Practicum

Research project

Learning contract

Supervision

\section{Changes in Practice}

Personal changes

Branch changes

ACC networks

Better outcomes

Consistency

\section{Organisational Supports}

Branch support

Opportunity to do course

Finance

More time
Organisational Detractions

Head Office problems

Lack of branch support 


\section{8 months}

\section{Personal Development \\ Increased confidence \\ Own attitude \\ Greater awareness \\ Increased self-awareness $\&$ insight \\ Less judgmental}

\section{Using a Holistic Approach}

Importance of needs assessment

Importance of context

Community resources

Organisational Supports

Positive changes

Branch support

Workable case loads

No significant changes

Respected for knowledge

\begin{tabular}{|c|}
\hline Praxis Development \\
New or seek new job \\
Future learning \\
Planning skills \\
Balanced life \\
Reflect more \\
Creativity \\
Risk taking \\
\hline
\end{tabular}

\section{Changes in Practice}

Good outcomes

Adapting learning to new situations

Has become second nature

Learning is working

Realistic approach

Changes made

\section{Organisational Detractions}

Negative changes

ACC not supportive

Conflict between own \& work knowledge

Concerns about $\mathrm{ACC}$ future

Follow-up needed

Work constraints 


\section{Course Components}

Marae

Personal \& professional day Practicum

\begin{tabular}{|c|}
\hline Praxis Development \\
Continuing to learn \\
New job \\
Perspective \\
Goal setting \\
Risk taking \\
Communication skills \\
Negotiating skills \\
Helping other staff \\
More creative \\
Reflect more \\
Conflict resolution \\
Planning skills \\
Professionalism \\
\hline
\end{tabular}

\section{Organisational Supports}

Branch support

Professional supervision

Organisational Detractions

Lack of Head Office support

Lack of branch support

Change in ACC emphasis

ACC changes unsettling

Less networking
Personal Development

Confidence

Personal change

Self knowledge \& insight

More assertive

More forthcoming

More proactive

More motivated

Using a Holistic Approach

Importance of clients needs

Working holistically

Conceptual approach

Changes in Practice

Course pivot point

Better outcomes

Skills to other areas

Become second nature

Consistent approach

Changes yes practice difficult

Interview approach

Course varies in importance 
APPENDIX 11 - EXAMPLE OF CLIENT CONTACT SHEET DEVELOPED BY ONE PARTICIPANT

\section{Contact Doodle Page}

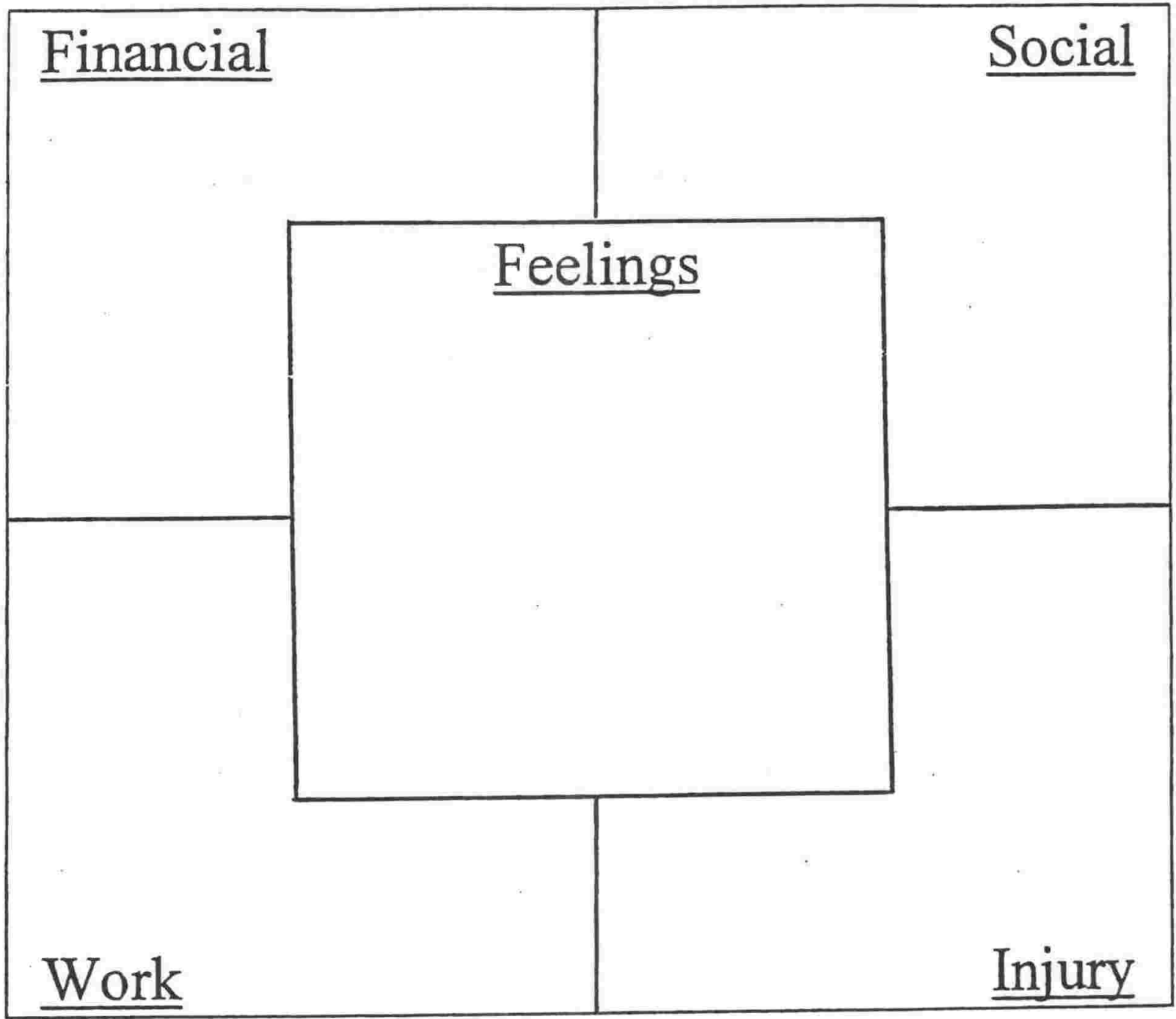

$\underline{\text { Issues }}$ 


\section{APPENDIX 12 - HYPOTHESES FOR TESTING TRANSFER MODEL}

The following tables provide the raw data in whole numbers for the relationships between the various components of the Transfer of Learning Model. The following example will demonstrate the process used:

\section{Hypothesis $\mathrm{H} 1$ in Chapter 6.}

HyperRESEARCH 1.56 searched for all participants who had been coded with Practicum and Personal Development and coded them with PRACT PLUS PERS DEVMENT (called A for ease of tabulation). Then it searched for all the participants who had been coded with Learning Context and Personal Development which were coded with LC PLUS PERS DEVMENT (called $\mathrm{B}$ for ease of tabulation). The final search of Hypothesis 1 involved searching all participants who had now been coded with both PRACT PLUS PERS DEVMENT and LC PLUS PERS DEVMENT, and to code those with LC PRAC PLUS PERS DEVMENT (called $C$ for ease of tabulation) indicating that the hypothesis was supported i.e. Educational Processes are associated with Personal Development. Where the hypothesis was not supported HyperRESEARCH 1.56 listed the components of the hypothesis which were supported i.e. PRACT PLUS PERS DEVMENT or LC PLUS PERS DEVMENT or none at all. An extract of the report is as follows, with $\mathrm{X}$ and $\mathrm{Y}$ having been substituted for the participants real names.

Testing your Hypothesis on Case: $\mathrm{X}$

The following rules apply to this case:

- Rule 1 was applicable: IF The Practicum AND Personal Development THEN ADD PRACT PLUS PERS DEVMENT

- Rule 2 was applicable: IF The Learning Context AND Personal Development THEN ADD LC PLUS PERS DEVMENT

- Rule 3 was applicable: IF PRACT PLUS PERS DEVMENT AND

LC PLUS PERS DEVMENT THEN ADD LC PRAC PLUS PERS DEVMENT,GOAL REACHED

- Enough rules were found to be applicable to this case to reach the GOAL of your hypothesis. Your hypothesis has been shown to be TRUE for this case.

\section{$\sim$}

Testing your Hypothesis on Case: Y

The following rules apply to this case:

- Rule 1 was applicable: IF The Practicum AND Personal Development THEN ADD PRACT PLUS PERS DEVMENT

. Not enough rules could be found to be applicable to this case to reach the GOAL of your hypothesis. Your hypothesis has been shown to be FALSE for this case. 


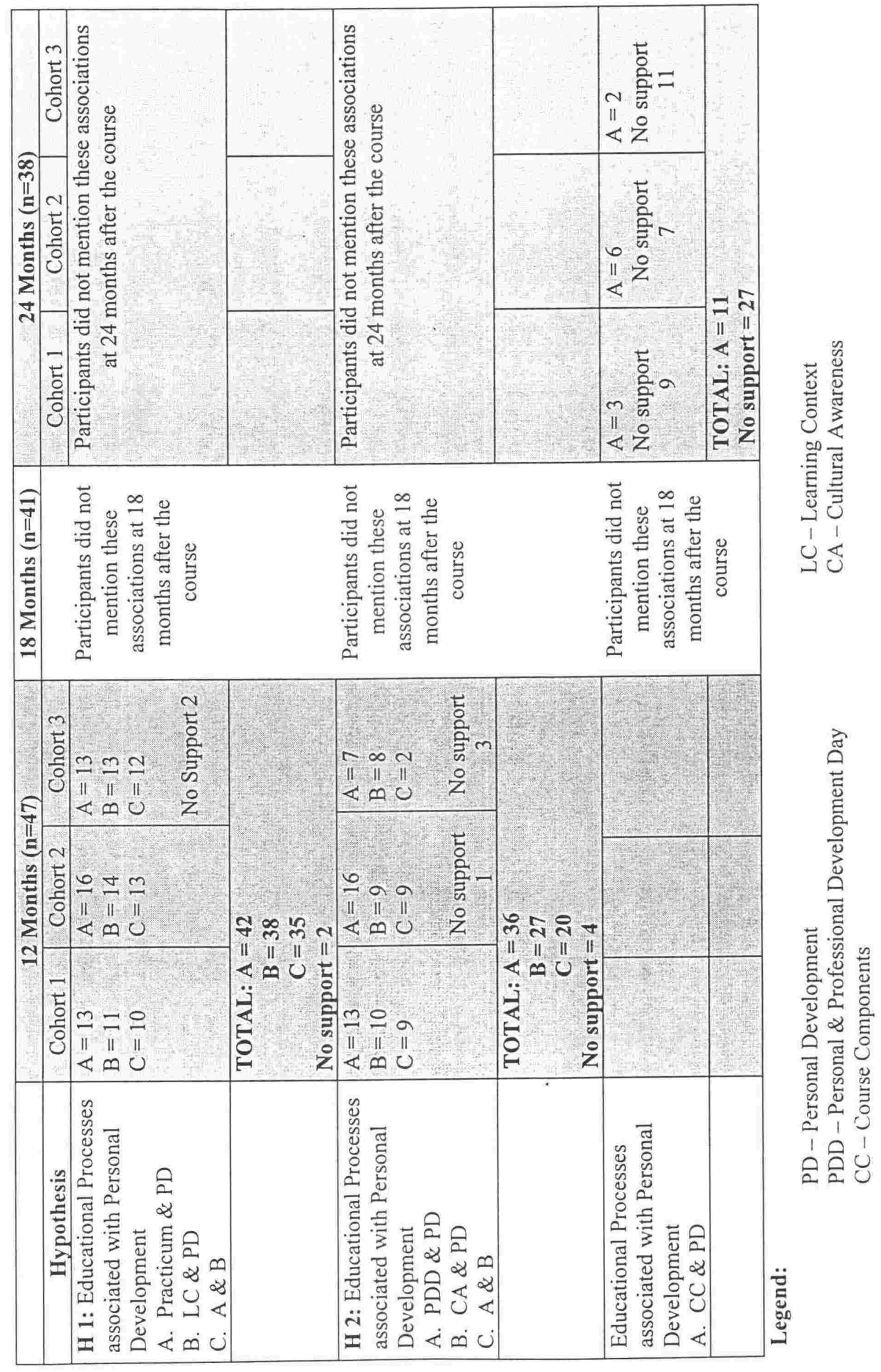




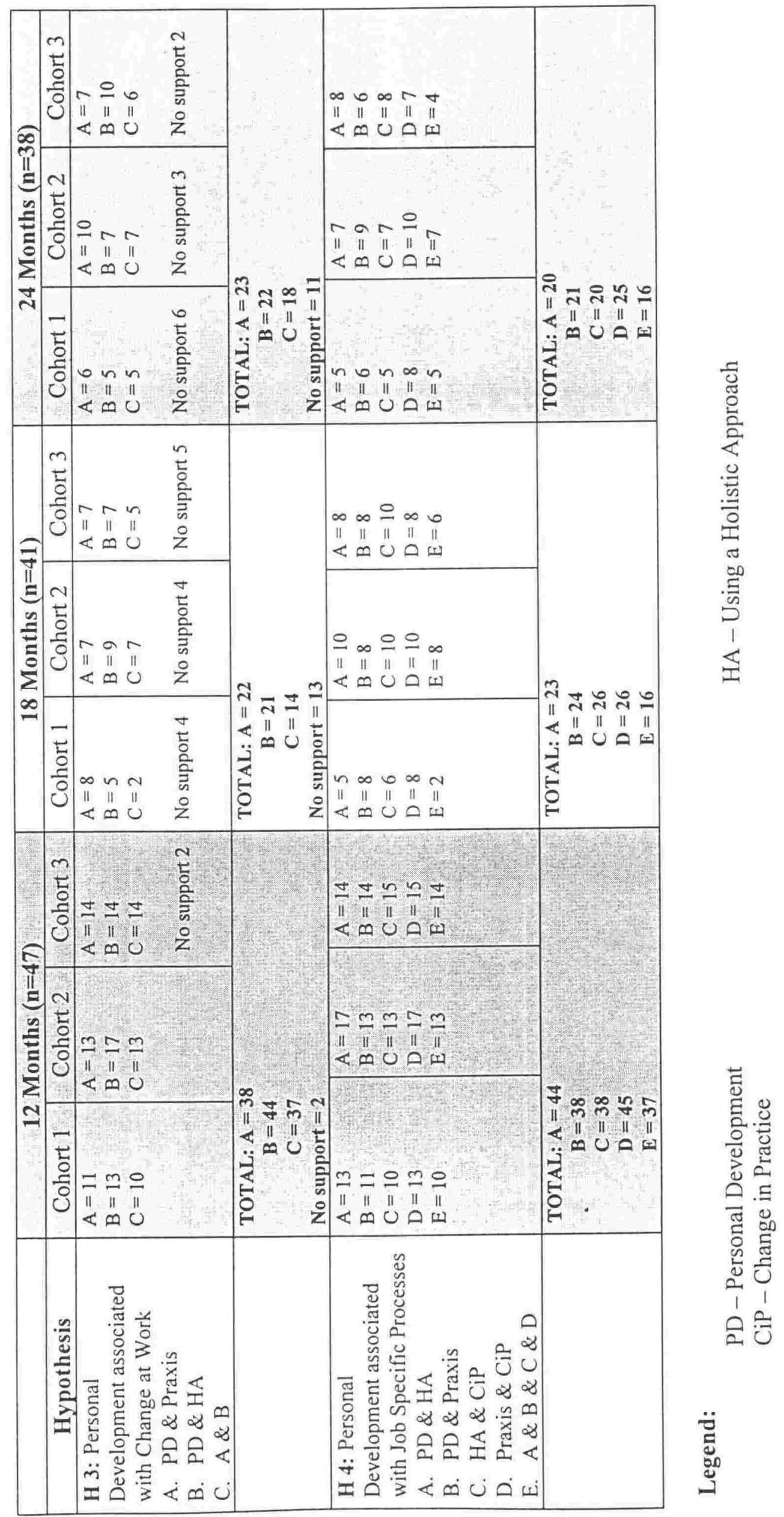




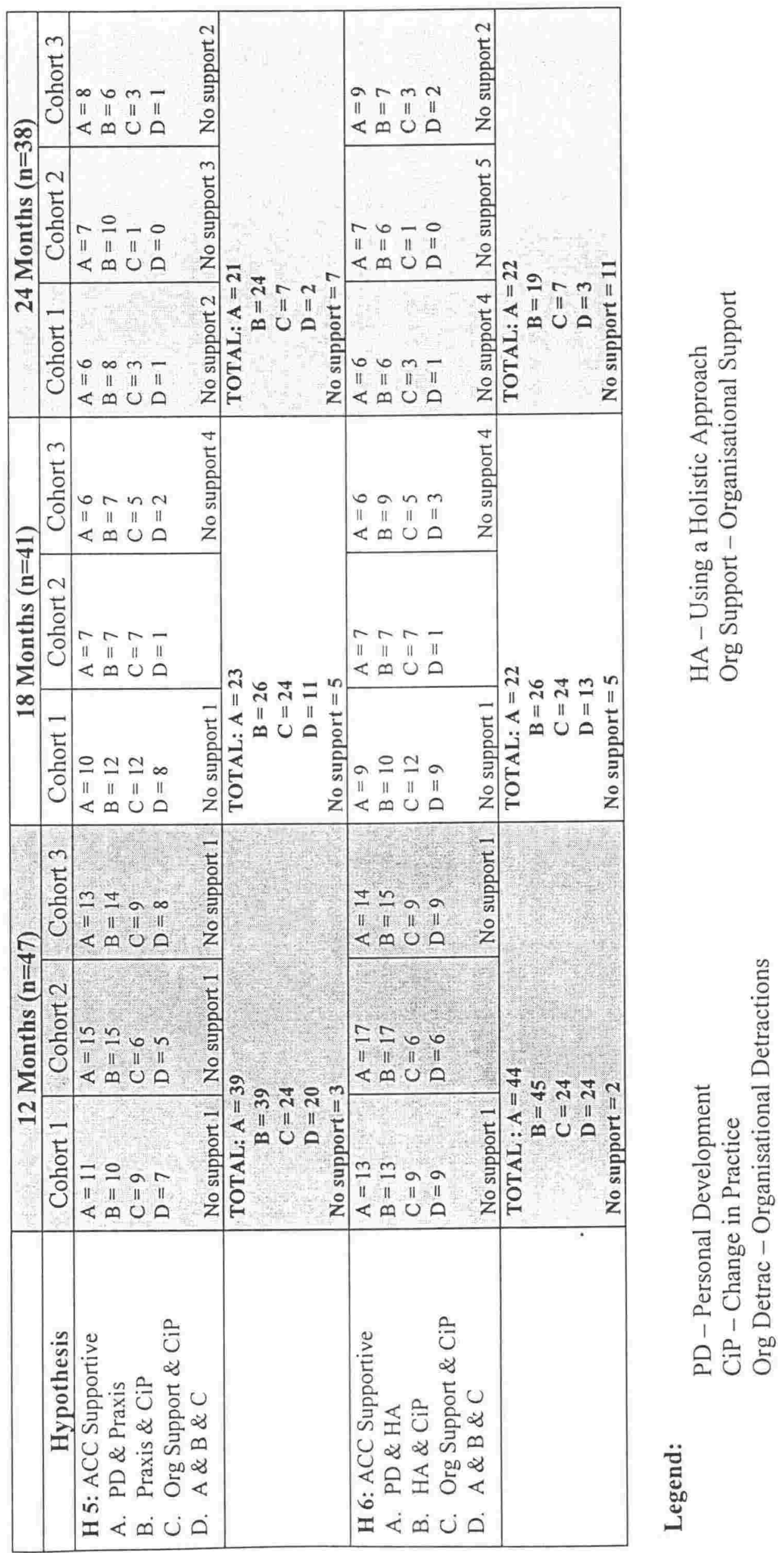




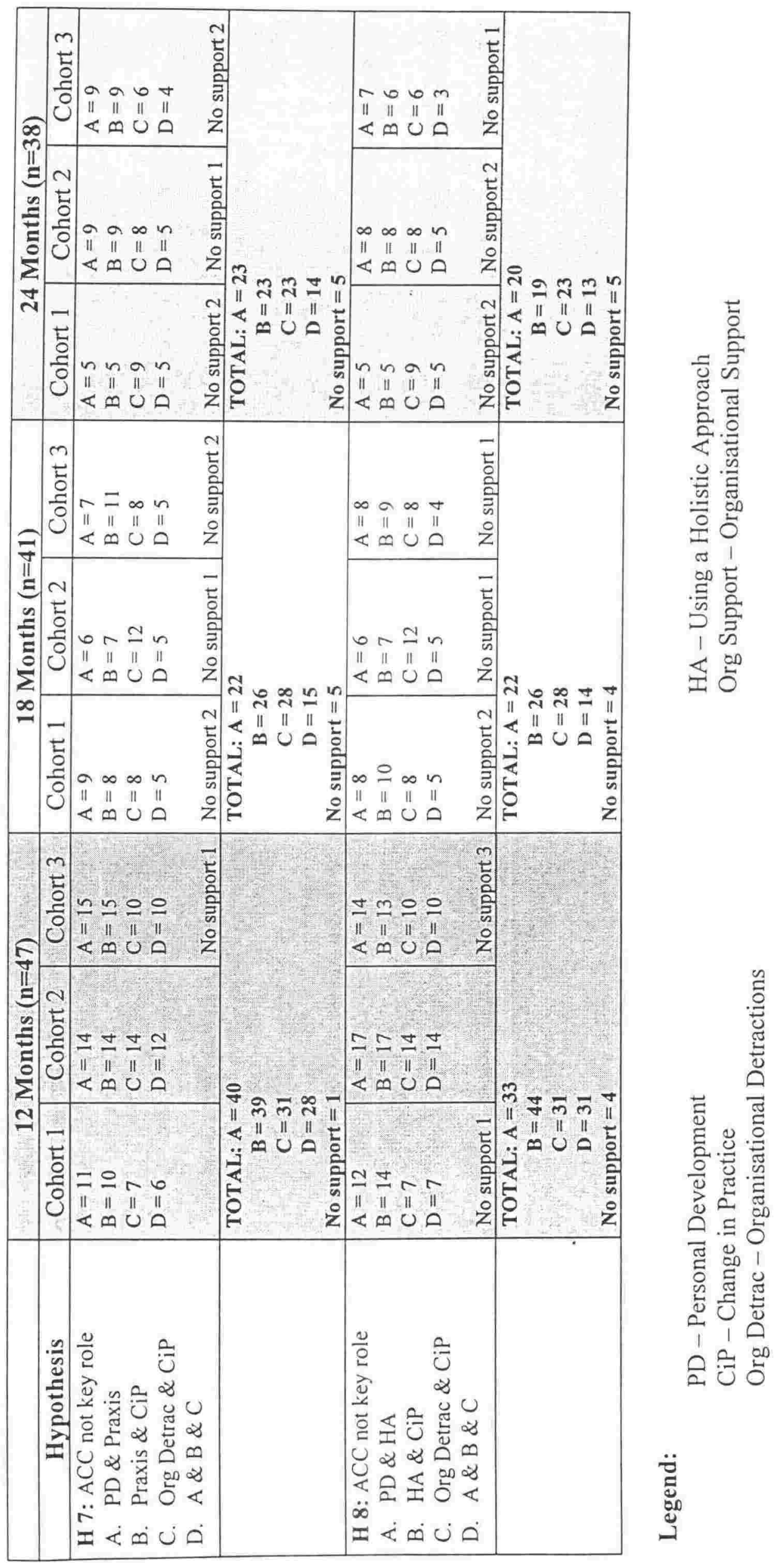




\section{GLOSSARY}

Claims Manager - file processing worker

High/low risk split - system of dividing cases into those needing intensive case management (high) and those needed straightforward claims management (low)

Homehelp Regulations - ACC legislation associated with homehelp

IRP - Individual Rehabilitation Plan

Isomorphic framing - providing connections from the adventure experience to the participant's life

Marae - Maori meeting house

Metaphoric transfer - generalising learning (principles and attitudes) which can then be applied to a future learning experience with similar elements

Ministerial - these occur when a claimant challenges an ACC decision

Noho marae - overnight stay at a marae

Non-specific transfer - generalising of learning (principles and attitudes)

OOS - Occupational Overuse Syndrome

Pathways team (Aaction) - ACC project team associated with implementing case management

Principal Case Manager (PCM) - responsible for Case Managers and Team Leaders PSA - Public Services Association

RARLTC - ACC programme for the Rehabilitation and Review of Long Term Claimants

Social Rehabilitation Regulations - ACC legislation associated with the social aspects of rehabilitation

Specific transfer - specific application of learning to tasks that are highly similar to those originally learned to perform

Team Leader - responsible for a group of Case Managers

Technical Claims Officer - file processing worker

The 'tail' - ACC's long term claimants

Weekly compensation - ACC payment to some claimants on a weekly basis

Whakapapa - genealogy

Whanau - Maori word for family/family group

Wharenui-house

Work Capacity Testing - ACC tool used for identifying skills of claimants 